\title{
Untersuchungen aus dem forstbotanischen Institut
}

zu München.

Heransgegehen

\section{Dr. Robert Hartig,}

I'rofessor an der Universitit Mûnchen.

II.

\section{Lelser dic}

\section{Vertheilung der organischen Substanz,}

des

\section{Wassers und Iuftraumes}

in den Bïmnen,

und über" die Urs:che der "Wasserbewegung" in transpirirenden Pflanzen.

Vion

Dr. Robert Harig,

Prutessur an der I"niversitit Muncluen.

Mit 4 Holzschnitten und 16 Jithographirten Tafeln.

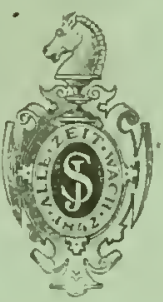

Berlill.

Terlag vou tulius Springer.

1882. 


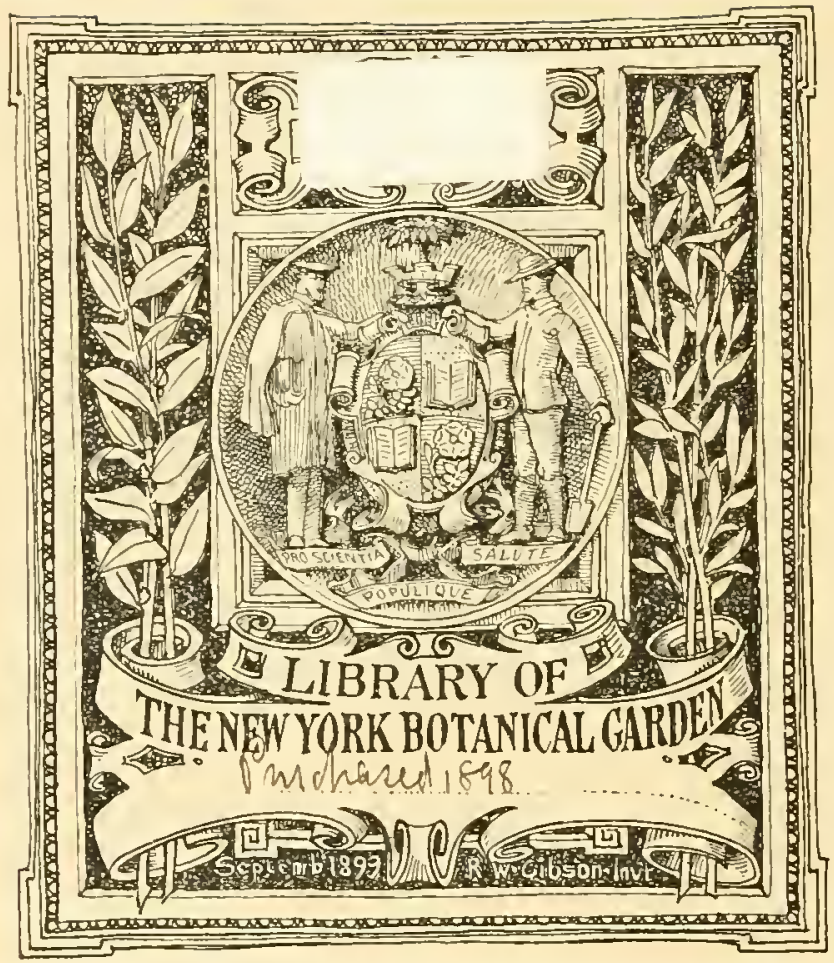

$\infty$ 




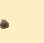




\section{Untersuchungen}

aus dem

\section{forstbotanischen Institut}

Zul

M ün chen.

Ifrausgegehen vou

\section{Dr. Robert Hartig,}

Professor an ler Universitit Munchen.

\section{II.}

Ueler die Vertheilung der organischen Substanz, des Wassers und luftraumes in den Bäumen, unt ïhor die Ursache iler. Wasserhewegung in transpirimenden Pflanzen

von

I) Robert Hatig.

Mit 4 Holzschnitten und 16 lithographirten Tafeln.

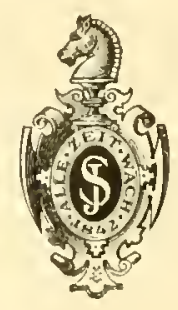

Berlin.

Verlag von Julius Springer.

1882. 


\section{NEW YORK \\ BOTANICAL GARDEN.}

Ueber die

\section{Vertheilung der organischen Substanz, des}

\section{Wassers und Luftrammes}

\section{in den Bïnmen,}

und über die Ursache der Wasserbewegung

in transpirirenden I'llanzen.

Von

D r. $R$ ob e r t Hartig, ['rofessor an der Universitat Múnchen.

Mit 4 Holzschnitten und 16 lithographirten Tafeln.

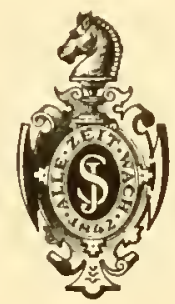

Berlin.

Verlag von Julius Springer.

1882. 
$x u$
N8
$0 . j$ 


\section{Inhaltsverzeichniss.}

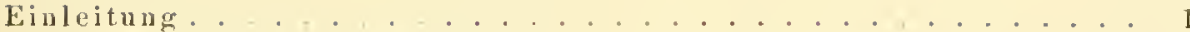

A. Die Mothote lev lutersuchung . . . . . . . . . . . . . . . :

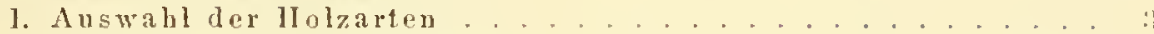

Birke. Rothbuehe. Eiehe. Läehe. liverer. Fichte.

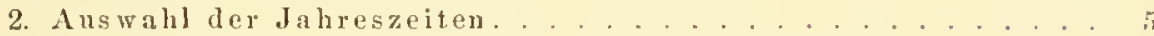

3. Die Untersuchung im Walde.......................6

Gewinnung und Wägung der Untersuchungsobjectı.

4. lie Untersuchung im Hause. . . . . . . . . . . . . . . . . .

Die Tolumbestimmung. Das Trocknen. Das specifische Frischgewicht und Trockengewicht. Das Schwinden. Das Gewicht der 'Trockensubstanz. Der Wassergehalt. Das Volumen der 'Trockensubstanz. 1uftlaum im Holze. Die Wassereapacitait der 1tolzwandung (Tabelle 1). Das Volumen der imbibirten organischen Substanz. Volumen des Wassers im Hohlraum des Holzes.

13. Hip. Darstollung der Untersuchungsergobnine in den 'Tabellen 2-44. . . . 20

C. Die liesnltate ler Intersnehne. . . . . . . . . . . . . . . 22

1. Das Verbailtniss zwischen liquidem Wasser und Luftram im 110 zae in Beziehung zux Trsache des Saftsteigens....... 22

Vorbennerkungen über die Struetur der organiselıen Substanz . . . . . . . 22

Die Quellungsfähigkeit. Imbibltion. Die Imbibitionstheorie. Dur Wurzeldruck. Der Gasdruck.

1)arstellung der aus den Untersuchungen gewonnenen Anschaumg über die Wege und Ursachen der Wasserbewegung in truspirionden PHanzen.

Holatheil. Organe der Wasserbewegung. Prifung der Imbilsitionstheoric. Verhältuiss zwischen Iuftraum und liquidem IVasser ("Tabelle 4.\%. 'Tafel 1-16). Die liedeutung des Gasdineks. Der Process des Wassersteigens. Bedeutung der Tipfel und der Spiralgefässe. Eintluss des Wrurzelbanes und der Bodenbeschaffeuheit auf die Wasseranfualume.

Vorinderungen des Wassergohalts und der Luftension bei den cinzelnen

Holzarter. . . . . . . . . . . . . . . . . . . . . . :

Birke . . . . . . . . . . . . . . . . . . . . . . . . . . .

Rothbuche ........................ . 40

Eielıe......... . . . . . . . . . . . . 42

Lärche . . . . . . . . . . . . . . . . . . . . 43

Kiefer . . . . . . . . . . . . . . . 4:

Fichte . . . . . . . . . . . . . . . 44 
2. Ueber den Einfluss des Alters auf die Substanz des Holzkïrpers. . . . . . . . . . . . . . . . . . . . . 46

Der Verholzungsprocess . . . . . . . . . . . . . . . . . . 46

Die Verånderungen des Holzes in späteren Jalıen (Tabelle 47) . . . . . . 47

Verinlerungen des Eichenholzes . . . . . . . . . . . . . . . . . 49

, liothbuchenholzes . . . . . . . . . 52

n Birkenholzes . . . . . . . . . . . . . 53

$n$, Fiehtenholzes . . . . . . . . . . 54

$n$, Kiefernholzes . . . . . . . . . . . 56

1. Upber den Linflus der Jahrringbreite auf die substanz des Hol\%körpers. . . . . . . . . . . . . . . . . . . . . 57

Vorbemerkungen ïber das Dickenwaehsthrm der Bïnme . . . . . . . . . 57

Einfluss der Jahringbreitc anf das Eiehenhohz . . . . . . . . . . . 59

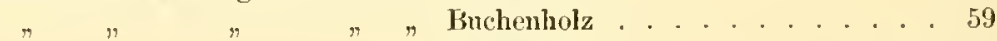

" " " " "Nadelholz (Fichte, liefer und Lärche) 61

Die Tabellen $1-47$. . . . . . . . . . . . . . . . . . . . 64 Die 'T'afeln $1-16$. 


\section{E in l e itung.}

Julius Sachs schliesst seinen hochinteressanten Aufsatz „Ueber die Porosität des Holzes“*) mit den Worten: „Ls wäre nun eine der lohnendsten Aufgaben, zu untersuchen, wie sich diese Verhältnisse (die Vertheihung von organischer Substinz, Wasser und Luftraum) im Holz der lebenden Bäume zu verschiedenen .Jahıeszeiten, besonders zu' Zeit des grössten und geringsten Wasserreichthmos, ferner in der Nacht und am Tage gestalten, dat man auf diese Art ein Urtheil uber die Volumen - und Spannungsänderungen der Luft und des Wasserdampfes in den Zellnäumen gewinnen und aus diesen die Filtrationsberegungen des Wassers in Holz beurtheilen könnte."

Es wirl mit diesen Worten auf eine Liicke in unserem Wissen hingewiesen, die wohl ein Jeder klar empfunden haben diurfte, der sich mit her Ergriundung der Ursachen und Kräfte befasst hat, wrohe die Wasserbewegung in den Pflanzen bewirken oder doch mit Interesse diese Frage in der Literatur verfolgte.

Die bezeiclmete Lïcke ein wenig auszufüllın, ist die erste Anfgabe der vorliegenden Untersuchungen. Es liess sich vorausschen, dass nebenbei noch eine Reihe anderer interessanter wissenschaftlicher Aufschlizse aus den Arbeiten gewounen werden wïrde. Insbesondere erschien es wiinschenswerth, einen klaren Einblick zu gewinnen in die Veränderungen, welchen der Holzkörper der Bäume durch die Processe der Verkcrnung und Verharzung nnterworfen ist, sowie den Einfluss der Jahrringbreite und des Baumalters auf die Qualität des neu sich bildenden Holzes zu untersuchen.

Die so ungemein giinstige Lage $\mathbb{I}$ în $\mathrm{chens}$ zum Walde. die Mögliclıkeit, in : "irzester Zeit Bestände verschiedener Holzarten zn erreichen, erlcichterte die Ausführmg dieser Untersuchungen in holem Grade. Es wäre gewiss wïnsehenswerth gewesen, wenn ich dieselben nicht auf ein Jahr beschränkt, wenn

*) Arbeiten des botanischen Instituts in Wïrzburg. 1879. Bd. I1. $\$ 3$. 
ich sie anch anf anderen Standorten durehgeführt hïtte u. s. w. Dem stand einerseits der Kostenaufwand und andererseits die Grösse der Arbeit selbst im Wege. Um für diese einen Anhaltspunkt zu gewinnen, sei nur erwihnt, dass die Zahl der Wägungen und der Tolumbestimmungen, bei deren Vornahme mir mein Assistent Dr. Heinrich Mayr in unermüdlicher und dankenswerthester Weise behuilflich war, sich anf 5-6000 belaufen hat. Es bleibt aber nicht ausgeschlossen, dass in der Folge zur Beantwortung dieser oder jener noch nicht völlig gelösten Frage weitere Untersuchungen ähnlicher Art von mir vorgenommen werden, und schon das nächste Heft wird die Ergebnisse weiterer Versuche bringen, die fü die Lehre vom Saftsteigen von grosser Bedeutung sein werden.

An dieser Stelle möchte ich dem Herrn Forstmeister Klansner in München und Herrn Oberförster von Fischer in Starnberg, welche mir die Vornahme der Untersuchungen in den von ihnen rerwalteten Forsten in entgegenkommendster Weise gestatteten und mir dabei behülflich waren, meinen rerbindlichsten Dank aussprechen. 


\section{A. Die Methode der Untersuchung.}

Indem ich eine Darstellung des Fanges der Untersuchungen und der Motive vormssende, die mich bei der Wahl der Untersuchungsmethode leiteten, beginne ich znerst mit der Darlegung der Grinde die fir mich bei der

\section{Auswahl der Holzarten}

bestimmend waren.

Die Birke (Betula verrueosa) reprïsentint eine Gruppe von Laublolzbäumen, deren Holzkörper nicht allein durchweg gleichgefïrlst ist, also keinen Kern bildet, sondern anch in seiner Wasseranfnahmefähigkeit unverindert bleibt, dessen inmerster Holzkörper auch an 85jährigen Bäumen noch chenso wasserreich, oder sogar wasserreicher ist, als die :iusserste jiingste Jahreslage. Aehnlich der Hainbuche und den Ahornarten tritt bei ihr im Frithjahre leblaftes Bluten nach Verwundungen ein. Unmittelbar bei Planegg fanden sich in einem jungen Eichenbestande 30-35jährige Birken ron ziemlich gleichen Dimensionen in geniigender Anzahl rorrathig. Um zu sehen, welche Veriinderungen in höherem Alter mit dem Holzkörper vor sich gehen, wurcle auch eine nicht fern davon in einem Buchenlichtschlage stehende 85 jährige Birke bei der letzten Untersuchung am 16. Februar 1882 gefällt; cf. Tab. 8.

Die Rothbuche (Fagus silvatica) ist eine Holzart, welehe im Gegensatz zur Birke eine grosse Verschiedenheit im Wassergehalt der älteren und juingeren Holzlagen zeigt. 1)ie jiingeren, wasserreicheren Holztheile bezeichnet man wohl als Splint. Die inneren, wasserärmeren nach den Vorgange Nördlinger's als "Reifholz", ein Ausclruck, cler mnglücklich gewälllt ist, da sich fuir den Laien gar zu leicht die unrichtige Vorstellung hiermit verknüpft, als sei das Reifholz in seineu Bestandtheilen wesentlicl verselieden von dem ,unreifen" Splintholze, was nicht der Fall ist.

Das innere, trockenere Holz ist fast ganz frei ron Stärkemehl und zeigt nur hier und da geringe Mengen einer brïunlichen, amorphen Substanz in den parenchymatischen Zellen, welche ähnlicher Beschaffenheit und gleichen 
Ursprunges ist, wie die Kernstoffsubstanz der Eiche, iiber deren Entstehung ich sprechen werde in dem Abschnitte, welcher den Einfluss des Alters auf die Substanz des Holzes behandelt. Die Menge dieser Substanz ist eine so geringe, dass dadureh kamm eine Farbenveränderung des Holzes hervorgernfen wird. Manche ältere Rothbuchen zeigen einen dunkelba aunen Kern. Dieser ist dann aber nicht , ̈icht". d. h. nicht durch Bildung von Kernstoffsubstanz an Ort und Stelle entstanden, sondern er hat sich dureh Zufuhr brauner Substanzen in gelöstem Zustande von wundfanlen Aesten her gebildet. Die braunen löslichen Zersetzungsprodukte, welche in wundfaulen Holze entstehen, werden von dem in die Astwunde gelangenden Regenwasser gelöst und besonders dlurch Vermittelung der Gefisse in das Innere des Baumes geführt.

Wie ich mehrfach festgestellt habe, sind solche dnnkelgefarbte, in der Regel völlig pilzfieie Holztheile erhcblich schwerer, als das normale Holz bei gleicher Ringbreite, dem eine Zersetzung der Zellwände hat noch nicht stattgefunden, das Lumen der Organe ist aber mit jenen bramen Stoffen theilweise ansgefiillt.

Ganz anders verhält sich ein ebenfalls oft anftretender falscher Kern, cler dureh Verbreitung parasitischer Pilzmycelien entstanden und bedeutend leichter ist, als gesundes Holz.

Die Rothbuche blutet nur in sehr vereinzelten Exemplaren und sind es vielleieht solche juingere Individuen, bei denen fast gar kein „Reifholz" sich findet, vielmehr der Wasserreichthum bis zur Markröhre ziemlich grleich ist. Dadureh bekommt ein solches Individum den Charakter der ächten Bluter, d. h. der Birke, Hainbuche, der Ahornarten. Nihe bei Planegg fand ich einen bereits in der Verjüngung stehenden, vor 8 .Tahren stark durchhanenen (in Besamungsschlag gestellten) Rothbuchenbestand. Die durchsehnittliche Höhe betrug 18 bis $20 \mathrm{~m}$; das Alter war, wie sich später herausstellte, ungleich. Von den sechs untersuchten Büumen waren vier Stiick zwischen $80-95$.Jahre alt, die beiden anderen zählten dagegen 130 - 185. .lahre.

Die Eiche (Quereus peduneulata) wurde als Repräsentant der äehten Kernholzbäume gewählt. Die Grenze zwischen Splint und Kern ist bei dieser Holzart selır regelmässig und scharf markirt, und konnte durch sorgfïltige scheidung des Splintes von dem Kernholze die Versehiedeuheit im Wassergelalte, sowie die beim Uebergange des Splintholzes in Kemholz eintretende Veränderung in der Substanz sicher bestimmt werlen. Die einander sehr gleichartigen ca. 50jahrigen zur. Untersuchung gezogenen Bäume stand'n dicht bei Planegg, in einem gleichartigen, geschlossenen Eichenbestande.

Die Lärehe (Larix europaeal) als sommergriner Nadelholzbaum stand mir leider nur in zwei 5ojihihigen Exemplaren bei Planegg zur Vertìgung, und zog ich die eine im März, die andere im Juli zur Untersuchung. 
Die Kiefer (Pinus silvestris) wurde als Kermholzbaum gewällt, wenn anch die clunkle Farbe des Kernholzes erst im trockenen Zustande leervortritt; die Fichte (Picea excelsa) endlich wurde gewählt, weil bei ihr eine Veränderung des Holzkörpers im höheren Alter nur durch den Verlust der Saftleitungsfähigkeit bedingt wird, eine Kernholzbildung nicht eintritt.

Im Forst Karsten (Miinchener Stadtwald) fand sich ein 75-80jälhriger Fichtenbestand, in welchen 70-75jährige Kiefern eingesprengt sind. Der Verwalter der städtischen Waldungen, Herr Forstmeister lilausner, hatte die grosse Güte, mir die Vornahme der Untersuchungen daselbst zu gestatten und konnte somit Kiefer und Fichte unter genau gleichen Standortsverhältnissen untersucht werden.

Im unmittelbaren Anschlusse an den 70-80jahrigen Bestand fand sich ein 20-3jjähriger Mischbestand der Kiefer und Fichte. Es schien mir die Gelegenheit günstig, auch auf dieses jugendliche Alter die Untersuchung auszudehnen, un den Einfluss des Baumalters auf Wassergehalt, Substanzverinderung u. s. w. festzustellen. Anfänglich beging ich abcr den Fehler, zu schwache Bäume zu fillen. Diese entsprechen nicht dem jiingeren Zustande der 70-80jährigen Bäume, welche letztere im 30jährigen Alter vielmelı zweifelsohne zu den stärksten Bïumen im liestande gezählt hatten.

Die schwächeren Bäume des Junghestandes gehen bis zum 70jährigen Alter fast alle durch Unterdriickung verloren und werden in den Durchforstungen ausgezogen. Erst bei der zweiten Hälfte der Untersuchungen suchte ich stärkere Individuen aus dem jungen Bestande aus, die als jüngere Repräsentanten der 70jälnrigen Versuchsbäume gelten können.

\section{Die Auswahl del Jahreszeiten.}

in denen die Cntersuchungen zur Durchfiihrung gelangten, musste unter Berücksichtigung der wichtigeren Vegetationsperioclen der Bäume erfolgen.

Die erste Untersuchung der Kiefer und Fichte wurde am 14. März 18SI, der Birke, Buche, Eiche und Lärche am 24. März 1881 vorgenommen. Wenngleich der Boden schon aufgethant war, so war doch noch keinerlei vegetative 'Thätigkeit zu bemerken und nur die Birke zeigte lebhaftes Bluten. Während die erste Untersuchung auf die Grenze des Winters und Frïhjahrs fiel, wurde die zweite Untersuchung in die Zeit der Knospenschwellung verlegt. Am 7. Mai wurden Eiche, Buche und Birke (letztere bereits mit neuen Blättern), am 19. Nai wurden Kiefer und Fichte untersucht.

Die dritte Untersuchung fällt in den Monat Juli, also in die Zeit voller Vegetationsthätigkeit und der noch nicht beendigten Jahrringbildung. Birke, 
Buche, Eiche und Lärche wurden am 2. Juli, Kiefer und Fichte am 9. Juli untersucht.

Bei Beurtheilung der Ergebnisse dieser Untersuchung darf nicht unberiicksichtigt blciben, dass der Vorsommer des Jahres 1881 durch Regenmangel und grosse Hitze sich auszeichnete und dass es etwa S Wochen lang vor der Untersuchung kaum vorîbergehend geregnet hatte. Alle Bedingungen lebhafter Verdunstung waren gegeben.

Nachdem es dann während der Monate Angust und September hier bei München sehr viel geregnet hatte, wurde am 8. Oktober die vierte Untersuchung der Kiefer und Fichte, am 12. Oktober der Birke, Buche und Eiche ansgefiłhrt. Die Laubhölzer waren noch im vollen Laube und nur die Birke zeigte einige gelbe Blätter.

Die Mlomate Oktober, November und Dezember 1881 waren fast völlig frostfrei und hatten wir ein selten schönes, klares Wetter mit wenig Niederschlägen. Um Weihnachten trat der erste Frost ein und gleich darauf nahm ich die fünfte Untersuchung vor, nämlich am 28. Dezember an Birke, Buche, Eiche und am 2. Jannar an Kiefer und Fichte.

Während der Monate Jannar und Februar 1882 herrschte andanernd mïssiger Frost bei meist völlig klarem Himmel. Noch bevor der Boden wieder anfgethant war, nalum ich die letzte, sechste Untersuchung vor und zwar am 16. Februar an Birke, Buche und Eiche und an 4. März an Kiefer und Fichte. Die Birke blntete noch nicht, wie am 24. März 1881, da der Boden völlig gefroren war, im Uebrigen bestätigte diese Untersuchung am Schluss des Winters 1882 die auffallenden Resultate der ersten Märzuntersuchung vollstïndig und sehloss ich damit die Versuchsreihe.

\section{Die Untersuchung in Malde}

hatte die Gewinnung der Versuchsstiicke und die sofortige Wägung derselben zur Aufgabe. Bei fast allen älteren Untersnchungen des Wassergehaltes, spezifischen Gewichtes n. s. w. der Hölzer ist nicht genügende Ríicksieht daranf genommen, dass der Verdunstungsverlust der Holzstiicke schon in kurzer Zeit so gross ist, dass die Hinausschiebung der Gewichtsbestimmung der Holzstiicke auf Stunden oder gar Tage die grössten Fehlerquellen in sich schliesst.

Um die Wägung mit der nöthigen Genauigkeit ansfïhren zn können, richtete ich nir in Walde in ummittelbarer Nähe der zu fällenden Bäume ein Waagezimmer ein, indem ich die Waage in einer geschlossenen, aber mit reichlichen Glasfenstern versehenen und desshalb sehr hellen, gerämigen Kutsche aufhing', die Sitzpolster entfernte und unter die Hiingewange einen 'Tiseh zur 
Aufstellung der Gewiehte u. s. w. eimichtete. Es wu'den möglichst windstille Tage zur Vornahme der Versuche gewiilhlt, und wurde der Wagen so aufgestellt, dass die eine geöffnete Thiure der Windrichtung entgegengesetzt war. So konnte von der" vol' der 'Thüre stehenden Person, durch deren Körper die Thiuröffumng grösstentheils noch verdeckt war, die Wägung mit grosser l'rizision ausgotiihrt werden. Auf diese Einrichtung kam ieh erst durch die Erfahrungen, die ieh bei der ursten, am 14. März 1881 ausgefuihrten Untersuchung im Forst Kasten gesammelt hatte.

Bei dieser ersten L'ntersuclung, die an einem selır winlstillen Tage vorgenommen wurde, hing ich die Waage frei im Walde, wenn anch im Felutze eines dicken Baumstammes auf. Es zeigte sich aber, dass der feine Luftzug: der stets im Walde herrscht, Störungen bei der Wägung hervorrief, die bei geringeren Belastungen so lästig waren, dass ich darauf verzichtet habe, dic Resultate der Rindenwägung vom 14. März zu veröffentlichen. Die schwereren Holzstiucke mögen wohl hier und da aueh etwas zu leicht oder zu sehwer ausgefallen sein, doeh waren diese Fehler nicht so bedentend, dass ich es für nöthig eraclitet hätte, die ganze Untersuehung vom 14. Mäiz 1881 zu kassiren.

Bei Planegg konuten die Wägungen in einem Zimmer vorgenommen werden, da wenige Hundert Suhritte von dem Fillungsorte ein grosses Restullrationslokal siclı befand.

Un aber jerlen Gewichtsvorlust zu vermeiden, wurden nicht die Versuclisstücke direkt in Walde herusugeschnitten, sondern es wurden die Biiume nach der Fällung in Walzen zerschnitten und dann wurden liingere Walzenstieke in das unmittelbar dabei gelegene Haus transportirt. Hier wurden crst un. mittelbar vor der Wägung aus den grösseren Walzen die Versuchsstiicke herausgeschnitten. Hinsiehtlich der 'lageszeit sei nur bemerkt, dass dieselbe Holzart immer etwa um dieselbe Zeit gefullt wurle, die Birke um 8 Uhr. die Eiche um 10 Uhr, die Buche un 1 Uhr, die Lỉrche um 4 Uhr, die Kiefer um 10 Uhr, die Fichte um 1 Uhr. Bei jüngeren Pflmzen werden die durch die Tageszeit bedingten Wassergehaltssehwankungen voraussichtlieh weit grösser sein, als an alten Bäumen. Eine Untersuchung des Einflusses der 'Tageszeit auf den Wassergehalt der Bäume konnte nicht zur Austïhrung gelangen.

Was num die Gewinnung der Versuchssticke betrifft, so wurde hierbei in folgender Weise verfahren. Nachdem der ausgewahlte Stamm grefällt und ausgeästet war, wurde zunächst $1 \mathrm{~m}$ iber dem unteren Sehnittrande eine Holzscheibe von genau $7 \mathrm{~cm}$ Höhe herausgeschnitten und der mittlere Durehmosser dieser Scheibe mit Aussehluss der Rinde durch wiederholte Messung ïber Kreuz festgestellt. Alsdann wurden von zwei einander gegeniiberliegenden Seiten Seheibenaussehnitte entnommen, deren Selnenlänge immer $10 \mathrm{em}$ betrug (Fig. 1 a). Jeder der beiden Sehcibenausschuitte wurde alsdann in vier Theile 
zerlegt. Der äusserste Theil (1) umfasst die gesammte lebende Rinde und Basthaut, die zuvor sorgfältig von allen todten Borketheilen und Korkschichten befreit worden war. Der zweite Theil (2) umfasst den Splint resp. die äusseren in der Regel wasserreicheren Theile des

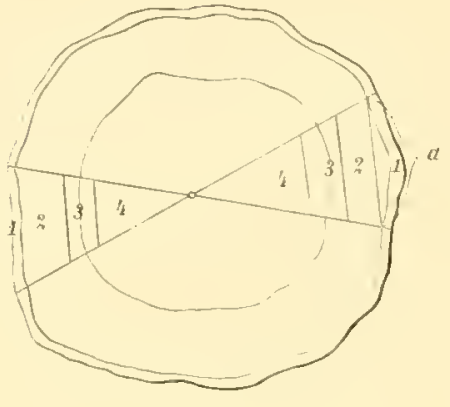

Fig. 1.

Querscheibe eines Tersuchsstammes, aus welcher zwei einander gegenüberstehende Aussehnitte zur Lntersuchung gezogen wuden, deren sehneulänge $a=10 \mathrm{ctm}$ beträgt. 1. Borketreie lebende Rinde resp. Bast. 2. Splint. 3. Mitte (theils splint, theils Kieru). 4. Kóen. Holzes. Der innerste Theil (4) ist der reine Kern resp. der wasserarme innere Theil des Reifholzes; das zwischen Sllint und Kern in der Mitte liegende Mittelstiick (3) umfasst oft meln rom Kern, oft mehr vom Splint und wurde nur desshalb ausgeschieden, unı einerseits völlig reinen Splint, andererseits röllig reinen Kern zur Untersuchung ziehen zu können. Bei der Birke wurde nur das innere, ältere und das äussere Holz von eimander geschieden. Bei den ersten Untersuchungen wurde nur ein Kreisausschnitt und zwar ron der Seite des Baumes entnommen, welche dem mittleren Radius der Scheibe entsprach. Die Entnahme zweier Kireis. ausschnitte hat aber nicht allein den Vortheil, dass grössere Quantitäten zur Untersuchung gelangten, sondern anch etwaige Verschiedenheiten der Banmseiten ansgeglichen wurden. Das Ausspalten der Versuclsstiicke geht sehr schnell ror sich und wurde dabei Ruicksicht darauf genommen, dass das Ilolz völlig astfrei war. Die beiden Splinte, Kernstiicke u. s. w. wurden auch zusammen sewogen. Abgesehen von den Rinden- und den Holzstïcken aus den obersten Sektionen der Bäume betrug das Gewicht der beilen stücke in der Regel zwischen 300 und 700 Gramm. Noch grössere Quantitäten zur Untersuchung zu ziehen, schien nicht rathsam, da erstens rlie Genauigkeit der Wägungen darunter hïtte leiden miussen, dic Vermeidung aller eingewachsenen Aeste u. dergl, nicht durchführbar und insbesondere das Trocknen in den Trockenkiisten zur Erzielung des absolnt trockenen Zustandes nicht mehr möglich gewesen wäre.

Es sei noch bemerkt, dass die grösste Sorgfalt darauf verwendet wurde, das Verdunsten der Objekte, die nicht sofort zur Wägung gelangten, möglichst zu verlindern und da meist nur wenige Mlinuten, im ungünstigsten Falle 10 Minuten verstrichen, bevor die Stiicke einer Querscheibe simmtlich gewogen waren, so glaube ich, die denkbar grösste Genauigkeit erreicht zu haben.

Eine neue Querscheibe wurle dem Baume erst dann entnommen, wenn die Stiicke der rorhergehenden Scheibe sümmtlich gewogen waren. 
Die Entfernung der einzehen Querscheiben von einander betrug 2 oder 3 m. Rücksichten auf die weitere Verwerthung und den Verkauf des Holzes nöthigten mich, den zwischen den Versuchssticken liegenden Walzen eine solche Länge zu geben, dass diese in volle Scheitlängen von 1 m zerlegt werden konnten. Daher kommt es, dass die Abstände der untersuchten Baumhöhen immer etwas melı als 2 oder $3 \mathrm{~m}$ betragen, ein Umstand, der ja völlig bedentungslos fiir die Zweeke der Untersuchung ist.

Die Rinderi wurden, sorgältig signirt, sofort in einer kleinen Botanisirbiichse untergebracht, die immer wieder versehlossen wurde und eine Verdunstung in dem Grade, dass anch eine Volumverminderung damit verknipft gewesen wäre, verhinderte.

Die Holzsticke wurden in Papier gewickelt und in Rucksäcke gepackt. Die Volumbestimmung sofort im Walde vorzunehmen, erschien einerseits nicht lurchfuihrbar, weil es ummöglich war, dies im Walde mit der nöthigen Sorgfalt aus\%ufuihren, andererseits war dies aber anch nicht notlwwendig. Zwar ändert sich das Gewicht der Holzstiicke durch Verdunstung in kurzer Zeit so bedeutend, dass dessen Ermittelung sofort erfolgen muss, eine Volum veränderung, ein, Schwinden" tritt dagegen erst mach bedentendem Wasserverlust ein, jedenfalls erst mehrere Tage, nachdem die Stiicke der Luft ausgesetzt sin $\mathrm{t}$.

Die Volumbestimmung durfte somit auf den Tag nach der Untersuchung im Walde versehoben und in forstbotauischen Institute vorgenommen werden.

\section{Die Tntersuchung im Hause}

hatte zuerst die Volumbestimmung der frischen Holzstiiclie resp. Zweige durchzufiihren, alsclann suchte ich den Lufttrockenzustand der Versuchssticke herzustellen, Gewicht und Volumen in diesem Zustande zu ermitteln und endlich mussten die (1bjekite absolut trocken gemacht und in diesem Zustande gewogen und gemessen werden.

Der vielfach von anderen Forschern eingeschlagene Weg der Volumbestimmung, der darin besteht, die Objekte vom Tischler oder Drechsler in bestimmte Formen arbeiten zu lassen, die mathematisch leicht messbar sind, musste als völlig unbrauchbar umberïcksichtigt bleiben. Jieser Untersuchungsmodus schliesst ja die Nothwendigkeit in sich, die Gewichtsermittehng erst nach Herstellung der gewïnschten Form vorzunehmen, bis zu welcher Zeit ein grosser Theil des Wassers schon verdunstet ist. Er schliesst auch die Möglichkeit aus, Kern, Mitte und Splint in demselben Verhältniss zur Untersuchung zu zichen, in welchem diese Sticke im Baum selbst rorkommen. Endheh 
wïden aber auch die beim Troeknen entstehenden Spalten bei Feststellumg des Trockenvolums gar nicht zu bestimmen sein.

Die Volumbestimmung durch Eintauchen in Quecksilber ist deshalb nicht mbedenllich, weil auf der Oberfläehe der Holzstiicke leicht Luftblasen lraften

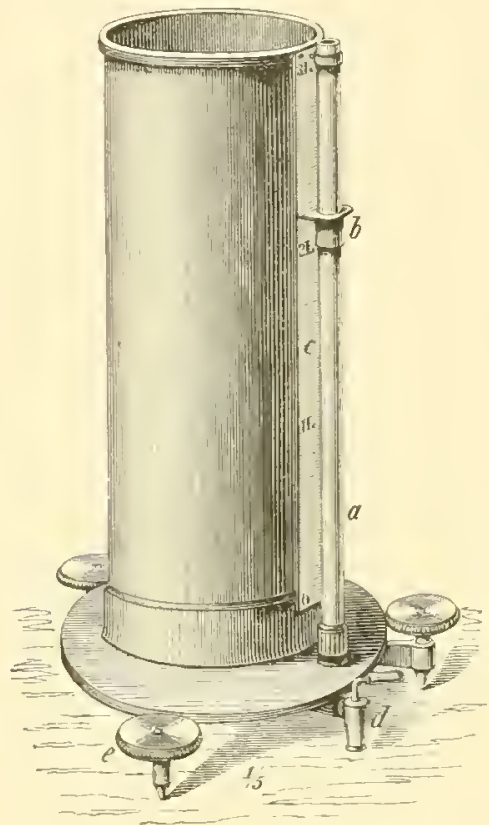

Fig. 2.

Xylometer mit Messingeylinder ron frebrïdes" Zimmer in ritutgart. Preis 99 Mark.

a Glasröhre zum Ablesen des Wasserstandes. $b$ shieher zu genauen Markirung der Wassethöhe sut der dahinter befindichen scala $c$, deren Theilstriche 0.01 Liter angeben, aber noch in 10 Theile eingetheilt wurlen können. d Abthsshalin. c Stellschambe zur Horizontalstellmug. Die obere Oeffiunng wird rumbl anen mit Libelle versehenen flachen Deckel versehlossen. Znm ['ntertauchen der 110lzstïcke ist eine lange Messingmadel heigegeben. bleiben, deren Gegenwart unter Quecksilber nicht controlirt werden kann. Nach sorgfiltigster Prüfung habe ich mich zur Anwendung ron mit Wasser erfuillten Xylometeru entschieden und kann ich die genügente Genaugkeit der Resultate garantiren. Für die grösseren Holzstücke wendete ieh einen sehr sorgfialtig in Messing gearbeiteten Xylometer an, wie ihn die nebenstehende Figur 2 darstellt. Die hinter der Glasröhre angebrachte Scala gestattet nnter Anwendung der Lupe und des genau gearbeiteten Schiebers nach einiger Uebung ein Ablesen von $1 \mathrm{ccm}$, und da die gemessenen Stiicke 200-700 cem Volumen enthielten, so war bei der Ablesung eine Genanigkeit an $0.2-0.5{ }^{\circ}{ }_{0}$ des Volumens erreielhbar.

Kleinere Holzstiieke wurden in genau graduirten Messeylindern geringen Durehmessers ron Glas gemessen und wurten die Holzstiicke zuror in solehe Stïcke gespalten, dass recht enge Cylinder benutzt werden konnten, in welche die Holzstiicke riber enander eingetaucht werden konnten. Die Ablesung in den benutzten Gefïssen konnte mit einer Genauigkeit erfolgen, dass der Allesungsfehler wohl nur selten bis zu $1 \%$ des zu messenden Volumens betrug, in der Regel aber die Ablesung viel genauter war.

Eine Felılerquelle, deren Grenzen von Anfang an genau festzustellen waren, lag in dem Umstande, dass das Wasser des Xylometers während des Eintauchens und vor erfolgter Ablesung in den Holzkörper einzudringen vermag und somit das al,gelesene Yolumen zu gering ansfallen muss. Die Menge dieses Wassers genau zu bestimmen, ist unmöglich, denn wollten wir auch die 
Holzstiicke vor und nach der Messung wägen, so würde die Gewichtszunalıme anch das nach der Ablesung, und während des Herausziehens noch ein. gedrungene Wasser umfassen, also mehr. Wasser ergeben, als in der That vom Eintanchen bis zu der ummittelbar daranf erfolgenden Ablesung des Wasserstandes eingedrungen ist.

Dagegen können wir den Gesammtverlust an Wasser feststellen, der durch die Operation der Tolumbestimmung ans dem Xylometer verloren gelıt. Dieser. Wasserverlust setzt siclı zusanmen aus

1) dem vor der Ablesung ins Holz eingedrungenen Wrsser;

2) dem nach der Ablesung und vor dem Herauszielıen des Stiickes eingedruugenen Wasser;

5) dem das Holzstiick änsserlich anhaftenden, dasselbe wie eine feine Hülle umgebenden Wasserschicht, die mit dem Stiicke herausgezogen wird;

4) dem beim Heranszichen der Holzstiicke noch ausserhalb des Xylometers ahtropfenden Wisser.

Zum öfteren wurde der Wasserstand im Xylometer bei Beginm der Untersnchnngen und dann an sehlusse derselben notirt, nachden $50-60 \mathrm{Holz}-$ stiicke gemessen waren. Es ergab sich hierbei, dass bei ler Messung ganz frischer Holzsticke etwa 1.4 "o des Gesammtvolumen aller Holzstiicke an Wasser in Verhust gegangen waren. Von diesem Quantum kann doch aber nur das sub 1 der vorstehenden Zusammenstellung bezeichnete Wasser als das Resultat fälschend bezeichnet werden. Sicherlich larf der, die Volumbestimmung fälschende Wasserverhst, $d$. h. das Quantm Wasser, das vom Moment des Eintauchens bis zum Ablesen in den Holzkörper eindringt, kaum auf etwa $0.5 \%$ anzunchmen sein. Es mögen durch diese. Ungenauigkeiten bei der Volumbestimmung lileine Schwankungen in den gefundenen Zahlen sich erklären, die Gesetze, die die Untersnchung urgeben hat, sind aber nicht hierdurcli verdunkelt worden.

Im lnfttrockenen und troekenen Zustande ist die Wassereinsaugung eine weit bedentendere und betrug z. B. 2.7 " " bei Untersuchung lufttroekener Hölzer. Bei absolut trockenem Holze würde die Menge des eingesogenen Wassers viel bedentender gewesen sein. Es war dies neben anderen Gründen die Veranlassung, dass ich von der Feststellung des lufttrockenen Zustandes bei der zweiten Hälfte der Entersuchnngen ganz Alsstand nahm und nur noch den alssolut troekenen "ustand genau untersuchte. Nachd'm das absolute Trockengewicht gefunden war, konnten die Holzstiicke durch Eintanchen in Leinöl, welches dann sorgfiltig vor der Messung abgetrocknet wude, gegen das Eindringen des Wassers geschützt werden. Da das Leinöl fast nur von den Hirnthiehen ans, hier aber mit grosser Begicrde eingesogen wurde, so hatte diese Opera- 
tion keine nachweisbare Veränderung des Vohmens zur Folge, verhinderte aber in sehr erfolgreicher Weise das Eindringen des Wassers. Die Probe ergab, dass bei der Xylometrirung dieser Stiicke noch weniger Wasser verloren ging, als bei der Messung der ganz frischen Holzstiicke.

Nachdem ich vorstehend die Methoden der Volumbestimmung dargestellt habe, gehe ich zur Besprechung des Untersuchungsganges iiber. Die Volumbestimmung des Frischzustandes crfolgte sogleich an Tage nach der Gewinnung der Stiicke. Sodann fand das Trocknen der Objecte etwa aeht Wochen hindurch an einem, dem fortwälurenden Luftzuge und der directen Insolation ausgesetzten Orte, nümlich am offenen Fenster eines Glashanses statt In den letzten Wochen zeigten anch die grösseren Holzstïcke kaum melı eine Gewichtsalonahme, dagegen eine Abhängigkeit von dem Feuchtigkeitszustande der Luit, die in mir die Ueberzengung reifte, dass die Ermittelung des luftrockenen Zustandes bei kleineren Holzstiicken gar keinen wissensehaftlichen Werth besitzt. Es ist bekannt, dass grössere Holzstiicke, zumal solche. die mit Rinde versehen sind, oft erst nach mehreren Jahren den sogenannten Lufttrockenzustand erreichen, d. h. einen Fenclitigkeitsgehalt zeigen, welcher dem mittleren Fenehtigkeitszustande der nugebenden Luftsehichten der betreffenden Localität entspricht. Es stellt sibh ein ziemlieh constantes Gewicht ein, da die Schwankungen im Wassergehalte der äusseren Holzsehichten gegeniiber dem Gesamntgewichte nicht so sehr in die Wagschale fallen. Bei kleineren Stiicken mit relativ grosser Oberfläche wiskt der schwankende Wassergehalt der äusseren Holzschichten so störend auf das Gesammtgewicht der Stiicke, dass eine wissenschaftliche Verwerthung des sogenamnten Lufttrockenzustandes dadurch vereitelt wird.

Nachdem die Versuchsstitcke nahezu lnfttrocken waren, wurden sie in Trockenkästen *) gebracht, in denen sie etwa $4 \times 24$ Stunden einer constanten Hitze von $105-110^{\circ}$ Celsins ausgesetzt wurden. Ich habe mich vielfach ïberzeugt, dass ein irgend beachtenswerther Wasserverlust durch langeres Trocknen nicht mehr herbeigeftihrt wird. Von Wichtigkeit crschien es mir aber, zu ermitteln, ol, nieht ctwa die Grösse der Holzstiieke ein Hinderniss des rollständigen Anstrocknens bilden möchte. Um dies festzustellen, wählte ich zwei Fichtenholzsticke aus, ron denen " im lufttrockenen Zustancle $59.60 \mathrm{gr}$, $b 77.26 \mathrm{gr}$ wogen.

*) Ich lıabe fiur solehe Zwecke cinen eisernen 'Troekenkasten ron $0.5 \mathrm{~m}$ Höhe, $0.5 \mathrm{~m}$ Tiefe und $1 \mathrm{~m}$ lireite anfertigen lassen, der dureh seehs Gasflanmen sehr gut auf eine constante Temperatur von $110^{\circ}$ Cels. erhalten werten kam, wem Fenster und Thüren des Laboratoriums gesehlossen und lachureh eine Temperatur der Laboratoriumsluft rou $35^{\circ} \%$ Cels. erzielt wude. Daneben benutzte ich noeh einen kleineren Trockenkasten, der dureh zwei Flammen heizlar war. 
Nachdem beide Stiicke $4 \times 24$ Stunden im Trockenkasten gelegen hatten, wog $a 53.25 \mathrm{gr}, b 68.50 \mathrm{gr}$. Nun zerspaltete ich $b$ in eine grosse Zahl klemer Stiicke und liess diese neben dem nicht zerkleinerten stiicke a weiter dörren. Nach $2 \times 24$ Stunden wog a $53.20 \mathrm{gr}, b$ dagegen $68.16 \mathrm{gr}$. Der Process wurde nochmals $4 \times 24$ stunden fortgesetzt und num, also nach 240 stïndigen Dörren bei $105-110^{\circ} \mathrm{C}$. wog a $53.17 \mathrm{gr}, b 68.00 \mathrm{gr}$. Die Fortsetzung des Dörrens über den vierten vollen Tag hinaus auf weitere 6 Tage und 6 Nächte hatte mithin fir das nicht zerkleinerte Stiick a einen weiteren Wasserverlust $\iota \mathrm{m} 0.150_{0}^{\circ}$ des Troekengewichtes am vierten Tage zur Folge gehabt. Beriicksichtigt man, dass der Wassergehalt des Fichtenholzes zwisehen $10.5{ }_{0}^{0}$ und $71.1 \%$ vom Frischgewicht schwankt, so kann jene weitere Abnahme um $0.15 \%$ nicht melır buachtenswerth sein, jedenfalls einen so bedeutenden Gasverbrauch nicht rechtfertigen, wie er eintreten wiirde, wenn man dis T'roekenzeit von 4 anf 10 Tage ansdehnen wollts.*)

Die Zerkleinerung des Holzstiekes $b$ lat dahin gefuihrt, dass dieses in den letzten 6 Tagen und Nächten um $0.73^{\circ} 0$ an Gewicht verlor, also in der That mehr, wie das Stiiek $\iota$. Gewiss dürfen wir dies zum Theil ciner intensiveren Anstroeknung zuschreiben, es ist aber fast mit Gewissheit anzunehmen, dass hierin aneh ein Verlust an Terpentin eingesehlossen ist, der bei dem flüchtigen Charakter dieses Oeles, der grossen Oberfïche des zerlkleinerten Objectes und der grossen Hitze nicht unbedeutend gewesen sein kann. Sei den, wie es wolle, ich glaube ans den Ergebnissen dicses Probeversuches zu der Anmahme. berechtigt zu sem, dass die Crösse 'der. Holzstiicke nu' minimale Wassermengen zuriekhielt, die fur die zu gewinnenden Resultate ganz ausser Betracht fallen. Es ist dabei noch zu beachten, dass ja die Holzsticeke alle gleichartig behandelt werden, somit jene geringen spuren von Wasser in allen Stiteken zurickgeblieben sind.

Nachdem die gedörrten Stiicke gewogen unıl gemessen waren, konnten die gewonnenen Resultate zur Berechnung folgender Zahlen benutzt werden:

1) Dis speeifisehe Frischgewicht $=$ Absol. Frischgewicht Frischivolumen.

2) Das specifisehe Trockengewicht $=$ Absol. Trockengewieht

Trockenrolumen.

3) Die Volumenverminderung (Sehwinden) $=$

Frischvolumen minus Trockenvolumen

Frischvolumen.

*) Zur Heizung der Trockenkästen brannten Tag und Nacht acht Gasflammen und berechnet sich der Gasverbranch der ganzen Untersuchung auf rund 10,000 Stunden bei einem Iinsensehen Brenner. 
4) Das Gewicht der organischen Substanz (incl. Asche) pro Frischrolumen= Trockengewicht

Frischvolumen.

5) Der Wassergelialt im Frischvolumen =

Frischgewicht minus Trockeng ewicht

Frischvolumen.

6) Der Wassergelualt in 100 Frischgewichtseinheiten $=$

Frischgewicht minus Trockengewicht

Frischgewicht.

Diese Verhältnisszahlen waren aber noch nicht geeignet, ein föllig klares Bild ìber die Tertheilung rom Luftraum und Wasser im Baume zu geben. Die Ausführungen in der schon oben erwälnnten Abhandlung ron J. Sachs iiber die Porositit des Holzes zeichneten selur klar den Weg vor, der einzuschlagen war, um zu dieser Einsicht zu gelangen.

Zunächst war es nothwendig, aus dem gefundenen Gewichte der organischen Substanz in einem Holzstucke das Tolumen zu bestimmen, rrelches dieselbe für sich in Anspruch nimmt.

Sachs hat auf frund sorgfaltiger Untersuchungen das specifische Gewicht der Holzwandung auf 1.56 festgestellt. Es schien mir wïnschenswertl zu sein, die von mir untersuchten Holzarten in gleicher Richtung zu untersuchen, um festzustellen, ob dis ron sachs ermittelte Fewicht ein allgemein giltiges sei, ob insbesondere durch die Processe der Verkeruung und Terharzung kieine Aenderungen des specifisehen Gewichtes herbeigeführt werden. Ich stellte zu dem Zwecke eine Reilhe von Lösungen salpetersauren Kalkes her mit den specifischen Gewichten von 1.57, 1.555, 1.540, 1.52, 1.50, die in holse Cylindergläser gefiillt wurden, um immer durch das Aräometer deren Gewicht controliren zu können. Stur zarte, mit scharfem Hobel hergestellte Querlamellen von Birken, Buchensplint, Buchenkern, Eichensplint, Eichenkern, Fichtensplint. Fichtenkeru. Kiefernsplint, Kiefernkern und Buchenrinde wurden sodann zuerst in einer Lösung von salpetersaurem Kalk einige Minuten erlitzt, um die Luft aus ilmen zu vertreiben und sodann in die Lösungen ron bekanntem specifischen Gewicht eingetaucht.

Es ergab sich nun das interessante Resultai, dass fast simmtliche Holzarten in der Lösung von 1.555 tagelang an jeder beliebigen stelle sich schwebend erhielten, so dass die sachssche Zilhl 1.50 lediglich bestïtigt werden kamn.

Insbesonrlere mag aber noch bemerkt werden, dass Eichenkern nach Vorlanf einiger Tage auf dem Grunde des Cylindergefässes ankam, Eichensplint dagegen selur langsam nuch oben stieg, wenn el mittelst Glasstabes nach nnten gebracht war. Harzreiches Kiefernkernholz aus dem harzreichsten Kern der 
untersten Baumsection erwies sich erheblich leichter, nämlich nur 1.52 schwer, eine Thatsache, lie sieh genuigend ans dem geringen specitisehen Gewicht des Terpentinöles erkliirt. Buchenrinde dagegen sank noch in der Lösung von 1.57 langsam zu Boden nnd dürfte wohl 1.58 specifisches Gewicht besitzen. Der reiche Gehalt an Aschenbestandtheilen erklärt das holıe Gervicht der Rinde zur Genüge.

Aus dem bekannten specifischen Gewicht der Holzwand berechnet sich somit

7) das Volumen der trockenen Wandung pro Frischrolumen durch Division von 1.56 in das Gewicht der organischen Substanz pro 100 Frisehvolumina.

Zieht man das Trockenvolumen der Substanz und dis Wasser rom Frischvolumen ab, so ergiebt sich

8) das Tolumen des Luftraumes im Holze.

Um zu erfahren, wie gross das Quantum flüssigen Wassers in Lumen der Organe sei, musste zuvor ermittelt werden, wie viel von dem Gesammtquantum les Wassers als Imbibitionswasser in der organischen Substanz sich befindet.

Mau darf wohl annehmen, dass die Substanz der Wandung so lange mit Wasser völlig gesỉttigt sei, als sich im Zelllumen noch flüssiges Wasser befindet; denn wenn anch das Wasser etwa mu im unteren laume des Zelllumens sich befindet, was ja walnscheinlich nicht der Fall ist, so werden doch anch die höheren Partien ciner Zcllwand änsserlich von dem Wasser der Nachbarzellen bespiilt. Es ist schwer zu glauben, dass cine Zellwand im nngesättigten Zustande sich befinden kann, die von innen oder von aussen mit liquidem Wasser in lieriilırung steht.

Die Ermittelung der Wassercapacitit der Holzwand nöthigte zur Vornahme einer sehr langwierigen und subtilen Unt rsuchung, deren Resultate zwar nicht im Widerspruche mit der Sachs'schen Untersuchung stehen, doch die Verwerthung der von Sachs gefundenen Zahl für eine andere, als die von ihm untersuchte Holzart (Weisstanne) als unzulïssig erscheinen liessen. Es war mir von vornherein zweifelhaft, ob die Wasserafnahnefahigkeit dieselbe sein wiirde bei splint und bei Kernholz, bei harzarmem und harzreichem Nadelholze und wurden desshalb, wie aus den in Tabelle 1 mitgetheilten Untersuchungsergebnissen zu ersehen ist, von ciner grösseren Reihe von Holzstïcken selır feine Ilobelspäne angefertigt, welche durch 18 stiindiges Dörren bei $105^{\circ}$ Cels. anf den ab. solut trockenen Zustand gebracht und dann gewogen wurden. Alsdamn wurden die Späne in einen mit Wasserdampf gesättigten Ramm gebracht, in welchem sie, ohne mit liquidem Wasser in Berïhrung zu liommen, durch Hygroscopicitit allmählich sich vollständig zu sättigen im Stande waren. Der Versuch wurde 
in der Weise durchgefulhrt, dass die erforderlichen Fenchtränme durch grosse iiber cinen mit Wasser angefüllten Teller gedeckte Glasglocken hergestellt wurden. Das Inncre der Glasglocken war mit Fliesspapier ansgelegt, welches von unten her sich stets völlig mass erhielt. Damit die Glasschalen, in denen die Hobelspaine sich befanden, mit dem Wasser auf dern Grunde des Tellers nicht in Beruhrung kamen, wurden sie auf kreuzweis iibcreinandergelegte Hölzer gestellt. Es war diese Vorsicht nothwendig, da bei einer etwaigen Temperaturdifferenz zwischen dem Wasser und der Luft im Feuchtraume sich auf der Innenwand des Glasgefässes Wasserdampf niederschlagen musste.

Es wurden ferner die Versuche im Kellerranm des forstbotanischen Institutes ausgefülnt, in welchem während zweier Monate die Temperatur nur zwischen $7^{\circ} \mathrm{R}$. und $8^{\circ} \mathrm{R}$. schwankte.

Die wiederholten Wägungen wurden ebenfalls im Keller ausgefiihrt, wo unmittelbar neben dem Orte der Aufstellung der Feuchtrïume die Wage ihren Platz fand. Da die Kellerhft der Wassersüitigung ziemlich nalse stind, so war auch während der Wägungen kam ein Wasserverlust dureh Verdunstung der Hobelspäne zu bemerken. Es ist kaum die Möglichkeit der Aufnalıme kapillaren Wassers geboten worden, wemn auch gegen Ende der Untersuchung bei einzelnen Glasschalen ein ganz geringer Beschlag auf der Innenseite zu beobachten war. Wo dies der Fall war, ist in Ruicksicht darauf, dass die der Wand anliegenden späne ein wenig Wasser aufgenommen haben, der Procentsatz um etwas verringert worden.

Die in der Tabelle I zusammengestellten Wägungsresultate zeigen, dass im Durchschnitt schon nach 2 Tagen die Hälfte der aufnehmbaren Wassermenge von der Substanz aus der Luft aufgenommen ist. Von da an verlangsamt sich die Wasseraufuahme immer mehr und hört nach Holzart und Ilolztheil verschieden spät auf, ja bei einzelnen Proben verringerte sich in den letzten Wochen das Crewicht sogar etwas.

Dic Wassercapacitiit scheint in enger Beziehung zu dem Vorhandensein oder Fehlen solcher Zellen zu stehen, die quelhungsfähigen Inhalt führen.

Wïhrend Buchenreifholz dessen parenchyunatische Zellen völlig leer sind, schon nach 17 Tigen kein Wasser mehr aufnimmt und damn $57 \%$ des Substanzvolumens an Wasser enthält und dann ein wenig abnimmt, nimmt das Buchensplintholz, welches lebende, stärkemehlfiihrende Parenchymzellen in grosser Zathl besitzt, noch bis zum 57. Tage zu und enthilt dann $72 \%$ Wasser. Die mikroskopische Untersuchung an diesem Tage ergab, dass sich im Kéene und im Splintholze einige Pilzfiden fanden, die genugsam die beginnende Gewichtsabnahme erklïren. Die grössere Wrassercapacitit des Splintholzes darf wohl rorzugsweise unf den Quellungsprocess des Inhaltes parenchymatischer Zellen zurickgefuihnt werden. 
Für Buehensplint wurden $72 \%$, für Buchenkern $57 \%$ und fiir die Mitte zwischen beiden $66 \%$ Imbibitionswasser angenommen.

Eichenkernholz enthilt $75 \%$, Eichensplintholz dagegen $92 \%$ lmbilitionswasser: Ersteres enthält zwas nur wenige lebende Parenchymzellen, lagegen ist das Innere vieler Parenchymzellen, sowie mancher 'Tracheiden und Áclerenchymfasern mit lorannem Kernstoft erfiult, der eine bescln:inkte Fähigkeit der Quelhng resp. Löslichkeit besitzt. Desshall, ist die Wasserapacitit des Eichenkernholzes eine grosse im Vergleich zum Buchenreitholz, in welchem der Kernstoff fehlt.

Weit grösser ist die Wassermenge in der Substanz des Eichensplintholzes. Die grosse Zahl der Stitukemehl fuhrenden Zellen des Strang- unI Strahlenparenchyms, die sich auf hygroscopischen Wege mit Wasser füllen, erklärt die lang andanemde und ein hohes Maass erreichende Wasseraufnahme. 1)as Gefäss, in welchem die Eichensplintspïne sich befanden, zeigte in den letzten Wochen auf der Innenseite fenchten Beschlag, wodurch einzelne, die Wand berïhrende Holztheilchen anf capillarem Wege Wasser halsen aufnehmen kömnen. Ith glaubte es desshalb angezeigt, anstatt $92 \%$ nur $90 \%$ hygroseopisches Wasser in Anrechung bringen zu sollen.

Eichensplint hat also $90 \%$,

Eichenkern dagegen $75 \%$ Imbibitionswasser.

Die Binke, deren Parenchymzellen meist ganz leer sind, oder doch nur wenige Reservestofte in Form ron Geltropfen führen, ist schon nach 4 Wochen mit $66 \%$ dem Maximum nahe gekommen. Zwar ergab 3 Wochen släter die Wägung $67 \%$, doch war 10 Tage spitter das Gewicht wieder etwas, nämlich auf $66 \%$ gesunken. Es wurde fir Birke eine Cipacitit von $66 \%$ angenommen.

Seln interessant ist das Verhalten ler luiden Nadrlholzbäume, insofern die Irenge des Harzgehaltes die Wassereapacität selur auffillig beeinflusst.

Ieh habe, um diese Verhältnisse klar zu stellen, von beiden Bäumen Kernholz und siplintholz aus der Krone und von dem untersten Stammende zur Untersuchung' gezogen.

Die Kiefer mit ihrem reichen Harzgehalte im Kernholze zeigt unten im Kerne $45 \%$, in der Krone dagegen $49 \%$; der splint zeigt unten $53 \%$, oben $57 \%$ : je harzärmer las Holz, $1 \mathrm{~m}$ so grösser ist also clie Wassercapacität.

Einestheils wird der. Harzgehalt auf die Wasscreapacität ungiinstig einwirken, weil das Harz resp. Terpentinöl sclbst kcin Wasser aufnimmt, anderentheils weil es einen Theil der Mlicellarinterstitien ausfült und anch die Wandungen vicler (1rgane mit (iner Schicht bekleidet, welche die Aufnahme des Wassers in die Wandung sehr erschwert. 
Der Kiefernsplint ist in den letzten 9 Wochen wieder leichter gerrorden, wahrscheinlich in Folge von Pilzbildungen. lch habe für den splint $\frac{57+53}{2}=$ $55^{\circ}$, fir den Kern $\frac{49+45}{2}=47+1=48$ angenommen. Die V'ermehrung: um $1 \% / 1$ 'rfolgte, weil die Masseraufnahme des Kernes noch nicht ganz beendigt ersehien. Fiir die Mittelsticke dagegen habe ich 50 o o gewählt.

Bei der Fichte ist dic Wassercapacitit des Kenholzes und Splintholzes sehr wenig verschieden, wohl nur zufilligerweise ist die Capacität in muteren Baumtheile um etwas grösser, als im oberu biumtheile.

Dil bei der fichte der Hauggehalt zwischen Splint und Ker'u kamm verschieden ist, so erkliirt sich jene Uebereinstimmung zur Geniige. Ich habe den Durchschnitt aus den + Untersuchungen mit $60^{\circ}{ }_{0}$ füi alles Fichtenholz angenommen.

Fuir Lårchenholz wurde keine Untersuchung angestellt, und da dasselbe dem Kiofornholz sehr ähnlich sein dürte, so mahm ich für splint $5.50 \%$. für Keln $50 "$ " an.

Es ist num die Frage aufzuwerfen, ob bei der Jiprechmung des Gelualtes an fuissigem Wasser nu das in den Wandungen enthaltene oder anch das ron den organischen stoffen im Innenrame der Zellen aufgenommene Wasser ron dem Gesammtwasser des Holzes in Abzug zu bringen sei. Jul. Sachs bringt nur das Wandungswasser in Alyug und wigt sehr diimne Holzscheiben in dem Augenblicke; in welchem die durch ras Trocknen entstandenen Spalten sich vollständig wieder geschlossen haben, von der Annahme ausgehend, dass der volle sittigungszustand der Wand cingetreten sei, wenn die durch das Trockenen entstandenen Spalten im Holze wierter verschwinden.

Es ist mir nicht ganz zweifellos, dass diese Amahme richtig sei. Der Spalt, welcher buim Trocknen iles Holzos entsteht, roprisentirt nicht das volle Maass der Volumrerminderung, sondern nur die Differenz zwischen dem Schwindon in peripherischer und radialer hichtung. Es ist siches, dass bereits eine Tolumvermintroung des ganzen Stiickes eingetreten ist, beror die Holzseheibe mit lautem Kinall aufreisst. Ebenso kam man sich denken, dass lie Spralten bei der Wiederaufnahme von Wasserdampef sich bereits geschlossen haben und doch die Volumvergrösserung in radialer und peripherischer Richtung eine Zeit lang noch fortdauert.

Es scheint mir auch wahrscheinlich zu sein, dass nach den Schlusse des Spaltes die Quellung der Zellwinde auf Kosten des Zellrammes noch ein wenig sich fortsetze.

Umgekehrt scheint as mir nicht ausgoschlossen zu sein. dass bis zu dem Zeitpunkte, bis zu wehchem die Spalten ilus Holzes sich iturch Quellung wieder 
schliessen, der Zelleninhalt ebenfalls schon riel Wasser angezogen liabe. Die Gewichtsdifferenz zwischen dem absolut trockenen Zustande und dem Stadium, in welchem die Holzspalten sich geschlossen haben, giebt somit schwerlich einen völlig sicheren Anhalt zur Beurtheilung der Wassermenge, welche in die Holzwandungen aufgenommen werden lasn.

Mir scheint es andererseits durchans zulässig, las $\mathbb{T}^{\top}$ asser, welehes rom Zellinhalt auf hygroscopischem Wege antgenommen wird, mit dem von den Zellwänden aufgenommenen Wassel gemeinsam von den Wasser zu tremen, welches im Innenraume der leitenden Organe sich befindet. Ich habe desshalb keimen Anstand genommen, das hygroscopisch anfgenommene Wasser unverkiuzt von dem Gesammtgehalt an Wasser in Abzug zu bringen, um das Quantum an Wasser zu finden, das in d'm Innenraum der leitenden (Jrgane sich befindet und dessen wechselnder Stand zu verschiedenen Jalıreszeiten uns Anfschluss zu geben vermag iiber den spannungszustand des in denselben Organen enthaltenen Luftquantums. Es ist ibrigens fiur die Resultate der Untersuchung nicht gerale von hoher Bedeutung, ob man ron clem sicher bestimmten Gesammtwasser etwils zu viel oder zu wenig als lmbibitionswasser in Aluzg bringt. Da derselloe Faktor fuir alle llolzstiicke derselben IIolzart in Anwendung kommt. so wird das Gesetz der Wasserstandsverinderungen dalurch nicht wesentlich alterirt werden.

9. Das Volumen der imbibirten Holzwand mit Einschluss des gesiittigten

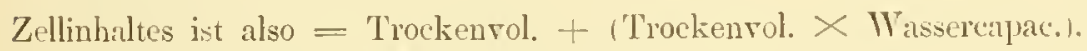

Durch eine einfiche subtraction findet man sodann:

10. Die Menge des flissigen Massers im Innenraum der Organe. Sie ist gleich dem ganzen Wassergehalt weniger der Wassemmenge, die ron der organischen Sulbstanz imbibint ist, also $=W^{\top}$ asser - (Trockenrol. $\times$ Wassercapac.). 


\section{B. Die Darstellung der Untersuchungsergebnisse}

$$
\text { in den Tabellen } 2-44
$$

bedarf nur einiger Erläuterungen,

Die Spalte a giebt vor dem Worte „Rinde“ diejenige Baumhöhe iiber dem Boden in Mletern an, woselbst die Versuchsscheibe entnommen wurde; die vor den Trorte ,.Holz $^{66}$ stehende Zahl dagegen bezciehnet den mittleren Durchmesser des Baumes an dieser Stelle in Centimetern.

Das Zeichen o bedentet, dass das auf gleicher Linie stehende Holzstiick ganz oder fast frei von Stärkemehl ist, während ein + reichliches Stärkemehl andeutet. + - 0 zeigt an, dass nur die letzten Jahresringe des Splintes Stärke fïhren.

Spalte $b$ bezeichnet die Versuchsstiicke und verweise ich beziiglich der Bedeutung der Worte „Riude, splint, Mitte, Kern" auf das Seite 8 Gesagte. Fs sei nur bemerkt, dass ich auch bei Birke, Buche und Fichte, welche Bäume kein kernholz laben, die innersten Holztheile im Gegensatz zu den äusseren "Kern" benannt lıabe. Die mit ,\%.Holz" bezeichnete Linie giebt nicht den Durchschnitt aus den vorangehenden Rubriken, vielmehr die für den ganzen Holzkörper ler betreffenden Baumhöhe gïltig'en Zahlen.

Um splint, Mitte und Kern genan in dem quantitativen Trerhältnisse, in welchem sie im Baume vertreten sind, zur Rechnung zu ziehen, musste fiewicht und Volumen von splint, Mitte und Kern zusammengezogen werden und aus dem Gesammtvolumen und Gesimmigewichte des ganzen Holzes ergaben sich dann erst die weiteren Zahlen dieser Linie.

Spalte $c$ giebt die mittlere Jahringsbreite der Probestiicke, gefunden durch Division der Jahrringszahl in den radialen Lurchmesser des Holzstickes.

spalte $d$ bis $n$ finden ihre Erläuterung durch den Kopt' der 'Tibellen und durch das bereits friiher Gesagte.

Es sei nur noch bemerkt, dass in den Fällen, in welchen die IVassereapacitait zwischen splint, Mitte und Kernholz verschieden ist, fiur den ganzen Holzkörper zur Berechmung der Ziffern in spalte $f$ nicht etwa eine mittlere Wrassercapacität angenommen werden durte, dass viehmehr für jede Baumhöhe 
unter Berieksichtigung des quantitativen Verhältnisses rou Splint, Mitte und Kern die Menge des imbibirten Wassers zuror festgestellt wurde. Ein Beispiel möge dies erläutern.

Die unterste Section einer Kiefer hatte folgende Volumina der Versuchsstiicke:

$$
\begin{aligned}
& \text { Splint } 637 \mathrm{ec} \\
& \text { Mitte } 485 \text { - } \\
& \text { Kern } 301 \text { - }
\end{aligned}
$$

Abgerundet verhalten sich die cinzelnen Theile zı einander wie $4: 3: 2$ und somit berechnet sicl,, da Splint 55, Mitte 50, Kem $48 \%$ Masser auf.nehmen, die Wassereapacitït des ganzen Holzstiickes wie folgt:

$$
\begin{aligned}
& 4 \times 55=220 \\
& 3 \times 50=150 \\
& 2 \times 48=\frac{16}{466}=52
\end{aligned}
$$

Die Methode der Untersuchung gestattete, auch fỉr den ganzen J' a um genau entsprechend der quantitativen Vertheilung der Substanz, des Luftraumes und des IVassers, das durchschnittliche Gewicht und Volumen der organischen Substanz (d. e.f.), den Luftraum $g$, den Gehalt an Wasser $h$ und $i$ und das durchschnittliche spezifische Frischgewicht $b$ festzustellen. Wie ich friilıer schon angab, ist die Länge der Tectionen eines Baumes immer die gleiche, fiir jule Section ist ein gleich langes Versuchsstick abgesehnitten und somit repriisentirt die Summe der Versuchsstücke den Baum in allen seinen Theilen gleichmässig. Addirt man die Kreisfïichen aller Sectionsmitten eines Baumes, multiplizirt man ferner jede Sectionsquerfläche mit dem zugelıörigen Procentsatz an organischer Substanz, Wasser und Luftraum, addirt die gefundenen Zahlen und dividirt mit der Gesammtkreisfïche in die reduzirten Kreisfächensummen, so erhüilt man den wirklichen Durchschnittsgelıalt des Baumes an Substanz, Wasser und Luftraum, wie solcher unter jeder Tabelle auf der mit "Ganzer Baum" bezeichneten Linie aufgefithrt ist. 


\section{Die Resultate der Untersuchung.}

\section{Ihas Verhältniss zwisehen liquidem Wasser und Luftram im Baume in Beziehung zur Lrsache des Saftsteigens.}

Es kann hier nicht meine Aufgabe sein, einen historischen und kritischen Ueberblick ïber die verschiedenen Hypothesen, welche sich mit der Erklïrung der Ursachen und Lrräfte des Wassersteigens in den Bäumen beschäftigen, zusammenzustellen. Ich beschränke mich darauf, die zur Zeit noch bestehenden Anschanungen über die Ursachen der Saftbewegung in gedringter Form einander gegenüber zu stellen, um dann zu prïfen, ob die Resultate unserer Untersuchungen zur Stiitze der einen oder der anderen Theorie dienen können orler ob aus denselben sich neue Gesiehtspunkte zur Erklärung des Saftsteigens ergeben.

Da ich unter einem Theile meiner verehrten Leser die Bekanntschaft mit dem gegenwärtigen stande dieser Frage nicht voraussetzen darf, so schicke ich eine kurze Darstellung der Molecularstructur der organischen Substanz vorans, die einem nur aus Pflanzenphysiologen bestehenden Leserkreise gegenüber nicht nötling sein wïrde.

Die organisirten Substanzen (Zellwand, Mehle, Plasma) besitzen das Termögen, Wasser bis zu einem gewissen Maasse in sich anfzusangen, wodurch die Substantheilchen, welche für Wasser nicht mehr durchdringluar sind, die sog. Nicelle, auseinandergedrängt werden und mithin die substanz ihr Volumen vergrössert (Quellung), während umgekehrt dureh Abgabe ron Wasser das Volumen der Sulsstanz sich vermindert, also ,schwinder".

Die Quellungsfâhigkeit erklärt sich ans der Structur der organisirten Substanzen, die nach den genialen Forschungen Na egeli's so anfgebaut sind, dass die Atomverbindungen (Molecile) zu Moleciilgruppen (Mlicelle) zusammentreten, die für Wasser völlig undurchdring bar werden. 
Die Micelle sind winzige, auch bei stärkster Vergrösserung noch nicht erkennbare polyedrische oder krystallinische Partikel. welche ähnlich einem Mosaik die Zellwand anfbauen, die in einem absolut troekenen Körper bis zur direkten Beribrung einander genähert sind. also keinerlei Capillarräume zwischen sich lassen, aljer dureh eindringendes WTasser aus einander gedrängt werden. Das Eindringen des Wassers in die rubstanz (Imbibition) ist Folge del allgemeinen Molecularattraction, welche bekanntlich mit der Entfernming von der Obertäiche des Moleciils sehr schnell abnimmt. Kommt Wasser mit einer trockenen Zellwand in Bertilnung, so umgeben sich zunächst die oberflachlich liegenden Nicelle mit einer. Wasserhible und worden dadurch von den im Inuern der Substanz gelagerten Micellen abgedrïngt.

Diese besitzen aber ebenfalls ein energisches Anziehungsbestrelren zu Wasser und entreissen desshalb den Oberflächenmicellen einen Theil ihres Massers, da diese die entfernteren Wassertheilchen ihrer Wasserhiille nicht mit ler Kraft festzuhalten in stande sind, mit welcher die noch trock nen Naehbarmiculle jene anziehen. Es findet somit eine Manderung der Massertheilehen von aussen nach innen statt, die ein Nachströmen von aussrn so linge zur Folge hat, bis die Sulstanz gresiittigt ist. Man verstcht hierunter don Zustand der unbölichen organisirten Substanz, in wehen die Anziehungskiaft der mit Thasserhüllen nmgebenen Micelle unter einander eloen so gross ist, als die Anziehungskiaft der Nicelle zu den entferntesten Theilchen ihrer Wrasserhiille resp. zu etwa neu hinzuströmenden Wassertheilchen. Die gegrenseitige Anziehung der Micelle gestattet alstann keine weitere Masserufnahme, bis das Gleichgewicht anf die eine oder ander' Weise gestört wird. Würle der Substanz durch Verdunstung an einem Punkte Wasser entzogen, so wiurde sotort eine Strömung dorthin eintreten miissen, bis die Anzichungskraifte durch die ganze Sulstanz glleichmïssig befrierligt sind.

Eine Bewegung des $\mathbb{W}$ assers wird aber auch dann eintreten können, wenn das Imbibitionswasser einem einseitig gesteigerten Druck ansgesetzt ist, und diese durch Druckrlifferenzen erzeugten Wasserbewegungen bezeichnet Jul. Sachs in seiner Seite 1 erwihnten Abhandlung als Filtrationsbewegungen.

Aendert sich zwischen zwei benachbarten, mit Wasser und Luft erfuilten Holzzellen der Druck der Luft auf das 11 asser im Innorn der Zelle, so erfolgt alsbald eine Filtration des Wassers durch die gesätigte Zellwand zu der Zelle, in welcher die geringere Lufteusion sich befindet.

Iie Imbibition ist nicht $z n$ verwechseln mit der Capillaritiit, wie J. Sachs in seinem Artikel iiber die Porositiit des Holzes sehr klar entriekelt hat. In der quellenden organisirten Substanz entstehen die mit Wasser erfiullten Räume (Micellarinterstitien) erst durch das Eindringen des Wassers und desshalb quillt eben die substanz. Bei den Capillarerscheinungen, wie wir sie z. B. bei Thon 
u. dgl. beobachten, werten vorhandene, mit Luft erfillte Räume von dem durch Molecularattraction hineingezogenen Wasser ausgefült. Die Luft entweicht. Das Volumen der Substanz rergrössert sich nicht.

Dic Anziehung der trockenen Substanz zu Wasser besehränkt sich nicht auf den liquiden /ustand des letzteren, sondern sie erstreekt sich auch auf das in der Luft vertheilte Wasser. Die hỵgroskopischen Eigenschaften der Hölzer habe ich bereits Seite $15 \mathrm{ff}$, zu besprechen Gelegenheit gehabt und rerweise ich auf den in Tabelle I dargestellten Gang der Wasseranfinahme des Holzes ans der Luft. Je näher der Wassergehalt dem vollen Sättigungszustande, um so schwächer ist die Kraft, mit welcher die Micelle Wassertheilchen aus der Luft anziehen, um so langsamer erfolgt die Wasseraufsaugung.

Wird einer mit Wasser mehr oder weniger gesättigten Pflanzensubstanz dureh die Processe der Assimilation, der Stoffverändernug oder der Transpiration W'assel entzogen, so muss zu dem Orte des Verbrauches eine Strömung eintreten, die eine nachhaltige ist, wenn der Wasserverbrauch andauert. Ist die Pflanze nicht im Stande, Wrasser von anssen. z. B. durch die W'urzeh aufzumehmen, so rertrocknet dieselbe endlich.

Termag sie ebenso schnell den Terlust an Wasser durch Anfuahme von anssen und durch Fortleitung des Wassers im Inneren zu ersetzen, so wird der Tassergehalt in der Pflanze nur wenig unter den vollen Saittigungsgrad herabsinken.

Ist die Wasseraufnalnme und Fortleitung in irgend einer Weise erschwert, so dass zur Zeit der lel,haftesten Verdunstung nicht schnell genug Ersatz für đen Verlnst eintreten kann, dann wir eine grössere Differenz im Wassergehalt der Pfanze zwischen dem Orte deś Verbrauches und der Anfnalume eintreten miissen.

Allgemein ist anerkannt, dass der Wasserverbrauch durch Transpiration der Blätter die hauptsächlichste Ursache der Wasserwanderung von den Wiurzeln zur Baumkrone ist, dass ferner der Ort der Wasserbewegung nach oben der Holzkörper des Baumes sei.

Bei einigen Holzarten betheiligt sich vermuthlich der ganze Holzstamm, bei anderen nur der jüngere äussere Theil desselben an der Leitung.

Dass die Tracheiten in ganz hervorragendem Mlaasse, unter Umständen sogar allein die Organe der Saftleitung sind, beweist der Holzkörper der Nadelholzbiimme. Ob bei den Laubhölzem die Gefässe und event. in welchem Marasse bei der Saftleitumg sich betheiligen, ist eine streitige Frage, auf die ich in der Folge zuriickkommen werde.

Unbestimmt ist es noch, ob und in welchem Grade die Sclerenchymfasern mit ilnen sparsamen, kleinen Tipfehn an der saftleitung theilnehmen. 
Meinungsverschiedenheiten prineipieller Bedeutung bestehen unter den hervorragendsten Physiologen über den Weg, Welchen das Wasser bei seiner Wanderung einschlägt, und über die Krâfte, welehe bei der Wasserbewegung in Tirksamkeit treten.

Die zur Zeit am meisten verbreitete Sachs'sche Theorie nimmt an, dass das Wasser wenigstens in den Perioden lebhafterer Terdunstungstlitigkeit nuw in den Micellarinterstitien der $W$ andungen aufwärts ströme und dass hierbei die Imbibitionskraft allein in Wirksamkeit sei.

J. Sachs nimmt an, dass die transpirirendeu Blattzellen den Verlust der Zellwände an Imbibitionsfliissigkeit auch aus dem Plasma und Zellsafte auszugleichen snchen und dass durch die Masserarmuth des Zellinhaltes und der Zellwandungen ein energisches Anzielungshestreben zu dem Wasser benachbarter, tiefer nach immen liegender Zellen und endlich zu dem ITasser der leitenden Organe der Gefässbindel hervorgerufen werde. Die wasserreiche Substanz der Holzzellen wirt einen Theil ihres Imbilitionswassers an die wasser. armen Blattzellen abgeben und dacturch selbst relativ wasserarm werden, falls die Holzorgane nicht in Lumen Wasser fuhren. So lange dies dev Fall ist, werden, wie Saclis ausdriicklich hervorhebt, die Wandungen der betreffenden Organe mit Wasser vollgesättigt sein.

Die Vertreter de1 Imbibitionstheori, geben zu, dass zu Zeiten, wo die Verdunstung sehr gering, die Bedingungen der Wrasseraufsangung sehr giinstige sind, auch Ueberschiisse flissigen Wissers im Lumen der leitenden Holzfasern sich ansammeln, die dann bei Eintritt lebhafterer Verdunstung zuerst verbraucht werden, bevor Differenzen in Wassergehalt der Wandungen sellost entstehen.

Die einzig bewegende Kraft ist aber nach ihnen docl nu die Imbibitionsliraft, und im Hochsommer und im Herbste ist nach deren Auschamung das Lumen der Holzorgane leer, das Wasser wandert in der Wandung anfwiirts, weil deren substanz je näher den Bläittern um so trockener sei.

Gewisse Erscheinungen, das Bluten und Thränen der Pflanzen, sind nicht wohl aus der Imbibitionskraft zu erklåren. Nlan nimmt desshalb die Existenz einer zweiten. das Wasser bewegenden Kraft, einer vis a tergo an, durch welche das Wasser im Holze der Pflanze emporgehoben wird. Uiese Hubliaft verlegt man in das Parenchym der Wurzeln. Das die Gefassbündel umgebende paren. chymatische Gewebe der jüngsten Wuzelspitzen ist sehr zartwandig, lückenlos und mit Colloidstoffen elfitllt. Letztere haben das Bestreben, Wasser aus der Umgebung aufzunehmen

Das aus dem Boden auf osmotischem Wege aufgenommene Wasser versetzt die Zellwand der Wurzelzellen in einen Zustand der Spannung, durch welchen auf den Zellinhalt ein Druck ausgeibt wird, der zum Durchfitriren 
des ïherschiïssig aufgenommenen Wassers durch den Theil der Zellwand führt, der im spannungszustande Wasser am leichtesten passiren lïsst. Man nahm num bisher an, dass die Aussenwandungen das Wasser selwwerer durchfiltriren liessen als die Innenwände, sei es, dass jene dicker oder stofflich ron den im Inneren des Zellgewebes liegenden Zellwänden etwas versehieden sind. Das Bodenwasser, welches vom Zellinhalt durch dessen osmotische Anziehungskraft eingesogen worden ist, soll dann durch den Druck, welchen die expandirte Zellluïlle auf den Inhalt ausübt, durch die leichter passirbare entgegengesetzte Wand hindurchfiltrirt und so sehliesslich dem fiefïssbündel zugefïhrt werden. Nenerdings hat man die Ammahme einer verschiedenen Filtrirfähigkeit der immeren nud :iusseren Zellwand fallen gelassen und die Ansscheidung des Wassers nach innen als eine Function des lebenden Protoplasmas bezeichnet. Je lebhafter die Endosmose des Wassers in das Wruzelparenehym erfolgt, $n$ um so energischer und erfolgreicher wird der Filtrationsprocess des Wassers nach innen von statten gehen. Diese Wurzeldruekkraft wird zu Zeiten, in denen der Baum wasserreich ist, das Wasser auch in den Gefíssen bis zu bedeutender Hölue emporheben und nach eventuell eingetretenen Verwundungen ein Ausströmen des Pflanzensaftes herbeifithren.

Die Vertreter der Imbibitionstheorie nehmen an, dass dann, wenn die Biume ihre Blitter entfaltet haben und durch den Verdunstungsprocess die Holzsubstanz aus dem gesättigten Zustande in den rer relativen Wasserarmuth übergetreten sei, dieser Wurzeldruck nicht zur Geltung kommen könne, weil ja das aufgenommene Wasser direkt zum Ersatz des nach oben geströmten Wandungswassers verwendet werde. Ein Wurzeldruck könne gar nicht entstehen, weil keine Uebersättignng der Wrurzelzellen eintrete, das anfgenommene Wasser schnell von der relativ trockenen Substanz der Zellwände aufgesogen resp. weiter geführt werde.

Der Imbibitionstheorie gegenüber hat sich in den letzten "Jahren immer. mehr die Anschaumng Geltung verschaftit, dass die Tension der Ilolzluft bei der Wasserbewegung eine hervorragende Rolle spiele. Ich erinnere an die juingsten Arbeiten ron Höhnel, Jos. Böhnn und Jul. Sachs. Die Wahrnehmung dass bei stark transpirirenden Zweigen die Luft der Gefísse in selır verdiinntem Zustunde sich befindet, die Schwierigkeit, die Imbilitionstheorie in Einklang: zu bringen mit der Thatsache, dass der Wassergehalt des Holzes auch zur Zeit der lebhaftesten Transpiration viel zu gross ist, um annehmen zu können, dass Differenzen im Wassergehalt der Holzwinde auftreten, denen die Wasserbewegung zuznschreiben sei und verschiedene andere Bedenken halyen zur Anfstellung einer Wasserbewegungstheorie gefuhrt, die man schlechtweg die Gas. druektheorie nennen kamn. 
Diese Theorie*) geht zunächst von der Anuahme aus, dass in den leitenden Holzschichten Luft und liquides Wasser das Lumen der Organe neben einander ausfullen, dass tie rerholzten Wandungen leicht für Wasser passirbar, nicht orler doch nur sehr schwer für Luft passirbar seien. Tirt durch den Transpirationsverlust ler Blattzellen den obersten Holzzellen Wasser entzogen, so ersetzen dicse den Verlust zunächst aus der Flissigkeit ihrer Lumina. Der Wasserspiegel sinkt in diesen und in gleichem Marsse verdiunnt sich tie Luft im Lumen diescr Organe. Der Druck, weichen die Luft auf das Wasser ausübt, vermindert sich in den obersten Zellen, in Folge dessen die dichtere Luft in den tieferstehenden Holzzellen das Wasser durch die Wandungen nach oben empordrickt, lis sich die Lnftichtigkeiten wieder ansgreglichen haben. Damert der Wasserverhust in den oberen l'flanzentheilen fort, so ernencrt sich einerseits die Verdinnung der Holzluft dort bestindig und es muss eine durch den ganzen Holzstamm bis zm Wurzelspitze sich fortpflanzende sangkraft zu Stande kommen, die auf der Differenz der Luftension zwischen je zwei iibereinanderstehenden Holzzellen beruht. Böh nimmt für die Laubhölzer auch eine Trasserleitung in den Gefässen an. Nach seiner Ansicht ist das Wasser in den Gefissen durch Luftblasen unterbrochen, deren Tension ebenfalls olom eine geringere sei, als unten. Diese I,uftblasen buwegen sich nicht mit dem Wisser nach oben, vielmehr weichen die Wrasertheilchen denselben seitlich aus, indem sie in die benachbarten Holzzellen strömen und arst oberhalb der Luftblase wieder in das Gefiss zuriuckkehren.

Die Aufnahme res Wassers aus dem Boden dureh die Wurzelzellen erfolgt nach Böhm's Ansicht aus demselben Grunde, aus welchem das Wassersteigen im Holzkörper vor sich geht.

Die dichtere Aussenluft presst das Wasser in die Pflanze hinein, deren Wasser unter geringerem Trucke steht, doch acceptirt derstbe ausnahmsweise auch das Vorhandensein einer Wurzelkraft.

Uebcrblicke ich die Ergebnisse der vorliegenden Tntersuchungen, so glaube ich, dass dieselben nicht ganz olıne Berleutung für die Klärung der vorbesprochenen interessanten Frage sind. Um mich bei der Besprechung der einzelnen Holzarten kitrzer fassen zu können, sende ich eine iibersichtliche Darstellung der Ergebnisse von allgemeinerem Interesse voran.

Was zuerst den Holztheil betrifft, in welchem die Wasserbewegung stattfindet, so sind nur indirekte Anlaltspunkte zur Beurtheilung dies« Frage in der Grösse und dem Wechsel des Wassergehaltes der einzelnen Holztheile geboten.

*) Jos. Böhm: Ueber die Ursache der Wasserbewegung und der geringen Lufttension in transpirirenden PHanzen. Bot. Zeitg. 1881. Ni. 49. 50. 
Da ist zunäclıst interessant, dass bei der Birke die inneren, älteren Holzlagen selır wisserreich, ja, wie die Tafel I zeigt, zu verschiedenen Jahreszeiten wasserreieher sind, als die jüngeren äusseren Holzschichten. Der ältere Holzkörper zeigt das ganze Jahr hinchurch fast denselben Wasserreichthum und nur zur Zeit der grössten Wasserarmuth, im Oetober ist derselbe auffällig. trockener. Die grösste Verïnderung des Wasserstandes zeigt dagegen der Splint, in welchem z. B. im Mai ca. $71 \%$ des Zelllumens, in Oetober nur $35 \%$ mit Wasser erfült ist. Wahrscheinlich erfolgt also auch im Splint der Birke die lebhaftere Strömung, während der Kern meln ein Wasserreservoir für Zeiten der Noth ist, ohne seine Wasserleitungsfahigkeit ganz verloren zn haben. Da dieses Reservoir auch im Winter bis Ende Februar vollständig gesättigt ist, so muss eine im Vorfrïhjahr plötzlich eintretende Steigerung der Wasserzufuhr im Splint sehr schmell die volle Sättigung des Baumes zur Folge haben. Bei Holzarten, deren Kern relativ wasserarm ist, wie z.' B. bei der Rothbuche wird eine Sïtigung seltener eintreten, da der Kern, wenn anch langsam, dem Splint Wasser entziehen wird.

Bei der Rothbuche ist der Kern zu jeder. Jahreszeit bedentend wasserärmer als der Splint, er enthält aber auch zur Zeit der grössten Trockenheit immer noch $10-20 \%$ des Zelllumens an liquidem Wasser.

Sein Wassergehalt ist kein constanter, nimmt vielmehr in Zeiten der Wasserarmuth al, und umgekehrt zu. Der Splint mit seinem grossen Wechsel an liquidem Wasser ist offenbar vorzugsweise der Ort der Saftleitung, der Kerm dagegen nimmt in beschränkterem Grade an der Wasserbewegung Theil.

Sehr anffallig ist die Thatsache, dass der Kern der Eiche ebenso wasserreich ist, als der Splint. Nur zu Anfang .Juli tritt ein grosser Unterschied zwischen dem sehr saftreichen Splint und dem relativ trockenen Kern hervor. Es verhält sich die Eiche etwa ähnlich wie die Birke, doch muss bericksichtigt werden, dass die Stämme noclı jung, d. h. Jujährig waren, dass also möglicherweise im höheren Alter das Verhältniss anders sein kann. Der Wassergehalt des Splintes ist mach der Jahreszeit sehr verschieden, so z. 13. Ende Februar $300_{0}^{0}$ des Zelllumens ausfüllend, wälnend Anfang Juli der Wasserstand $54 \%$ des Lumens ausmacht. Da wesentliche Verinderungen nur im Splint auftreten, so seheint die Wasserleitung auch auf den splint beschränkt. der Kern nur untergeordnet oder gar nicht dabei betheiligt zu sein.

Kiefer, Fichte und Lärehe stimmen darin iiberein, dass der Kern zu jeder ,Tahreszeit leere Traeheiden führt, willurend der Splint sely wasserreich ist. Jedenfalls sind wir berechtigt, darnach anzunelmen, dass die Saftleitung fin gewöhnlich auf den Splint beschränkt ist. Ob auch in anssergewöhnlichen Fisllen der Kern an der Wasserleitung wieder theilnimmt, wäre noch genauer zu prïfen. Ich habe im Frülijahr 1871 drei 110jährige Kiefern dicht über der 
Erde ringsherum so tief durchsägen lassen, dass der ganze Splint und walırscheinlieh noch ein Theil des Kernholzes dmehsehnitten worden war und doch erhielten sich zwei der Stämme bis zum Sommer 1872 frisch, während ein Stamm schon im Sommer $187 \mathrm{I}$ durch den Wind geworten worden war. Es wäre nun bei Wiederholung ähnlieher Versuche zu ermitteln, ob etwa das Kernholz in der Höhe des Pingsehnittes dann wasserreieher geworden ist, als an gesunden Bäumen.

Hinsichtlieh der Organe der Saftleitung geben msere Lntersuchungen keine neuen Anhaltspunkte. Dass die Traeheiden des Nadelholzes die Saftleitung vermitteln, ergiebt sich von selbst und liegt kein genïgender Grund vor: anzunehmen, dass die Tracheiden des Laubholzes diesem Zweeke nicht dienen. Zur Beurtheilung der Frage, ob die Gefässe Luft oder Wasser fülren, diurtte der Umstand Beachtung verdienen, dass das Eichenholz mit seinen zallireiehen und weiten Gefissen sich dureh einen auffallenden Luftreichthum auszeiehnet. Bereehnet man das Verhältniss zwischen Luftraum und liøuidem Wasser; so nimmt der Wasserstand der Eiche die tiefste Stufe unter den untersuchten Holzarten ein. Es sprieht das jedenfalls für die Annalıme. dass die Gefảsse Luft führen, doch kann diese Frage nieht als abgesehlossen betrachtet werden.

Prífen wir dann, wie sich die Voranssetzungen der l mbibitionstheorie zu den Resultaten der Untersuchung stellen, so erinnere ich daran, dass jene Theorie zweierlei voraussetzen muss, einmal, dass wenigstens zur Zeit der lebhafteren Verdunstung die Lumina der leitenden (rrgane kein fluissiges Wasser enthalten, da jal sonst von einer dureh die I mb ibition sk ra f't bewirkten Wasserbewegung in den Zelhwïnden nieht geredet werden kann und zweitens, dass der Wassergehalt des Holzes im oberen Baumtheile geringer sein muss, als im unteren.

Da nun zu jeiler olaheszeit der leitende Holzkörper aller untersuchten bäume in allen Theilen noch sehr reichliehe Wassermengen in fliissigem '/ustande zeigt, da ferner bei mehreren Holzarten (Rothbuche, Fichte, Kiefer) in jeder Jahreszeit der Splintkörper nach oben wasserreicher wird, so lisst sich die Imbibitionstheorie nieht woll mit den thatsäehliehen Verlältnissen in Einklangluingen. Es seheint mir undenkbar zu sein, dass die Zellwandungen trocken werden, wemn sie von Wasser bespült sind.

Un so giinstigere Resultate erhalten wir, wenn wir die sogenannte Gasdruektheorie auf ihre Richtigkeit an der Hand der Untcrsuchungsergebnisse prïten.

Ich labe das Verhältniss des liquiden Wassers zum Luftranm in der Tabelle 45 und auf deu T'ateln $1-16$ in Procentsätzen des Zelllumens bereehnet resp. zur Darstellung gebracht. Aus den so gewonneneu Zahlen resultirt bei aller Mannigfaltigkeit der Wasserstandsver:inderungen, welche dureh die 
specifische Eigenthümlichkeit der IIolzarten bedingt wird. das durchgehende Gesetz, dass mit jeder Abnahme des Wassergehaltes im Banme der Luftraum in der Krone sich mehr vergrösert als im schaft und zumal am unteren Theile desselben. Dadurch, dass sich die Luft oben mehr verdinnt als unten, muss eine nach oben an Intensitä zunehmende Sangkraft entstehen. Eine zweite Thatsache von allgemeiner Bedentung ist die, dass die Art der Wasservertheilung im Baume eine für jede Holzart specifisch verschiedene ist und dass sich die eigenthümlichen Veränderungen des Wassergehaltcs zum Theil sofort in augenfälliger Weise erklären lassen aus der Verschiedenheit des IT urzelbaues, je nachdem dic Wurzeln flachstreichend oder tiefgehend sind, aus dem friiheren oder späteren Erwachen vegetativer Thätigkeit, aus der grösseren oder geringeren Verdunstungsfähiglieit im Winter und Sommer u. s. w.

Eine dritte beachtenswerthe Thatsache ist die, dass für die Wasseraufnahme des Baumes in hohem Grade bestimmend ist einmal die Temperatur, und sodaun der Feuchtigkeitsustand derjenigen Bodenschicht, in welcher das Wurzelsystem des Bames vorzugsweise rerbreitet ist.

Will man die Ursache der Veränderungen in Wassergehalt der Bäume erkennen, so muss man desshalb nicht allein auf die Verdunstungsgeschwindigkeit derselben im Winter und Sommer, sondern auch auf die grössere oder geringere Leichtigkeit, wit welcher die Wurzeln ihren Wasserbedarf ans dem boden beziehen kümnen, Rï̈.ksicht nehmen.

Der Process des Wassersteigens in der transpirirenden l'flanze scheint mir in folgender Weiseror sich zugehen.

Stellen wir uns schematisch den Aufban einer Nadelholzptlanze so vor, wie er in Fig. 3 dargestellt ist, so hat das Wasser folgenden Weg zu durchlaufen. Zunächst dringt es in das zarthäutige, völlig liickenlose. mit Plasma reich erfüllte Turzelparenchym a ein, grelangt sodam in die äussersten Ausläufer der Gefässbuindel, nämlich in die zuerst zur Ausbildung gelangenden Ring- und Spiralgefasse, in welche es durch den zarten, zwischen den Verdickungen liegenden Wandungstheil leicht zu filtriren vermag. Weiter aufwärts wandernd gelangt es seitlich durch die Tipfel in die später entstandenen Tracheiden. (In der Zeichnung habe ich die Markröhre mit den sie umgebenden spiral- und Ringgefïissen nicht dargestellt, sondem den Uebergang aus Sipinalgefïss in getipfelte Tracheiden ummittelbar ausgefihth, was ja in einer sehematischen Zeichnung gestattet ist.) Diese sind wie die spiralgefisse theils mit Wasser, theils mit Luft erfiillt, und inden das Wasser durch die zarte Schliesshat der Tipfel ron einer Tracheide in clie nächsthöhere tiltrirt, gefangt es bis in die letzten 
Ausläufer der Gefissbuindel, in die Nerren des Blattes, die wiederum aus spiralgefissen bestehen. Diese lassen allseitig an die anstossenden Blattparenchymzellen diurch den verdimnten Theil der Wandung Wasser durchfiltriren und das Blattparenchym $\mathrm{c}$ mit seinen zahireichen Intereellularrïumen transpirirt das Wasser nach aussen.

In dem einfach gebauten Holzkörper der Nadelholzbäume sind in bezug anf dessen saftleitende Function drei anatomische Eigenthiimlichkeiten näher ins Auge zn fassen: die gegunseitige Stellmg der Urane zn einandre, der Bau unł die stellung der 'Tipfel und der spiralig rerdimnte W'antumgsbau der mit dem Parenchỵm in Beriihumg tretendien Organe.

Lis ist bekannt, dass in Folge ihres gemeinsamen Irsprunges aus den Cambialmutterzellen die Tracheiden desselben Radius ziemlich genau in gleicher Höhı, diıs dlagegen die Nachbarrihen in sehr ungleicher $\mathrm{H} \not ̈ h \mathrm{~h}$ stehen. wie ein jeder Tangentalschnitt unter dem Mikroskop $t r-$ kemnen lässt, mu in der nebenstehenden Figur dargestellt ist. Nimmt man num an, dass fiir gewöhnlich die Luft in den Tracheiden den oberen Theil des Lumens. das WTasser den unteren Theil einnimmt, so wiirden bei ien in demselben Radius liegenden Tracheiden immer die mit Luit erfiillten oberen und die mit Wasser erfiillten unteren Enden in gleicher Höhe stehen, ein Umstand, der. wie wir später sehen werden, der Wasserbewegung in radialer Richtung
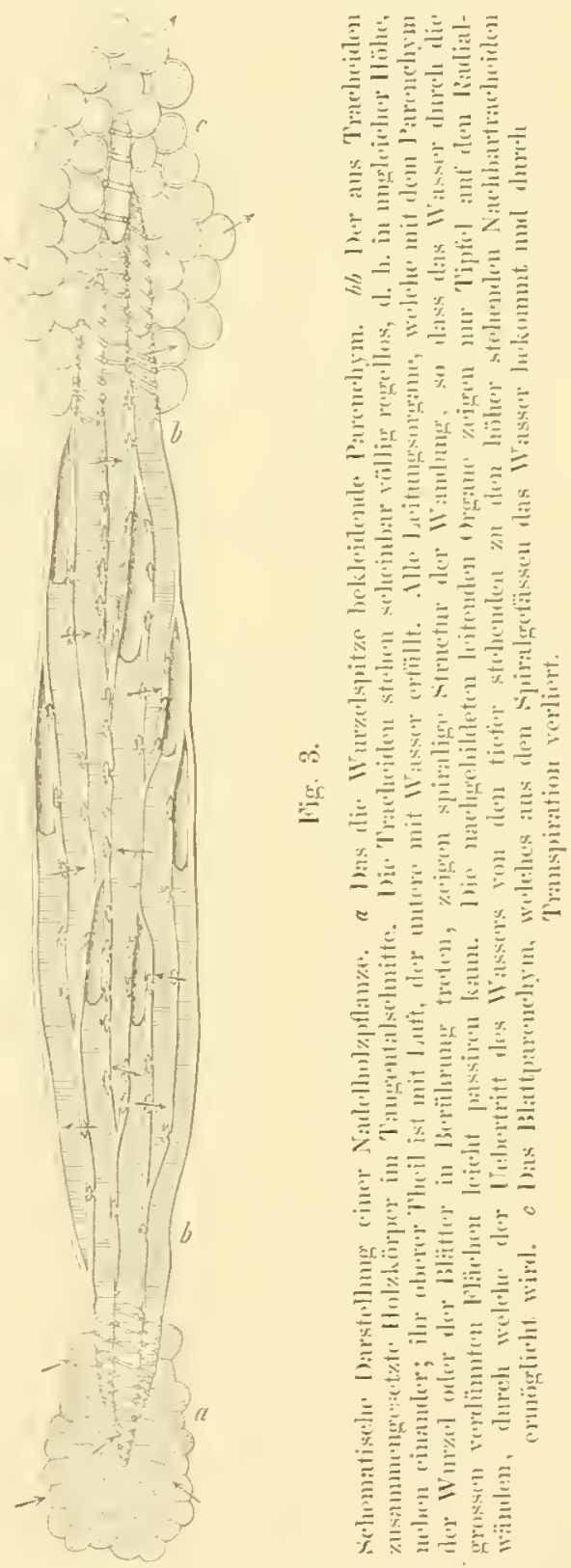

sehr hinderlich sein muss, während die Anordnung der Tracheiden in tangentaler Richtung das Wassersteigen sehr fördern muss, ja vielleicht bedingt. 
Von noch grössever Bedeutung für den Process der Wasserbewegung scheint mir die stellung der Tipfel an den Radialwänden im Frühjahrsholze und an den Tangentalwänden in den letzten Herbstholzfasern zul sein.

Sachs hat nachyewiesen, dass in Nadelholzjahrringen die Wasserleitung hast allein im Friihjahrsholze stattindet, dass innerhalb der Jahrringe in peripherischer Richtung die Wasserberregung leicht erfolgt, dass dagegen die feste Herbstholzzone die Communication des Wassers von einem Jahresringe zum anderen sehr erschwert. Es liegt nahe, diese Thatsachen einmal aus der Dickwandigkeit der Tracheiden, dam aber aus der Stellung und Zahl der Tipfel zu erkliiren. Im Frithjahrsholze sind die Tandungen diumer, und zahlreiche, grosse Tipfel mit zarter Schliesshaut stehen auf den Radialwänden. Jedenfalls wird der Filtrationsprocess des Wassers durch die zarte Schliesshant der Tipfel am leichtesten, wabrscheinlich fast allein erfolgen, es muss somit eine liewegung des Tassers, wenn solehe dureh Druckdifferenzen der Holzluft herrorgerufen wird, in peripherischer fichtung' schneller erfolgen können, als durch die tipfellosen Tangentalwände. Im Ilerbstholze ist einestheils die Filtration durch die dieken Holzwände sehr erschwert, dann aber ist auch die /ahl der weit kleineren Tipfel nuf den Radialwänden geringer. Es muss somit der Uebergang des Wassers von einer Tracheide zur anderen in radialer Richtung noch viel schwieriger sein, aber auch in tangentaler Richtung niclit so leicht ror sich gehen, als im Frithjahrsholze. Dass die Leitung des Trassers nach oben bei der geringen Weite der Lumina der Herbstholzfasern weniger im Herbst- als Frïlijahrsholze erfolgen kann, leuchtet ron selbst ein, sobahl man die Annahme, dass die Wandungen als Strombahnen des Wassers fungiren, aufgiebt. Wären die Wandungen die eigentlichen Strombahnen, tann bliebe es röllig unerklärlich, wesshalb das dickwantige Herbstholz so schwer wasserleitend ist, das dümwandige Frühjahrsholz fast allein die Leitung izbernimmt.

Für die Beclentung der Tipfel als Wasserwege spricht aber vor allen Dingen die bekannte Thatsache, dass die letzten Herbstholztracheiden mit reichlichen Tipleln anf den Tangentalwänden ausgestattet sind. Diese Tipfel haben offenbar die Bedeutung, im Frihlighre bei beginnender cambialer Thätigkeit den Cambialzellen solnnge Wasser ans dem letzten Jahresringe zuzuftühren, als der neue Holztheil noch nicht in Stande ist, selbst Wasser - emporzuleiten durch direkten Bezug ans den TVurzeln. Diese Möglichkeit tritt erst selı spät cin, denn es ist bekannt, lass die cambiale Thätigkeit bei den meisten Bäumen, und so auch bei der Kiefer, wie ich ans eigenen Untersuchungen weiss, im unteren stammtheile und in den Wurzeln um mehrere Wochen spitier erwacht, als in den oberen Baumtheilen. 
Könnte das Cambium seinen Wasserbedarf direkt aus der dicken Wandung der letzten IIerbstholztracheiden beziehen, dam wäre das Auftreten jener Tipfel in derselben ganz unerklälich. Da aber die dicke Wandung den Filtrationsprozess des Wassers ans dem Lumen der Tracheiden nach dem Cambium hin nicht oder doch nur in ungenitgendem Maasse auszufithren vermag, ist dieselbe mit zahlreichen Tipfeln zum Cambium hin ausgestattet.

Terfen wir nun auch noch einen Blick auf den bekannten Bau der Nadelholztipfel, so muss zunäclist auffallen, dass die urspringlich in der Mitte des Linsenraumes ausgespannte Schliesshaut bei den fertigen Frühjahrstracheiden meistens aut die eine oder andere Seite des Linsenraumes, ja oft genug selbst etwas in den engen 'Tipfelkanal dieser seite hineingedrängt ist. In dem dickwandigen Herbstholze steht die Schliesshant sehr oft, wie hei den Laubhölzern, in der Mitte des Linsenraumess und zeigt, wie bei jenen, cine deutliche Verdickung in der Mitte. Mir scheint die Lagerung der Schliesshaut auf der einen reite des Linsenraumes ans der lichtung des Wasserstromes erklärbar zu sein, welcher den Tipfel beim Uebergang alus einer Tracheide in die andere passirt.

Ich glaubte zunächst annelmen zu dürfen, dass in dem untcren T'heile einer jeden Tracheide die Schliesshänte nach aussen geilrängt sein, während die oberen Spitzen derselben Tracheiden, welche mit Luft erfillt sind, Tipfel ohne linsenfömige Anssackungen besitzen müssten. Um dies zu prüfen, wiederholte ieh das bekannte Experiment Th. Hartigs, indem ich Wasser mit fein zertheiltem Karmin cimnal in dic untere und ein anderes Ial in die obere schnittfäche eines frischen Nadelholzstannmstickes einjresste. Die feinen Karminkörnchen, welche mit dem Wasser in die schnittližche und in die geöffneten Tracheiden eindringen, füllen alsdann die Tipfelkanäle und Linsenräıme der dưchschnittenen Organe völlig aus und zeigen dadureh schon den Weg an, den in der That das Wasser genommen hat. Es zeigte sich num, dass, wie vorausgesehen, die Tipfelkanile am unteren Ende der Tracheiden sich in den meisten Fällen in den Linsenraum erweitern, während nahe der oberen Spitze der Tracheiden meistens die Karminkörnchen nur in den feinen Kanal, nicht aber in den Linsenraum eingudrungen waren. Ich muss aber betonen, dass anch sehr oft Ausnahmen von dieser Regel vorkommen. Sehen wir uns die Anordnung der Tracheiden in Tangentelschnitte :u, so darf uns dies nicht gerade verwundern, denn oft genug ist ein Tipfel von beiden Seiten (Iurch Wasser bespïlt oder durch den Luftraum der zugehörigen Tracheide begrenzt und in solchen Fällen bleibt die Schliesshaut entweder in der Mitte oder legt sich auch einer Seite des Linsenranmes an, an welcher er nach seiner Stellung in der Tracheide nicht liegen sollte. Es ist auch nicht unwahrscheinlich, dass gerade der oberste, sich verengende Raum der Hartig, Untersuchungen. 11. 
Tracheidun mit Wasser erfült ist. Ich glaube wenigstens bei der Ammalme bleiben zu diurfen. dass es Druckdifferenzen zwischen benachbarten Zellen sind, welche die schliesshant ans der mittleren stcllung an die eine oder andere WTand des Limsenraumes dringren.

Bei den Lanhlolatrachenlen ist der Mechanismus etwas anchers. Die Schliesshant (Fig. 4) stellt hier eine verdickte, in der Mitte des Linsenmanmes ausgespannte Ficheibe dar, welche mit der Zellwand dureh

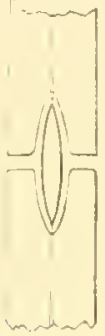

Fig. 4.

Tipfel einer Eichenlulztracheide. Die schlipshant stellt eine schmal linsenfömige solneilse lar, welche mittedst eines sehr zarten Haut in ihrem gaszen C'unfinge mit der primïren Manding, der sugen. Mittellamelle in Ferbindumg stelit. eine äusserst zarte, elastische Haut in Verbindung stcht. ${ }^{*}$ ) Dies äusserst zarte Ram ler scheibe wird bei einseitigem brucke anf die licke scheibe sich ausdehnen und den Filtrationsprozess noch erleichtern. Es ist wohl gestattet, den Gedanken auszusprechen, dass die rerdiclite scheibe dazu dient, in Fallen allzugrosser ])ruckdifferenzen das Zerreissen der zarten Schliesshaut zu verhindern, indem erstere sich vor die Miundung des Tipfelkanals auf die eine reitedes Linsenraumes legt und dadurch das Organ schliesst. aber anch eine nachtheilige Ausdelmung der zarten peripherischen schliesshaut, welche zum Zerreissen derselben fïhren könnte. volhindert. In jener eigenartig gebauten Schliesshaut haben wir also eine Art ron Sicherheitsventil ror uns, das im Falle einer zu grossen Druelidifferenz die -angpmpe schliesst und so das Zerreissen der zarten Schliesshaut vorhindert.

Es mitg endlich noch auf the Thatsache hingewiesen werden. thass diejenigen Elemente des Holzkörpers, welche einerseits mit dem Blattparenehym. antererseits mit dem Parenchym der. Turzelspitzen in nächste Berühung treten, denen also die Aufgabe zusteht, das Wasser möghichst leicht aus den Parenchymzellen anfzunelmon resp. an diese abzngeben, die spirst-, Ring - und Truppengelässe sind, reren Wände in weit reichlicherem Maasse verdiunnt sind, als die grosse Masse der erst später. d. lı, in grösserer Entfermung ron den letzten Ausläufern der Getässhiundel entstehenden Tracheiden u. s. w. Tollte nicht auch diese Thatsache dafü sprechen, dass das Wasser aus dem Lumen der Organe allein oder doch rorwiegend dureh die verdiunten Stellen der Wandungen aufgrenommen und abgegeben wird, dass die dicke Wandung nu eine schlechte Filtrationsfihigkeit fiör Wassur besitze? Aus jenen, mit lem Parenchym der Wurzelspitzen in clirekte Verbindung tretenden Ring- und

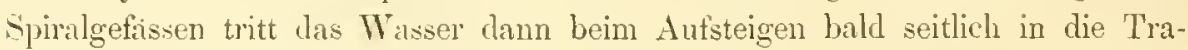
cheiden und Holzfasem ein, welehe den weiteren Transport remitteln. Die spiralige

*) ef. Die Zersetzungserscheinungen des Nadeltolzes und der Eiche. 1850. Sexite 44. 
oder ringtörmige Terilickıng der mit dem Parenchym in Beruhrung tretenten Gefässe hat doch offenbar nur die mechanisehe Bedentung, das Collabiren der zarthäutiğen Wände zn verhüten, wenn dem Innemramme Trasser entzogen wird. Durch jene Fpiralen wird es möglich, dass sich im Lmmen ein luftrerdïnnter Ramu bildet, der das Zuströmen von Wasser zur Folge hat. Fo viel mij bekannt ist, felılte bisher ein physiologische Erklärung für jene eigenartige und beschrainkt auftretende Wandverdickung, die vorstehend geboten ist.

Nach den rorangeschiekten Bemerkungen iiber den Bau des leitenden Holzkörpers sei noch anf die 'T'hatsache lingewiesen, dass dann, wenn die Wandungen vollstaindig mit Wasser gesättigt sind. jerlerzeit noeh die Hiilite bis Dreiviertel, ja bei der Fichte sogal ibber ${ }_{10}^{\prime \prime}$ des Zellumens mit Wasser erfillt sind. Nur bei der Fine sinkt der Masserstand in oberen Baumtheik. zeitenweise anf $15^{0:}$ des Zelllumens herab, was aber. wie ich bereits frihur bemerkte, darauf zurickzufuhren sein diirte, dass die Grefässe rorwiewen] mit Luft erfullt sind und somit las Verhältniss von Lnft und Trasser im Holze sehr zu Ungunsten des Wisser's herabuedrickt wird.

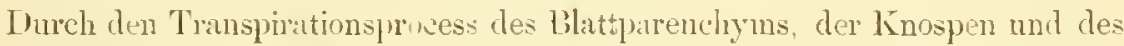
Rindengewebes der jüngeren, von Borke oller Kork noch wenig geschuitzten Zweige gehen das ganze Jahr hindurch grosse Missermengen rerloren. Dil die leitenden Organe geschlossen und für Luft nicht oder doch nur sehr langsam permeabel sind, so muss der Wrasserverhust aus den obersten Organen des Holzes das Sinken des Wasserspiegels in denselben und somit eine Verminderung der Luttension herbeifihmen, welche sofort eme Filuation des Massers aus ien tieter stehenden 1 rganrn, in welchen die Luft eine stirkere Tension besitzt, und zwar durch die reriunnten Wandstellen veranlasst. Diesur Process der Filtration wirl sich nach unten fortptlanzen, so lange eine Drucklifferenz zwischen der Bimenluft der oberen und unteren llolztheile resp. der Aussenjuft besteht und lis unter Atmosphïrendruck stehende Bodenwasser wiri in dic I'Hanzenwurzeln gleichsam hineingepresst. Der Massergehalt des Bauminneren hängt nun daron ab, in welchom Verhailtnisse die Verdumstung zu der Wasseranfuahme aus dem Boden steht.

Die Verdunstungsgrösse hïngt von mendlich zahlreichen Factoren ab; sie ist nach Holzart, vielleicht auch individuell versehieden, sie wird bedingt durch den Vegetationszustand der PHanze, und muss ich insbesondere hervorheben, dass bei Buche und Eiche anch in mbelaubten Zustande die Vurdunstung der nur von zarterem Periderm bekleideten Triebe besondrs aber der knospen luei trockenem Frostwetter so gross sein kamn, dass kräftige, $1 \mathrm{~m}$ hohe P'tlanzen, die in Töpfen iiberwintert wurlen, im strengen Tinter $187: 80$ schon nach zwei Monaten völlig vertrocknct waren, weil dis Topferde ausgefioren, also eine Wasseraufnahme fïr die Pflanzen nmmöglich geworden war. 
Temperatur, Fenchtigkeitszustand, Bewegung der umgebenten Luftschichten, Insolation u. s. w. sind bekannte maassgebende Factoren fur die Schnelligkeit der Transpiration.

Dem gegenüber hängt die Schnelligkeit der Wasseraufnahme aus dem Boden ebenfalls von zahllosen Verhältnissen ab. Einestheils wirkt die Tension der Batumluft darauf ein, insofern die Wassereinsaugung um so energischer eintreten wird, je mehr die Bimenhuft verdiinnt ist. Dann aber entseheidet auch die Grösse des Wurzelsystems, zumal der feineren Faserwurzehn und der Tegetationszustand derselben über die Leichtigkeit, den Verhust durch Wasseraufnahme zu ersetzen. Die ungïnstigste Zeit ist zweifellos der Nachwinter, denn das Wurzelwachsthum, das ja bei manchen Holzarten bis in den Winter hinein fortdauert und die Wasseraufnalune im Vorwinter wesentlich befördert, ist alsdam beendet, die Faserwurzeln haben sich bis nahe der Spitze mit Korkmänteh umgeben und die Wurzelhaare sind verschwunden. Erst mit der Riıckkehr höherer Bodentemperatur entstehen nene Saugwiuzelchen durch das Austreiben der Faserwuzelspitzen, und diese ron Kork nicht bekleideten jungen saftigen Wurzelspitzen, sowie die daran sich bildenden Wurzethare sind es, die mit Beginn oder schon vor dem Erwachen der Vegctation an den oberirdischen Ptanzentheilen die Wasseraufnahmefähigkeit steigern, wobei osmotische Kräfte sicherlich eine wesentliche Rolle mitspielen.

Die Gestalt des Wurzelsystemes ist ron grösstem Einflusse, insofern ein ganz flach, nahe der Oberfliche des Bodens hinstreichendes Wrurzelsystem (Birke, Fichte) beziiglich seiner Wasseraufnahme abhängig von Temperatur und Feuchtigkeitsverhältnissen der obersten Bodenschichten sein wird, während Holzarten mit in die Tiefe dringenden Wurzeln ihre Wasseraufnahme von dem Zustande der tieferen Bodenschichten abhängen lassen.

Der Zustand des Bodens, vor allen Dingen dessen Temperatur und Wassergehalt entscheidet wesentlich über die Leichtigkeit, mit welcher der Wasserbedarf der Pflanzen befriedigt wird. Im Vorwinter ist in der Regel der Boden wenigstens in den oberen Schichten reichlich feucht und noch warm genug, um die Wasseraufnahme zu beförderm. Während des Winterfrostes hört fast jede Wasseraufnalıme auf; im Frihjahre werden Bäume mit Hach streichenden Wurzeln zeitig, Bäume mit tiefer gehenden Wurzeln später wieder die Tasseraufnahme beginnen. Im Vorsommer, Hai und .luni, erreicht dieselbe ihr Maxinum, weil Feuchtigkeit und Wärme im Boden rereint wirken. In der zweiten IIälfte des Sommers bis zum Herlsste lässt die Wasserantnihme nach, weil der Boden zu trocken geworden ist.

In Zeiten, in denen die Verdunstung weniger Wasser consumirt, als durch die Wurzeln anfgenommen wird, muss der Wasserstand allmälig sich 
heben und wir sehen, dass in solchen Faillen zuerst der Tasserstand im unteren Stammtheile steigt.

Die Frage, ob es lediglich die geringe T'ension der Baumluft sei, welche die Wanderung des Wassers anch dureh das Wurzelparenchym reranlasse, oder ob osmotische Kräfte, der sogen. Wurzeldruck, bei der Wasseraufnahme mitwirken, möchte ich in letzterem sinne beantworten, und zwar im Hinblick auf' den grossen Einfluss, den eine höhere Bodentemperatur auf die Schnelligkeit der Wasseraufsangung ausibt. Ist der Boden kalt, wenn auch nicht gefroren, so vermindert sich die Wasser:ufnahme und ungekehrt ist ja allgemein bekannt, wie fördernd für die Wurzelthätigkeit das Begiessen des Bodens mit warmem Wasser ist. Abstrahirt man auch von den bekannten Blutungserscheinungen annueller Pflanzen, die doch zur Annahme eines Wurzeldruckes nöthigen, so glanlse ich nicht zu irren, wenn ich den holıen Wasserstand, zumal im unteren Stammtheile der Birke Ende Närz, der Mitwirkung einer Wurzeldruckkraft zusehreibe.

In der Tabelle 45 ist das Raumverhïiltniss zwischen Luft und flüssigem Wasser nach Holzart, Individuum, Baumhöhe und Holztheil (Splint und ganzer Holzkörper) getrennt in P'rocentsiitzen zusammengestellt.

Da es ungemein schwer ist, aus solehen Zahlentabellen ein klares Bild der darin enthaltenen Gesetze zu erlangen, so habe ich die Höhe des Wasserstandes bildlich darzustellen gcsucht, und zwar zunäclsst in den Tafeln 1, t. 7, 11, It für den mittleren Wassergehalt der Bäune an den einzelnen Untersuchungsterminen.

Um die Veränderungen des Wasserstandes in Lumen der leitenden Organe während des Jahres dentlicher erkennen zu lassen, habe ich den Gang durch zwei Kalender-Jahre hindurch dargestellt, die durch einen vertikalen Strich von einander getrenut sind. Die Verbindungsinien der einzelnen 'Termine bezeichnen die Grenze zwischen der Höhe des Wasserstandes und dem iiber den Linien betindlichen Luftraum.

Fs war nicht uninteressant, zu erfahren, in welchem Verhiiltniss sich Luft und Wasser im lebenden Rinden- resp. Bastgewebe zu einander verhalten. Da eine Trennung zwischen Imbibitionswasser und flïssigem W'asser der leitenden Organe hier nicht möglich war oder, richtiger gesagt, alles Wasser den Charakter des Imbibitionswassers trägt, so ist las Verhältniss zwisehen Luft und Gesammtwasser berechnet (Tab. 46).

Es bedarf kamm der Erwahlnung, dass in quantitativer Beziehung ein Vergleich dieser Zalılen mit den Verhältnisszahlen zwischen Luftraum und flïssigem Masser des Holzes nicht zulässig ist, denn letztere beziehen sich nur auf einen Theil des Wassers, erstere dagegen auf die ganze Quantität des in der Rinde enthaltenen Wassers. 
Ich habe die Tateln $1,4,7,11,14$ benutzt, m die im Terlanfe des Jahres hervortretenden Verinderungen im mittleren Wassergehalt der Rinde durch eine Punktlinie zu markiren.

In den Tafehn 2, 3, 5, 6, 8, 9, 10, 12, 13, 15, 16 hate ich bildlich die Höhe des Wasserstandes im Lumen der saftleitenden Crgane dargestellt, wie solche an den einzelnen Bäumen von unten (links) nach oben (rechts) sich gestaltet.

Die Veränderungen des $W$ assergehaltes und der Luftension bei den einzelnen llolzarten.

\section{Die Birke.}

Tafel 1. ¿ u. 3.

Tafel 1 zeigt, dass iler grösste Wassergehalt der Firke in die Zeit der Blutung, in den März und April fällt und schon im Mai ein wenig abnnmmt, allerdings im Splint noch nahezu die Maximalgrösse sich bewahrt hat.

Die Transpiration überwiegt im Sommer die Grösse der Wasserzufulur so sehr, dass bis zum October. Wahrscheinlich bis zum Eintritt des Blattabfalles, der Massergehalt auf ein Ilinimum sinkt, der Iuftraum aut ein Maximum sich vergrössert.

Der splint trocknet bis dahin mehr noch als der Kern aus und sinkt dessen Wassergehalt unter den Durchschnittsgehalt des ganzen Holzkörpers hinab. Im frostfreien Torwinter steigt zumal im Splint der Wassergehalt um $10 \%$ des ganzen Zellhmens empor, vermindert sich dann in der Frostperiode bis Ende Februar zwar nicht im ganzen Holzkirper, wohl aber im Splint.

Das Sinken des Wasserstandes in den Frostmonaten Januar und Februar ist eine auch bei den anderen untersuchten Holzarten beobachtete Erscheinung, die der fortdaueruden Verdunstung bei anfhörender oder stark beschränkter Wisseranfnahme aus dem gefrorenen Boden zuzuschreiben ist.

Die plötzliche Wasseranfnalme im ersten Frithjahre nach Exwärmung der oberen Bodenschichten hat mit dem Erwachen der Vegetationsthätigkeit im oberen Baumtheile noch nichts zu schaffen, denn der Wassergehalt des Rinden- und Bastgewebes ist noch am 24. März weit hinter dem Maximnm zuriickstehend. Er cuhminirt wie bei allen anderen Bitumen im Mai. Jenes mit periodischem Phuten verbundene Saftsteigen darf wohl dem Wiedererwachen der Wuzelthätigkeit und der damit in Beziehung stehenden Murzeldruckkraft zugeschrieben werten.

Gelıen wir zur Betrachtung der in Tafel a dargestellten Vertheilung des Lutt- und Wasselraumes in den Bümmen uber, so reprisentirt der Stamm III 
vom 24. Mirz den Maximalwasserstand im eigentlichen schafte, wälnend in der Krone das Maximum noch nicht erreicht ist

Unter dem saugenden Einflusse der noch in Februar sehr stark verdinnten Luft und bei wahrseheinlich mitwirkender ITurzeldruckkraft, welche nach der Erwärmung der oberen Bodenschicht, in cler ja die Bewurzelung der Birke fast allein verbreitut ist, ins Leben getreten ist, hat sich die Birke im unteren Stammtheile so mit Wasser durelsittigt, dass eine Frwirmung der Baumluft bei Tage, insbesondere bei direkter Insolation, ein Bluten ans Wundstellen hervorrufen muss.

Die Mårzlinie entspricht im unteren stammtheile walıscheinlich dem vollen Sättigungszustande bei mittlerer 'Tagestemperatur der Batumluft. Erwïnumg hat Bluten, Abkïhlung Sangen zur Folge. Bis zum 7. Mai, zu welcher Zeit das volle Ergrinen der Birke eingetreten ist, hat sich der Baum anch in der Krone voll mit Wasser gesittigt, während unten der Wasserstand schon gesumken ist. Es muss unentschieden bleiben, ob dies nư Folge der durch höhere Temperatur erfolgten Luftusdelnnung ist, odcr ob bereits eine Luftverdiunnung durch gesteigerte Transpiration eingretreten ist.

Bis zum 2. Juli sinkt der Wasserstand gleichmässig in der ganzen baumlänge. Dildurch wird aber eine nach oben bedentend zunchmende Siugliraft erzeugt; denn die Luft in der obersten Scetion erweitert sich von 15 anf 33.3 , also aut 0.5 der luttdichtigkeit des Jlaistammes; wilnend unten eine Ausdehnumg von 37.8 auf 55.7. also aut 0.65 erfolgt.

Bis zum 8. October sinkt der Trasserstand des ganzen Paumes auf das Minimum und insbesondere biegt die Linie innerhall, der Taumkrone nach unten, wemn auch noch nicht atuf clen Stand des Decemberstammes Wa noch im Laufe des October die Verdunstung der Bammkrone sich fortsetzt, so ist es wahrscheinlich, dass mit dem 8. October das Minimum wenigstens im oberen Stammtheil noch nicht erericht ist.

Vergleicht man den Maistamm mit dem Uetoberstamm, so rerhält sich der Inftraum oben wie $15: 60: 2=1: 4$, unten dagegen wie $37.8: 198.7$ $=1: 1.82$. Die Luftverdimmung betrigt also oben 0.25 , mnten $0.5 \%$ der Luftdichte les Maistammes.

Bis zum December ist zwar oben der Wasserstand noch tiefer gesunken, unten dagegen beginnt der Baum wieder, lebhaft Wasser aufzusaugen. In den Frostmonaten Jamur und Februar hört die W'asseraufnahme fast gauz auf, aber es finden Ausgleichungen des Wassergehaltes im Inneren des Baumes nach zwei Richtungen hin statt. Iw oberen Bummtheile, woselbst lie groosste Luftverdiunung sich findet, steigt das Wasser auf Kosten der unteren Section, die sogar unter den Jecemberstamm hinabsinkt. 
Zweitens scheint der Splint einen Theil seines Wassers an den Keru abzugeben. Der Wassergehalt des splintes sinkt, wie Taf'el 3 zeigt. ganz bedeutend unter den des Decemberstammes.

Vom 16. Februar bis 24. März steigt das Wasser auf den Maximalstand und nur der Kern hat sich noch nicht auf denselben erloben.

\section{I ie Rothbuche.}

\section{Taf. 4. 5. 6.}

Der mittlere Wassergehalt des ganzen Baumes hat bei der Rothbuche zwei Maxima und zwei Minima. Wie bei der Birke zeigt der ganze Holzkörper sein Minimm an Wasser im October, also vor Blattabtall im Herbste. Die Wasseranfsaugung in der frostfreien ersten Winterhälfte ist aber viel :usgiebiger und hebt den Wasserreichthum bis zum 28. Iecember auf ein Maximum. ( $b$ b ein lis in den Winter hinein fortgesetztes Wurzelwachsthum, verbunden mit dem Umstande, dass die Wurzeln der Rothbuche sowohl flachstreichend, mithin in den oberen durchnässten Bodenschichten sich verbreitend, theils in die Tiefe gehend sind, die Ursache der lebhaften Einsaugung ist oder welche anderen Unstănde hierbei mitwirkend sind, muss unentschieden bleiben. Bis zum 16. Februar, also wïhrend der Frostperiode, sinkt der Wasserstand ungemein schnell, in langsamerem Tempo setzt sich das sinken des Wrasserspiegels sogar bis Aufang Mai, also bis zum Schwellen der linospen fort und sinkt der Gesammtwassergehalt ebenso tief, wie im Monat October. Mit dem Laubausbruch, der grösseren Erwärmung des Bodens, der neu erwachten Murzelthaitigkeit steigt das Wasser zu einem zweiten Maximum, das im Juli allerdings nicht die Höhe des 28. December erreicht.

Beruclisichtigt man nur den splint, dessen $W^{r}$ assergehalt jederzeit bedentend grösser ist, als der des sogenannten Reifholzes oder Kernes, so fällt das Minimum ant den 24. März, zu welcher Zeit die Birlie mit ihrem geringeren Wämelsediurfniss, ilsen flachstreichenden Wurzeln, deren Saftwirzelchen und Wurelhaare schon neu gebildet sind, ihr Maximum zeigt. Am 7. Mai ist der Splint bercits ziemlich wasserreich, was ja anch im $W^{r}$ assergehalt der Rinde sich äussert; das Maximum fällt auf den 2. Juli und steht höher, wie das des Decemberstrmmes.

$W_{\text {as }}$ die Vertheilung von Luft und $\mathbb{T}^{\top}$ asser in den verschiedenen Bäumhöhen betrifft, so zeigt Tafel 5 im Decemberstamm den Maximalstand, mit

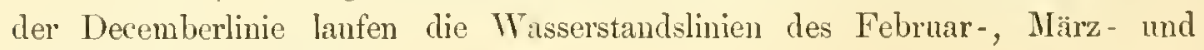
Maibaumes fast parallel.

Wie jch schon für die Birke gezeigt habe, schliesst aber ein gleichmissiges Sinken der Wasserstandslinie, wenn diese nach oben steigt. einc nach 
oben zunehmende Luftverdünnung in sich; denn vergleichen wir beispielsweise den Febritastamm oben und unten mit dem Decemberstamm, so sehen wir, dass die Luft unten von 52.1 auf 62.1 sich erweitert, also von I auf 0.84 sich verdiunt, während die Luft der obersten Section sieh ron 25.3 auf 41.8 ausdehnt, also von 1 auf 0.60 sich rerdiunt.

Mit der steigenden Bodentemper:itur und der durch die Neubildung von Saftwürzelchen erhöhten Wurzelthïtigkeit wird die Wisseraufnahme in bohem Gratde erleichtert und die Julibuche zeigt unten sogar mehr Wasser, als tlie Deemberbuehe, die lebhafte Transpiration entzielt den oberen Bauntheilen aber so schnell das Wasser, dass dadurch die Julilinie eine ganz andere Richtung bekommt, d. h. die Differenz der Luftlichtigkeit zwisehen den olveren und unteren Baumtheilen eine ganz bedentende wird. Mit der Julihie läuft die () ctoberlinic fast parallel, nur nimmt letztere den tiefsten Stand ein. Im Vergleieh zum Decemberstamm stellt sich dic Lufttension unten wie 52.I : 63.6 =0.82: I, während in der Baumkrone die Luftension sich rerhält wie $25.3: 46.5=0.54: I$, womit also eine von unten nach oben bedentend zunehmende Luftrerduinnung angezeigt ist.

Tafel 6 giebt die Wasservertheilung in dem vorzugsweise der Wasserleitung dienenden Splintkörper der Rothbuche. Es fällt zunächst auf, dass in den einzelnen Linien grössere Unregelmässigkeiten zu erkennen sind. Letztere erkliiren sich wohl zur (Yenüge aus dem l'mstande, dass ohne seharfe Grenze zwischen Splint und lieifholz der Wassergelalt allmailig von aussen nach imen abninmt. Je nachdem num die silintsticke bei der Abspaltung etwas schmaler oder breiter ausfielen, stcllte sich deren. Wassergehalt etwas grösser oder geringer.

Immerhin lässt sieh clas Cresetzmässige in der Wasservertheilung geniigend klar erkennen.

Als besonders beaehtenswerth ist der reiche Wassergehalt des splintes in Julistamme bei relativer Trockenheit des Reifholzes hervorzuheben. Erst bei $12^{1}$ a m Höhe wird der Splint schnell naeh oben hin troeken, ja erreicht das Hinimum des ganzen Jahres. Wie bedeutend die Druekdifferenz zwischen der oberen Baumkrone und der Schaftmitte ist, tritt dadurch scharf in die Augen.

Es ist ferner viel deutlicher, als auf Tafel 5 zu erkennen, dass der Wasserstand rom 28. December gleiehmässig durch den Februar auf den Minimalstand des 24. März fält und dann bis zum 7. Mai bereits die Nlitte des Weges zum Maximum des 2. Juli zuriickgelegt hat.

Was innere Holz (Reifholz, Kernholz) nimmt in geringerem Mlaasse an den Veränderungen les Wasserstandes Theil. Im Frïhjahre, zur Zeit des Wassersteigens im Splint vermindert dasselbe auffilligerweise seinen Wasser- 
gehalt noch fortlanernd bis zum Mai und bereichert sich auch im Sommer bei weitem nicht in dem Verhältnissc mit Wasser, als das splintholz.

\section{Dic Eiche.}

Tafel 7. 8 แ. 9.

Der Gehalt an flüssigem Wasser ist im Verhältnisse zum Luftgehalte des Eichenholzes ein sehr geringer, wie dies sofort aus dem ticfen Stande der Wasserlinie in Tafel $7 \mathrm{zu}$ erselıen ist. Diese Thatsache spricht selır fiu die Annahme, dass die zahlreichen und grossen Gefísse der Fiche lnftfïhrende Organe sind und dadurch das Verhältniss zwischen Binnenluft und Wasser zn Ungunsten des letzteren selır herabgedriickt wird.

Mit Ansnahme des Juli mol December führt der Splint der Eishe immer etwas weniger Masser, als der Kern und das Mittelstick. Dadurch, dass der Splint einen grösseren Antheil an Wasser als hygroskopisches resp. Imbibitionswasser führt, und zwar im Inlialte des noch lebenden Holzparenchyms wird die Menge des in den leitenden Organen vorhandenen flüsigen Wassers noch mehr vermindert.

So kommt es, dass der Wasscrstund des splintes nur im Julistanme den Wasserstand des ganzen Bammes iibersteigt. Beachtenswerth und von den beiden vorbesprochenen Laublotzbämnen abweichend ist die stetige Abnalme des Wassers vom Juli bis zu Ende Februar, also meh durch die Perioule des Vorwinters. Die Eiche zeigt wie die Buche auch an älteren Zweigen nur eine dünne Korkhaut und setzt sich der Verdunstmmgsprocess durch Rinde und Knospen auch den Winter über fort. Die tiefergehende Bewurzelmg erliärt es wohl, dass die Herbstregen und die dureh sie lierbeigefiilıte Anfrischung des Bodens noch nicht bis an die Hauptbewurzelung der Eiche gelangt ist. Auch im Früljalhre erlebt sich der Masserstand erst spät, d. h. nach dem 7. Mai, was wiederum dem tief eindringenden Wurzelsystem znzuschreiben ist, da die Erwärmung des Bodens nur langsam bis zu grösserer Tiefe vordringt.

Die Vertheilung des Wassers im Bamme, Tafel 8, zeigt eine von allen untersuchten Holzarten völlig abweichende Form. Es ist nämlich num am 2. Juli der Wassergehalt des ganzen Holzkörpers von unten nach oben etwas zunehmend, im splint bleibt er sich fast im ganzen Längsverlaufe des Bammes gleich. Zu jeder anderen Jahreszeit sinkt der Wasserstand von unten nach oben in zunehmender Geschwindigkeit. Es wird dadurch wiederum eine starke Zugkraft nach oben gebildet, denn wilhrend z. B. zwisclien Juli- und Octoberstamm unten das Dichtigkeitsverhältniss wie $1: 0.89$ sich vorhält, verhält sich die Luftension in der obersten Section wie $1: 0.60$. Der Wasserstand sinkt 
gleichmässig bis zum 16. Februar, wilhrend die Mailinie schon wieder in der aufsteigenden Richtung sich befindet.

Aelnnliches zeigt die Splintholztafel 9, nur mit dem Untersehiede, dass der Splint weit wasserreieler ist.

\section{Die Lirche.}

Taf. 10.

Da nur zwei Lärchenstämme zur Untersuehung gezogen sind, so kounte die Veränderung des mittleren Wassergehaltes im Laufe des Jahres nicht erkannt werden. Es ergiebt sich nur, dass das Kernholz selır wasserarm ist und kaum an der Wasserleitung hetheiligt sein diurfte. Die grösste Achnlicllkeit in der Vertheilung des Wassers auf die verseliedenen Baumböhen zeigt die Lärche mit der Eiche. Der Wasserstand des splintkörpers vom 2. Juli ähnelt der Julieiche, nur nimmt das Wasser nach oben entschieden ab, während es bei der Eiche sich fast gleich bleibt, ler Märzsplint ist sehr wasserarm und reprisentirt dieser Termin wahrscheinlich den trockensten Zustand der Lärche.

\section{Lie Kiefer.}

\section{Taf. 11. 12. 13.}

Die Verïnlerungen im Wassergehalt der Kiefer ähmeln am meisten der Rothbuche. Der eigentliche Kern ist aber ganz leer von flissigem Wasser, die Wasserstandsverïnderungen beschrinken sich auf den splint und die Jittelstiicke. Der Splint besitzt wie die Rothbuche zwei Maxima, am 2. Januar und am 3. Juli.

Mit Eintritt der Frostperiode vermindert sich der Wasserstand im splinte sehr wenig, wn so mehr in den Mittelstiicken, so dass der ganze Holzkörler bis zum 4. Miirz erheblich wasserärmer geworden ist, als Anfing Januar. Der Wassergehalt des ganzen Holzstanmes sinkt sogar bis zmu 19. Nai, wie bei dor Rothbuche, wälırend (r im Splinte vom 14. März bis 19. Mai sich gleich bleibt. Mit dem Austreiken der Knospen beginnt das Saftsteigen, d. h. die in den Boden eingedrungene Wärme und die neu entstandenen Saugwürzelchen

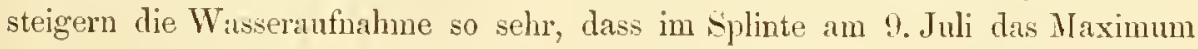
dcs 2. Januar wieder erreicht wird, wïhrend die inneren Holzschichten noch relativ trocken sind. Letztere erhöhen ihren Wassergehalt noch bis zum October hin, so dass die vom Juli bis Getober eintretende Wasserverninderung des Splintes kaum ein Sinken des Wasserstancles im ganzen Holzstamme bis zum Oetober veranlasst. 
Splint und iunere Holzlagen sangen sich auch im Vorwinter bis zum 2. Januar andanernd voll.

Die Vertheihng des Wassers und Luftraumes im ganzen Holzstamme der Kíiefer (Tafel 12) zeigt zunächst die Eigenthümlichkeit, dass am 2. Januar der Wasserstand unten am Baume bis zir $11 \mathrm{~m}$ Höhe das Maximum erreiclit hat, während im oberen Stammtheile der Wasserstanr ziemlich tief steht. Bis zum 4. März ist er unten gesunken, oben dagegen gestiegen; es hat also ohne Zunahme des ganzen Wassergehaltes em Ausgleich zwischen den oberen und unteren Baumtheilen stattgefunden.

Ein gleiches Sinken des Wasserstandes setzt sich bis zum 19. Mai fort.

Beriicksichtigt man nur den hauptsiichlich dis Wasser leitenden Splintkörper, so nimmt die Julilinie die höchste Stelle ein. Nit ihr fast parallel lanfend, aber viel tiefer stehend ist die Octoberlinie. Die Differenz im Wassergehalte zwischen oben und unten ist nicht sehr bedeutend, wenn auch die steigende Richtung nach oben sich zu erkennen giebt. Bis zum 2. Januar hat sich anch der Splint im unteren Baumtheil so reich mit Wasser versehen, dass er sogar über den Julistand emporsteigt, oben dagegen ist die volle Sättigung noch nicht eingetreten. In den Frostmonaten sinkt der Wasserstand im ganzen Baume etwas mit Ausnahme der Krone, deren Wassergehalt sich der Julilinie nähert. In den trockenen Frïhjahrsmonaten sinkt der Wassergehalt bedentend bis auf den Minimalstand des 19. Nai. Lis scheint aus der bedentenden Steigung der Hailinie in den unteren Sectionen, als ob an diesem Bamme bereits das Saftsteigen im splint unten begonnen hätte.

\section{Wie Fichte.}

Taf. 14.15 .16 .

Der Kern der Fichte enthält wie der der Kiefer und Lärche gerade so viel Wasser, als zur vollen Süttigung der Holzwände erforderlich ist. Die Tracheiden sind also nur luftfiihrend und enthalten in ihren Hohlrïumen kein Wasser.

Andererseits ist der Wasserreichthum des Splintes im ganzen Bamme und zu jeder Jahreszeit ein sehr grosser und so hoher, dass mu geringe Veränderungen sich erkennen lassen, wic Taf. 14 in der Wasserstandslinie des Splintes darstellt.

Diese Veränderungen stimmen mit denen der Kiefer, Eiche und Buche itberein, sind nu' quantitativ weniger herrortretend. Das Maximum fiillt auf den 9. Juli, also in die heisseste Keit, in der aber die Bedingungen der Wasseraufnahme durch die Wurzeln die giinstigsten sind. Bis zum 12. October sinkt 
der Wassergehalt allmälig, um im frostfreicn Vorwinter das zweite Maximum zu erreichen.

In der Frostperiode sinkt der Wassergehalt dureh den t. März bis zum 14. März, an welchem Termine der splint sein Minimum erreicht. Das flachstreichende Wu'zelsystem der Fichte ist den Einwirkungen der Frithjalıswärme schneller ausgesetzt, als das Wurzelsystem der Kiefer und Eiche, deren Splint erst Anfang Mai wassereicher wirk.

Der Splint der Fichte wird ïhmlich der Rothbuche schon bis zum 1?. Mai so wasserreich, dass er dem Maximalwassergehalt selır nahe steht.

Auch bei der Fichte wiederholt sich die Erscheinung, dass der Kerm, oder richtiger gesagt, die innersten (im Mittelstiiek gelegenen) splintsehichten während des Fribjalurs, d. h. im Monat April noel an Wasser bedentend abnimmt, so dass der ganze Holzkörper sein Minimum an Wasser am 19. Mai zu erkennen gielot. In .Juni steigt dann der Wasserreichthum aneh der inneren Splintsehichten so sehr, dass das Maximum des ganzen Holzstammes am 9. Juli hoch über dem Wrasserstand der ïbrigen Jahreszeiten emporragt.

Der grosse Wassergehalt des Fichtensplintes, welcher zwischen 77 und $85 \%$ des ganzen vorlandenen Holılraumes einnimmt, die geringen schwankungen, welehe im Baume iiberhaupt vorkommen $(70-93 \%)$, lassen sehr sehwer das Gesetzmässige in der Vertheilung von Luftram und Wrasser erkennen. Geringr, auf Zufälligkeiten beruhende Unregelmäissigkeiten stören bei den nahen Zusammenstehen der einzelnen WVasserstandslinien die klare Ëinsieht der gesetzmässigen Veränderungen der Wasservertheihung:

Es ist noch hinzuzufügen, dass bei lieiner anderen Holzart solche auffällige individuelle Verschiedenheiten anch bezüglieh der Holzqualitit auftreten, als bei der Fichte. Ich verzichte dosshalb darauf, die Abweichungen in der Vertheilung des Wrassers im Einzehen zu elläuterm. Beachtenswerth ist einmal die Thatsache, dass jederzeit im Fiehtensplint der Wasserreichthum ein sehr grosser und von unten naeh oben zunehmender ist, dass die geringen Differenzen fiur eine grosse Leichtbeweglichkeit des Wassers im Holzkörper sprechen, dmeh welehe schneller Ersatz des Transpirationsverlustes bewirkt wird.

Die jungen Kiefern und Fichten sind bezüglich ihrer Wasservertheilung nicht vergleiehbar aus Grïnden, die ich bereits Seite 5 anseinandergesetzt habe.

Die Untersuchungsergelmisse dieser Bäume habe ich in Tabelle 34-44 zusammengestellt, da sie nach maneher anderen Richtung hin, inslesondere in Betreff des Einflusses der Ringbreite auf die Qualität des Ilolzes, von Bedentung sind. 


\section{Ceber den Einfluss des Ilters anf die Substanz des Holzkïlpels. (Tabelle 47.)}

Der Uebergang der cambialen, mit Plasma und Zellsaft erfüllten Organe des Jungholzes in den der Saftleitung dienenden Zustand des splintholzes besteht bekanntlich darin, dass Plasma und Zellsaft aus den Organen verschwinden und Wasser (mit gelösten Nählrstoffen) sowie Luft an die stelle treten. Ein grosser Theil des Zellinhaltes, insbesondere die Proteinstoffe wantern durch die Zellwand auf osmotischem Wege fort, ein anderer Theil dient zur Bildung der secundären Zellwand und zur Terholzung derselben. Da die Zellwand mit Wasser gesättigt ist, so kann die Lnft in das Innere der Zelle nur im gelösten Zustande gelangen, loch fehlt es uns zumächst noch an Anhaltspunkten, mш mit Sicherheit bestimmen zu können, ob diese Luft in gelösten Zustande mit dem Bodenwasser anfgenomnen oder auf anderem Wege, etwa durch Intercellularräume, welche das Markstrahlparenchym begleiten, mit der Zellwandung in Beriihrung tritt und in das Lumen der Organe diffundirt.

Der Verholzunesprocess der in cambialen Zustande ans C'ellulose bestehenden Wandungen erfolgt zuweilen so unvollständig, dass das gebränchliche Reagenz auf Cellulose (Chlorzinljod) die Wandungen des fertigen Holzes schnell blau fürbt. So ist z. B. das Holz anch ans der Nitte ca. 40 jähriger Weymouthskiefern so wenig rulholzt, dass eine Benetzung des Holzes mit Chlorzinkjod dasselbe sofort intensiv blau färbt. Auch bei anderen Narlelholzbäumen bleibt wenigstens der an das Lumen grenzende Theil der Wandungen oft für alle Zeit unvollkommen verholzt und färbt sich mit Chlorzinkjod schön blau. Aehnliches ist nicht selten bei Eichunholzsclerenchymfasern zu bemerken.

Die Ansichten ïber den chemischen Charakter des Verholzungsprocesses sind getheilt. Einerseits wird angenommen, dass die Cellulosemicelle unter dem Einflusse des Sanerstofts eine Uwwandlung in Ligninmicelle erleiden, andererseits betrachtet man den Verholzungsprocess als eine Einlagerung kohlenstoffreicherer Micelle zwischen die vorlandenen und im Wesentlichen unverändert bleibenden Cellulosemicelle und bezeichnet jene mit dem Verluste des Zellinhaltes in der Zellwand sich ablagernden Stoffe als incrustirende Substanzen.

lch schliesse mich der letzteren Ansicht an in Hinblick auf die Thatsache, dass die fertige Holzwand weit kohlenstoffreicher ist als die Cellulose. Diese Thratsache scheint mir leichter ans einer Einlagerung kohlenstoffreicher Substanzen vor und während des Entweichens des Zellinhaltes erklärbar zu sein, als ans einer Einwirkung des Sanerstoffs anf die Cellulosesubstanz.

Läge ein Uxydationsprocess ror", so könnte die Steigerung des Kollenstoffgehaltes bei gleichzeitiger Terdickung der Wandung doch nur so zu Stande 
kommen, dass gewisse Oxydationsproducte entwichen und eine kohlenstoffreichere Substanz zuriekbliebe unter gleiehzeitiger lebhafter Zufuhr nener Bildungsstoffe. Es ist schwer zu glauben, dass dieser Oxydationsprocess sich auf die kurze Zeit des Ueberganges der Cellulose in Holz beschränken wiirde. Die Verholzung miisste anch in der Folgezeit sich fortsetzen, das ältere Holz miisste entweder inmer kollenstoffreicher und leichter werden oder man muisste annehmen, dass auch in dem alten Holzkörper neben dem Oxydationsprocess eine bestïndige Neubildung in Innern der Holzwandung duch zugeführte Nïhrstoffe erfolgte zum Ersatz der V'erbrennungsproducte.

Diesen Annalmen widerspricht der thatsiichliche Befund, insofern eine in ersten Jalıre unvollstiindig verholzte Wanclung auch nach 49 , ja nach 100 Jahren noch unvollständig verholzt ist, insofern keinerlei Veränderungen in Sul,stanz und Gewicht zwischen Holz des einjihhrigen und res 100 jährigen Alters nachweisbar ist, falls nicht die weiter unten zu besprechenden Processe der Verharzung oder Verkernung bei einzelnen Holzirten eintreten.

Der Verholzungsprocess ist in der Regel bei unseren cinheimischen Holzarten vor Eintritt des Winters durch den ganzen letzten Jahresring abgeschlossen und wo derselbe, wie z. B. bei l'inus Strobus u. s. w. iiberhaupt ein unvollstindiger ist, da sehen wir auch in ganz altem Holze noch denselben schlecht verholzten Zustand der Zellwand erhalten.

Auch die Erscheinungen der Zersetzung, welehe durch parasitïre Pilze herbeigefuhrt werden, sprechen dafiur, dass die Verholzung in einer Linlagerung kohlenstoffreicher Substanzen zwischen die Celhulosemicelle besteht. Unter den Holzparasiten seheiden einige ein solches Ferment aus, welches die Holzwand zunächst wierler in Cellulose verwandelt, luevor diese sich auflöst. Derartige Fermente scheinen zunächst die inerustirenden Substanzen, mögen sie aus Lignin oder Cutin bestehen, aufzulösen und da die primäre Wandung d. h. die sogenannte Mittellamelle am meisten incrustirente Substanz zwischen den Cellulosemicellen zu besitzen scheint, so erhält sich dieselbe nach Auflösung der incrustirenden Substanzen nur sehr kurze Zeit als Cellulose. Es ist wohl erlaubt, anzunehmen, dass nach Entfernung der incrustirenden Substanzen aus der Mittellamelle ein so lockeres Celluloseskelett zurückbleibt, dass dieses der weiteren Fermentwirkung bald erliegt und völlig verschwindet. Dadurch erfolgt die Isolirung der einzelnen Holzelemente gerade so, wie bei Behandlung mit chlorsanrem Kali und Salpetersiüre. Ueber die chemische Natur des sogenannten Lignin sind wir noch nicht vollständig unterrichtet, weil es noch nicht hat gelingen wollen, das Lignin rein darzustellen. Fine Reihe werthvoller neuerer Untersuchungen berechtigt aber zu der Annahme, dass das Lignin ein Gemenge mehrever chemisch von einander verschiedener Stoffe sei, von denen einzelne bereits isolirt darzustellen getumgen ist. 
Zu diesen in Holze allgemein verbreiteten Stoffen gehört das Vanillin, Coniferin, der Holzgummi u. s. w.

Um zu erkennen, ob und welche Verändermugen quantitativer Art in höherem Alter mit dem Holzkörper vor sich gehen und gleichzeitig; um den Finfluss der Jahrringbreite auf die Holzbeschaffenheit darzustellen, habe ich die Tabelle 47 berechnet. Es sind einerseits alle Splintholzsticke, andererseits alle Kern- und Mittelsticke nach Jahringsbreiten gruppirt. Innerhalb jeder Gruppe wurde das mittlere Gewicht der Trockensubstanz pro 100 Volum. theile frischen Holzes, ferner das mittlere specifische Trockengewicht und endlich der mittlere Procentsatz des Schwindens, d. h. der Volumverminderung aus dem frischen in den absolut trockenen Zustand berechnet. Um den Werth der Zahlen als Durchschnittsgrössen richtiger beurtheilen zu können, haJe ich die Zahl der Holzstiicke, aus denen das Mittel gezogen wude, in die Tafel anfgenommen. Die unter dem Strich aufgefuhrten Durclıschnittsgrössen bilden nicht das arithmetische Mittel der darunter stehenden Zahlen, sondern bilden wiederum für sich das Mittel aus allen Holzstiicken des Splintes, des Kernes oder endlich der ganzen Holzart.

Durch die Trennung einerseits nach der . Thluringbreite, andererseits nach dem Alter (in Splint und Keru) lässt sich zur Beurtheilung des Einfusses des Holzalters der Einfluss der Jahrringbreite eliminiren mnd umgekehrt.

Ueher den Charakter des K ernholzes bestehen in der Missenschaft Anschaumgen, denen ich mich nicht anzuschliessen vermag:

Dasselbe wird als ein in Zersetzmng begriffener Holzkörper aufgefisst, in welchem nur durch nachträgliche Einlagerung gewisser. Substanzen Verändermgen der technischen Eigenschaften hervorgerufen werden. Es muss, wenn dies richtig wäre, zunächst aufallen, dass nur einige Holzarten und zwar im Allgemeinen sind dies die dauerhaftesten, schon mach wenig Jahren plützlich in eine Zersetzung eintreten, welche mit einer Gewiehtszunahme verknüpft ist und dass die Bodingmengen dieser Zersetzung nur ein Jahr lang wïhren, denn 1000 jühriges Eichenkernholz zeigt keinen nachweisbaren Untersehied von eben gehildetem Krernholz, wenn nicht durch den Eingriff parasitirer Holzpilze Veränderungen hervorgerufen werden, die ich frïher) eingehend untersucht habe.

Es unterliegt keinem Zweifel, dass die Verkernung, insoweit sie mit Farbenverïnderungen verknïpft ist, nicht in einer chemischen Verändernng der Substanz der Zellwände selbst, sondern in einel Ablagermg von Stoffen im Lumen der Zellen und in den Wandungen derselben besteht, und dass diese Stoffe

*) lie Zersetzungserscheinungen des Holzes der Nadelholzbiinme und der Eiche. Berlin 1878. J. Npringer. 
aus dem Inneren der parenchymatischen Zellen des Holzkörpers stammen. Am deutlichsten erkennt man dies bei solehen Ilolzarten, die, wie z. B. Taxus, Larix u. s. w. intensive Kernbildung zeigen und im Wesentlichen mur Markstrahlparenchym besitzen. Auf der Grenze zwischen Splint und Kern erkennt man, dass sich zunäehst der Inhalt der Markstrahlzellen röthet, dass von la ans die rothe Firbung sich auf die Nachbartracheiden verbreitet, gleichsim die Wandungen inprägnirt. Dass liese lösliche Substanz die Wandungen durehdringt, ist zweitellos, da man sie tropfenweise auf der Innenwand der geschlossenen Tracheiden niudergeschlagen findet. Es bleibt ein gewisses Quantum dieser Kernstoffsubstanz in den Micellarinterstitien der Wandung stecken Bei Kernhölzern mit Strangparenchym geht die Briunung auch von dem Inneren der letateren aus. Man sieht, dass sich die farbige Substanz theils den. Wandungen selbst mittheilt, theils im Lumen der Gefässe, Tracheiden, Fidereneliymfasem unt des Holzparenchyms meh* oder weniger reichlich ablagert. Es kommen Stoffe, die ja mach Holzart sehr verschiedener Natur sein können (Ferbstoffe, Gummiarten, Harze u. s. w.), die aber aus einer Unwandlung gelöster Reservestoffe stammen dürften, zu dem im Wesentlichen unverindert gebliebenen Splintholz hinzu und die einzige, wesentliche Veränderung des Splintholzes besteht darin, dass die meisten Parenchymzellen, keineswegs aber alle, functionslos werden, keine stärke mehr führen. Ich weiss nicht, aus welchen Grunde man den Jroeess der Verkernung als becimnende Zersetzung braichnen soll, denn mit derselben Berechtigung wiirde man dann auch den Verholzungsprocess als Zersetzung bezeichnen müssen.

Blicken wir zunichst auf die Veränderungen, denen das Eichenholz beim Uebergange aus dem splintzustande in len des Kernes unterliegt, so weist Tabelle 47 unzweifelhaft nach, dass dabei eine nicht unerhebliche Vermehrung der Substanz selbst erfolgt, denn das Splintlolz besitzt durelischnittlich $56.8 \mathrm{gr}$ Trockensulsstanz auf $100 \mathrm{chcm}$ frischen Holzes, während Kernholz $59.7 \mathrm{gr}$, d. h. $2.9 \mathrm{gr}$ mehr Substanz zeigt. Da nun das Splintholz der Eiche seln reich an Stiokemelı] ist, Krmholz aber nur in einzelnen Parenchymzellen noeh Stälke führt, so folgt daraus, dass beim Uebergang von Splint zu Kern an Kernstoff nicht allein $2.9 \mathrm{gr}$, sondern noch soviel meh" hinzukoumt, als an Stärkemehl verloren gegangen ist. Der jüngste Kernholzring der Eiche war am 2. Juli ummittelbar nach der Fällung noch dem Splinte gleich gefärbt und erst beim Trocknen, als die Luft ungehindert mit lem Zellinhalt in Berihlung treten konnte, firlste sich der Jalırring tief dunkel und zwar viel dunkler, als das ältere Kenholz war.

Die Untersuchung zeigte, dass alle Parenchymzellen, die im näclist jüngeren Jahresringe mit Stärlie erfüllt waren, vollgefüllt mit der braunen Substanz waren, über deren Charakter weiter unten Näheres mitgetheilt werden wird. 
Ob diese Substanz theilweise aus einer Umwandlung der in den Zellen enthaltenen körnigen Kohlenhydrate leerrorgegangen war, oder ob dieselbe nach vorgän wiger Auflösung und Fortfïhrung derselben vom Splint aus dorthin gefülurt worden sind, muss unentschieden bleiben. Dass eine solche Zufiuhrung von löslichen Stoffen zu jenem juingsten Kernholzringe vom splint ans erfolgt, scheint mir zweifellos zu sein, theils im Hinblick auf die Anfüllung aller Zelllumina mit diesen Stoffen, theils in Rücksicht auf den Umstanu, dass das Kernholz um $2.9 \mathrm{gr}$ substanzreicher geworden ist.

Im :ilteren Kernholze ist die Firbung eine etwas andere, melm gelbbraune und rïhrt dies, wie es scheint diher, dass sich die brame substanz aus dem Inneren der Parenchymzellen gleichmïssig durch die Holzwandungssubstanz verbreitet hat, die Zellhmina nummehr geringere Mengen des braunen Stoffes zeigen.

Seln interessint ist die 'Thatsache, dass das Kernholz bei weitem weniger" schwindet, als das splintholz. Jenes zeigt eine mittlere sichwindung von 12.8 "/o, das Splintholz eine solche von $17.6 \%$ des Frischvolumens. Wie kann man diese Erscheinung anders erklïren, als ans dem Umstande, dass jene Kermsubstanz zum grossen Theil in die Micellarinterstitien eingetreten ist und somit beim Trocknen der Substanz die Holzmicelle nicht so eng zusammentreten können, als im splintzustande. Kernholz schwindet um 4.8 Proc. weniger als Splintlolz, ist aber doch nur nu $2.90^{0}$ o substanzreicher geworden als Splintholz. Zur Erklärnng dieses scheinlaren Widerspruches darf woll daraut hingewiesen werden, dass im splinte ein gewisser Procentsatz der Substanz als Stärke von der ganzen Substanz in Abzug gebracht werden muss, um die Menge der für die Quellung resp. Schwindung des Holzstickes allein in Betracht kommenden Wandungssubstanz zu finden.

Im Kernholz ist nicht nur die Substanz an sich um 2.9\% Kernstoff vermehrt, sondern auch um ein weiteres Quantum Kernstoff. welches dem Gewicht der Stärke im Splinte entspricht. Der grrïste Theil des Kernstoffes sitzt aber in der Wandung, die somit um $4.5 \%$ weniger schwindet, als der splint. Ich eriunere darn, dass anch das Kernholz der Eiche nur $75 \%$ Imbibitionswasser aufzunehmen vermag, während der Splint $90 \%$ Wasser aufnimmt. Zum Theil diirfte diese verschiedene Wassercapacitit gleicher Gewichtsmengen Eichenkernholzes und splintholzes der Einlagerung von Kermsubstanz zuzuschreiben, grösseren 'Theils aher wohl auf die grössere Imbibitionsfähigkeit der plasmahaltigen Parenchymzellen des splintes zurïckzuftihiren sein. Line weitere interessante Thatsache ist die, lass das specifische Trockengewicht des Kernholzes und des Splintholzes tast vollständig gleich ist. Ich erinnere daran, dass die Untersuchung des speeifischen Gewichtes der Ilolzsubstanz dalhin tührte, dass Eichenkern und Eichensplint gleichmässig ein Gewicht von 1.56 zeigte. Da wir num wissen, dass das stärkennehlreiche splintholz im Frisch- 
volumen erheblich weniger Substanz besitzt, als das stärkemehlfieie Kernholz, dass ferner absolut trockener Kern und Splintholz bei gleichem Volımen völlig gleiche Substanzmengen" besitz nu, so ergiebt sich, dass es nur das ungleich grosse Schwinden ist, welches die letztere Thatsache erkliart. Gleiche Tolumina völlig trocknen Splintes und Kernholzes besitzen also gleichen Brennwerth, gleiche Volumina frischen Holzes ungleichen W'rth.

Es liandelt sich num noch um die Frage, welcher Natur der Kernstoff der Eiche sei. Wir wissen, dass splint und Kern der Eiche reich an Gerbstoff ist. Alugesehen von mehrfachen quantitativen Untersuchungen des Gerbstoffgelaaltes des Eichenholzes, insbesondere der Sägespäne älteren Eichenkernholzes, welches nach Th. Hartig $130_{0}^{0}$ Gerbstoff enthält, ergiebt der einfache Augenschein an jedem frisch gefültten oder bearbeiteten Eichenholze durch die bekannte Eisenreaktion der Sclmittfliclıe, dass das Eichenkernholz sehr gerbstoffreich ist. Dasselbe verschwimlet erst, wie ich frïher nachgewiesen habe, unter der Einwirkung des Mycels holzzerstörender I'ilze, für welche der Gerbstof' ein sehr willkommenes Nahrungsmittel ist.

Herr Dr. Oscar Linw in Minchen, in botenischen Kreisen bekannt durelı seine interessanten und werthvollen pflanzenchenischen Forschungen, war so giitig, dis Splintholz und Kernholz der Eiche chemisch zu prifen und theilte mir derselbe als Ergebniss seiner Untersuchung Nachstehendes mit: "1)ie Braunfirbung des Kernholzes der Eiche bernht nach meiner (O. Löw) Ansicht auf einer allmiiligen, unter Gelbfirbung fortschreitenten Oxylation des darin enthaltenen G(r)jstoffes, wobei zuletzt durch Conlensationsvorgänge ein unlös licher gelbbrauner Körper gebililet wird. Dass durch beschrinkte Oxydation Condensationsvorgånge herbeigeführt werden können, wobei Körper von höherem Moleculargewichte und relativ geringerem Wasserstoffgehalte entstehen, ist eine bekannte Thatsache und liessen sich hierfir viele Reispiele eitiren; so liefert besonders die der Gallusgerbsäure so nahe stehende Pyrogallussĭure bei gelinder Oxydation Körper von höherem Moleculargewicht, die entweder sehr schwer löslich (wie Pyrogallochinon) oder gamz unlöslich sind. Ein solcher unlöslieher Körper von sehr dunkler Farbe entsteht schon bei längerem Stehen einer mit Dinatriumphosphat versetzten Pyrogallussäurelösung, wobei Sanerstoft aus der Luft aufgenommen wird. Da das Holz ebenfalls Alkaliphosphate enthält, so mag dieser Umstand die Oxydation des Gerlustoffs beförlern."

„Das Kernholz der Eiche zeigt einen auffallend höheren Gierbstoffgehalt als der Splint. Am besten ergehen sich diese Verhältnisse, wenn man Sehnitte in einer einprocentigen frischbereiteten Eisenvitriollösung einen Tag lang liegen lässt; die Blaufärbung ist viel intensiver beim Kern; das alte Kernholz giebt auch nahezu diesellue Intensität der Reaction, wie tas junge, im letzten Jahre erst aus Splint hervorgegangene Kernholz." 
nit Kalilange von 1.33 specitischem Gewicht betupit, giebt Kernholz eine viel intensivere braungelbe Färbung als der splint; ferner zeigt auch Leberosmiumsiaure von $0.1 \%$ nach längerer Zeit durch eine viel intensivere Schwilrzung einen höheren Gerbstoffgehalt an. Die Schwarzfärbung tritt in der Lösung der Säure durch ausgetretenen Gerbstoff ein, welcher schwarzes Osmimoxyd erzengt und ist mit der Fettreaction in den Zellen nicht zu verwechseln."

Furr diese Ansicht, dass die Verkernung des Eichenholzes im Wesentlichen anf Oxyclation des Gerbstoffes berulht, spricht die von mir schon oben erwahnte Thatsache. dass nach Fällung des Julistammes der seiner Fürbung nach noch zum Splint gehörige Jahresring auf der Grenze von Kern und splint nach einigen Tagen an den Probestïcken sich dunkel tärbte, was doch nur einer Oxydation zuzuschreiben sein duirfte. Eine zweite Thatsache sei hier noch angeführt, die bei den Versuchen iiber die Wasseranfnahmefälnigkeit feiner Hobelspähne (ef. S. 15) hervortrat. Das Splintholz, welehes in den ersten Wochen schön weiss blieb, färbte sich nach etwa drei Wochen allmälig ebenso braun, wie das Kernholz, so dass später liein Farbenunterschied zwischen den Hobelspähnen des Kerns und des Splintes erkennbar war. Allerdings darf nicht unerwähnt bleiben, dass sich im Laufe der Zeit feine Pilzfiden in dem splinthoize ans zugeflogenen Sporen entwickelt hatten und somit die Möghichkeit besteht, dass die Braunfärbung der Einwirkung les Pilzmycels zuzuschreiben ist.

Die Rothbuche bildet kein ächtes Kermholz, häufig genug einen falschen Kem, der dadurch entsteht, dass von faulen Aesten her die braunen Zersctzungsproducte sich im Stamm abwairts senken und das Innere des Holzes dunkler färben. So lange als in solehes $11 \mathrm{olz}$ noch keine Pilze eingedrungen sind, ist dasselbe schwerer, wie gewöhnliches, helles Rothbuchenholz. Dass wir keinen ächten Fern vor uns haben, können wir in jedem Falle dadurch nachweisen. dass wir den Zusammenhang der Bräunung mit einer Wundstelle nachweisen. dass auch oftmals der Stammabschnitt ïber der Erde an alten Bäumen völlig kernlos ist, während höhere stammdurchschnitte falschen Keru zeigen.

Die normale Veränderung des Rothbuchenholzes besteht darin, dass iler Splint wenigstens in den oberen Baumtheilen Stiirkemehl im Parenchym zeigt, das inmere Holz (Reifholz) dagegen fist ganz frei von Stïrkemehl ist O. Löw hatte die Giite, auch verschiedene Buchenholzstiicke auf Gerbstoff zu prifen. Er sagt über das Buchenholz, dass bekanntlich dessen Gerbstoffgehalt ein sehr geringer md dass der Gerbstoff ein etwas ron dem Eichengerbstoff verschiedener, eisengruinenter sei. Falscher Kern, Reitholz und splint geben nur schwache gelbbrame Färbungen mit Kalilauge; mit Eisenvitriol aber giebt der falsche 
Kern gar keine Reaction melır, das Reiflolz aber eine eiwas schwächere als der splint.

Nit diesem Befunde und mit der mikroskopisch nacligewiesenen (ef. Tabelle $9,10,13)$ Vertheilung des Stärkemehls iibereinstimmend ergiebt die Zusammenstellung, dass das Kernlıolz (Mittelstiick und Reifloolz) nicht unwesentlich leichter ist, als das Splintholz, nämlich un $58.4-513.6=1.8 \mathrm{gr}$ pro $100 \mathrm{cbem}$. Diese Gewichtsverminderung können wir allein dem Fehlen des Stärkemellls und anch der von O. Löw beobachteten Verminderung des Gerbstoffgrehaltes zusclreiben, eine anderweite Substanzverënderung ist wenigstens nicht nachweishar. Die Rothbuche ist die einzige von den untersuchten Holzarten, deren Kernholz etwas mehr sehwindet als das splintholz, nïmlich um $17.3-16.5=0.8{ }^{\circ}$ n. Wïhrend bei der Eiche mit der Vermehrumg des Gerbstoffes im Kernholze ein geringeres Schwinden verbunden ist, darf umgekehrt die Zunahme des Sehwindeprocentes in Reifholz der Buche der Verminderung an Gerbstoff zugeschrieben werden, der wie das stärkemehl und andere Rescrvestoffe der Rothbuche auf das Splintholz bescluränkt bleibt

Das specifische Trockengewicht des Kermholzes ist entsprechend dem geringen Gehalt an Stärkemehl geringer als das des Splintes, nämlich um $70-$ $68.4=1.6 \%$

Die Differenz wïrde wolıl noch etwas grösser sein, wenn nicht das Kernholz etwas mehr zusammentrocknete als das Splintholz. wie vorluer besproclıen ist.

Die nachweisbaren Veränderungen des liuchenholzes bestehen also lediglich im Fehlen des Stiirkemelıls und in Verminderung des Ferbstoffgelaalts, sowie in einer Verminderung des Wassergehaltes. Da übrigens auch der Splint in den unteren Stammtheilen der untersuchten älteren Buchen zu keiner Jahreszest Stärkemehl fuilrte, so ist in dem Mangel an Stärke noch durchaus kein specitischer Unterschied zwisehen Reifhol 2 und Splint gegelsen und es fohlt somit jedweder nachweisbare charalsteristische Unterschied der Substanz des Splintes und des Reifholzes selbst bei 130jährigen Bäumen

Die Birke bildet weder Kern- noch Reifholz, vielmelnr zeigt sich noch bei 85jährigen Bäumen das innerste $\mathrm{Hol} z$ völlig unverändert und ebenso wasserreich als das äussere, ja meist sogar wasserreicher. Allerdings weist unsere Tabelle 47 eine Verschiedenheit zwischen. Splint und Kernholz der Birke insofern nach, als das Kernholz etwas leiehter ist, als das Splintholz. Diese Terschiedenheit berult num nicht etwa, wie bei der Rothbuche auf einem nachtrïghichen Substanzverlust durch Leerwerden der im Splint Stärkemell fiuhrenden Holzparenchymzellen, sondern auf anatomischen Eigenthümlichkeiten der inneren, d. h. der Narkröhre eines Stammtheiles zunächst liegenden Jahresringe des Baumes, auf die ich später bei Besprechung des Einflusses der Jahrringbreite 
anf die Innlzqualität näher eingehen werde. Hier sei nur erwälmt, dass ‘n einem Stammtheile, so lange derselbe noch jung ist und mithin breitere Jahresringe hat, mehr Gefisse, mehr Holzparenchym und dümwandigere Holzfasem gebildet werden, als spïter. Das Kieruholz ist aber das zuerst gebildete Holz und desshalb ist es leichter als das Splintholz. Wir sehen aber auch, dass das den obersten Banmtheilen angehörige breitringige splintholz viel leichter ist, als das den mnteren, d. h. älteren Baumtheilen zugehörige engringige splintholz und dass das erstere nur $49.9 \mathrm{gr}$ wiegt, also ebenso leicht ist, als das Kernholz. Eine durch das Holzalter bedingte Veränderung der Holzsubstanz, d. l. eine Art Verkernung oder ein Leichterwerden derselben Holztheile wie bei der Buche ist nicht nachweisbar. Das Schwindeprocent des Kernholzes ist aller. dings mit $15.7 \%$ etwas geringer, als das des splintes mit $16.7 \%$ und muss es zmächst noch eine offene Frage bleiben, ob das geringere Schwinden des ilteren Holzes etwa auch mit cler V'ermehrung von Gerbstoff oder eines anderen Stoftes und der Einlagerung desselben in die Wandung verbumden ist.

Die Fichte ist eine Holzart, die anch im höchsten Lebensalter keinerlei Kernbildung zeigt. Einjąaluriges nnd hundertjähriges $\mathrm{Holz}$ sind von einander nur Iurch den Wassergehalt und durch die Vertheilung des Harzgehaltes verschieden. Im wasserreichen splintholze findet sich das in den Auskleidungszellen der Harzkanäle entstandene Terpentinöl theils in den Kanitlen selbst, theils in den Zellen in mmittelbarster Umgebung derselben*), es tritt nach Verwundungen alshald ans den geöffneten Harzkanälen lurvor, die, wie ich gezeigt und dureh Abbildung in meinem Lehrbnch der Baumkrankheiten ilhustrirt habe, eine offene Communication der horizontalen und verticalen kianäle besitzen. Im relativ trockenen älteren Holze der Fichte ist das Terpentinöl mehr durch den ganzen Holzkörper verbreitet in Folge davon, dass clas flüchtige Oel Gelegenheit findet, die Zelhwände hier und da zn durchdringen. Die Harzbildung der Fiehte scheint sich im Wesentlichen auf die jüngsten Holzlagen zu beschränken. Aeltere Harzkanäle besitzen meist dicke Auskleidungszellen und nur vereinzelte zarthäutige, plasmariehe, harzbildende Zellen zwisehen diesen zerstreut. Fine Steigerung les Harzreichthums der Fichte von aussen nach innen, wie solche bei den Kiefern $\mathrm{zu}$ beobachten ist, kommt dem Anscheine nach nicht vor, jedenfalls ist sie nur eine sehr unbedentende.

Die normale Allagerung des Terpentins im splinte erleidet inrch den

*) Eine sehr eingehende Bearbeitung der Ilarkanile und Harbildung der wiehtigsten Xadelholabänme wird demnïclsst von meinem Assistenten Dh. Heinrich Ma y veriffentlicht werden, weshall) ich hier nieht nither auf die Processe der IIarzbilung und Verharzing eingehe. 
Process der Dörung eine Veränderung. Die Erhitzung des Holzes auf 100 $105^{\circ}$ C. durch vier Tage und Nächte hat zur Folge, dass das Terpentinöl sich gerade so durch den Holzkörper verbreitet, wie dasselbe in Kernholz der stehenden Bäume sich allmälig verbreitet hat, und nur geringe Mengen schon melı erstarten und verharzten 'Terpentins bleiben in den Harziingen sitzen.

Zur Beurtheilung der etwaigen Veränderungen, denen das Holz der Fichte im Lanfe der Zeit unterworfen ist, steht uns nicht bloss der Verglcich zwischen splint und Kernholz derselben Altersstufe, sondern auch der Vergleich des Holzes junger ea. 30 juilriger Bäume mit dem Kernholze der alten Bímme zu Gebote.

Die unter dem strich stehenden 1)urchsehnittszahlen für die Gesammtheit der untersuchten Holzsticke dürfen nieht ohne Weiteres mit einander verglichen werden, denn der Einfluss der Jahringbreite auf die Qualität des Holzes ist ein so crosser, dass nur Molzsticke gleicher Ringlneite mit einander verglichen werden können. Jch habe desshalb in Klammern hinter jenen lurehschnittsgrössen den Durchschnitt fïr diejenigen Holzstiick gegehen, von lenen sowohl Splint als Kernholz vorlag. Die in Klammern stwhenden Zahlen geben also den Durchschnitt der Fichtenholzstilcke mit einer Jaluringlreite von 1.6-3.5, wälrend die Holzstucke mit $1.1-1.5$ und mit 3.6-5.5 eliminirt worden sind.

Wir haben durch diese Beschrinkung auf Holzstiieke mit gleichen Ringbreiten vergleichbare Grössen bekommen und gelangen zu dem interessanten Resultat, diss Splintholz alter Bămme $98.1 \mathrm{gr}$, Kernlılz altcr Bäume $38.0 \mathrm{gr}$, - Flintholz junger Bäume $38.3 \mathrm{gr}$ organische Substanz auf 100 ceu Frischvolumen besitzen. Es sind das so verschwindend kl(ine Vifferenzen, dass wir wohl berechtigt sind, zu behaupten, dass bei gleicher Ringbreite dis Fichtenholz alter und junger Biime unverindert sei.

Das Schwindeprocent des Kernholzes ist mit 12.6\% fist dasselbe, wie das des splintholzes junger Ibiume 12.4\%. Wem das sylintholz alter Bitume mit $13.9 \%$ ctwas mehr schwindet, so ist es allerdings schwierig, hierfir eine befriedigende Erklärung zu finden.

Denkbar wäre es, dass rlas Splintholz alter Baume nicht so viel T'erpentin, dafiur etwas dickere Wandungen enthielte und dass der geringere Terpentingehalt ein stirkeres Schwinden der Wandungssulustanz zur Folge gehalst hatte. Doch dis ist nur eine zunächst umbegrindete Vermuthung

Das specifische Trockengewicht des alten Kernholzes $(43.4$ "10) und des Splintholzes junger Bäume $(\$ 3.7 \%)$ ist wiederum kaum verschieden, während das splintholz alter Bäume in Folge dor stärkeren Schwindmg ein etwas höheres Trockengewicht, näimlich $41.9 \%$, bekommen liat. 
Alogesehen von der etwas grösseren Schwindung des Splintholzes alter Bäume ist also das Fichtenholz nnveriindert dasselbe vom ersten Jahre seiner Entstelnung an bis zum 80jührigen Alter und sicherlich noch weit diruber hinaus.

Völlig versehieden davon verhält sich das Holz der Kiefer. Diese Holzart bildet nicht nur einen rothbraunen Kern, der zwar erst unter der Einwirkung des Sanerstoffes der Luft nach der Fällung hervortritt, sondern sie produzirt auch nachhaltig bis zu höherem Alter him Harz, da die Auskleidungszellen der Kanäle sich nicht verdieken, wie bei der Fichte. Das ïltere, innere Kiefernholz ist weit reicher an Terpentin resp. Harz, wie das äussere Splintholz alter Biume oder das Holz junger Kiefern.

In Tab. 47 kömnen die Holzstïcke der jungen Kiefern fast direkt mit den Kernlrolzstïcken der alten Bäume verghichen werden, doch habe ich anch hier noch den Durchschnitt unter Ausschluss aller derjenigen Jahrringsbreiten extra berechnet, von welchen entweder nur im Kernholz oder nur im Splinte Stücke vorhanden waren.

Kiefernsplintholz junger Bäume zeigt $37.5 \mathrm{gr}$ Substanz, das Kiernlılz alter Bitume dagegen $41.6 \mathrm{gr}$, mithin $4.1 \mathrm{gr}$ mehr. In wie weit diese Substanzvermehrung dem zunehmenden Harzgehalt oder der Verkernung zugeschrieben werden muss, ist nicht zu erkennen. Das Schwindeprocent des Splintes alter und junger Büume ist fast gleich 11.8 und 11.6 resp. 12.I\%.

Das Kernholz dagegen schwindet nur 10.1 resp. $10.5^{\circ}{ }_{0}$, was theils der Verkernung, theils der Einlagerung des Terpentins in die Wandsubstanz zuzuschreiljen ist.

Uas specitische Trockengewicht des Kernes aller Bäume ist mit $46.6 \%$ erheblich grösser, als das des splintholzes jumger Bäme $(41.1 \%$. Dis hohe specifische Gewicht des Splintes der alten Bäume ist in der Schmahringigkeit begründet, iljer deren Einfluss auf die Holzqualität weiterhin gesprochen werden soll.

Ls darf noch auf die interessante Thatsiche anfmerksam gemacht werden, dass für das Kiefernlıolz die Grösse des specifischen Gewichtes keinen richtigen Naassstab zur Beurtheilung der Substanzmenge im gegebenen Volumen dirbietet. Splintholz besitzt ein specifisches Gewicht der Substanz von 1.56, ähnlich der Laubholzfaserwandung; Kemholz dagegen ist ein Gemisch ron Holzmicellen, zn 1.56 specifischem Gewicht und Terpentin resp. Ilarz von sehr geringem specifischem Gewichte. Wie ich fruilher gezeigt habe, besitzt das Kemholz ein specifisches Gewicht rou 1.52. Gleiche Gewichtstheile Kern und Splint entsprechen somit nicht gleichen Volumtheilen fester Substanz.

Was endlich die Lia rehe betrift, so bieten die wenigen Unterssuchungsobjekte keine brauchbaren Anhaltspunkte zur Beurtheilung der etwaigen Ver 
änderungen, welchen das Holz mit zunehmendem Alter unterworfen ist. Eine Veränderung erleidet dasselbe ersichtich durch friih eintretende Kiembildung, die auch schion am frischen Holze eine tief braunrothe Farbung hervorruft. Die in Riicksicht auf die grossen Jaluringsbreiten selır gute Qualität des Kernholzes berechtigt zu der Annahme, dass mit der Verkernung eine bedeutende Vermehrung der Substanz verbunden ist. In wie weit auch ein mit zunelmendem Alter sich steigernder Harzreichthum bei der Substanzvermelırung betheiligt ist, muss unentsehieden bleiben. Der Bau der Harzkanäle, weleher mit dem der Fichte grosse Aehnlichlieit hat, lässt vermuthen, dass eine bedeutende Harzzunahme bei der Lärche in höherem Alter nicht eintritt.

\section{Ueber den Einfluss der "Jahrringlreite aul die Substanz des Holzkörpers. (Tabelle 47.)}

Die Grösse des jährlichen Zuwachses an einen Baume resp. cinem bestimmten Baumtheile ist fortwährenden Schwankungen unterworfen, bedingt durch die Witterungsverhältnisse eines Jahres, durch Veränderungen in der Bodenbeschaffenheit, durch gesteigerten oder verminderten Lichtgenuss u. s. w. und iiberhaupt durch alle jenc äusseren Einfliisse, die wir in ihrer Gesammtlıeit als Standortsfaktoren bezeichnen.

Neben diesen schwankenden Einflüssen, die sich in der weehsehnden Breite der Jahresringe äussem, ändert sich anch die Zuwaehsgrösse des Baumes mit dessen Alter und zwar in Folge seiner zunehmenden Wurzelverbreitung, Blattmenge u. s. w.

Zur Beurtheilung der Zuwahsgrösse eines bestimmten Baumtheiles geniigt selbstredend die Breite des gebildeten Holzmantels nicht. Da der Baum alljährlich semen Durchmesser vergrössert, so kann nur die Zunahme des Stammquerschnittes an Fläche einen Maassstab fiur die Zuwachsgrösse darbieten.

Es lenchtet sofort ein, dass dann, wenn der Jahreszuwachs derselbe bleibt, wie der der Yorjahre, die Ringbreite constant abnehmen muss. Bleibt sich die Ringbreite gleieh, so ist damit eine Zunahne des Jahreszuwachses indicirt.

Mit Ausschluss der ersten Jugendzeit, in welcher der Zuwachs noch im Vergleieh zur Masse des Baumes ein sehr grosser ist und mit Aussehluss des jugendlichen Alters eines jelen Sehafttheiles oder Astes, in welehen der Querschint desselben noch klein ist, nimot die Jahrringsbreite im Algemeinen von aussen nach innen ab, wenn auch der. Flächenzuwachs oder, was damit gleichbedentend ist, der Nassenzuwachs an einem bestimmten Baumtheil noch in der Zunahme begriffen ist. Die Jahrringbreite für sich allein giebt also weder für 
die Beurtheilung des Zuwachses desselben Stammtheiles, noch beim Vergleich der Zuwachsgrösse in rersehiedenen Baumhöhen einen branelıbaren Anhalt, es muss viehnehr stets dabei die Stanmdicke mit berieksichtigt rerden, es kann mit anderen Worten immer nur die Grösse des Flächenzmwaelıses Aufschluss iiber die Wachsthmosgesetze des Bammes geben.

Ueber die Gesetze des Dickenwachsthumes dor Bämme habe ieh sehr eingehende Untersuchungen veröffentlicht*, deren Resultate sich in der Kuirze in folgende Sïtze zusammenfassen lassen.

Bei Beurtheilung des Diekenwachsthumes der Bäume sind diese in drei Abschnitte zu zerlegen, in den beasteten Theil (Baumkrone), in den astfreien Sehaft, und den unteren Theil desselben, den sogenannten Wurelanlauf, der aber zuweilen bis anf $2-3 \mathrm{~m}$ hoch emporsteigt. Innerhall, des bensteten Baumtheiles nimmt der Zuwachs stets ron oben nach unten zu, indem jeder lebende und noch reichliche Bildnngsstoffe producirende Seitenast dem Hauptschafte neue Stoffe zufïhrt, die lessen Zuwachs vergrössern.

Der astfreie Schaft zeigt dasselbe Wachsthumsgesetz, d. h. einen von oben nach unten sich steigernden Zuwachs bei allen Bïumen, deren Krone reich entwiekelt und voll belenchtet, mithin reichliche Bildungsstoffe zu produciren im Stande ist. Die Zuwachssteigerung nach unten kann in manchen Fiillen so bedentend sein, dass sogar die .Tahrringshreite unten grösser wird, als sie oben ist.

Bei allen Bäumen mit sehwach entwickelter oder sehr beschatteter Krone, deren Bildungsstoffjroduktion in Vergłeich zur laaungrösse gering ist, nimmt die Zuwachsgroosse von oben nach unten ab, ja in extremen Fällen werden die Bildungsstoffe vom Cambium der oberen Baumtheile ganz verluncht und gelangen gar nicht bis zum Fusse des Stammes.

Dic cambiale Thätigkeit erlischt aus Nahrumgsmangel in den unteren baumtheilen vollstandig, interessanterweise ohue dass dasselbe abstirbt. Treten später wieder günstigere Bedingungen der Ernährung ein, so setzt ras Cambium seine Jahre lang unterbrochene Thätigkeit wieder fort, wie dies anch für stark ausgeästete Bäume zu beobachten ist.

Kwischen der arsten und dieser zweiten Wuehsform giebt es nun selbstverständlich eine Mittelform, lie darin besteht, dass in der ganzen Lünge des Schaftes der Zuwachs viele Jahrzehnte hindureh fast gleich gross bleibt, in welchen Fällen natürlich die Ringbreite nach unten abnimmt. Diese Wuchsform tritt sehr häufig bei Bäumen mittlerer Stärke und Höhe in geschlossenen gleichalterigen Waldbeständen auf.

*) Zeitschrift fuir das Forst- und Jagdwesen. Berlin 1870. - Botanische Zeitung 1870, Nr. 32. 98. 
Das unterste Stammende zeichnet sich, abgesehen von stark unterdrückten Bäumen, immer durch eine lokale Zuwachssteigerung aus, die dahin führen kann, dass sellst eint starke Anschwellung dortselbst zu bemerken ist.

bie in den Tafeln 2-44 mitgetheilten Jahringbreiten eignen sich allerdings nicht dazu, diese Gesetze zu erkennen, weil die Eintheilung der Splinte, Mittelstiicke und Kernholzstiicke olne Riicksicht anf die Zahl der Jahresringe erfolgen musste.

Die mittlere .Tahrringsbreite der einzelnen Sektionen entspricht ganz ungleichen Jahrringszahlen.

Der Einfluss der Jahrringsbreite anf die Meschaffenheit des Holzes ist ein sehr bodeutungsvoller, aber nach der Holzart durchaus verschiedener.

Sehen wir zunäelıst auf die Eiche (Tab. 47), so fallt sofort in rie Augen, dass mit zunchmender lingbreite die sulıstanzmenge sich vergrössert.

Bei Hölzern mit $1-1.5 \mathrm{~mm}$ Ringlıreite kommen nur 55.5 wr, bei solchen mit 2.6-3 mm lingbreite $59.1 \mathrm{gr}$ anf 100 cet. Das Schwinden dagegen ist ein ziemlich gleichmässiges bei schmalen und breiten Ringen, während, wie früher besprochen, zwischen Kern und Splint eine grosse Verschiedenheit des Schwindens lyestelit.

Da das Schwinden gleichmässig elfolgt, so bleibt die bifferenz in der Quilitit schmal- und breitringigen Holzes bestehen. Fngringiges Eichenholz hat 67.2, breitringiges Holz $72.2 \%$ specitisches Trockengewicht.

Wie der Augenschein lehrt, beruht die vorbesprochene Verschiedenlucit darauf, dass die vorzugsweise aus grossen, weithmigen Gefïssen bestehende Friilujahrszone jedes Ringes einen um so grösseren Antheil an dem ganzen Jahresinge nimmt, je schmaler derselbe ist.

Sehr engringiges Eichenholz erscheint fast gleichnäissig sieburtig durch. löchert, breitringiges Holz dagegen ist ausserhalb des Porenkreises durch eine feste substanzreiche schicht ausgezeichmet, die grossentheils aus sehr dickwandigen enghumigen Sklerenchymfasern besteht. Je breiter der Jihrring, um so melır prövalirt in ihm der teste Pestandtheil desselben. Die dünnwandigen Tracheiden und das Holzparenchym befinden sich mels in der Näho der Gefässe und daher kommt es, dass engringiges Holz nur selı geringe Mengen der festen Sklerenchymfasern besitzen.

Auch bei der Rothbuche nimmt die Substanz mit der Jahrringbreite zu. Bei Jahresringen von $0.5-1 \mathrm{~mm}$ enthalten 100 eet sjulint $57.6 \mathrm{gr}$, bei Holz von durchischnittlich 2.6-3.0 mm Ringbreite dagegen 62.t gr. Dass das Kernholz durchschnittlich leichter ist, als das splintholz und zwar wegen des fehlenden Stäkemehlgehaltes, wurde bereits oben hervorgehoben. Das schwinden des Splintes und Kernes ist wie bei der Eiche unibhängig von der Jahrringbreite. 
Das specifische Trockengewicht nimmt desshalb wie der Substanzgehalt im Frischvolumen mit der Ringbreite zu und zwar im splinte ron 67.8 auf $76.1 \%$.

Jie gewonnenen Zahlen bestätigen die allgemeine Ammahme, nach welcher das junge breitringige, sowie das auf kräftigem Boden erwachsene Holz höheren Werth besitzt, als das engringige ältere, sowie das auf dürftigem Boden erwachsene Rothbuchenholz.

Die mikroskopische Untersuchung zeigt, dass die Zahl der Fefässe bei gleicher Qnerschnittsfäiche etwas grösser ist bei engringigem Holze, als bei breitringigem Buchenholze und diufte dieser Umstand für sich schon geniigen, die Geringwerthigkeit des schmalringigen Holzes zu erklären.

Ganz abweichend von der Rothbuche verhält sich die Rirke. Die Tab. 47 zeigt, dass die schmalsten Jahresringe das Maximum an Substanz (51.7 gr), die breitesten dageg*en das Minimum $49.9 \mathrm{gr}$ enthalten, dass also der Einfluss der Ringbreite gerade der entgegengesetzte ist, wie bei der Rothbnche. Es ist fermer noch hervorzuheben, dass das innere Holz (Kem) leichter ist als das äussere splintholz.

Die Untersuchung hat nun das interessante Resultat ergeben, dass bei der Birke nicht die Ringbreite an sich bestimmend fur die Qualitït des Holzes sei, sondern das Alter des Baumtheiles, an welchem der Jahresring gebildet worden ist, und nur desshalb, weil das Holz an juingeren Bam theilen leichter ist, als dis an älteren Stammtheilen gebildete, erscheinen die breiten Ringe als solche substanz:̈rmer.

Yergleicht man das Holz der breitringigen jüngeren Schafttheile odor des Kernes am unteren Sehafttheile mit dem sehmalringigen Holze aus dem Splinte des unteren Schaftheiles, so treten drei Verschiedenheiten in die Augen. Erstens ist die Zahl der Gefisse auf einem bestimmten Querschnitte bei breiten Jahresringen grösser als bei schmalen, also umgekehrt, wie das bei der Rothbuche ist. Zweitens sind die Holzfisern bei engringigem Holze dickwandiger, als im Holze junger Axentheile; drittens zeigt das Birkenholz, je näher der Markröhre, um so mehr Strangparenchym. Die grössere Schwere des in höherem Alter eines Stammtheiles gebildeten IIolzes ist also begriundet in geringerer Gefässzahl, in grösserer Diekwandigkeit der Organe und im Nangel an Holzparenchym, während das bei der Rothbuche und Fiche im Splint rorkommende Stärkemehl so gut wie ganz fehlt, wofiur sich im Parenchym geringe Mengen von Fett zeigen.

Dass die vorgenannten drei Eigenthimlichkeiten im anatomischen Bau des Holzes melı von dem Alter des Baumtheiles, als von der Ringbreite abhängig sind, geht aus dem Umstande hervor, dass in solehen Fällen, in denen die Jahrringe an unteren Stammtheile periodisch breiter geworden waren, diese Breitenzunahme keine V'erschlechterung des IIolzes zur Folge hatte. Etwa bis 
zum 15. Jahrringe (von der Markröhre ab gezihlhlt) zeigt das Birkenholz mit wenig Ausnahmen unter $50^{\circ}{ }_{0}$ organiseher Substanz; es ist reich an Gefässen. an Strangpajenehym und die Faserwandungen sind relativ diinn; die weitel aussen gelegenen Jahresringe werden ämer an Gefässen und Parenchym und zeigen dickwandigere Holzfasern; in den unteren Stammtheilen der 85jährigen Birke (Tabelle 10) besitzen die äusseren Jahressehichten tast gar kein Strangparenchyn, die Zahl der Gefïsse sinkt daselbst auf etwa $2 / 3$ ron der Zahl, die in den inneren Jahresringen auf gleicher Fläche zu zählen sind.

Bei allen untersuchten Birken mit Ansnahme des Deeemberstammes zeigt das Holz, welches ausserhalb der innersten 15 Ringe liegt, mehr als $50 \mathrm{gr}$ organischer Substanz.

Aus dem Gesagten erklärt sich, wesshalb das Kernlıolz bei gleicher Ringbreite leichter ist als das splintholz nnd ferner auch, wesshalb das breitringige Splintholz leichter ist, als das engringige, dem die Jahresringe nehmen, wie ich oben amsgreführt labe, von unten nach oben an Breite zu, mithin näheru sich die breiteren Jahresringe der oburen Bauntheile immer mehr der Markrölıre, sie gehören einem jüngeren Axentheile an und sind desshalb leiehter.

Der Mangel an Holzparenchym im Splinte älterer Banmtheile dürfte im Zusammenhang stehen mit der Erscheinung, dass auch die sogenaunten Markwiederliolungen, Markflecke, Markgiinge nur im jüngeren Alter des Bammtheiles geljildet werlen, im lıöheren Alter fast ganz fehlen. "

bie Organe der Reservestoffablagerung werden mit der bei der Birke schon frïhzeitig eintretenden Verminderung des Jahreszuwachses in den unteren Baumtheilen ïberflüssig, da die Menge der producirten Billungsstoffe mur hinreicht, flas Cambium im unteren Banmtleile zu einer änsserst beschrinkten Zuwaclistlütigkeit zu bofihigen. Eine Ablagerung von Reservestoffon erfolgt im unteren Stamntheile gar nicht mehr, beschrinkt sich vielmelı auf die oberen Bammeile und die Zweige und in diesen jungeren Axentheilen ist ja reichlich Holzparenchym vorlanden.

Soweit bisher Untersuchungen am Holz der Nadelhölzer ausgeführt wurden, hat sich ibbereinstimmend ergeben, dass, abgesehen von den Verharzungsprocessen, für die Guite desselben allein das Verlältniss der dickwandigen Herlsstholzzone zu der dünnwandigen Frihjahrsschicht massgebend ist. Im Allgemeinen steht fest, dass bei breiten Jahresringen die Herbstholzzone einen verhältnissmässig geringeren Antheil am ganzen Holzkörper nimmt als bei schmalen Ringen, dass die feste Herbstholzzone gleichsam cine konstante Breite hesitzt, während die Breite des ganzen Ringes mehr von der Entwickelung der lockeren Frihjahrszone abhängig ist. Es gilt desshalb nicht mit Unrecht der Satz, dass breitringiges Nadelholz scllechter sei, als schmalringiges. 
Eine Ausnahme von dieser Regel habe ich schon friher nachgewiesun, inden ich zeigte, dass bei sehr engen Jahresingen der Kiefer, wie solche sich im höheren Alter an den unteren Stammtheilen bilden, oder wie sie an stark unterdricksten Bäumen zur Ausbildung gelangen, die feste Herbstholzzone fast ganz verloren geht. Es reichen die nur dürtig zugeftihrten Bildungsstoffe wohl noch aus, um eine schmale, aus diumnwandigen 'Tracheiden gebildete Zone zu erzeugen, nicht aber, auch eine aus dickwandigen Breitfasem bestehende Herbstschicht zu bilden.

1)ie vorliegenten Untersuchungen- betreffen meist Bämme, die noch im besten Wuchse sich befanden, und doch tritt bei den alten Kieferm, die ron dem höheren Fichtenbestande, in welchem sie eingesprengt waren, etwas im Wuchse beeintriachtigt wurlen, schon die erwähnte Verschlechterung des Holzes bei dem Jahresringe von $05-1$ mm denthich herrol.

Noch melı zeigte dic eine Lärehe, welehe trotz ilues 5jjährigen Alter's schon im Wuchse sehr zurickthlieb, die Geringwerthigkeit des sehr schmalringigen Holzes. Holz mit $0.5-1 \mathrm{~mm}$ Ringbreite zeigt $43.1 \mathrm{gr}$, solehes mit 1.1-1.5 mm Ringbreite dagegen 47 gr Substanz pro 100 cet.

Von dem sehr schmalringigen Holze unter $1 \mathrm{~mm}$ mittlerer Ringloreite abgesehen, zeigen die Untersuchungen des Nadelholzes, dass mit zunehmender Ringbreite die Qualität, d. h. die Substanzmenge der Hölzer abnimmt.

Die alten und jungen Fichten zeigen bei gleicher Ringbreite, abgesehen von umberlentenden schwankungen dieselbe Substanzmenge; diese ist am höchsten bei Ringbreiten von 1-2 mm mit abgerundet $41 \mathrm{gr}$ und sinkt bei Ringbreiten von $5.1-5.5 \mathrm{~mm}$ auf $34.1 \mathrm{gr}$ herab. Beim Trocknen verliert das leichte breitringige Holz weit weniger an Ramm, als das schwerere engringige Ilolz. Das Schwindeproeent des letzteren steigt anf 15.3, während Ilolz mit $5.1-5.5 \mathrm{~mm}$ Ringbreite nur $8.5{ }^{\circ}{ }_{0}$ schwindet. Das verschiedenartige Schwindeprocent steigert noch die Untersehiede in der Qualitït des absolut trockenen Fichtenholzes. Das specifische Trockengewicht sinkt ron $47.8^{0_{0}}$ auf $37.2{ }_{0}$ hinab.

Bei der Kiefer treten die Unterschiede zwischen der Qualitit des breitund engringigen Holzes noch viel schärfer in die Augen. Allerdings muss man in Riucksicht auf die mit der Verkernung und Verharzung eintretende nachträgliche Substanzvermelurung nur das Splintholz der jungen und alten Kiefern beriticksichtigen. Die sehr schmalen Jahresringe des splintes der alten Kiefern zeigen den schon besprochenen Riickgang in der Qualitiit.

Sehen wir hiervon ab, so sinkt die Fubstanzmenge mit zunehmenter Ringbreite von 43.9 (44) bis auf $33.8 \mathrm{gr}$, also ron I auf ${ }^{3}$, der Substanzmenge pro 
Frischvolumen. Das Schwindeprocent sinkt wie bei der Fichte mit zunehmender Ringbreite und ebenso vernindert sich das specifische Trockengewicht von 49.9 bei engringigem, auf 37.4 bei breitringigem Holze.

Die schlechte Qualität des in der Jugend gebildeten breitringigen Holzes der Kiefer wird aber mit höherem Alter total umgeändert durch den Process der Verkermung und Verharzung. Ein Blick auf die organische Substanz des Kiefernkernholzes belehrt uns, dass das breitringigste Holz mit 6.1-8.5 1 mm Durchschnittsringbreite, welches dem Kern der untersten stammsektionen angehörte und das siclıerlich in der Jugend renig über $30 \mathrm{gr}$ substanz enthielt, auf $43.1 \mathrm{gr}$ sich verbessert hat, also in der Qualität obenan steht.

Was nun endlich die Lärche betrifft, so fehlt leider die Möglichkeit des Vergleiches zwischen Splint und Kernholz gleicher Ringbreiten. Das engringige Splintholz ist bedentend substanzïrmer, als das etwas breitringigere splintholz. In Kernholze ist erhebliche Abnahme der Qualitit mit zunehmencler Ringbreite zu erkennen; doch ist die Zahl der Versuchsstircke nicht recht geniigend, um weitere Schliisse aus den gewonnenen Zahlen ziehen zu können. 
64

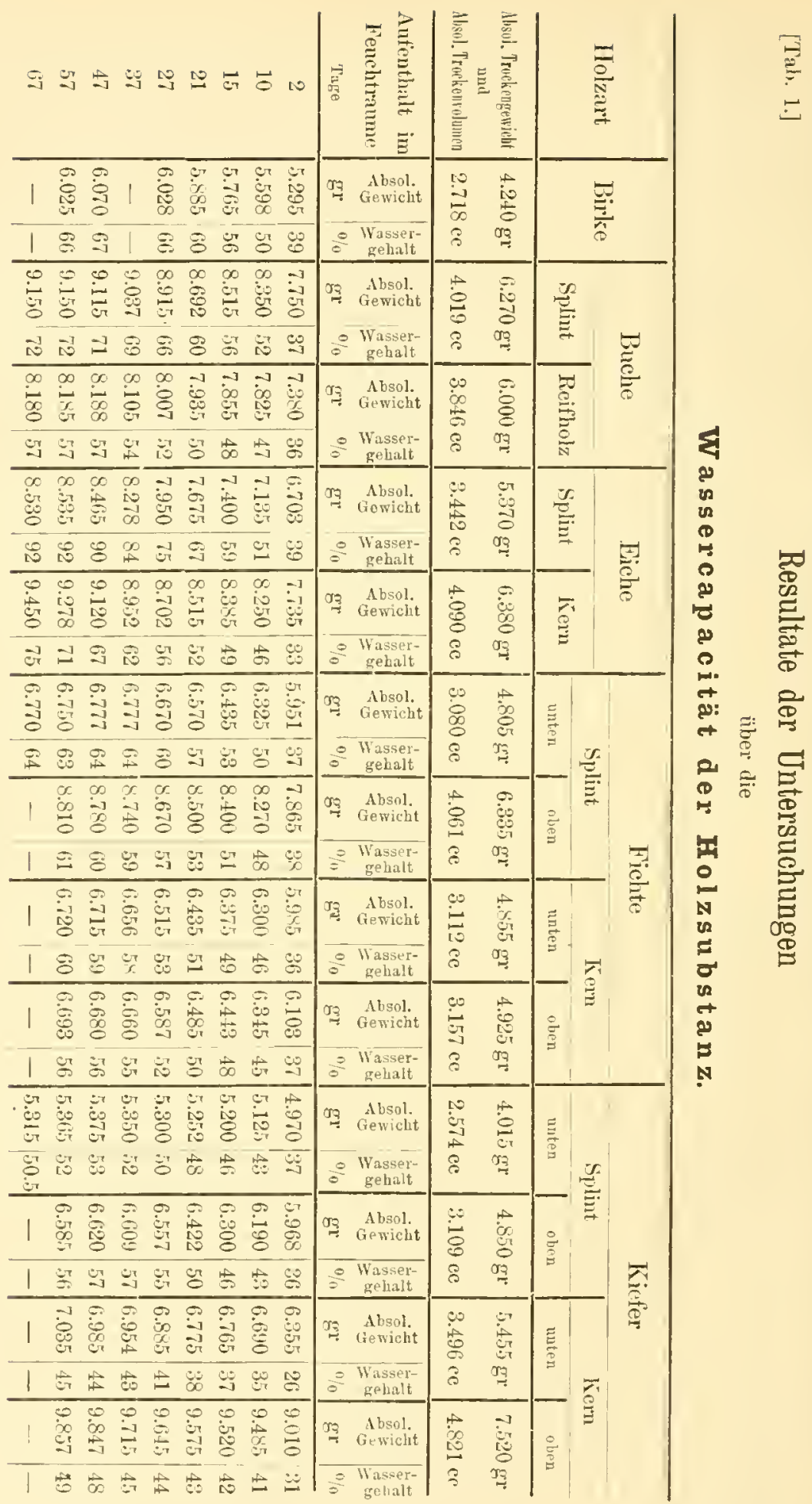




\section{Birke.}

Alter 30 Jahre.

2ミ. December 1881.

Höhe $13 \mathrm{~m}$. Kronenansatz ${ }^{\circ} \mathrm{m}$ m. Inhalt $0.113 \mathrm{~cm}$. Wasser $41.5 \% \%$. Substanz $30.2 \mathrm{ccm}$.

\begin{tabular}{|c|c|c|c|c|c|c|c|c|c|c|c|c|}
\hline \multirow{3}{*}{ 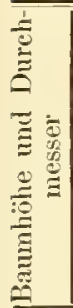 } & \multirow{3}{*}{ Batumtheil } & \multirow{3}{*}{ 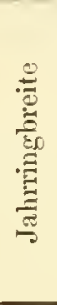 } & \multicolumn{3}{|c|}{$\begin{array}{l}\text { Organische Substanz } \\
\text { in } 100 \text { Raumtheilen } \\
\text { irischen Holzes }\end{array}$} & \multirow{3}{*}{$\stackrel{\Xi}{\Xi}$} & \multicolumn{3}{|c|}{ Wassergehalt } & \multicolumn{2}{|c|}{$\begin{array}{l}\text { Specifisches } \\
\text { Gewicht }\end{array}$} & \multirow{3}{*}{ 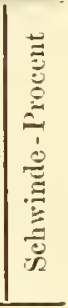 } \\
\hline & & & \multirow{2}{*}{ Gramme } & \multicolumn{2}{|c|}{ Laumtheile } & & \multicolumn{2}{|c|}{ in 100 Raumtheil. } & \multirow{2}{*}{$\begin{array}{l}\text { anf } \\
100 \mathrm{Ge}- \\
\text { wichts- } \\
\text { Ein- } \\
\text { heiten }\end{array}$} & \multirow{2}{*}{ friseh } & \multirow{2}{*}{ trockent } & \\
\hline & & & & trocken & imbibirt & & $\mid \begin{array}{l}\text { limzen } \\
\mid\end{array}$ & $\begin{array}{l}\text { In Inuss: } \\
\text { Zustand }\end{array}$ & & & & \\
\hline a & b & c & d & e & f & $g$ & li & $\mathrm{i}$ & k & 1 & m & $\mathrm{n}$ \\
\hline 1.3 & Rinde & - & 49.6 & $31.2^{1}$ & - & 14.4 & 54.4 & - & 52.3 & 104.0 & 80.7 & 38.4 \\
\hline - & Splint & 3.3 & 47.0 & 30.1 & 50.0 & 25.0 & 44.9 & 25.0 & 48.9 & 91.9 & 55.5 & 15.3 \\
\hline - & Kien & 2.8 & 42.1 & 27.0 & 44.8 & 33.4 & 39.6 & 21.8 & 48.5 & 81.7 & 50.1 & 15.9 \\
\hline 18.0 & $\because \mathrm{Holz}$ & 3.0 & 45.3 & 29.0 & 48.1 & 27.9 & 43.1 & 24.0 & 48.7 & 88.4 & 53.6 & 15.5 \\
\hline 3.5 & Rinde & - & 53.6 & 34.4 & - & 14.8 & 50.8 & - & 48.7 & 104.4 & 84.7 & 36.7 \\
\hline - & Splint & 3.2 & 47.2 & 30.3 & 50.3 & 26.5 & 43.2 & 23.2 & 47.8 & 90.4 & 55.4 & 14.9 \\
\hline- & liern & 3.8 & 42.6 & 27.3 & 45.3 & 31.7 & 41.0 & 23.0 & 49.0 & 83.6 & 50.6 & 15.7 \\
\hline 15.5 & . Holz & 3.5 & 45.6 & 29.2 & 48.5 & 28.3 & 42.5 & 23.2 & 48.2 & 8.1 & 53.8 & 15.1 \\
\hline 5.7 & Pinde & - & 57.8 & 36.7 & - & 18.6 & 44.7 & - & 43.8 & 102.0 & 83.4 & $: 31.4$ \\
\hline$\ldots$ & Splint & 3.0 & 48.2 & 30.9 & 51.3 & 31.8 & 37.3 & 16.9 & 43.2 & 85.5 & 57.0 & 15.4 \\
\hline - & liern & 2.6 & 44.6 & $2 \times .6$ & 47.5 & 28.4 & 43.0 & 24.1 & 49.1 & 87.6 & 52.8 & 15.5 \\
\hline 9.5 & . $\mathrm{Holz}$ & 2.8 & 47.1 & 30.2 & 50.1 & 30.6 & 39.2 & 19.3 & 45.3 & 86.3 & 55.7 & 15.4 \\
\hline 7.9 & Rinde & - & 57.3 & 36.7 & - & 18.4 & 44.9 & - & 43.9 & 102.2 & 86.0 & 33.3 \\
\hline 6.5 & Holz & 3.2 & 43.4 & 27.8 & 46.1 & 36.1 & 36.1 & 17.8 & 45.4 & 79.5 & 51.3 & 15.4 \\
\hline 10.1 & Rinde & - & 56.7 & 36.3 & - & 24.4 & 47.1 & - & 37.8 & 103.8 & 87.8 & 35.5 \\
\hline 4.0 & Holz & 4.0 & 43.4 & 27.8 & 46.1 & 38.7 & 33.5 & 15.2 & 43.5 & 76.9 & 51.4 & 15.5 \\
\hline 12.3 & Holz mit & inde & 42.5 & 27.2 & - & 35.5 & 37.3 & - & 46.7 & 79.8 & 54.6 & 22.2 \\
\hline $1=2$ & 2jährige $Z$ & eige & 49.9 & 32.0 & - & 20.2 & 47.8 & - & 48.9 & 97.7 & 73.6 & 32.2 \\
\hline & anze & & 47.1 & 30.2 & 50.1 & 28.3 & 41.5 & 21.6 & - & 88.6 & - & - \\
\hline
\end{tabular}




\section{Birke.}

Alter 35 Jahre.

16. Februar 1882.

Hölı $12 \mathrm{~m}$. Kronenansatz $5 \mathrm{~m}$. Inlalt $0.102 \mathrm{~cm}$. Wasser $41.5^{0} 0$. Substanz $33.3 \mathrm{ccm}$.

\begin{tabular}{|c|c|c|c|c|c|c|c|c|c|c|c|c|}
\hline \multirow{3}{*}{ 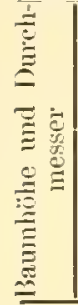 } & \multirow{3}{*}{ Baumtheil } & \multirow{3}{*}{ 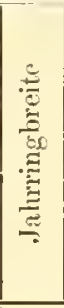 } & \multicolumn{3}{|c|}{$\begin{array}{l}\text { Organische Substanz } \\
\text { in } 100 \text { Raumtheilen } \\
\text { frischen Holzes }\end{array}$} & \multirow{3}{*}{ 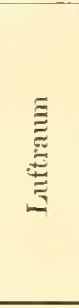 } & \multicolumn{3}{|c|}{ Wrassergehalt } & \multicolumn{2}{|c|}{$\begin{array}{l}\text { Specifisches } \\
\text { Gewicht }\end{array}$} & \multirow{3}{*}{ 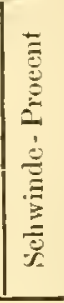 } \\
\hline & & & \multirow{2}{*}{ Gramme } & \multicolumn{2}{|c|}{ Raumtheile } & & \multicolumn{2}{|c|}{ in 100 Ranmtheil. } & \multirow{2}{*}{$\begin{array}{c}\text { anf } \\
100 \mathrm{Ge}- \\
\text { wichts- } \\
\text { Ein- } \\
\text { heiten }\end{array}$} & \multirow{2}{*}{ frisch } & \multirow{2}{*}{ trocken } & \\
\hline & & & & trocken & imbibirt| & & Ganzen & 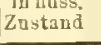 & & & & \\
\hline a & b & e & d & e & $f$ & $g$ & h & $\mathrm{i}$ & k & 1 & $\mathrm{~m}$ & n \\
\hline 1.3 & Rinde & - & 55.6 & 35.6 & - & 22.4 & 42.0 & - & 43.0 & 97.6 & 86.8 & 36.0 \\
\hline - & Splint & 2.3 & 54.7 & 35.1 & 54.3 & 25.1 & 39.8 & 16.6 & 42.2 & 94.5 & 64.9 & 15.7 \\
\hline - & Kern & 3.0 & 53.2 & 34.1 & 56.6 & 22.3 & 43.6 & 21.1 & 45.1 & 96.8 & 64.9 & 19.0 \\
\hline 17.0 & - H. Holz & 2.7 & 54.0 & 34.5 & 57.3 & 23.9 & 41.4 & 18.6 & 43.4 & 95.4 & 64.9 & 16.7 \\
\hline 3.5 & Riude & - & 58.0 & 37.2 & - & 21.2 & 41.6 & 一 & 41.8 & 99.6 & 83.7 & 30.6 \\
\hline - & Splint & 2.0 & 51.0 & 32.7 & 54.3 & 25.8 & 41.5 & 19.9 & 44.8 & 92.5 & 61.1 & 16.5 \\
\hline- & Kiern & 2.8 & 47.2 & 30.3 & 50.3 & 23.7 & 46.0 & 26.0 & 49.3 & 93.2 & 56.6 & 16.6 \\
\hline 13.0 & $\therefore$ Holz & 2.3 & 50.0 & 32.0 & 53.1 & 25.3 & 42.7 & 21.6 & 46.1 & 92.7 & 59.8 & 16.5 \\
\hline $5 . i$ & Pinde & - & 59.4 & 38.1 & - & 22.5 & 39.4 & - & 39.9 & 98.8 & 84. & 30.0 \\
\hline - & Splint & 2.1 & 54.4 & 34.9 & 57.9 & 30.0 & 35.1 & 12.1 & 89.2 & 89.5 & 66.0 & 17.9 \\
\hline - & Kiern & 2.2 & 48.7 & 31.2 & 51.8 & 20.4 & 48.4 & 27.8 & 49.8 & 97.1 & 59.3 & 17.8 \\
\hline 10.5 & $\cdot \mathrm{Holz}$ & 2.1 & 52.1 & 33.4 & 55.4 & 26.0 & 40.6 & 18.6 & 43.8 & 92.7 & 63.0 & 17.8 \\
\hline 7.9 & Rinde & - & 61.7 & 39.5 & - & 21.1 & 39.4 & - & 39.0 & 101.1 & 89.5 & 31.1 \\
\hline 8.0 & Holz & 2.5 & 49.3 & 31.6 & 52.5 & 27.5 & 40.9 & 20.0 & 45.4 & 90.2 & 59.1 & 10.6 \\
\hline 10.1 & Rinde & - & 64.7 & 41.5 & - & 18.3 & 40.2 & - & 38.4 & 104.9 & 92.6 & 30.3 \\
\hline 4.0 & $\mathrm{Hol}_{\mathrm{z}}$ & 2.6 & 47.8 & 30.6 & 50.8 & 29.2 & 40.2 & 20.0 & 45.6 & 88.0 & 57.7 & 17.1 \\
\hline \multicolumn{3}{|c|}{ 1-2jähr. Zweig m. Kin. } & 52.5 & 33.6 & - & 20.9 & 45.5 & - & 46.4 & 98.0 & 70.6 & 25.6 \\
\hline \multicolumn{3}{|c|}{ Ganzer Stanm } & 52.0 & 33.3 & 55.3 & 25.2 & 41.5 & 19.5 & - & 93.5 & - & - \\
\hline
\end{tabular}




\section{Birke.}

Alter 35 Jahre.

24. März 1881.

Höhe $12 \mathrm{~m}$. Ĺronenansatz $-\mathrm{m}$. Inhalt $0.100 \mathrm{~cm}$. Wasser $52.1 \%$. Substanz $33.8 \mathrm{ecm}$.

\begin{tabular}{|c|c|c|c|c|c|c|c|c|c|c|c|c|}
\hline \multirow{3}{*}{ 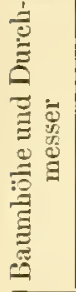 } & \multirow{3}{*}{ Baumtheil } & \multirow{3}{*}{ 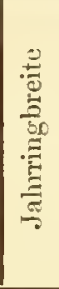 } & \multicolumn{3}{|c|}{$\begin{array}{l}\text { ()rganische Substanz } \\
\text { in } 100 \text { Rammtheilen } \\
\text { frischen Holzes }\end{array}$} & \multirow{3}{*}{$\stackrel{\Xi}{\Xi}$} & \multicolumn{3}{|c|}{ Wassergehalt } & \multicolumn{2}{|c|}{$\begin{array}{l}\text { Specifisches } \\
\text { Gewicht }\end{array}$} & \multirow{3}{*}{ 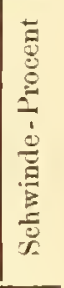 } \\
\hline & & & \multirow{2}{*}{ Granme } & \multicolumn{2}{|c|}{ Raumtheile } & & \multicolumn{2}{|c|}{ in 100 Raumtheil. } & \multirow{2}{*}{$\begin{array}{l}\text { auf } \\
100 \text { Ge- } \\
\text { wichts- } \\
\text { Ein- } \\
\text { beiten }\end{array}$} & \multirow{2}{*}{\multicolumn{2}{|c|}{ frisch trocken }} & \\
\hline & & & & trocken & imlibirt & & $\operatorname{im}_{\text {Ganzen }}$ & $\begin{array}{l}\text { in flüss: } \\
\text { Zustand }\end{array}$ & & & & \\
\hline a & b & e & d & e & $\mathrm{f}$ & $g$ & h & $\mathrm{i}$ & $\mathrm{k}$ & 1 & $\mathrm{~m}$ & n \\
\hline 1.3 & Rinde & - & 59.6 & 38.2 & - & 16.9 & 44.9 & - & 43.0 & 104.4 & 86.9 & 31.5 \\
\hline - & Splint & 2.6 & 56.0 & 35.9 & 59.6 & 12.6 & 51.5 & 27.8 & 47.9 & 107.5 & 66.4 & 15.7 \\
\hline - & liem & 2.6 & 52.9 & 33.9 & 56.3 & 15.4 & 50.7 & 28.3 & 48.9 & 103.6 & 61.6 & 14.1 \\
\hline 16.5 & Holz & 2.6 & 55.0 & 35.3 & 58.6 & 13.4 & 51.3 & 28.0 & 48.3 & 106.3 & 64.8 & 15.2 \\
\hline 3.5 & Rinde & - & 66.8 & 42.8 & - & 12.6 & 44.6 & - & 40.0 & 111.4 & 97.4 & 31.4 \\
\hline - & Splint & 2.4 & 52.8 & 33.8 & 56.1 & 11.8 & 54.4 & 32.1 & 50.7 & 107.2 & 64.1 & 17.6 \\
\hline - & Kern & 3.7 & 47.1 & 30.2 & 50.1 & 22.2 & 47.6 & 27.7 & 50.3 & 94.7 & 55.9 & 15.7 \\
\hline 13.0 & $\%$ Holz & 2.6 & 51.0 & 32.7 & 54.3 & 15.1 & 52.2 & 30.6 & 50.6 & 103.2 & 61.4 & 16.9 \\
\hline 5.7 & Rinde & - & 67.9 & 43.5 & - & 15.1 & 41.4 & - & 37.8 & 108.5 & 91.2 & 25.5 \\
\hline - & Splint & $\therefore .2$ & 51.5 & 33.0 & 54.8 & 13.5 & 53.5 & 31.7 & 51.0 & 105.1 & 62.0 & 16.9 \\
\hline - & Kern & 2.1 & 48.0 & 30.8 & 51.1 & 19.8 & 49.4 & 29.1 & 50.7 & 97.4 & 55.0 & 12.6 \\
\hline 11.0 & $\cdot \%$ Holz & 2.8 & 50.9 & 32.6 & 54.1 & 14.7 & 52.7 & 31.2 & 50.9 & 103.6 & 60.7 & 16.6 \\
\hline 7.9 & Rinde & - & 62.7 & 40.2 & - & 15.2 & 44.6 & - & 41.5 & 107.2 & 89.4 & $2 y .8$ \\
\hline 7.5 & Holz & 3.0 & 53.0 & 34.0 & 56.4 & 13.1 & 52.9 & 30.5 & 49.9 & 105.9 & 64.1 & 17.1 \\
\hline 10.1 & Rinde & - & 64.5 & 41.3 & - & 20.7 & 38.0 & - & 37.1 & 102.5 & 99.2 & 35.0 \\
\hline 4.0 & Holz & 2.2 & 50.6 & 32.4 & 52.8 & 11.2 & 56.4 & 35.0 & 52.7 & 107.0 & 57.2 & 11.6 \\
\hline 1-2jär & 11. Zweige & Kn. & 58.4 & 37.4 & - & 11.5 & 51.1 & - & 46.7 & $109 . \overline{5}$ & 67.9 & 13.9 \\
\hline & zzer & & 52.8 & 33.8 & 56.1 & 14.1 & 52.1 & 29.8 & - & 104.9 & - & - \\
\hline
\end{tabular}




\section{Birke.}

Alter 35 Jahre.

7. Mai 1881 .

Höhe $12 \mathrm{~m}$. Kronenansatz $5 \mathrm{~m}$. luhalt $0.101 \mathrm{~cm}$. Wasser $50.5 \%$. Substanz $33.6 \mathrm{ccm}$.

\begin{tabular}{|c|c|c|c|c|c|c|c|c|c|c|c|c|}
\hline \multirow{3}{*}{ 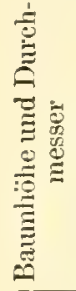 } & \multirow{3}{*}{ Baumtheil } & \multirow{3}{*}{ 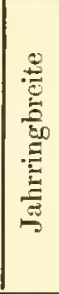 } & \multicolumn{3}{|c|}{$\begin{array}{l}\text { Organische Substanz } \\
\text { in } 100 \text { Raumtheilen } \\
\text { frischen Holzes }\end{array}$} & \multirow{3}{*}{ 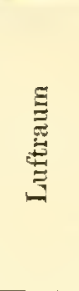 } & \multicolumn{3}{|c|}{ Wassergehalt } & \multicolumn{2}{|c|}{$\begin{array}{l}\text { Specifisches } \\
\text { Gewicht }\end{array}$} & \multirow{3}{*}{ 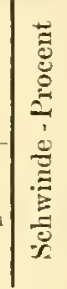 } \\
\hline & & & \multirow{2}{*}{ Gramme } & \multicolumn{2}{|c|}{ Raumtheile } & & \multicolumn{2}{|c|}{ in 100 Raum theil. } & \multirow{2}{*}{$\begin{array}{l}\text { and } \\
100 \mathrm{Ge}- \\
\text { wiehts- } \\
\text { Ein- } \\
\text { heiten }\end{array}$} & \multirow{2}{*}{ frisch } & \multirow{2}{*}{ trocken } & \\
\hline & & & & trocken & imbibirt & & $\operatorname{inz}_{\text {Ganzen }}$ & $\begin{array}{l}\text { in flūss, } \\
\text { Wasser }\end{array}$ & & & & \\
\hline a & b & e & $\mathrm{d}$ & $\mathrm{e}$ & f & $\mathrm{g}$ & $\mathrm{b}$ & $\mathrm{i}$ & $\mathrm{k}$ & 1 & $\mathrm{~m}$ & $n$ \\
\hline 1.3 & Rinde & - & 44.6 & 28.6 & - & 9.5 & 61.9 & - & 58.1 & 106.5 & 83.9 & 46.9 \\
\hline 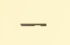 & Splint & 3.0 & 54.7 & 35.1 & 58.3 & 13.8 & 51.1 & 27.9 & 48.3 & 105.8 & 68.4 & 20.0 \\
\hline - & Kern & 2.1 & 52.3 & 33.5 & 55.6 & 19.9 & 46.6 & 24.5 & 47.1 & 98.9 & 64.2 & 18.6 \\
\hline 5.5 & $\cdot /$. Holz & 2.4 & 53.8 & 34.4 & 57.1 & 16.2 & 49.4 & 26.7 & 47.9 & 103.2 & 66.9 & 19.5 \\
\hline 3.5 & Rinde & - & 51.3 & 32.9 & - & 15.0 & 52.1 & - & 50.4 & 103.4 & 81.7 & 37.7 \\
\hline- & Splint & 3.0 & 55.7 & 35.7 & 59.3 & 13.0 & 51.3 & 27.7 & 47.9 & 107.0 & 68.4 & 18.5 \\
\hline - & Kern & 2.7 & 47.6 & 30.5 & 50.6 & 27.0 & 43.5 & 23.4 & 47.8 & 91.1 & 60.9 & 21.7 \\
\hline 13.5 & Hlolz & 2.9 & 52.7 & 33.8 & 56.1 & 17.8 & 48.4 & 26.1 & 47.9 & 101.1 & 65.7 & 19.7 \\
\hline 5.7 & Rinde & - & 63.3 & 40.6 & - & 7.8 & 51.6 & - & 44.9 & 114.9 & 89.6 & 29.3 \\
\hline- & splint & 3.8 & 51.5 & 33.0 & 54.8 & 13.0 & 54.0 & 32.2 & 51.2 & 105.5 & 63.1 & 18.4 \\
\hline - & Kern & 2.6 & 48.7 & 30.6 & 50.8 & 26.3 & 43.1 & 22.9 & 47.0 & 91.8 & 59.7 & 18.5 \\
\hline 11.5 & $\%$ Holz & 3.3 & 50.8 & 32.5 & 54.0 & 16.3 & 51.2 & 29.7 & 50.2 & 102.0 & 62.2 & 18.4 \\
\hline 7.9 & Rinde & - & 59.7 & 38.3 & - & 12.5 & 49.2 & - & 45.2 & 108.9 & 90.5 & 34.0 \\
\hline 8.0 & Holz & 3.2 & 51.3 & 32.9 & 54.6 & 12.0 & 55.1 & 33.4 & 52.0 & 106.4 & 63.8 & 19.6 \\
\hline 10.1 & Rinde & - & 59.0 & 37.9 & - & 9.7 & 52.4 & - & 46.9 & 110.4 & 94.4 & 37.5 \\
\hline 5.0 & Holz & - & 49.6 & 31.8 & 52.8 & 7.1 & 61.1 & 40.1 & 55.2 & 110.7 & 59.5 & 16.7 \\
\hline \multicolumn{3}{|c|}{ 1-2jähr. Zwg. olne Bl. } & 47.1 & 30.2 & 一 & 12.9 & 56.9 & - & 54.7 & 104.0 & 75.5 & 42.2 \\
\hline \multicolumn{3}{|c|}{ Ganzer Stamm } & 52.5 & 33.6 & 55.8 & 16.3 & 50.5 & 28.3 & - & 103.0 & - & - \\
\hline
\end{tabular}




\section{Birke.}

Alter 30 Jahre.

2. Juli 1881 .

Höhe $11.5 \mathrm{~m}$. Kronenansatz $4.5 \mathrm{~m}$. Inhalt $0.084 \mathrm{~cm}$. Wasser $43.8^{\circ} \%$. Substanz $32.4 \mathrm{ecm}$.

\begin{tabular}{|c|c|c|c|c|c|c|c|c|c|c|c|c|}
\hline \multirow{3}{*}{ 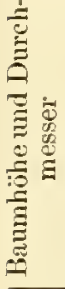 } & \multirow{3}{*}{ Baumtheil } & \multirow{3}{*}{ 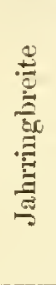 } & \multicolumn{3}{|c|}{$\begin{array}{c}\text { Organische Substanz } \\
\text { in } 100 \text { Raumtheilen } \\
\text { frischen Holzes }\end{array}$} & \multirow{3}{*}{$\stackrel{\Xi}{\underline{\Xi}}$} & \multicolumn{3}{|c|}{ Wassergehait } & \multicolumn{2}{|c|}{$\begin{array}{l}\text { Specifisches } \\
\text { Gewicht }\end{array}$} & \multirow{3}{*}{ 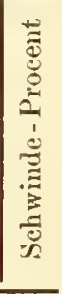 } \\
\hline & & & \multirow{2}{*}{ Gramme } & \multicolumn{2}{|c|}{ Raumtheile } & & \multicolumn{2}{|c|}{ in 100 Raum theil. } & \multirow{2}{*}{$\begin{array}{l}\text { naf } \\
100 \text { Ge- } \\
\text { wichts- } \\
\text { Ein- } \\
\text { beited }\end{array}$} & \multirow{2}{*}{ frisch } & \multirow{2}{*}{ trocken } & \\
\hline & & & & trockeu & imbibirt & & Ganzen & $\begin{array}{l}\text { In nu } \\
\text { Zust: }\end{array}$ & & & & \\
\hline a & 1) & $\mathrm{c}$ & d] & e & f & $g$ & h & i & $k$ & 1 & $\mathrm{~m}$ & n \\
\hline 1.3 & Rinde & - & 51.5 & $33.0^{\circ}$ & - & 18.4 & 45.6 & - & 48.6 & 100.1 & 81.9 & 37.1 \\
\hline - & Splint & 3.7 & 51.1 & 32.8 & 54.4 & 23.6 & 43.6 & 22.0 & 46.0 & 94.7 & 62.0 & 17.5 \\
\hline- & Kiern & 4.6 & 50.6 & 32.4 & 53.8 & 27.3 & 40.1 & 18.7 & 44.2 & 90.7 & 60.2 & 15.9 \\
\hline 15.5 & $\cdot / . \mathrm{Holz}$ & 4.5 & 50.8 & 32.6 & 54.1 & 25.4 & 41.7 & 20.2 & 45.0 & 92.5 & 61.0 & 16.7 \\
\hline 3.5 & Rincle & - & 52.1 & 33.4 & - & 20.1 & 46.5 & - & 47.2 & 98.6 & 83.4 & 37.5 \\
\hline - & Splint & 2.3 & 51.6 & 33.1 & 54.9 & 22.3 & 44.6 & 22.8 & 46.4 & 96.2 & 63.7 & 19.0 \\
\hline - & Kem & 3.0 & 49.9 & 32.0 & 53.1 & 23.7 & 44.3 & 23.2 & 47.0 & 94.2 & 58.4 & 14.7 \\
\hline 13.0 & $\%$ Holz & 2.7 & 50.8 & 32.6 & 54.1 & 22.9 & 44.5 & 23.0 & 46.7 & 95.3 & 61.4 & 17.2 \\
\hline 5.7 & Rinc & - & 52.6 & 33.7 & - & 18.2 & 48.1 & - & 47.7 & 100.7 & 86.8 & 39.3 \\
\hline - & Splint & 3.4 & 50.6 & 32.4 & 53.8 & 18.9 & 48.5 & 27.1 & 48.9 & 99.1 & 61.1 & 17.1 \\
\hline - & Kern & 3.3 & 47.4 & 30.4 & 50.5 & 25.5 & 44.1 & 24.0 & 48.2 & 91.5 & 55.8 & 14.9 \\
\hline 10.0 & . Holz & 3.4 & 49.8 & 31.9 & 53.0 & 20.8 & 47.3 & 26.2 & 48.7 & 97.1 & 59.6 & 16.3 \\
\hline 7.9 & Rinde & - & 49.0 & 31.4 & - & 16.1 & 52.5 & - & 51.7 & 101.5 & 83.7 & 41.5 \\
\hline 5.0 & Holz & 2.4 & 48.0 & 30.8 & 51.1 & 23.3 & 45.9 & 25.6 & 48.9 & 93.9 & 58.7 & 18.2 \\
\hline 10.1 & Rinde & - & 42.2 & 27.0 & - & 11.0 & 62.0 & - & 59.5 & 104.2 & - & - \\
\hline 2.0 & Holz & 2.2 & 47.7 & 30.6 & 50.8 & 16.4 & 58.0 & 32.8 & 52.6 & 100.7 & 62.4 & 23.5 \\
\hline \multicolumn{3}{|c|}{ 2jährige Zweige } & 39.6 & 25.4 & - & 10.1 & 64.5 & - & 61.9 & 104.1 & 74.7 & 47.0 \\
\hline \multicolumn{3}{|c|}{ 1jähr. Zweig mit Laub } & 41.0 & 26.3 & - & 7.1 & 66.6 & - & 61.9 & 107.6 & 87.1 & 53.0 \\
\hline \multicolumn{3}{|c|}{ Ganzer Stamm } & 50.5 & 32.4 & 53.8 & 23.8 & 43.8 & 22.4 & - & 94.3 & - & - \\
\hline
\end{tabular}




\section{Birke.}

Alter 30 Jahre.

8. October 1881.

Höhe $13 \mathrm{~m}$. Kronenansatz $\& \mathrm{~m}$. Inhalt $0.126 \mathrm{~cm}$. Wasser $38.6^{\circ} \mathrm{\rho}$. Substauz $32.9 \mathrm{ccm}$.

\begin{tabular}{|c|c|c|c|c|c|c|c|c|c|c|c|c|}
\hline \multirow{3}{*}{ 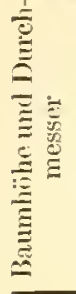 } & \multirow{3}{*}{ Bauntheil } & \multirow{3}{*}{ 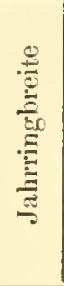 } & \multicolumn{3}{|c|}{$\begin{array}{l}\text { Organische Substanz } \\
\text { in } 100 \text { Raumtheilen } \\
\text { frischen Holzes }\end{array}$} & \multirow{3}{*}{$\stackrel{\Xi}{\stackrel{\Xi}{\Xi}}$} & \multicolumn{3}{|c|}{ Wassergehalt } & \multicolumn{2}{|c|}{$\begin{array}{c}\text { Specifisches } \\
\text { Gewicht }\end{array}$} & \multirow{3}{*}{ 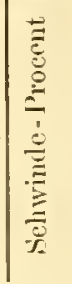 } \\
\hline & & & \multirow{2}{*}{ Gramme } & \multicolumn{2}{|c|}{ Raumtheile } & & \multicolumn{2}{|c|}{ in 100 RaumtheiJ. } & \multirow{2}{*}{$\begin{array}{l}\text { auf } \\
100 \text { che- } \\
\text { wichts- } \\
\text { Ein- } \\
\text { heiten }\end{array}$} & \multirow{2}{*}{ frisch } & \multirow{2}{*}{ trocken } & \\
\hline & & & & trocker & imbihirt & & im & $\begin{array}{l}\text { in fusss. } \\
\text { Zustand }\end{array}$ & & & & \\
\hline$a$ & $\mathrm{~b}$ & c & d & $\mathrm{e}$ & $f$ & $g$ & $\mathrm{~h}$ & $\mathrm{i}$ & $\mathrm{k}$ & 1 & $\mathrm{~m}$ & $\mathrm{n}$ \\
\hline 1.3 & Rinde & - & 60.3 & 38.7 & 一 & 16.8 & 44.5 & 25.2 & 42.5 & 104.8 & 96.3 & 37.3 \\
\hline - & Splint & 4.2 & 52.6 & 33.7 & 55.9 & 31.5 & 34.8 & 12.6 & 39.8 & 87.4 & 61.8 & 15.0 \\
\hline - & Kem & 3.4 & 51.7 & 33.1 & 54.9 & 28.9 & $3 \div .0$ & 16.2 & 42.4 & 89.7 & 59.6 & 13.2 \\
\hline I8.5 & - Holz & 3.6 & 52.2 & 33.5 & 55.6 & 30.5 & 36.0 & 13.9 & 40.8 & 88.2 & 60.9 & 14.2 \\
\hline 3.5 & Rinde & - & 65.7 & 41.9 & - & 18.2 & 39.9 & - & 37.8 & 105.6 & 93.6 & 29.8 \\
\hline - & Splint & 4.1 & 51.2 & 32.2 & 53.5 & 28.8 & 39.1 & 17.8 & 43.3 & 90.3 & 58.5 & 12.5 \\
\hline - & Kern & 4.8 & 51.2 & 32.2 & 53.5 & 27.7 & 40.2 & 15.9 & 43.9 & 91.4 & 58.5 & 12.4 \\
\hline 15.0 & $\cdot$. Holz & 4.2 & 51.2 & 32.2 & 53.5 & 28.4 & 39.5 & 18.2 & 43.5 & 90.7 & 58.5 & 12.5 \\
\hline 5.7 & rivde & - & 68.9 & 44.2 & - & 15.3 & 40.5 & - & 37.0 & 109.4 & 94.0 & 26.7 \\
\hline - & splint & 3.9 & $51.6^{\circ}$ & 33.1 & 54.9 & 26.5 & 40.4 & 18.6 & 43.1 & 92.0 & 59.6 & 13.3 \\
\hline - & Kern & 4.0 & 51.0 & 32.7 & 54.3 & $25 . I$ & 42.2 & 20.6 & 45.3 & 93.2 & 58.0 & 12.1 \\
\hline 12.0 & Holz & 4.0 & 51.4 & 32.9 & 54.6 & 26.2 & 40.9 & 19.2 & 44.3 & 92.3 & 59.1 & 13.0 \\
\hline 7.9 & Rinde & - & 68.2 & 43.7 & - & 15.4 & 40.9 & - & 37.5 & 109.1 & 92.3 & 26.1 \\
\hline 8.5 & Holz & 4.0 & 47.8 & 30.6 & 50.8 & 27.7 & 41.7 & 21.5 & 46.6 & 89.5 & 55.2 & 13.5 \\
\hline 10.1 & lỉinde & - & 64.8 & 41.5 & - & 12.5 & 46.0 & - & 41.5 & 110.8 & 98.5 & 35.0 \\
\hline 4.5 & Holz & 3.1 & 46.5 & 20.8 & 49.5 & 30.4 & 39.8 & 20.1 & 46.1 & 86.3 & 57.1 & 18.6 \\
\hline \multicolumn{3}{|c|}{ I- u. 2jühr. Zwg. ohne B. } & 48.0 & 30.8 & - & 11.9 & 57.3 & - & 54.4 & 105.3 & 78.6 & 38.9 \\
\hline \multicolumn{3}{|c|}{ 1jähr. Zwg.m. Blättern } & 44.2 & $2 s .3$ & - & 13.9 & 57.8 & - & 56.7 & 102.0 & 76.5 & 42.2 \\
\hline \multicolumn{3}{|c|}{ Ganzer Stamm } & 51.3 & 32.9 & 54.6 & 28.5 & 38.6 & 16.9 & - & 89.9 & - & - \\
\hline
\end{tabular}




\section{Birke.}

Alter 85 Jahre.

16. Februar 1882.

Höhe $21 \mathrm{~m}$. Kronenausatz $12 \mathrm{~m}$. Inhalt $0.442 \mathrm{~cm}$. Wasser $42.1 \%$. Substanz 32.4 ccm.

\begin{tabular}{|c|c|c|c|c|c|c|c|c|c|c|c|c|}
\hline \multirow{3}{*}{ 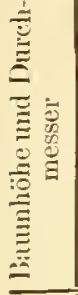 } & \multirow{3}{*}{ Baumtheil } & \multirow{3}{*}{ 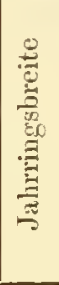 } & \multicolumn{3}{|c|}{$\begin{array}{c}\text { Organische Substanz } \\
\text { in } 100 \text { raumtheilen } \\
\text { frischen Holzes }\end{array}$} & \multirow{3}{*}{ 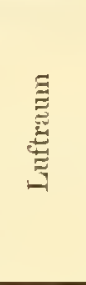 } & \multicolumn{3}{|c|}{ Wassergehalt } & \multicolumn{2}{|c|}{$\begin{array}{l}\text { Specifisehes } \\
\text { Gewicht }\end{array}$} & \multirow{3}{*}{ 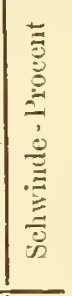 } \\
\hline & & & \multirow{2}{*}{ Gramme } & \multicolumn{2}{|c|}{ Raumtheile } & & \multicolumn{2}{|c|}{ in 100 Raumtheil. } & \multirow{2}{*}{$\begin{array}{l}\text { auf } \\
100 \mathrm{Ge}- \\
\text { wichts- } \\
\text { Ein- } \\
\text { beiten }\end{array}$} & \multirow{2}{*}{ friseh } & \multirow{2}{*}{ trocken } & \\
\hline & & & & trocken & imbibirt & & $\begin{array}{c}\text { im } \\
\text { Ganzen }\end{array}$ & $\begin{array}{l}\text { in fluss. } \\
\text { Zustind }\end{array}$ & & & & \\
\hline a & b & c & d & e & f & $g$ & h & $\mathrm{i}$ & $\mathrm{k}$ & l & $m$ & n \\
\hline 1.5 & Rinde & - & 59.6 & 38.2 & - & 20.2 & 41.6 & - & 41.1 & 101.2 & 85.9 & 30.6 \\
\hline - & Splint & 0.9 & 53.4 & 34.2 & 56.8 & 28.3 & 37.5 & 14.9 & 40.5 & 92.9 & 63.5 & 15.9 \\
\hline- & Kern & 2.0 & 49.6 & 31.8 & 52.8 & 23.9 & 44.3 & 23.3 & 47.2 & 93.9 & $58 . \overline{1}$ & 15.3 \\
\hline .1 & $\because \mathrm{Holz}$ & 1.3 & 51.9 & 33.3 & 55.8 & 25.4 & 41.3 & 19.3 & $\$ 4.4$ & 93.2 & $61 . j$ & 1.5 .6 \\
\hline 4.7 & & - & 63.2 & .5 & - & 19.1 & 40.4 & - & 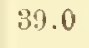 & 103.6 & 88.7 & 28.7 \\
\hline - & Splint & 0.9 & 51.4 & 32.9 & 54.6 & 25.3 & 41.8 & 20.1 & 44.9 & 93.2 & 62.1 & 17.2 \\
\hline - & Kien'n & 3.3 & 46.2 & 2 & 49.1 & 27.8 & 42.6 & 23.1 & 48.0 & 88.8 & 53.8 & 14.2 \\
\hline 21.0 & $\therefore$ Holz & 1.5 & 49.5 & 7 & 52.6 & 26.2 & 42.1 & 21.2 & 45.9 & 91.6 & 59.0 & 16.1 \\
\hline 7.9 & ade & - & 66.5 & .7 & - & 16.4 & 0.9 & - & 8.1 & 107.4 & 90.7 & 13.7 \\
\hline - & Splint & 0.8 & 50.4 & 32.3 & 53.6 & 25.5 & .12 .2 & 20.9 & 45.6 & 92.6 & 60.2 & 16.3 \\
\hline - & $\mathrm{Holz}$ & 3.0 & 47.6 & 30.5 & 50.6 & 26.2 & 43.3 & $2:$ & 47.6 & 90.9 & 56.6 & 15.8 \\
\hline 9.0 & Holz & 1.4 & 49.2 & 31.5 & 52.3 & 25.8 & 42.7 & 21.9 & 46.5 & 91.9 & 58.6 & 16.1 \\
\hline .1 & & - & 64.7 & & 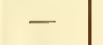 & 17.5 & 41.0 & -- & 38.8 & 105.7 & 89.8 & 27.1 \\
\hline - & Splint & 0.9 & 51.2 & 32.8 & 51.4 & 27.8 & 39.4 & 17.8 & 43.5 & 90.6 & 61.3 & 16.6 \\
\hline- & liern & 2.7 & 48.2 & 30.9 & 51.3 & 22.0 & 47.1 & 26.7 & 49.5 & 9.5 .3 & $\pi 7.2$ & 15.9 \\
\hline 16.5 & $\% \mathrm{Holz}$ & 1.4 & 50.1 & 32.1 & 53.3 & 25.7 & 42.2 & 21.0 & 45.7 & 92.3 & 60.0 & 16.3 \\
\hline 14.3 & twe & - & 6 & 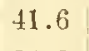 & 一 & 1 & 41.3 & 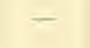 & .8 & 106.2 & .7 & 27.6 \\
\hline- & Splint & 1.2 & 53. & & 56.8 & 25.3 & 40.5 & 17.9 & 43.2 & 93.8 & 0.4 & 17.0 \\
\hline- & Kern & 2.0 & 50. & & 54 & i & 49.8 & 28 & 49.9 & 100.5 & 60.8 & 16.6 \\
\hline 11.5 & $\because \mathrm{Holz}$ & 1.4 & 52.4 & 33.6 & 55.8 & 23.1 & $43 .: 3$ & 21.1 & 45.2 & 95.7 & 63.1 & 16.9 \\
\hline 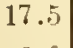 & & - & 64.4 & & - & 17.3 & 41.4 & - & 89.2 & 105.8 & 93.0 & 30.8 \\
\hline 6.0 & Holz & 0.9 & 50.4 & 32.3 & 53.6 & 20.3 & 47.4 & 26.1 & 48.5 & 97.8 & 60.4 & 16.6 \\
\hline 20.7 & \multicolumn{2}{|c|}{ Holz ohne Rinde } & 46.5 & 29.8 & 49.5 & 19.7 & 50.5 & 30.8 & 52.0 & 97.0 & 55.5 & 16.1 \\
\hline \multicolumn{3}{|c|}{$1-2$ jälirige $Z$ weigc } & 52.9 & 33.9 & - & 1. & 47.8 & $\cdots$ & 47.5 & 100.7 & 66.1 & 20.0 \\
\hline \multicolumn{3}{|c|}{ anzer } & 00 & 32.4 & 54.0 & 25.5 & 42.1 & 20.5 & - & 92.6 & - & \\
\hline
\end{tabular}




\section{Rothbuche.}

Alter 80 Jahre.

28. December 1881.

Höhe $20 \mathrm{~m}$. Kroneuansatz $7.5 \mathrm{~m}$. Inhalt $0.594 \mathrm{em}$. Wasser $47.3^{\%}$. Substanz $34.1 \mathrm{cem}$.

\begin{tabular}{|c|c|c|c|c|c|c|c|c|c|c|c|c|}
\hline \multirow{3}{*}{ 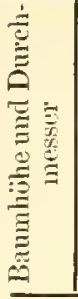 } & \multirow{3}{*}{ Banmtheil } & \multirow{3}{*}{ 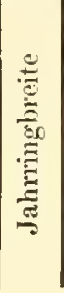 } & \multicolumn{3}{|c|}{$\begin{array}{c}\text { Organisehe Substanz } \\
\text { in } 100 \text { Ranmtheilen } \\
\text { frischen Holzes }\end{array}$} & \multirow{3}{*}{$\stackrel{\Xi}{\Xi}$} & \multicolumn{3}{|c|}{ Wassergehalt } & \multicolumn{2}{|c|}{$\begin{array}{l}\text { Specifisches } \\
\text { Gewieht }\end{array}$} & \multirow{3}{*}{ 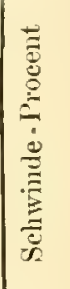 } \\
\hline & & & & Raut & & & \multicolumn{2}{|c|}{ in 100 Raumtheil. } & \multirow{2}{*}{$\begin{array}{l}\text { auf } \\
100 \mathrm{Ge-} \\
\text { wichts- } \\
\text { Eiu- } \\
\text { heiten }\end{array}$} & \multirow{2}{*}{ friscle } & \multirow{2}{*}{ trocken } & \\
\hline & & & & \multicolumn{2}{|c|}{ trocken imbivirt } & & $\operatorname{im}_{\text {Ganzen }}$ & $\begin{array}{l}\text { in firss, } \\
\text { Zustand }\end{array}$ & & & & \\
\hline a & b & c & d & $\mathrm{e}$ & f & $g$ & $\mathrm{~h}$ & $\mathrm{i}$ & $\mathrm{k}$ & 1 & $\mathrm{~m}$ & $\mathbf{n}$ \\
\hline $\begin{array}{c}0 \\
0 \\
30.0\end{array}$ & $\begin{array}{l}\text { linde } \\
\text { Splint } \\
\text { llitte } \\
\text { Kern } \\
\% \text { IIolz }\end{array}$ & $\begin{array}{l}- \\
3.0 \\
1.9 \\
1.5 \\
2.0\end{array}$ & $\begin{array}{l}56.5 \\
63.7 \\
57.5 \\
56.0 \\
61.4\end{array}$ & $\begin{array}{l}36.2 \\
40.8 \\
36.8 \\
35.9 \\
39.4\end{array}$ & $\begin{array}{l}70.2 \\
61.1 \\
56.4 \\
67.0\end{array}$ & $\begin{array}{l}18.9 \\
11.7 \\
26.6 \\
32.2 \\
17.2\end{array}$ & $\begin{array}{l}44.9 \\
47.5 \\
36.6 \\
31.9 \\
43.4\end{array}$ & $\overline{18.1}$ & $\begin{array}{l}44.2 \\
42.7 \\
38.9 \\
36.3 \\
41.4\end{array}$ & $\begin{array}{r}101.1 \\
111.2 \\
94.1 \\
87.9 \\
104.8\end{array}$ & $\begin{array}{l}82.3 \\
75.9 \\
68.7 \\
69.2 \\
73.4\end{array}$ & $\begin{array}{l}31.2 \\
16.1 \\
16.3 \\
19.1 \\
16.3\end{array}$ \\
\hline $\begin{array}{c}0 \\
0 \\
26.0\end{array}$ & $\begin{array}{l}\text { liinde } \\
\text { Splint } \\
\text { Mitte } \\
\text { Kiern } \\
\text {. Holz }\end{array}$ & \begin{tabular}{|l|}
-- \\
2.2 \\
1.8 \\
1.8 \\
1.9
\end{tabular} & $\begin{array}{l}53.4 \\
60.7 \\
54.6 \\
56.2 \\
58.0\end{array}$ & & $\begin{array}{l}-\overline{-} \\
66.9 \\
58.1 \\
56.5 \\
63.2\end{array}$ & $\begin{array}{r}15.8 \\
9.5 \\
26.6 \\
31.8 \\
17.5\end{array}$ & $\begin{array}{l}50.0 \\
51.6 \\
38.4 \\
32.2 \\
45.3\end{array}$ & - & $\begin{array}{l}48.6 \\
46.0 \\
41.3 \\
36.4 \\
43.8\end{array}$ & $\begin{array}{r}103.4 \\
112.3 \\
93.0 \\
88.4 \\
103.3\end{array}$ & $\begin{array}{l}80.6 \\
71.7 \\
65.4 \\
67.8 \\
69.1\end{array}$ & $\begin{array}{l}10.4 \\
16.5 \\
17.2 \\
16.0\end{array}$ \\
\hline $\begin{array}{c}0 \\
0 \\
24.0\end{array}$ & $\begin{array}{l}\text { Rinde } \\
\text { Splint } \\
\text { Nitte } \\
\text { Kirmu } \\
\% \text {. } 110 \mathrm{olz}\end{array}$ & \begin{tabular}{|l|}
$2 .-1$ \\
2.1 \\
2.2 \\
3.1
\end{tabular} & \begin{tabular}{|l|}
57.8 \\
59.0 \\
54.9 \\
54.3 \\
57.3
\end{tabular} & & 65.0 & $\begin{array}{l}20.0 \\
10.9 \\
20.1 \\
32.6 \\
15.3\end{array}$ & $\begin{array}{l}43.0 \\
51.3 \\
44.7 \\
32.6 \\
48.0\end{array}$ & $\begin{array}{l}2 \overline{24.1} \\
21.5 \\
12.8 \\
22.7\end{array}$ & 45.6 & $\begin{array}{r}100.8 \\
110.3 \\
99.6 \\
86.9 \\
105.3\end{array}$ & $\begin{array}{l}82.4 \\
70.4 \\
65.5 \\
66.9 \\
68.5\end{array}$ & $\begin{array}{l}16.3 \\
18.5 \\
16.3\end{array}$ \\
\hline .0 & $\begin{array}{l}\text { linde } \\
\text { Splint } \\
\text { Mitte } \\
\text { Kiern } \\
\text {. Holz }\end{array}$ & \begin{tabular}{|l|}
-2 \\
2.8 \\
2.2 \\
2.1 \\
2.3
\end{tabular} & $\begin{array}{l}58.6 \\
60.3 \\
55.6 \\
57.0 \\
58.2\end{array}$ & $\begin{array}{l}37.6 \\
38.6 \\
35.6 \\
36.5 \\
37.3\end{array}$ & $\begin{array}{l}57.3 \\
63.0\end{array}$ & $\begin{array}{r}20.2 \\
9.3 \\
16.4 \\
2 . .6 \\
13.1\end{array}$ & $\begin{array}{l}42.2 \\
52.1 \\
43.0 \\
34.9 \\
49.6\end{array}$ & $\overline{24.3}$ & $\begin{array}{l}41.9 \\
46.4 \\
46.3 \\
37.7 \\
46.0\end{array}$ & $\begin{array}{r}100.8 \\
112.4 \\
103.6 \\
91.9 \\
107.8\end{array}$ & $\begin{array}{l}83.1 \\
72.4 \\
66.7 \\
69.8 \\
70.0\end{array}$ & $\begin{array}{l}2 ! 9.6 \\
16.8 \\
16.7 \\
18.3 \\
16.8\end{array}$ \\
\hline 0.0 & $\left|\begin{array}{c}\text { Rinde } \\
\text { Splint } \\
\text { Mitten.Kern } \\
\text {. Holz }\end{array}\right|$ & $\begin{array}{l}- \\
2.4 \\
2.8 \\
2.4\end{array}$ & $\begin{array}{l}59.4 \\
54.8 \\
57.8\end{array}$ & $\begin{array}{l}- \\
38.1 \\
35.1 \\
37.0\end{array}$ & $\begin{array}{l}-5 \\
65.5 \\
58.3 \\
62.9\end{array}$ & $\begin{array}{r}\overline{9.0} \\
15.1 \\
11.2\end{array}$ & $\begin{array}{l}- \\
52.9 \\
49.8 \\
51.8\end{array}$ & - & $\begin{array}{l}47.1 \\
47.6 \\
47.3\end{array}$ & $\begin{array}{l}\overline{112.3} \\
104.6 \\
109.6\end{array}$ & $\begin{array}{l}-\overline{70.5} \\
66.6 \\
69.2\end{array}$ & $\begin{array}{l}- \\
15.8 \\
17.8 \\
16.5\end{array}$ \\
\hline $\begin{array}{c}12.5 \\
+ \\
0 \\
16.0\end{array}$ & $\begin{array}{c}\text { Rinde } \\
\text { Sylint } \\
\text { Mlitten.Fern } \\
\therefore .1 \text { 110lz }\end{array}$ & $\begin{array}{l}- \\
2.5 \\
2.8 \\
2.4\end{array}$ & $\begin{array}{l}62.8 \\
63.3 \\
60.8 \\
62.8\end{array}$ & $\begin{array}{l}40.6 \\
39.0 \\
40.3\end{array}$ & $\begin{array}{l}-\overline{69.8} \\
64.7 \\
68.7\end{array}$ & $\begin{array}{r}18.9 \\
7.6 \\
12.3 \\
8.6\end{array}$ & $\begin{array}{l}40.8 \\
51.8 \\
48.7 \\
51.1\end{array}$ & $\begin{array}{l}-\overline{-} \\
22.6 \\
23.0 \\
22.7\end{array}$ & $\begin{array}{l}45.0 \\
44.5 \\
44.9\end{array}$ & $\begin{array}{l}115.1 \\
109.5 \\
113.9\end{array}$ & $\begin{array}{l}85.3 \\
74.1 \\
73.9 \\
74.1\end{array}$ & $\begin{array}{l}26.8 \\
14.6 \\
17.8 \\
15.3\end{array}$ \\
\hline 10.7 & 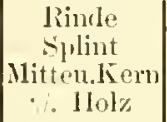 & $\begin{array}{l}- \\
2.3 \\
2.0 \\
2.2\end{array}$ & $\begin{array}{l}60.5 \\
61.6 \\
61.3 \\
63.9\end{array}$ & $\begin{array}{l}38.8 \\
41.4 \\
39.3 \\
40.9\end{array}$ & $\begin{array}{l}7 \overline{1.2} \\
65.2 \\
69.9\end{array}$ & $\begin{array}{r}22.2 \\
7.4 \\
7.3 \\
7.3\end{array}$ & $\begin{array}{l}39.0 \\
51.2 \\
53.4 \\
51.6\end{array}$ & $\begin{array}{l}\overline{21.4} \\
27.5 \\
22.6\end{array}$ & $\begin{array}{l}39.2 \\
44.2 \\
46.6 \\
44.6\end{array}$ & $\begin{array}{r}99.5 \\
115.8 \\
114.7 \\
115.5\end{array}$ & $\begin{array}{l}85.3 \\
75.7 \\
73.6 \\
75.3\end{array}$ & $\begin{array}{l}24.0 \\
14.7 \\
16.8 \\
15.1\end{array}$ \\
\hline .0 & \begin{tabular}{|c|} 
Rinde \\
Splint \\
Mitten.Kern \\
$\therefore$. Mol\%
\end{tabular} & $\begin{array}{l}-5 \\
3.0 \\
1.6 \\
2.6\end{array}$ & $\begin{array}{l}58.6 \\
66.8 \\
60.9 \\
65.8\end{array}$ & $\begin{array}{l}37.6 \\
42.8 \\
39.0 \\
42.1\end{array}$ & $\begin{array}{l}73.6 \\
64.8 \\
72.0\end{array}$ & $\begin{array}{r}25.1 \\
6.1 \\
11.9 \\
7.1\end{array}$ & $\begin{array}{l}37.3 \\
51.1 \\
49.1 \\
50.8\end{array}$ & $\begin{array}{l}-\overline{20.3} \\
23.3 \\
20.9\end{array}$ & $\begin{array}{l}38.9 \\
43.4 \\
44.6 \\
43.6\end{array}$ & $\begin{array}{r}95.9 \\
117.9 \\
110.0 \\
116.6\end{array}$ & $\begin{array}{l}82.0 \\
79.4 \\
73.1 \\
78.3\end{array}$ & $\begin{array}{l}28.6 \\
15.9 \\
16.7 \\
16.0\end{array}$ \\
\hline & $Z$ " & & 58.3 & 37.3 & - & 10.0 & 45.9 & - & 44.1 & 104.2 & 76.9 & 24.2 \\
\hline & zer S & & 59.4 & 38.1 & 61.7 & 14.6 & 47.3 & 20.7 & - & 106.7 & - & - \\
\hline
\end{tabular}


Rothbuche.

Alter 95 Jahre.

16. Februar 1882.

Höhe $21 \mathrm{~m}$. Kiñonenansatz $10 \mathrm{~m}$. Inhalt $0.584 \mathrm{~cm}$. Wasser $41.7 \%$. Substanz $36.9 \mathrm{ccm}$.

\begin{tabular}{|c|c|c|c|c|c|c|c|c|c|c|c|c|}
\hline \multirow{3}{*}{ 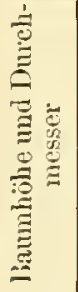 } & \multirow{3}{*}{ Baumtheil } & \multirow{3}{*}{ 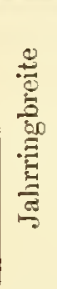 } & \multicolumn{3}{|c|}{$\begin{array}{c}\text { Organisehe Substanz } \\
\text { in } 100 \text { Raurntheileu } \\
\text { frischen Holzes }\end{array}$} & \multirow{3}{*}{$\underset{\Xi}{\stackrel{\Xi}{\Xi}}$} & \multicolumn{3}{|c|}{ WV assergelalt } & \multicolumn{2}{|c|}{$\begin{array}{c}\text { Speeifisehes } \\
\text { Gewieht }\end{array}$} & \multirow{3}{*}{ 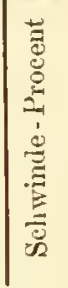 } \\
\hline & & & \multirow{2}{*}{ Gramme } & \multicolumn{2}{|c|}{ Raumtheile } & & \multicolumn{2}{|c|}{ in 100 Raum theil. } & \multirow{2}{*}{$\begin{array}{l}\text { auf } \\
100 \mathrm{Ge-} \\
\text { wichts- } \\
\text { Ein- } \\
\text { Leiten }\end{array}$} & \multirow{2}{*}{ frisch } & \multirow{2}{*}{ trocken } & \\
\hline & & & & trocken & oibirt & & $\lim$ & & & & & \\
\hline a & b & e & $d$ & e & $\mathrm{f}$ & $\mathrm{g}$ & li & $\mathrm{i}$ & $\mathrm{k}$ & 1 & $\mathrm{~m}$ & $n$ \\
\hline $\begin{array}{c}1.5 \\
0 \\
0 \\
0 \\
27.5\end{array}$ & $\begin{array}{l}\text { Rinde } \\
\text { Splint } \\
\text { Mitte } \\
\text { Kern } \\
\text { Holz }\end{array}$ & $\begin{array}{l}2.1 \\
1.4 \\
1.2 \\
1.5\end{array}$ & $\begin{array}{l}64.9 \\
61.9 \\
58.2 \\
61.4 \\
60.2\end{array}$ & $\begin{array}{l}41.6 \\
39.7 \\
37.3 \\
39.4 \\
38.6\end{array}$ & $\begin{array}{l}6 \varsigma .3 \\
61.9 \\
61.9 \\
65.2\end{array}$ & $\begin{array}{l}17.4 \\
15.8 \\
26.5 \\
2 \% .7 \\
21.6\end{array}$ & $\begin{array}{l}41.0 \\
44.5 \\
36.2 \\
31.9 \\
39.8\end{array}$ & $\begin{array}{r}15.9 \\
11.6 \\
9.4 \\
13.2\end{array}$ & $\begin{array}{l}38.7 \\
41.8 \\
38.4 \\
34.2 \\
39.8\end{array}$ & $\begin{array}{r}105.9 \\
106.4 \\
94.4 \\
93.3 \\
100.0\end{array}$ & $\begin{array}{l}83.2 \\
74.9 \\
70.9 \\
76.4 \\
73.3\end{array}$ & $\begin{array}{l}22.0 \\
17.5 \\
18.0 \\
19.6 \\
17.9\end{array}$ \\
\hline $\begin{array}{c}3.7 \\
0 \\
0 \\
0 \\
26.0\end{array}$ & $\begin{array}{l}\text { Rinde } \\
\text { Splint } \\
\text { Mitte } \\
\text { Kerul } \\
\text { \%. Holz }\end{array}$ & \begin{tabular}{|l|}
2.0 \\
1.4 \\
1.2 \\
1.5
\end{tabular} & $\begin{array}{l}62.6 \\
58.4 \\
55.1 \\
57.2 \\
57.1\end{array}$ & & \begin{tabular}{r|}
- \\
64.3 \\
58.6 \\
57.6 \\
62.2
\end{tabular} & $\begin{array}{l}18.4 \\
17.4 \\
29.3 \\
35.0 \\
23.5\end{array}$ & $\begin{array}{l}41.5 \\
45.2 \\
35.4 \\
28.3 \\
39.9\end{array}$ & $\begin{array}{r}-\overline{18.3} \\
12.1 \\
7.4 \\
14.3\end{array}$ & $\begin{array}{l}39.9 \\
43.6 \\
39.1 \\
33.1 \\
41.2\end{array}$ & $\begin{array}{r}104.1 \\
103.6 \\
90.5 \\
85.5 \\
97.0\end{array}$ & $\begin{array}{l}84.6 \\
71.2 \\
66.7 \\
69.5 \\
69.4\end{array}$ & $\begin{array}{l}25.9 \\
17.9 \\
17.4 \\
17.6 \\
17.7\end{array}$ \\
\hline $\begin{array}{c}5.9 \\
0 \\
0 \\
0 \\
24.0\end{array}$ & $\begin{array}{l}\text { Rinde } \\
\text { Splint } \\
\text { Mitte } \\
\text { Krru } \\
\text { Holz }\end{array}$ & $\begin{array}{l}1.6 \\
1.5 \\
1.4 \\
1.5\end{array}$ & $\begin{array}{l}64.4 \\
56.1 \\
55.1 \\
56.6 \\
55.8\end{array}$ & $\begin{array}{l}36.3 \\
35.8\end{array}$ & $\begin{array}{l}61.9 \\
58.6 \\
57.0 \\
60.5\end{array}$ & $\begin{array}{l}19.4 \\
18.0 \\
32.2 \\
34.1 \\
23.9\end{array}$ & $\begin{array}{l}39.3 \\
46.0 \\
32.5 \\
29.6 \\
40.3\end{array}$ & $\begin{array}{r}20.1 \\
9.2 \\
8.9 \\
15.6\end{array}$ & $\begin{array}{l}37.9 \\
45.1 \\
37.1 \\
34.8 \\
41.9\end{array}$ & $\begin{array}{r}103.7 \\
102.1 \\
87.6 \\
86.2 \\
96.1\end{array}$ & $\begin{array}{l}84.0 \\
67.0 \\
66.3 \\
69.4 \\
67.0\end{array}$ & $\mid \begin{array}{l}23.3 \\
18.3 \\
17.0 \\
18.5 \\
16.7\end{array}$ \\
\hline $\begin{array}{r}8.1 \\
+-0 \\
0 \\
0 \\
22.0\end{array}$ & $\begin{array}{l}\text { linde } \\
\text { Splint } \\
\text { Mitte } \\
\text { Kem } \\
\text {. Holy }\end{array}$ & $\begin{array}{l}1.9 \\
1.6 \\
1.7 \\
1.7\end{array}$ & $\begin{array}{l}62.2 \\
56.5 \\
54.7 \\
58.8 \\
56.1\end{array}$ & $\begin{array}{l}35.1 \\
37.7 \\
36.0\end{array}$ & $\begin{array}{l}-\overline{62.3} \\
58.3 \\
59.2 \\
60.8\end{array}$ & $\begin{array}{l}17.3 \\
18.4 \\
30.0 \\
31.4 \\
21.9\end{array}$ & $\begin{array}{l}42.5 \\
45.4 \\
34.9 \\
30.9 \\
42.1\end{array}$ & $\begin{array}{r}\overline{19.3} \\
11.7 \\
9.4 \\
17.3\end{array}$ & $\begin{array}{l}40.8 \\
43.8 \\
39.0 \\
34.4 \\
42.9\end{array}$ & $\begin{array}{r}105.0 \\
101.9 \\
89.6 \\
89.7 \\
99.2\end{array}$ & $\begin{array}{l}63.5 \\
69.4 \\
65.3 \\
71.6 \\
68.1\end{array}$ & $\begin{array}{l}25.6 \\
18.5 \\
11.3 \\
17.9 \\
17.7\end{array}$ \\
\hline $\begin{array}{c}10.3 \\
+ \\
0 \\
0 \\
20.5\end{array}$ & $\begin{array}{l}\text { Rinde } \\
\text { Splint } \\
\text { Mlitte } \\
\text { Kern } \\
\text {. llolz }\end{array}$ & \begin{tabular}{|l|}
1.6 \\
1.4 \\
1.8 \\
1.6
\end{tabular} & $\begin{array}{l}65.4 \\
58.0 \\
53.7 \\
55.8 \\
56.6\end{array}$ & $\begin{array}{l}41.9 \\
37.2 \\
34.4 \\
35.8 \\
36.3\end{array}$ & $\begin{array}{l}6 \overline{-} .0 \\
57.1 \\
56.2 \\
61.7\end{array}$ & $\begin{array}{l}18.8 \\
14.4 \\
25.2 \\
33.8 \\
18.6\end{array}$ & $\begin{array}{l}39.3 \\
48.4 \\
40.4 \\
30.4 \\
45.1\end{array}$ & $\begin{array}{l}-\overline{21.6} \\
17.7 \\
10.0 \\
19.7\end{array}$ & $\begin{array}{l}37.5 \\
45.5 \\
42.9 \\
35.3 \\
44.4\end{array}$ & $\begin{array}{r}104.7 \\
106.4 \\
94.1 \\
86.2 \\
101.7\end{array}$ & $\begin{array}{l}86.7 \\
68.9 \\
65.1 \\
69.5 \\
67.8\end{array}$ & $\begin{array}{l}24.5 \\
15.8 \\
17.6 \\
19.7 \\
16.5\end{array}$ \\
\hline $\begin{array}{c}12.5 \\
+ \\
0 \\
0 \\
17.0\end{array}$ & $\begin{array}{l}\text { Rinde } \\
\text { Splint } \\
\text { Mitte } \\
\text { Kern } \\
\text { \% Holz }\end{array}$ & \begin{tabular}{|l|}
1.6 \\
1.8 \\
1.2 \\
1.5
\end{tabular} & $\begin{array}{l}57.6 \\
57.6 \\
55.1 \\
57.5\end{array}$ & $\begin{array}{l}- \\
36.9 \\
37.0 \\
35.8 \\
36.9\end{array}$ & $\begin{array}{l}\overline{33.5} \\
61.4 \\
55.4 \\
62.7\end{array}$ & $\begin{array}{l}\overline{14.2} \\
22.6 \\
31.7 \\
17.7\end{array}$ & $\begin{array}{l}-\overline{-} .9 \\
40.4 \\
33.0 \\
45.4\end{array}$ & $\begin{array}{l}\overrightarrow{22.3} \\
16.0 \\
12.9 \\
19.6\end{array}$ & $\begin{array}{l}-\overline{45.9} \\
41.2 \\
37.5 \\
44.2\end{array}$ & $\begin{array}{r}1 \overline{106.5} \\
98.1 \\
88.1 \\
102.9 \\
\end{array}$ & $\begin{array}{r}-\overline{68.6} \\
70.8 \\
67.9 \\
69.2 \\
\end{array}$ & $\begin{array}{l}1 \overline{16.1} \\
18.5 \\
18.8 \\
17.0\end{array}$ \\
\hline $\begin{array}{c}14.7 \\
+ \\
0 \\
12.0\end{array}$ & \begin{tabular}{|c|} 
Rinde \\
Nplint \\
Mlitteu.Keru \\
. Molz
\end{tabular} & \begin{tabular}{|l|}
1.7 \\
2.0 \\
1.7
\end{tabular} & $\begin{array}{l}59.6 \\
60.2 \\
59.5 \\
60.1 \\
\end{array}$ & $\begin{array}{l}38.2 \\
38.6 \\
38.1 \\
35.5\end{array}$ & $\begin{array}{l}6 \overline{-} \\
63.4 \\
63.2 \\
63.8\end{array}$ & $\begin{array}{l}21.4 \\
14.0 \\
23.6 \\
15.1\end{array}$ & $\begin{array}{l}40.4 \\
47.4 \\
3 \% .3 \\
46.4\end{array}$ & $\overrightarrow{19.6}$ & $\begin{array}{l}40.4 \\
44.1 \\
39.1 \\
43.6\end{array}$ & $\begin{array}{r}100.0 \\
107.6 \\
97.8 \\
106.5\end{array}$ & $\begin{array}{l}\$ 3.2 \\
71.2 \\
72.1 \\
71.3\end{array}$ & $\begin{array}{l}28.4 \\
15.5 \\
17.5 \\
15.7\end{array}$ \\
\hline $\begin{array}{c}\overline{16.9} \\
+ \\
+ \\
7.0\end{array}$ & \begin{tabular}{|c|} 
lincle \\
Splint \\
Jitte u.liern \\
$\cdot \%$. Holz
\end{tabular} & \begin{tabular}{|l|}
- \\
1.2 \\
1.5 \\
1.3
\end{tabular} & $\begin{array}{l}63.3 \\
63.0 \\
58.2 \\
62.4\end{array}$ & $\begin{array}{l}40.6 \\
40.4 \\
37.3 \\
40.0\end{array}$ & $\begin{array}{l}- \\
69.5 \\
61.9 \\
68.4\end{array}$ & $\begin{array}{r}20.9 \\
9.8 \\
25.5 \\
13.2\end{array}$ & $\begin{array}{l}38.5 \\
49.8 \\
37.2 \\
46.8\end{array}$ & $\begin{array}{l}\overline{20.7} \\
12.6 \\
18.4\end{array}$ & $\begin{array}{l}37.8 \\
44.2 \\
38.1 \\
42.9\end{array}$ & $\begin{array}{r}101.8 \\
112.8 \\
97.4 \\
109.2\end{array}$ & $\begin{array}{l}84.4 \\
75.8 \\
72.1 \\
74.9\end{array}$ & $\begin{array}{l}25.0 \\
16.9 \\
16.3 \\
16.7\end{array}$ \\
\hline 19.11 & $\therefore$ Holz & 0.9 & 63.8 & 40.9 & 70.3 & 11.3 & 47.8 & 18.4 & 42.8 & 111.6 & 75.5 & 15.4 \\
\hline Pjial & Zweige $\mathrm{m}$. & Kn. & 54.0 & 37.8 & - & 13.7 & 48.5 & - & 45.1 & 107.5 & 75.9 & 122.2 \\
\hline & Sanzer Star & & 57.6 & 36.9 & 62.5 & 21.4 & 41.7 & 16.1 & - & $\overline{99.3}$ & $\overline{-}$ & - \\
\hline
\end{tabular}


Rothbuche.

Alter 85 Jahre.

24. März 1881 .

Höhe $18 \mathrm{~m}$. Lironenansatz $-\mathrm{m}$. Inhalt $0.547 \mathrm{em}$. Wasser $41.1 \%$. Substanz 35.1 eem.

\begin{tabular}{|c|c|c|c|c|c|c|c|c|c|c|c|c|}
\hline \multirow{3}{*}{ 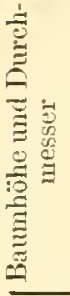 } & \multirow{3}{*}{ Bauntheil } & \multirow{3}{*}{ 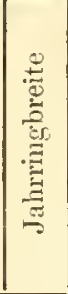 } & \multicolumn{3}{|c|}{$\begin{array}{c}\text { Organisehe Substanz } \\
\text { in } 100 \text { Rantheilen } \\
\text { frischen Holzes }\end{array}$} & \multirow{3}{*}{ 䮍 } & \multicolumn{3}{|c|}{ Wassergehalt } & \multicolumn{2}{|c|}{$\begin{array}{c}\text { Specifisches } \\
\text { Gewicht }\end{array}$} & \multirow{3}{*}{ 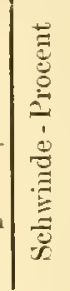 } \\
\hline & & & \multirow{2}{*}{ Grasume } & \multicolumn{2}{|c|}{ Raumtheile } & & \multicolumn{2}{|c|}{ in 100 Raumtheil. } & \multirow{2}{*}{$\begin{array}{c}\text { auf } \\
100 \mathrm{Ge-} \\
\text { wichts- } \\
\text { Ein- } \\
\text { heiten }\end{array}$} & \multirow{2}{*}{ frisch } & \multirow{2}{*}{ trocken } & \\
\hline & & & & ocken & i & & en & 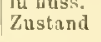 & & & & \\
\hline$a$ & 1) & c & d & $\mathrm{e}$ & $f$ & $\mathrm{~g}$ & h & $\mathrm{i}$ & $k$ & l & $\mathrm{m}$ & $\mathrm{n}$ \\
\hline $\begin{array}{c}1.5 \\
- \\
\overline{-} \\
23.5\end{array}$ & $\begin{array}{l}\text { Rinde } \\
\text { Splint } \\
\text { Mitte } \\
\text { liern } \\
\text {. Holz }\end{array}$ & \begin{tabular}{l|}
- \\
1.5 \\
2.0 \\
2.2 \\
1.8
\end{tabular} & $\begin{array}{l}56.0 \\
52.7 \\
53.3 \\
58.0 \\
53.8\end{array}$ & $\begin{array}{l}35.9 \\
33.8 \\
31.2 \\
37.2 \\
34.4\end{array}$ & $\begin{array}{l}-\overline{58.1} \\
56.8 \\
58.4 \\
57.8\end{array}$ & $\begin{array}{l}15.5 \\
97.2 \\
32.6 \\
28.6 \\
29.7\end{array}$ & $\begin{array}{l}48.6 \\
39.0 \\
33.2 \\
33.9 \\
35.9\end{array}$ & $\begin{array}{l}\overline{-} \\
14.7 \\
10.6 \\
12.7 \\
12.5\end{array}$ & $\begin{array}{l}46.4 \\
42.5 \\
38.4 \\
36.9 \\
40.1\end{array}$ & $\begin{array}{r}104.6 \\
91.7 \\
86.5 \\
91.9 \\
89.7\end{array}$ & $\begin{array}{l}71.8 \\
61.9 \\
63.1 \\
68.5 \\
63.3\end{array}$ & $\begin{array}{l}22.0 \\
14.7 \\
15.5 \\
15.3 \\
15.1\end{array}$ \\
\hline $\begin{array}{c}3.7 \\
-\overline{-} \\
25.5\end{array}$ & \begin{tabular}{|c|} 
Rinde \\
Splint \\
Mitteu.liern \\
$\%$. Holz
\end{tabular} \mid & $\begin{array}{l}-1.7 \\
1.6 \\
1.6\end{array}$ & $\begin{array}{l}58.4 \\
52.1 \\
54.1 \\
52.8\end{array}$ & $\begin{array}{l}37.4 \\
33.4 \\
34.7 \\
33.9\end{array}$ & $\begin{array}{l}5 \overline{57.4} \\
56.2 \\
57.6\end{array}$ & $\begin{array}{l}15.2 \\
32.5 \\
29.4 \\
24.7\end{array}$ & $\begin{array}{l}47.4 \\
44.1 \\
35.9 \\
11.4\end{array}$ & $\begin{array}{l}-\overline{0} \\
14.1 \\
17.7\end{array}$ & \begin{tabular}{|l|}
44.5 \\
45.8 \\
39.9 \\
44.0
\end{tabular} & $\begin{array}{r}105.8 \\
96.2 \\
90.0 \\
94.2\end{array}$ & $\begin{array}{l}71.0 \\
61.3 \\
64.6 \\
62.4\end{array}$ & $\begin{array}{l}17.8 \\
15.0 \\
16.3 \\
15.4\end{array}$ \\
\hline $\begin{array}{l}5.9 \\
- \\
23.0\end{array}$ & $\begin{array}{c}\text { linde } \\
\text { splint } \\
\text { Mitte u.Kern } \\
\text {. Holz }\end{array}$ & $\begin{array}{l}-7 \\
1.7 \\
1.7 \\
1.7\end{array}$ & $\begin{array}{l}61.2 \\
53.8 \\
53.9 \\
53.8\end{array}$ & $\begin{array}{l}39.2 \\
34.5 \\
34.6 \\
34.4\end{array}$ & $\begin{array}{l}-\overline{-} \\
59.8 \\
58.1 \\
58.1\end{array}$ & $\begin{array}{l}12.7 \\
20.4 \\
29.8 \\
23.3\end{array}$ & $\begin{array}{l}48.1 \\
45.1 \\
35.6 \\
42.3\end{array}$ & $\begin{array}{l}-\overline{-} \\
20.3 \\
14.1 \\
18.6\end{array}$ & $\begin{array}{l}44.0 \\
45.6 \\
39.8 \\
44.0\end{array}$ & $\begin{array}{r}109.3 \\
98.9 \\
89.5 \\
96.1\end{array}$ & $\begin{array}{l}73.5 \\
65.5 \\
65.7 \\
65.6\end{array}$ & $\begin{array}{l}16.7 \\
17.9 \\
17.9 \\
17.9\end{array}$ \\
\hline $\begin{array}{c}\frac{8.1}{-} \\
23.0\end{array}$ & $\left|\begin{array}{c}\text { liinde } \\
\text { Splint } \\
\text { Mitte u.Kem } \\
\% \text {. Holz }\end{array}\right|$ & $\begin{array}{l}-1 \\
2.1 \\
2.1 \\
2.1\end{array}$ & $\begin{array}{c}- \\
55.2 \\
56.2 \\
55.6\end{array}$ & $\begin{array}{l}-\overline{-} \\
35.4 \\
36.3 \\
35.6\end{array}$ & $\begin{array}{l}- \\
60.9 \\
58.8 \\
60.2\end{array}$ & $\begin{array}{l}-\overline{19.0} \\
25.1 \\
20.7\end{array}$ & $\begin{array}{l}-\overline{45.6} \\
88.6 \\
43.7\end{array}$ & $\begin{array}{l}-\overline{0} \\
20.1 \\
19.1\end{array}$ & $\begin{array}{l}- \\
45.2 \\
40.5 \\
44.0\end{array}$ & \begin{tabular}{|}
$\overline{100.8}$ \\
94.8 \\
99.3
\end{tabular} & $\begin{array}{l}-\overline{65.2} \\
69.4 \\
66.3\end{array}$ & $\begin{array}{l}-\overline{15.3} \\
18.4 \\
16.1\end{array}$ \\
\hline $\begin{array}{c}\frac{10.3}{-} \\
2 \overrightarrow{0} .0\end{array}$ & $\left|\begin{array}{c}\text { liinde } \\
\text { splint } \\
\text { Mitten.Kern } \\
\% \text { Holz }\end{array}\right|$ & $\begin{array}{l}- \\
2.1 \\
2.1 \\
2.1\end{array}$ & $\begin{array}{l}59.8 \\
55.5 \\
56.4 \\
55.8\end{array}$ & $\begin{array}{l}38.3 \\
35.6 \\
36.1 \\
35.8\end{array}$ & $\begin{array}{l}-\overline{61.2} \\
58.5 \\
60.5\end{array}$ & $\begin{array}{l}13.8 \\
19.1 \\
22.1 \\
20.0\end{array}$ & $\begin{array}{l}47.9 \\
4.5 .3 \\
41.8 \\
44.2\end{array}$ & $\begin{array}{l}\overrightarrow{19.7} \\
19.4 \\
19.5\end{array}$ & $\begin{array}{l}44.5 \\
44.9 \\
42.5 \\
44.2\end{array}$ & $\begin{array}{r}107.7 \\
100.8 \\
98.2 \\
100.0\end{array}$ & $\begin{array}{l}77.1 \\
65.3 \\
69.1 \\
66.3\end{array}$ & $\begin{array}{l}22.4 \\
14.9 \\
18.4 \\
15.9\end{array}$ \\
\hline $\begin{array}{c}12.5 \\
\frac{-}{13.5}\end{array}$ & $\begin{array}{c}\text { limule } \\
\text { Splint } \\
\text { Mitte n.Jiern } \\
\% \text {. Holz }\end{array}$ & $\begin{array}{l}- \\
1.7 \\
1.8 \\
1.7\end{array}$ & $\begin{array}{l}60.9 \\
60.2 \\
62.4 \\
60.7\end{array}$ & $\begin{array}{l}39.0 \\
38.6 \\
40.0 \\
38.9\end{array}$ & $\begin{array}{l}-\overline{6} .4 \\
64.8 \\
66.1\end{array}$ & $\begin{array}{l}16.1 \\
15.9 \\
20.1 \\
16.9\end{array}$ & $\begin{array}{l}44.9 \\
45.5 \\
39.9 \\
44.2\end{array}$ & $\begin{array}{l}\overline{17.7} \\
15.1 \\
17.0\end{array}$ & $\begin{array}{l}42.5 \\
43.1 \\
39.0 \\
42.2\end{array}$ & \begin{tabular}{|l|}
105.8 \\
105.7 \\
102.3 \\
104.9
\end{tabular} & $\begin{array}{l}77.9 \\
72.0 \\
73.5 \\
72.3\end{array}$ & $\mid \begin{array}{l}21.8 \\
16.4 \\
15.1 \\
16.1\end{array}$ \\
\hline $\begin{array}{r}14.7 \\
7.5\end{array}$ & $\begin{array}{l}\text { Pinde } \\
\text { IIolz }\end{array}$ & - & $\begin{array}{l}61.1 \\
62.7\end{array}$ & $\begin{array}{l}39.2 \\
40.2\end{array}$ & $\frac{-}{69.1}$ & $\begin{array}{l}12.7 \\
11.5\end{array}$ & $\begin{array}{l}48.1 \\
48.3\end{array}$ & $-\overline{19.4}$ & $\begin{array}{l}44.0 \\
43.6\end{array}$ & $\begin{array}{l}109.2 \\
111.0\end{array}$ & $\begin{array}{l}78.6 \\
70.9\end{array}$ & $\begin{array}{l}22.2 \\
11.7\end{array}$ \\
\hline 16.9 & \multicolumn{2}{|c|}{ Holz mit Rinde } & 61.5 & 39.4 & 67.8 & 10.4 & 50.2 & 21.8 & 45.0 & 111.7 & 75.6 & 10.7 \\
\hline \multicolumn{3}{|c|}{ 1-2jühn. lieiser m. Kun. } & 59.3 & 37.4 & - & 11.8 & 50.8 & - & 46.6 & 109.1 & - & - \\
\hline \multicolumn{3}{|c|}{ Ganzer Stamm } & 54.7 & 35.1 & 59.1 & 23.8 & 41.1 & 17.1 & - & 95.8 & - & - \\
\hline
\end{tabular}


Tab. 12.

Rothbuche.

Alter 85 Jahre.

7. Mai 1881.

Höhe $18.5 \mathrm{~m}$. Kronenansatz $9 \mathrm{~m}$. Whalt $0.353 \mathrm{~cm}$. Wasser $41.5^{\circ} \mathrm{o}$. Substanz $34.6 \mathrm{cem}$,

\begin{tabular}{|c|c|c|c|c|c|c|c|c|c|c|c|c|}
\hline \multirow{2}{*}{ 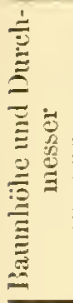 } & \multirow{2}{*}{ Baumtheil } & \multirow{2}{*}{ 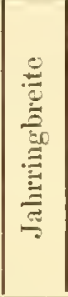 } & \multicolumn{3}{|c|}{$\begin{array}{l}\text { Organische Substanz } \\
\text { in } 100 \text { Raumtheilen } \\
\text { frischen Hoizes }\end{array}$} & \multirow{2}{*}{ 䲶 } & \multicolumn{3}{|c|}{ Wassergelnalt } & \multicolumn{2}{|c|}{$\begin{array}{l}\text { specifisches } \\
\text { Gewicht }\end{array}$} & \multirow{2}{*}{ 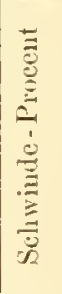 } \\
\hline & & & Gramme & \multicolumn{2}{|c|}{ Raumtheile } & & \multicolumn{3}{|c|}{ 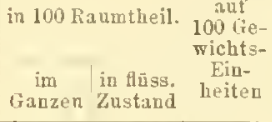 } & \multicolumn{2}{|c|}{ friscle trocken } & \\
\hline a & b & c & d & $\mathrm{e}$ & $f$ & $\mathrm{~g}$ & h & $\mathrm{i}$ & $\mathrm{k}$ & 1 & $\mathrm{~m}$ & $n$ \\
\hline $\begin{array}{l}1.5 \\
- \\
- \\
23.5\end{array}$ & & $\begin{array}{l}-1 . \\
3.0 \\
1.0 \\
1.4 \\
1.4\end{array}$ & $\begin{array}{l}58.9 \\
51.1 \\
55.5 \\
54.6\end{array}$ & $\begin{array}{l}37.6 \\
37.7 \\
32.8 \\
35.6 \\
35.0\end{array}$ & $\begin{array}{l}-\overline{64.8} \\
54.4 \\
55.9 \\
58.1\end{array}$ & $\begin{array}{l}13.2 \\
15.9 \\
30.4 \\
32.4 \\
25.8\end{array}$ & $\begin{array}{l}49.2 \\
46.4 \\
36.8 \\
32.0 \\
39.2\end{array}$ & $\begin{array}{l}19.3 \\
15.2 \\
11.7 \\
16.1\end{array}$ & & $\begin{array}{r}107.9 \\
105.3 \\
87.9 \\
87.5 \\
93.8\end{array}$ & $\begin{array}{l}79.4 \\
76.9 \\
63.5 \\
67.3 \\
68.4\end{array}$ & $\begin{array}{l}26.2 \\
22.6 \\
19.6 \\
17.6 \\
20.3\end{array}$ \\
\hline $\begin{array}{l}3.7 \\
- \\
22.0\end{array}$ & & $\begin{array}{l}- \\
1.4 \\
1.9 \\
1.7 \\
1.5\end{array}$ & $\begin{array}{l}4 \\
5 \\
5\end{array}$ & & $\begin{array}{l}-\overline{6} .4 \\
53.0 \\
56.7 \\
56.3\end{array}$ & $\begin{array}{l}10.4 \\
15.3 \\
32.5 \\
29.1 \\
25.5\end{array}$ & $\begin{array}{l}51.5 \\
49.6 \\
35.6 \\
34.8 \\
40.6\end{array}$ & & & $\begin{array}{r}111.0 \\
104.3 \\
85.4 \\
91.1 \\
93.4\end{array}$ & $\begin{array}{l}76.9 \\
67.5 \\
61.9 \\
69.9 \\
65.5\end{array}$ & $\begin{array}{l}22.6 \\
18.9 \\
19.5 \\
19.5 \\
19.3\end{array}$ \\
\hline $\begin{array}{c}5.9 \\
- \\
\overline{-} \\
19.0\end{array}$ & $\begin{array}{l}\text { Rin } \\
\text { Spli } \\
\text { Mlit } \\
\text { Ker } \\
\text { H }\end{array}$ & $\begin{array}{l}1.5 \\
1.0 \\
1.6 \\
1.2\end{array}$ & & & $\begin{array}{l}-\overline{60.0} \\
53.8 \\
56.1\end{array}$ & $\begin{array}{l}32.9 \\
24.4\end{array}$ & $\begin{array}{l}53.5 \\
48.1 \\
37.7 \\
31.4 \\
41.7\end{array}$ & & & $\begin{array}{r}110.0 \\
102.5 \\
83.3 \\
87.1 \\
94.6\end{array}$ & $\begin{array}{l}78.7 \\
69.2 \\
64.1 \\
68.0 \\
60.8\end{array}$ & $\begin{array}{l}28.1 \\
21.3 \\
21.1 \\
18.0 \\
20.9\end{array}$ \\
\hline $\begin{array}{c}8.1 \\
- \\
\overline{-} \\
17.0\end{array}$ & $\begin{array}{l}\text { Splint } \\
\text { llitte } \\
\text { Kern } \\
\text {. Holz }\end{array}$ & $\begin{array}{l}- \\
1.4 \\
1.2 \\
2.1 \\
1.3\end{array}$ & $\begin{array}{l}50.4 \\
57.8 \\
53.5\end{array}$ & & $\begin{array}{l}62.8 \\
53.6 \\
57.8 \\
58.3\end{array}$ & $\begin{array}{l}13.6 \\
28.0 \\
32.6 \\
22.8\end{array}$ & $\begin{array}{l}50.9 \\
49.9 \\
40.7 \\
31.6 \\
42.9\end{array}$ & $\begin{array}{l}-\overline{23.6} \\
19.4 \\
10.6 \\
18.9\end{array}$ & & $\begin{array}{r}111.4 \\
106.9 \\
91.1 \\
88.9 \\
97.4\end{array}$ & $\begin{array}{l}82.9 \\
70.6 \\
63.1 \\
67.7 \\
156.4\end{array}$ & $\begin{array}{l}27.0 \\
19.2 \\
20.1 \\
15.6 \\
19.5\end{array}$ \\
\hline$\frac{10.3}{-}$ & $\begin{array}{c}\text { Rinde } \\
\text { spint } \\
\text { Mitteu.Kern } \\
\text {. Holz }\end{array}$ & $\begin{array}{l}- \\
1.5 \\
1.3 \\
1.4\end{array}$ & $\begin{array}{l}54.9 \\
56.9\end{array}$ & & $\begin{array}{l}- \\
66.2 \\
58.4 \\
61.3\end{array}$ & $\begin{array}{l}12.6 \\
10.4 \\
25.1 \\
19.4\end{array}$ & $\begin{array}{l}51.1 \\
39.7 \\
44.1\end{array}$ & $\begin{array}{l}-\overline{3.4} \\
16.5 \\
19.3\end{array}$ & & $\begin{array}{r}106.8 \\
111.2 \\
94.6 \\
101.0\end{array}$ & $\begin{array}{l}77.0 \\
72.8 \\
68.8 \\
70.4\end{array}$ & $\begin{array}{l}29.7 \\
17.5 \\
20.2 \\
19.2\end{array}$ \\
\hline $\begin{array}{c}12.5 \\
\bar{z} \\
10.0\end{array}$ & $\begin{array}{c}\text { Rinde } \\
\text { Splint } \\
\text { Mitte u. Kern } \\
\text {. Holz }\end{array}$ & $\begin{array}{l}-1.9 \\
1.4 \\
1.5\end{array}$ & $\begin{array}{l}59.8 \\
53.2 \\
55.6\end{array}$ & $\begin{array}{l}38.3 \\
34.1 \\
35.6\end{array}$ & $\begin{array}{l}- \\
65.9 \\
56.6 \\
59.8\end{array}$ & $\begin{array}{l}11.4 \\
10.1 \\
23.2 \\
18.9\end{array}$ & $\begin{array}{l}51.0 \\
51.6 \\
42.7 \\
45.5\end{array}$ & $\begin{array}{l}\overline{24.0} \\
20.2 \\
21.3\end{array}$ & & $\begin{array}{r}107.7 \\
111.4 \\
9.5 .9 \\
101.1\end{array}$ & $\begin{array}{l}83.2 \\
71.5 \\
64.5 \\
66.7\end{array}$ & $\begin{array}{l}29.5 \\
16.4 \\
17.5 \\
17.2\end{array}$ \\
\hline $\begin{array}{r}14.7 \\
5.0\end{array}$ & $\begin{array}{l}\text { Pinde } \\
\text { Holz }\end{array}$ & $0 . \overline{7}$ & $\begin{array}{l}61.0 \\
55.9\end{array}$ & $\begin{array}{l}39 . \\
35 .\end{array}$ & $6 \overline{1.6}$ & $\begin{array}{l}10.7 \\
17.9\end{array}$ & $\begin{array}{l}50.2 \\
46.3\end{array}$ & $2 \overline{0.5}$ & $\begin{array}{l}45.1 \\
46.3\end{array}$ & $\begin{array}{l}111.2 \\
104.2\end{array}$ & $\begin{array}{l}84.2 \\
64.5\end{array}$ & $\mid \begin{array}{l}27.4 \\
13.2\end{array}$ \\
\hline 16.9 & Holz in. Find. & 0.5 & 58.5 & 37.5 & 64.5 & 13.8 & 51.3 & 24.3 & 46.7 & 109.8 & 72.5 & 19.3 \\
\hline-2$]$ & wet & ת. & 51.8 & 50.6 & - & 10.0 & 61.0 & - & 50.0 & 108.6 & 66.8 & 22.4 \\
\hline & & & 0 & 10 & . & 20.0 & 41.0 & 16.7 & - & 95.5 & 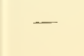 & - \\
\hline
\end{tabular}


Tab. 13.

\section{Rothbuche.}

Alter 135 Jahre.

2. Juli 1881 .

Höhe $19 \mathrm{~m}$. Kronenansatz $9.5 \mathrm{~m}$. Inlalt $0.473 \mathrm{~cm}$. Wasser $43.4^{\circ} \mathrm{o}$. Substanz $37.7 \mathrm{cem}$.

\begin{tabular}{|c|c|c|c|c|c|c|c|c|c|c|c|c|}
\hline \multirow{4}{*}{ 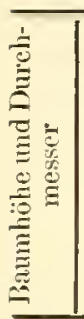 } & \multirow{4}{*}{ Baumtheil } & \multirow{4}{*}{ 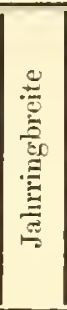 } & \multirow{2}{*}{\multicolumn{3}{|c|}{$\begin{array}{c}\text { Organisehe Substanz. } \\
\text { in } 100 \text { Raumtheilen } \\
\text { frischen Holzes }\end{array}$}} & \multirow{4}{*}{$\stackrel{\Xi}{\Xi}$} & \multirow{2}{*}{\multicolumn{3}{|c|}{ Wassergehalt }} & \multirow{2}{*}{\multicolumn{2}{|c|}{$\begin{array}{c}\text { Specifisches } \\
\text { Gewicht }\end{array}$}} & \multirow{4}{*}{ 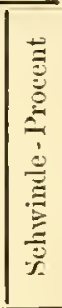 } \\
\hline & & & & & & & & & & & & \\
\hline & & & \multirow{2}{*}{ Gramme } & \multicolumn{2}{|c|}{ Raumtheile } & & \multicolumn{2}{|c|}{ in 100 Ranmtheil. } & \multirow{2}{*}{$\begin{array}{l}\text { auf } \\
\text { loo Ge- } \\
\text { wichts- } \\
\text { Ein- } \\
\text { leiten }\end{array}$} & \multirow{2}{*}{ frisch } & \multirow{2}{*}{ trocken } & \\
\hline & & & & 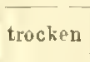 & aribint & & $\operatorname{im}_{\text {Ganzen }}$ & $\begin{array}{l}\text { in flüss: } \\
\text { Znstand }\end{array}$ & & & & \\
\hline$a$ & b & $\mathrm{e}$ & $d$ & e & $\bar{f}$ & $g$ & h & $\bar{i}$ & $k$ & 1 & $\mathrm{~m}$ & $\mathrm{n}$ \\
\hline $\begin{array}{c}1.5 \\
0 \\
0 \\
0 \\
26.11\end{array}$ & $\begin{array}{l}\text { Rinde } \\
\text { Splint } \\
\text { Jitte } \\
\text { Kernz } \\
\text { Holz }\end{array}$ & \begin{tabular}{|l|}
-1.0 \\
0.8 \\
1.0 \\
1.0
\end{tabular} & $\begin{array}{l}51.0 \\
58.8 \\
59.3 \\
65.3 \\
60.6\end{array}$ & $\begin{array}{l}32.7 \\
37.7 \\
38.0 \\
41.9 \\
38.8\end{array}$ & $\begin{array}{l}64.7 \\
63.1 \\
65.8 \\
64.0\end{array}$ & $\begin{array}{l}14.5 \\
12.7 \\
24.1 \\
17.4 \\
18.5\end{array}$ & $\begin{array}{l}52.8 \\
49.6 \\
37.9 \\
40.7 \\
42.7\end{array}$ & $\begin{array}{l}\overrightarrow{22.6} \\
12.8 \\
16.8 \\
17.5\end{array}$ & $\begin{array}{l}50.9 \\
45.7 \\
39.0 \\
38.4 \\
41.3\end{array}$ & $\begin{array}{r}103.8 \\
108.4 \\
97.2 \\
106.0 \\
103.3\end{array}$ & $\begin{array}{l}76.0 \\
72.8 \\
72.9 \\
78.4 \\
74.2\end{array}$ & $\begin{array}{l}32.9 \\
19.0 \\
18.8 \\
16.7 \\
18.3\end{array}$ \\
\hline $\begin{array}{c}3.7 \\
0 \\
0 \\
0 \\
24.0\end{array}$ & $\begin{array}{l}\text { Rinde } \\
\text { Splint } \\
\text { Mitte } \\
\text { Kern } \\
\text {. Holz }\end{array}$ & \begin{tabular}{|l|}
1. \\
1.4 \\
0.7 \\
1.0 \\
0.9
\end{tabular} & $\begin{array}{l}48.2 \\
59.4 \\
60.1 \\
60.8 \\
60.1\end{array}$ & & $\begin{array}{l}- \\
65.5 \\
63.9 \\
61.2 \\
63.9\end{array}$ & $\begin{array}{r}14.6 \\
9.8 \\
23.2 \\
19.9 \\
17.7\end{array}$ & $\begin{array}{l}54.5 \\
52.1 \\
38.3 \\
41.1 \\
43.8\end{array}$ & $\begin{array}{l}\overline{24.7} \\
12.9 \\
18.9 \\
18.4\end{array}$ & $\begin{array}{l}53.1 \\
46.7 \\
39.0 \\
40.3 \\
42.2\end{array}$ & \begin{tabular}{|r|}
102.7 \\
111.5 \\
98.4 \\
101.9 \\
103.9
\end{tabular} & $\begin{array}{l}78.0 \\
73.2 \\
73.2 \\
72.6 \\
73.0\end{array}$ & $\begin{array}{l}38.9 \\
17.9 \\
18.0 \\
16.2 \\
17.8\end{array}$ \\
\hline $\begin{array}{l}5.9 \\
+\quad \\
0 \\
0 \\
21.5 \\
\end{array}$ & $\begin{array}{l}\text { Rinde } \\
\text { Splint } \\
\text { Mitte } \\
\text { Kerm } \\
\text {. Holz }\end{array}$ & $\begin{array}{l}0.9 \\
0.7 \\
1.1 \\
0.9\end{array} \mid$ & $\begin{array}{l}52.8 \\
57.6 \\
5.5 .8 \\
58.7 \\
57.1\end{array}$ & & $\begin{array}{l}-\overline{63.5} \\
59.4 \\
59.0 \\
60.4\end{array}$ & $\begin{array}{r}14.9 \\
9.9 \\
21.0 \\
30.4 \\
20.1 \\
\end{array}$ & $\begin{array}{l}51.3 \\
53.2 \\
43.3 \\
32.0 \\
43.3\end{array}$ & $\begin{array}{l}- \\
26.6 \\
19.7 \\
10.6 \\
19.5\end{array}$ & $\begin{array}{l}49.3 \\
4 \supsetneq .0 \\
43.7 \\
35.3 \\
43.1\end{array}$ & $\begin{array}{r}104.1 \\
110.8 \\
99.1 \\
90.7 \\
100.4 \\
\end{array}$ & $\begin{array}{l}79.8 \\
70.5 \\
67.8 \\
70.2 \\
69.3 \\
\end{array}$ & $\begin{array}{l}133.9 \\
18.3 \\
17.7 \\
16.4 \\
17.5\end{array}$ \\
\hline $\begin{array}{c}0 \\
9.0 \\
\end{array}$ & $\begin{array}{l}\text { Rinde } \\
\text { Splint } \\
\text { Mitte } \\
\text { líen } \\
\text {. Holz }\end{array}$ & $\begin{array}{l}1.2 \\
0.9 \\
0.9 \\
1.0\end{array}$ & $\begin{array}{l}50.8 \\
58.9 \\
55.6 \\
59.7 \\
57.6\end{array}$ & & $\begin{array}{l}-\overline{64.8} \\
59.1 \\
60.0 \\
60.9\end{array}$ & $\begin{array}{r}15.2 \\
7.8 \\
19.5 \\
31.5 \\
18.7\end{array}$ & $\begin{array}{l}52.3 \\
54.5 \\
44.9 \\
30.3 \\
44.4\end{array}$ & $\begin{array}{r}- \\
27.4 \\
21.4 \\
8.5 \\
20.4\end{array}$ & $\begin{array}{l}50.7 \\
48.1 \\
41.6 \\
33.7 \\
43.4\end{array}$ & $\begin{array}{r}103.1 \\
113.4 \\
100.5 \\
90.0 \\
102.0\end{array}$ & $\begin{array}{l}80.1 \\
73.4 \\
67.8 \\
71.2 \\
70.2\end{array}$ & $\begin{array}{l}36.5 \\
19.8 \\
18.0 \\
16.1 \\
18.1\end{array}$ \\
\hline .0 & $\begin{array}{l}\text { Rinde } \\
\text { Splint } \\
\text { Witte } \\
\text { Iiern } \\
\text {. Holz }\end{array}$ & \begin{tabular}{|l|}
- \\
- \\
0.9 \\
1.1 \\
-
\end{tabular} & $\begin{array}{c}52.8 \\
- \\
54.1 \\
56.2 \\
-\end{array}$ & $\begin{array}{c}33.8 \\
- \\
34.7 \\
36.0 \\
-\end{array}$ & $\begin{array}{c}- \\
57.6 \\
56.5 \\
-\end{array}$ & $\begin{array}{c}16.2 \\
- \\
22.5 \\
32.7 \\
-\end{array}$ & $\begin{array}{c}50.0 \\
- \\
42.8 \\
31.3 \\
- \\
\end{array}$ & $\begin{array}{c}- \\
\overline{19.9} \\
10.8 \\
-\end{array}$ & $\begin{array}{c}48.6 \\
44.2 \\
35.8 \\
-\end{array}$ & $\begin{array}{c}102.8 \\
-7 \overline{.9} \\
87.5 \\
- \\
\end{array}$ & $\begin{array}{c}79.9 \\
- \\
65.0 \\
67.8 \\
-\end{array}$ & $\begin{array}{l}38.9 \\
- \\
16.7 \\
16.7 \\
-\end{array}$ \\
\hline 5.0 & $\begin{array}{l}\text { Pinde } \\
\text { Splint } \\
\text { Mitte } \\
\text { Kern } \\
\text {. Holz }\end{array}$ & \begin{tabular}{|l|}
- \\
0.8 \\
0.6 \\
1.2 \\
-
\end{tabular} & $\begin{array}{l}54.9 \\
55.0 \\
53.8 \\
56.6 \\
54.9\end{array}$ & & $\begin{array}{l}6 \overline{-} .7 \\
57.3 \\
57.0 \\
58.4\end{array}$ & $\begin{array}{l}15.0 \\
10.0 \\
19.6 \\
31.6 \\
18.6\end{array}$ & \begin{tabular}{|l|}
49.8 \\
54.7 \\
45.9 \\
32.1 \\
46.2 \\
\end{tabular} & $\begin{array}{l}- \\
29.3 \\
23.1 \\
11.4 \\
23.0\end{array}$ & $\begin{array}{l}47.6 \\
49.9 \\
46.1 \\
36.1 \\
45.7\end{array}$ & $\begin{array}{r}104.7 \\
109.7 \\
99.7 \\
88.7 \\
101.1\end{array}$ & $\begin{array}{l}79.9 \\
66.1 \\
65.2 \\
69.6 \\
66.6\end{array}$ & $\begin{array}{l}31.3 \\
16.8 \\
17.5 \\
18.7 \\
17.5\end{array}$ \\
\hline 4.7 & \begin{tabular}{|c|} 
Rincle \\
Splint \\
Witte u.Kem \\
. HoLz
\end{tabular} & \begin{tabular}{l|}
-1 \\
0.7 \\
0.7 \\
0.7
\end{tabular} \mid & $\begin{array}{l}55.7 \\
54.9 \\
56.3 \\
55.2 \\
\end{array}$ & $\begin{array}{l}36.1 \\
35.4\end{array}$ & $\begin{array}{l}\overline{60.5} \\
59.9 \\
60.5\end{array}$ & $\begin{array}{l}13.1 \\
15.5 \\
30.7 \\
18.8\end{array}$ & \begin{tabular}{|l|}
51.2 \\
49.3 \\
33.2 \\
45.8 \\
\end{tabular} & $\begin{array}{r}-\overline{24.0} \\
9.4 \\
20.7\end{array}$ & $\begin{array}{l}47.9 \\
47.3 \\
37.0 \\
45.4\end{array}$ & $\begin{array}{r}106.9 \\
104.2 \\
89.5 \\
101.0\end{array}$ & $\begin{array}{l}83.6 \\
65.5 \\
67.9 \\
66.0\end{array}$ & $\begin{array}{l}33.3 \\
16.1 \\
17.0 \\
16.3\end{array}$ \\
\hline $\begin{array}{l}6.9 \\
3.5\end{array}$ & $\begin{array}{l}\text { Rinde } \\
\text {. Holz }\end{array}$ & 0.6 & $\begin{array}{l}53.2 \\
57.0 \\
\end{array}$ & $\begin{array}{l}34.1 \\
36.5\end{array}$ & $\overline{62.4}$ & $\begin{array}{l}13.3 \\
17.1\end{array}$ & $\begin{array}{l}52.6 \\
46.4\end{array}$ & $\overline{20.3}$ & $\begin{array}{l}49.7 \\
44.9\end{array}$ & $\begin{array}{l}105.8 \\
103.4\end{array}$ & $\begin{array}{l}81.6 \\
67.6\end{array}$ & $\begin{array}{l}34.8 \\
15.7\end{array}$ \\
\hline \multicolumn{3}{|c|}{ 1-2jihr. Zweig ohne $B 1}$. & 53.6 & 34.3 & - & 12.9 & 52.8 & - & 49.8 & 106.4 & 78.0 & 31.3 \\
\hline \multicolumn{3}{|c|}{ Granzer Stanm } & 58.2 & 37.7 & 61.8 & 18.9 & 43.4 & 19.3 & - & 101.6 & - & - \\
\hline
\end{tabular}




\section{Rothbuche.}

Alter 130 Jahre.

8. Uctober $1 \times 81$.

Höle $20 \mathrm{~m}$. Kronenansatz $10.4 \mathrm{~m}$. Inhalt $0.910 \mathrm{~cm}$. Wasser $40.6^{\circ}$ o Substauz $37.0 \mathrm{ccm}$.

\begin{tabular}{|c|c|c|c|c|c|c|c|c|c|c|c|c|}
\hline \multirow{2}{*}{ 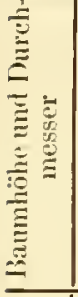 } & \multirow{2}{*}{ Baumtheil } & \multirow{2}{*}{ 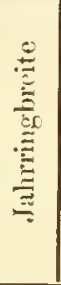 } & \multicolumn{3}{|c|}{$\mid \begin{array}{c}\text { Organische Substanz } \\
\text { in } 100 \text { Rauntbeilen } \\
\text { frischen Holzes }\end{array}$} & \multirow{2}{*}{$\stackrel{\Xi}{\stackrel{\Xi}{\Xi}}$} & \multicolumn{3}{|c|}{ Wassergehalt } & \multicolumn{2}{|c|}{$\begin{array}{l}\text { Specifisches } \\
\text { Gewicht }\end{array}$} & \multirow{2}{*}{ 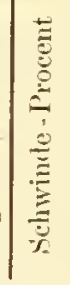 } \\
\hline & & & Granme & \multicolumn{2}{|c|}{ Raumtheile } & & \multicolumn{3}{|c|}{ 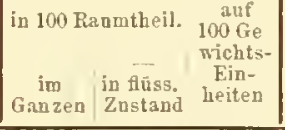 } & \multicolumn{2}{|c|}{ frisch trocken } & \\
\hline a & b & e & d & $\mathrm{e}$ & $f$ & $g$ & li & i & k & 1 & $\mathrm{~m}$ & n \\
\hline $\begin{array}{l}1.5 \\
- \\
- \\
5.0\end{array}$ & & & 5.7 & 5.7 & $\begin{array}{l}-\overline{6.7} \\
2.2\end{array}$ & $\begin{array}{l}30 \\
27 . \\
22 .\end{array}$ & $\begin{array}{l}32.6 \\
39.3\end{array}$ & $\begin{array}{r}\overline{15} \\
7.9 \\
9.9 \\
12.6\end{array}$ & $\begin{array}{l}44.3 \\
42.0\end{array}$ & $\begin{array}{r}100.0 \\
104.3 \\
90.3 \\
94.8 \\
99.7\end{array}$ & $\begin{array}{l}83.0 \\
72.4 \\
70.2 \\
74.1 \\
72.2\end{array}$ & $\begin{array}{l}32.8 \\
16.4\end{array}$ \\
\hline 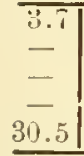 & & 1.0 & & & 63.5 & & $\begin{array}{l}43.9 \\
46.2\end{array}$ & & & $\begin{array}{r}100.3 \\
106.2 \\
88.8\end{array}$ & $\begin{array}{l}82.2 \\
71.6 \\
67.7 \\
69.4 \\
70.2\end{array}$ & $\begin{array}{l}31.4 \\
16.1 \\
16.3 \\
15.2 \\
15.9\end{array}$ \\
\hline $\begin{array}{l}5.9 \\
- \\
- \\
- \\
9.0\end{array}$ & & 0.9 & $\begin{array}{l}59.2 \\
57.6 \\
\end{array}$ & & $\begin{array}{l}59.5 \\
61.6 \\
\end{array}$ & $\begin{array}{l}29.2 \\
22.3 \\
\end{array}$ & 40.8 & $\begin{array}{r}-\overline{-} \\
21.2 \\
7.5 \\
11.8 \\
16.1 \\
\end{array}$ & & $\begin{array}{r}101.8 \\
105.1 \\
87.9 \\
92.1 \\
98.4 \\
\end{array}$ & $\begin{array}{l}85.7 \\
67.6 \\
67.6 \\
69.7 \\
68.0 \\
\end{array}$ & $\begin{array}{l}30.9 \\
15.0 \\
16.2 \\
15.1 \\
15.3 \\
\end{array}$ \\
\hline $\begin{array}{l}-1 \\
- \\
- \\
7.0\end{array}$ & & $\begin{array}{l}2.0 \\
1.3 \\
\end{array}$ & $\begin{array}{l}56.0 \\
60.3 \\
57.2 \\
\end{array}$ & & & & $\begin{array}{l}42.7 \\
48.5 \\
31.1 \\
37.8 \\
42.1\end{array}$ & $\begin{array}{r}7.4 \\
15.8 \\
17.5 \\
\end{array}$ & & $\begin{array}{r}104.1 \\
105.1 \\
87.1 \\
98.1 \\
99.3\end{array}$ & $\begin{array}{l}86.6 \\
66.6 \\
67.0 \\
69.0 \\
67.2\end{array}$ & $\begin{array}{l}29.0 \\
14.9 \\
115.5 \\
12.5 \\
14.8\end{array}$ \\
\hline $\begin{array}{l}0.3 \\
- \\
-\end{array}$ & $\begin{array}{l}\text { Pinde } \\
\text { Splint } \\
\text { Jitte } \\
\text { Kern } \\
\text { Holz }\end{array}$ & \begin{tabular}{|l|}
1.0 \\
1.0 \\
2.0 \\
1.3
\end{tabular} & $\begin{array}{l}53.5 \\
55.0 \\
54.4\end{array}$ & & - & 24.7 & $\begin{array}{l}11.1 \\
47.6 \\
29.6 \\
34.2 \\
40.5 \\
\end{array}$ & 7 & & $\begin{array}{l}102.7 \\
102.1 \\
83.1 \\
89.2 \\
94.9 \\
\end{array}$ & & $\begin{array}{l}30.4 \\
14.2 \\
16.7 \\
18.5 \\
15.6\end{array}$ \\
\hline$\overline{-}$ & $\begin{array}{l}\text { Rinde } \\
\text { splint } \\
\text { Ilitte } \\
\text { Kcrn } \\
\text { Holz }\end{array}$ & $\left|\begin{array}{|l}1.8 \\
1.2\end{array}\right|$ & $\begin{array}{l}63.9 \\
55.3 \\
53.6 \\
57.5 \\
54.1\end{array}$ & & $\begin{array}{l}51.8 \\
57.9\end{array}$ & & $\begin{array}{r}40.8 \\
48.6\end{array}$ & $\begin{array}{r}9.8 \\
18.0\end{array}$ & & $\begin{array}{r}104.7 \\
103.9 \\
88.6 \\
88.3 \\
95.3\end{array}$ & $\begin{array}{l}89.3 \\
64.2 \\
63.1 \\
69.9 \\
65.0\end{array}$ & $\begin{array}{l}28.4 \\
13.9 \\
15.0 \\
17.2 \\
15.0\end{array}$ \\
\hline 14.7 & $\begin{array}{l}\text { Rinde } \\
\text { splint } \\
\text { Hitte } \\
\text { Kern } \\
\text { Holz } \\
\end{array}$ & \begin{tabular}{l|}
1.0 \\
0.8 \\
1.3 \\
1.0 \\
\end{tabular} & $\begin{array}{l}61.4 \\
57.2 \\
52.2 \\
55.6 \\
55.5 \\
\end{array}$ & & - & & 41.3 & $\begin{array}{r}17.7 \\
9.2 \\
17.5 \\
\end{array}$ & & $\begin{array}{r}101.5 \\
105.5 \\
92.0 \\
85.1 \\
96.8 \\
\end{array}$ & $\begin{array}{l}83.9 \\
65.9 \\
62.7 \\
66.5 \\
65.2 \\
\end{array}$ & $\begin{array}{l}26.8 \\
13.2 \\
16.7 \\
16.4 \\
14.9\end{array}$ \\
\hline 16.9 & 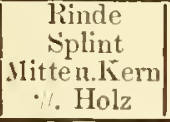 & $\begin{array}{l}-\overline{0.9} \\
0.7 \\
0.8\end{array}$ & $\begin{array}{l}61.7 \\
5 \times .7 \\
54.6 \\
57.5 \\
\end{array}$ & & $\begin{array}{l}\overline{64.7} \\
58.1 \\
62.6\end{array}$ & & & & & $\begin{array}{r}103.3 \\
108.2 \\
91.1 \\
103.3 \\
\end{array}$ & $\begin{array}{l}86.1 \\
67.9 \\
66.0 \\
67.3\end{array}$ & $\begin{array}{l}28.3 \\
13.5 \\
17.0 \\
14.6 \\
\end{array}$ \\
\hline .11 & $\because \mathrm{Holz}$ & 0.61 & 60.0 & 38.5 & 66.2 & 18.6 & 42.9 & 15.2 & 41.8 & 102.9 & 70.0 & $\sqrt{14.5}$ \\
\hline 200 & Zweigoh & $\$ 31.1$ & 57.0 & 36.5 & - & 20.4 & 43.1 & - & 45.5 & 100.1 & 79.3 & 28.1 \\
\hline & er & & 57.7 & 37.0 & 62.1 & 22.4 & 40.6 & 15.5 & 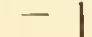 & 98.3 & - & - \\
\hline
\end{tabular}


Tab. 15.

Eiche.

Alter 50 Jahre.

28 December 1881.

Höhe $13 \mathrm{~m}$. Kronenansatz $5.4 \mathrm{~m}$. Inlalt $0.141 \mathrm{~cm}$. Wasser $43.0 \%$. Substanz $33.1 \mathrm{ccm}$.

\begin{tabular}{|c|c|c|c|c|c|c|c|c|c|c|c|c|}
\hline \multirow{3}{*}{ 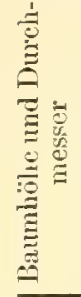 } & \multirow{3}{*}{ Baumtheil } & \multirow{3}{*}{ 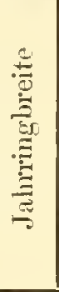 } & \multicolumn{3}{|c|}{$\begin{array}{c}\text { Organische Substanz } \\
\text { in } 100 \text { Raumtheilen } \\
\text { frischen Holzes }\end{array}$} & \multirow{3}{*}{ 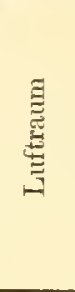 } & \multicolumn{3}{|c|}{ W'assergehalt } & \multicolumn{2}{|c|}{$\begin{array}{c}\text { Specifisches } \\
\text { Gewicht }\end{array}$} & \multirow{3}{*}{ 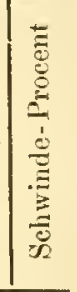 } \\
\hline & & & Granme & Rau & heile & & \multicolumn{2}{|c|}{ in 100 Faum theil. } & \multirow{2}{*}{$\begin{array}{l}\text { anf } \\
100 \text { Ge- } \\
\text { wichts- } \\
\text { Ein- } \\
\text { hiten }\end{array}$} & \multirow{2}{*}{ frisch } & \multirow{2}{*}{ trocken } & \\
\hline & & & & troch & ithirt & & $\operatorname{im}_{\text {Ganzen }}$ & $\begin{array}{l}\text { in flusss. } \\
\text { Zustand }\end{array}$ & & & & \\
\hline a & b & c & d & e & f & $g$ & $\mathrm{~h}$ & $\mathrm{i}$ & $\mathrm{k}$ & 1 & $\mathrm{~m}$ & n \\
\hline $\begin{array}{c}1.3 \\
+ \\
0 \\
0 \\
18.0\end{array}$ & $\begin{array}{l}\text { Rinde } \\
\text { Splint } \\
\text { Mitte } \\
\text { Kiem } \\
\text {. Holz }\end{array}$ & $\begin{array}{l}-1.5 \\
1.5 \\
2.1 \\
1.9\end{array}$ & $\begin{array}{l}37.9 \\
57.5 \\
58.3 \\
58.6 \\
58.1\end{array}$ & $\begin{array}{l}24.3 \\
36.9 \\
37.4 \\
37.6 \\
37.2\end{array}$ & $\begin{array}{l}7 \overline{70.1} \\
65.4 \\
65.8 \\
67.0\end{array}$ & $\begin{array}{l}28.5 \\
17.6 \\
19.1 \\
19.3 \\
18.9\end{array}$ & $\begin{array}{l}47.2 \\
45.5 \\
43.5 \\
43.1 \\
43.9\end{array}$ & $\begin{array}{l}\overline{12.3} \\
15.5 \\
14.9 \\
14.1\end{array}$ & $\begin{array}{l}55.5 \\
44.2 \\
42.7 \\
42.4 \\
42.9\end{array}$ & $\begin{array}{r}85.1 \\
103.0 \\
101.8 \\
101.7 \\
102.0\end{array}$ & $\begin{array}{l}78.1 \\
70.2 \\
68.8 \\
66.7 \\
68.4\end{array}$ & $\begin{array}{l}51.5 \\
18.2 \\
15.3 \\
12.2 \\
15.1\end{array}$ \\
\hline $\begin{array}{c}3.5 \\
+ \\
0 \\
0 \\
1.5 .0\end{array}$ & $\begin{array}{l}\text { Rinde } \\
\text { Splint } \\
\text { Mlitte } \\
\text { Kern } \\
\text { Holz }\end{array}$ & $\begin{array}{l}- \\
1.6 \\
1.5 \\
2.3 \\
1.9\end{array}$ & $\begin{array}{l}36.0 \\
58.0 \\
60.3 \\
61.5 \\
60.0\end{array}$ & $\begin{array}{l}23.1 \\
37.2 \\
38.7 \\
39.4 \\
38.4\end{array}$ & $\begin{array}{l}7 \overline{70.7} \\
67.7 \\
69.0 \\
69.1\end{array}$ & $\begin{array}{l}29.8 \\
19.1 \\
20.3 \\
17.6 \\
18.9\end{array}$ & $\begin{array}{l}47.1 \\
43.7 \\
41.0 \\
43.0 \\
42.7\end{array}$ & $\begin{array}{l}10.2 \\
12.0 \\
13.4 \\
12.0\end{array}$ & $\begin{array}{l}56.7 \\
43.0 \\
40.5 \\
41.2 \\
41.6\end{array}$ & \begin{tabular}{|r|}
83.1 \\
101.7 \\
100.3 \\
104.5 \\
102.7
\end{tabular} & $\begin{array}{l}73.4 \\
71.0 \\
71.5 \\
69.2 \\
70.5\end{array}$ & $\begin{array}{l}50.9 \\
18.3 \\
15.7 \\
11.1 \\
14.9\end{array}$ \\
\hline $\begin{array}{c}5.7 \\
+ \\
0 \\
0 \\
13.0\end{array}$ & $\begin{array}{l}\text { Rinde } \\
\text { Splint } \\
\text { Mlitte } \\
\text { liprn } \\
\text { Holz }\end{array}$ & $\begin{array}{l}- \\
1.8 \\
1.7 \\
2.1 \\
1.9\end{array}$ & $\begin{array}{l}35.9 \\
58.1 \\
60.5 \\
60.7 \\
59.4\end{array}$ & $\begin{array}{l}23.0 \\
37.2 \\
38.8 \\
38.9 \\
38.1\end{array}$ & $\begin{array}{l}7 \overline{-} \\
67.9 \\
68.1 \\
69.3\end{array}$ & $\begin{array}{l}29.2 \\
18.7 \\
19.5 \\
19.5 \\
19.1\end{array}$ & $\begin{array}{l}47.8 \\
44.1 \\
41.7 \\
41.6 \\
42.8\end{array}$ & $\begin{array}{l}\overline{10.6} \\
12.6 \\
12.4 \\
11.6\end{array}$ & $\begin{array}{l}57.1 \\
43.1 \\
40.8 \\
40.6 \\
41.8\end{array}$ & \begin{tabular}{|r|}
83.7 \\
102.2 \\
100.2 \\
102.3 \\
102.2
\end{tabular} & $\begin{array}{l}74.0 \\
71.4 \\
71.3 \\
70.6 \\
71.2\end{array}$ & $\begin{array}{l}51.5 \\
18.7 \\
15.1 \\
14.0 \\
16.5\end{array}$ \\
\hline $\begin{array}{c}7.9 \\
+ \\
0 \\
0 \\
12.0\end{array}$ & $\begin{array}{l}\text { Rinde } \\
\text { Splint } \\
\text { Mlitte } \\
\text { Kern } \\
\% \text { Holz }\end{array}$ & $\begin{array}{l}- \\
2.2 \\
2.0 \\
2.0 \\
2.1\end{array}$ & \begin{tabular}{l|}
41.7 \\
59.5 \\
62.1 \\
63.5 \\
60.9
\end{tabular} & $\begin{array}{l}26.7 \\
38.1 \\
39.8 \\
40.7 \\
39.0\end{array}$ & $\begin{array}{l}7 \overline{2.4} \\
69.6 \\
71.2 \\
71.4\end{array}$ & $\begin{array}{l}28.0 \\
19.4 \\
18.1 \\
17.8 \\
18.8\end{array}$ & $\begin{array}{l}4.5 .3 \\
42.5 \\
42.1 \\
41.5 \\
42.2\end{array}$ & $\begin{array}{r}- \\
8.2 \\
12.3 \\
11.0 \\
9.8\end{array}$ & $\begin{array}{l}52.1 \\
41.4 \\
40.4 \\
39.5 \\
40.9\end{array}$ & $\begin{array}{r}87.0 \\
102.0 \\
104.2 \\
105.0 \\
103.1\end{array}$ & $\begin{array}{l}76.4 \\
71.9 \\
74.2 \\
70.1 \\
72.1\end{array}$ & $\begin{array}{r}45.5 \\
17.2 \\
16.3 \\
9.5 \\
15.5\end{array}$ \\
\hline $\begin{array}{r}10.1 \\
5.5\end{array}$ & $\begin{array}{l}\text { Rinde } \\
\mathrm{Holz}\end{array}$ & -2.0 & $\begin{array}{l}43.5 \\
61.4\end{array}$ & $\begin{array}{l}27.9 \\
39.4\end{array}$ & $7 \overline{4.9}$ & $\begin{array}{l}28.4 \\
19.2\end{array}$ & $\begin{array}{l}43.7 \\
41.4\end{array}$ & $\overline{5.9}$ & $\begin{array}{l}50.0 \\
40.3\end{array}$ & $\begin{array}{r}87.2 \\
102.8\end{array}$ & $\begin{array}{l}76.8 \\
74.3\end{array}$ & $\begin{array}{l}13.3 \\
17.4\end{array}$ \\
\hline $\begin{array}{r}12.3 \\
2.8\end{array}$ & $\begin{array}{l}\text { Rinde } \\
\text { Holz }\end{array}$ & $\overline{1.7}$ & $\begin{array}{l}46.8 \\
60.7\end{array}$ & $\begin{array}{l}30.0 \\
38.9\end{array}$ & $7 \overline{3.9}$ & $\begin{array}{l}26.0 \\
20.9\end{array}$ & $\begin{array}{l}44.0 \\
40.2\end{array}$ & $\overline{5.2}$ & $\begin{array}{l}48.4 \\
39.8\end{array}$ & $\begin{array}{r}90.8 \\
100.9\end{array}$ & $\begin{array}{l}89.8 \\
70.7\end{array}$ & $\begin{array}{l}47.8 \\
14.1\end{array}$ \\
\hline \multicolumn{3}{|c|}{ 1-2jührige Zreige } & 55.4 & 35.5 & - & 16.0 & 48.5 & 一 & 46.6 & 103.9 & 83.9 & 33.9 \\
\hline \multicolumn{3}{|c|}{ Ganzer Stamm } & 59.4 & 38.1 & 69.2 & 18.9 & 43.0 & 11.9 & 一 & 102.4 & - & - \\
\hline
\end{tabular}


Eiche.

Alter 50 Jabre.

16. Februar $18 \div 2$.

Höhe $14 \mathrm{~m}$. Kronenansatz.9 m. Inbalt $0.200 \mathrm{~cm}$. Wasser $41.8 \%$. Substanz $36.4 \mathrm{cem}$.

\begin{tabular}{|c|c|c|c|c|c|c|c|c|c|c|c|c|}
\hline \multirow{3}{*}{ 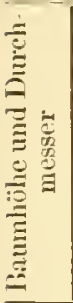 } & \multirow{3}{*}{ Baumtheil } & \multirow{3}{*}{ 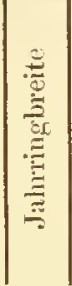 } & \multicolumn{3}{|c|}{$\begin{array}{c}\text { Organische Substanz } \\
\text { in } 100 \text { Ramtheilen } \\
\text { frischen Holzes }\end{array}$} & \multirow{3}{*}{ 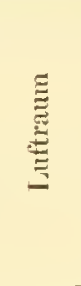 } & \multicolumn{3}{|c|}{ Wrassergehalt } & \multicolumn{2}{|c|}{$\begin{array}{l}\text { Specifisches } \\
\text { Gewiclit }\end{array}$} & \multirow{3}{*}{ 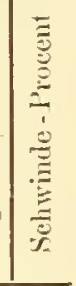 } \\
\hline & & & & Raum & eile & & \multicolumn{2}{|c|}{ in 100 Ran mutheil. } & \multirow{2}{*}{$\begin{array}{c}\text { anf } \\
100 \text { Ge- } \\
\text { wichts- } \\
\text { Ein- } \\
\text { heiten }\end{array}$} & \multirow{2}{*}{ fijsch } & \multirow{2}{*}{ trocken } & \\
\hline & & & & trocker & int & & $\begin{array}{c}\text { inz } \\
\text { Ganzen }\end{array}$ & $\begin{array}{l}\text { in flüss. } \\
\text { Znstand }\end{array}$ & & & & \\
\hline$a$ & $\mathrm{~b}$ & $\bar{c}$ & $d$ & e & $\mathrm{f}$ & $g$ & h & $\mathrm{i}$ & $\mathrm{k}$ & 1 & $\mathrm{~m}$ & 11 \\
\hline $\begin{array}{c}1.3 \\
+ \\
0 \\
0 \\
21.5\end{array}$ & $\begin{array}{l}\text { Rinde } \\
\text { Splint } \\
\text { Mitte } \\
\text { Kern } \\
\therefore \text { Holz }\end{array}$ & $\begin{array}{l}- \\
2.0 \\
1.5 \\
2.9 \\
2.3\end{array}$ & $\begin{array}{l}37.9 \\
54.2 \\
56.9 \\
57.7 \\
56.7\end{array}$ & $\begin{array}{l}24.3 \\
34.7 \\
36.5 \\
37.0 \\
36.3\end{array}$ & $\begin{array}{l}- \\
65.9 \\
63.9 \\
64.7 \\
64.6\end{array}$ & $\begin{array}{l}30.4 \\
22.0 \\
20.5 \\
21.1 \\
21.1\end{array}$ & $\begin{array}{l}4.5 .3 \\
43.3 \\
43.0 \\
41.9 \\
42.6\end{array}$ & $\begin{array}{l}\overline{-} \\
12.1 \\
15.6 \\
14.2 \\
14.3\end{array}$ & $\begin{array}{l}54.4 \\
44.4 \\
43.1 \\
42.1 \\
42.9\end{array}$ & $\begin{array}{l}83.2 \\
97.5 \\
99.9 \\
99.6 \\
99.3\end{array}$ & $\begin{array}{l}75.9 \\
65.0 \\
63.5 \\
64.7 \\
64.4\end{array}$ & $\begin{array}{l}50.0 \\
16.6 \\
10.4 \\
10.9 \\
12.0\end{array}$ \\
\hline $\begin{array}{c}3.5 \\
+ \\
0 \\
0 \\
18.5\end{array}$ & $\begin{array}{l}\text { Rinde } \\
\text { Sulint } \\
\text { Mitte } \\
\text { Kiern } \\
\text {. Holz }\end{array}$ & $\begin{array}{l}- \\
2.0 \\
1.9 \\
2.5 \\
2.3\end{array}$ & $\begin{array}{l}38.6 \\
54.0 \\
56.9 \\
57.7 \\
513.5\end{array}$ & $\begin{array}{l}21.5 \\
34.6 \\
36.5 \\
37.0 \\
36.2\end{array}$ & $\begin{array}{l}- \\
65.7 \\
63.9 \\
64.7 \\
64.8\end{array}$ & $\begin{array}{l}32.5 \\
23.2 \\
20.6 \\
21.5 \\
21.7\end{array}$ & $\begin{array}{l}46.0 \\
42.2 \\
12.9 \\
41.5 \\
42.1\end{array}$ & $\begin{array}{l}-- \\
11.1 \\
15.5 \\
13.8 \\
13.5\end{array}$ & $\begin{array}{l}54.4 \\
43.9 \\
43.0 \\
41.8 \\
49.7\end{array}$ & $\begin{array}{l}84.6 \\
96.2 \\
99.8 \\
99.2 \\
98.6\end{array}$ & $\begin{array}{l}73.1 \\
65.7 \\
63.7 \\
63.4 \\
64.1\end{array}$ & $\mid \begin{array}{r}47.2 \\
17.9 \\
10.7 \\
8.9 \\
11.8\end{array}$ \\
\hline $\begin{array}{c}5.7 \\
+ \\
10 \\
0 \\
15.0\end{array}$ & $\begin{array}{l}\text { Rinde } \\
\text { Splint } \\
\text { llitte } \\
\text { liem } \\
\text {. Holz }\end{array}$ & $\begin{array}{l}-\overline{1.9} \\
1.5 \\
2.5 \\
2.0\end{array}$ & $\begin{array}{l}41.0 \\
55.2 \\
59.2 \\
160.8 \\
58.5\end{array}$ & $\begin{array}{l}26.3 \\
35.4 \\
37.9 \\
39.0 \\
37.5\end{array}$ & $\begin{array}{l}- \\
67.3 \\
66.3 \\
68.3 \\
67.5\end{array}$ & $\begin{array}{l}2 \checkmark .5 \\
24.4 \\
20.0 \\
19.4 \\
21.1\end{array}$ & $\begin{array}{l}45.2 \\
40.2 \\
42.1 \\
41.6 \\
41.4\end{array}$ & $\begin{array}{r}8.3 \\
13.7 \\
12.3 \\
11.4\end{array}$ & $\begin{array}{l}52.4 \\
42.1 \\
41.6 \\
40.6 \\
41.4\end{array}$ & $\begin{array}{r}46.2 \\
95.4 \\
101.3 \\
102.4 \\
99.9\end{array}$ & $\begin{array}{l}76.6 \\
65.9 \\
66.4 \\
67.9 \\
66.7\end{array}$ & $\begin{array}{l}46.4 \\
16.1 \\
10.8 \\
10.5 \\
12.8\end{array}$ \\
\hline $\begin{array}{c}7.9 \\
+ \\
0 \\
0 \\
12.0\end{array}$ & $\begin{array}{l}\text { Rinde } \\
\text { Splint } \\
\text { llitte } \\
\text { Kerw } \\
\text {. Holz }\end{array}$ & \begin{tabular}{|l|}
1.9 \\
1.7 \\
1.9 \\
1.8
\end{tabular} & $\begin{array}{l}40.2 \\
52.8 \\
55.5 \\
58.1 \\
55.3\end{array}$ & $\begin{array}{l}25.8 \\
33.9 \\
35.10 \\
37.2 \\
35.5\end{array}$ & $\begin{array}{l}- \\
64.4 \\
62.3 \\
65.1 \\
64.2\end{array}$ & \begin{tabular}{l|}
27.9 \\
26.2 \\
25.4 \\
21.4 \\
24.6
\end{tabular} & $\begin{array}{l}46.8 \\
39.9 \\
39.0 \\
41.4 \\
40.0\end{array}$ & $\begin{array}{r}\overline{y .4} \\
12.3 \\
13.5 \\
11.3\end{array}$ & $\begin{array}{l}53.5 \\
43.1 \\
41.3 \\
41.6 \\
42.1\end{array}$ & $\begin{array}{l}86.5 \\
92.7 \\
94.5 \\
94.5 \\
95.3\end{array}$ & $\begin{array}{l}77.2 \\
63.0 \\
64.7 \\
65.7 \\
64.4\end{array}$ & $\begin{array}{l}47.9 \\
16.2 \\
14.3 \\
11.6 \\
14.2\end{array}$ \\
\hline $\begin{array}{c}10.1 \\
+ \\
0 \\
9.0\end{array}$ & \begin{tabular}{|c|} 
Rinde \\
Splint \\
Mitteu.Kern \\
Holz
\end{tabular} & $\left|\begin{array}{l}- \\
2.5 \\
2.2 \\
2.3\end{array}\right|$ & $\begin{array}{l}43.6 \\
56.0 \\
57.4 \\
56.7\end{array}$ & $\begin{array}{l}27.9 \\
35.9 \\
36.7 \\
36.3\end{array}$ & $\begin{array}{l}-\overline{68.2} \\
64.2 \\
66.1\end{array}$ & $\begin{array}{l}27.7 \\
22.4 \\
23.3 \\
23.1\end{array}$ & $\begin{array}{l}44.4 \\
41.3 \\
40.0 \\
40.6\end{array}$ & $\begin{array}{r}9.0 \\
12.5 \\
10.8\end{array}$ & $\begin{array}{l}50.5 \\
42.4 \\
41.1 \\
41.7\end{array}$ & $\begin{array}{l}88.0 \\
97.3 \\
97.4 \\
97.3\end{array}$ & $\begin{array}{l}78.0 \\
66.8 \\
66.2 \\
66.5\end{array}$ & $\begin{array}{l}44.1 \\
16.2 \\
13.3 \\
14.7\end{array}$ \\
\hline $\begin{array}{r}12.3 \\
4.0\end{array}$ & $\begin{array}{l}\text { Rinde } \\
\text { Holz }\end{array}$ & $\overline{1.5}$ & $\begin{array}{l}40.2 \\
59.8\end{array}$ & $\begin{array}{l}25.8 \\
38.3\end{array}$ & $7 \overline{2.5}$ & $\begin{array}{l}30.4 \\
23.7\end{array}$ & $\begin{array}{l}43.8 \\
38.0\end{array}$ & $\overline{3.5}$ & $\begin{array}{l}52.1 \\
35.9\end{array}$ & $\begin{array}{l}84.0 \\
97.8\end{array}$ & $\begin{array}{l}77.5 \\
70.6\end{array}$ & $\begin{array}{l}48.1 \\
15.3\end{array}$ \\
\hline \multicolumn{3}{|c|}{ 1-2jäbrige Zweige } & 53.1 & 34.0 & - & 19.0 & 47.0 & - & 46.9 & 100.1 & 81.3 & 34.7 \\
\hline \multicolumn{3}{|c|}{ Ganzer Stamm } & 56.8 & 36.4 & 64.6 & 21.8 & 41.8 & 13.6 & - & 98.6 & - & - \\
\hline
\end{tabular}




\section{Eiche.}

Alter 50 Jahre.

7. Mai 1881.

Höhe $13 \mathrm{~m}$. Kronenansatz $-\mathrm{m}$. Inhalt $0.171 \mathrm{~cm}$. Wasser $42.6 \%$. Substanz $37.0 \mathrm{ccm}$.

\begin{tabular}{|c|c|c|c|c|c|c|c|c|c|c|c|c|}
\hline \multirow{3}{*}{ 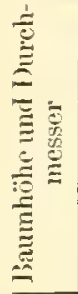 } & \multirow{3}{*}{ Baumtheil } & \multirow{3}{*}{ 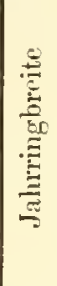 } & \multicolumn{3}{|c|}{$\begin{array}{l}\text { Organische substanz } \\
\text { in } 100 \text { Rantheilen } \\
\text { frischen Holzes }\end{array}$} & \multirow{3}{*}{ 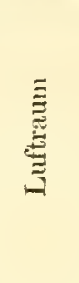 } & \multicolumn{3}{|c|}{ Wassergehalt } & \multicolumn{2}{|c|}{$\begin{array}{c}\text { Specifisches } \\
\text { Gewicht }\end{array}$} & \multirow{3}{*}{ 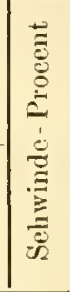 } \\
\hline & & & & \multicolumn{2}{|c|}{ Raumtheile } & & \multicolumn{2}{|c|}{ in 100 Raumt heil. } & \multirow{2}{*}{$\begin{array}{l}\text { auf } \\
100 \mathrm{Ge}- \\
\text { wichts- } \\
\text { Ejn- } \\
\text { beiten }\end{array}$} & \multirow{2}{*}{ frisch } & \multirow{2}{*}{ trocken } & \\
\hline & & & & trocken & imbibirt & & $\operatorname{im}_{\text {Gazen }}$ & $\begin{array}{l}\text { in flüss. } \\
\text { Zustand }\end{array}$ & & & & \\
\hline$a$ & $\mathrm{~b}$ & $\mathrm{c}$ & $d$ & e & $f$ & $g$ & h & $\mathrm{i}$ & k & 1 & $\mathrm{~m}$ & $\mathrm{n}$ \\
\hline$\overline{\overline{18}} .0$ & $\begin{array}{l}\text { Rincle } \\
\text { Splint } \\
\text { Mitte } \\
\text { Kern } \\
\because \text {. Holz }\end{array}$ & $\begin{array}{l}- \\
1.0 \\
1.7 \\
2.4 \\
1.8\end{array}$ & $\begin{array}{l}40.6 \\
53.7 \\
56.7 \\
58.9 \\
57.0\end{array}$ & $\begin{array}{l}26.0 \\
34.4 \\
36.3 \\
37.7 \\
36.5\end{array}$ & $\begin{array}{l}-\overline{65.4} \\
63.5 \\
66.0 \\
65.0\end{array}$ & $\begin{array}{l}21.8 \\
23.0 \\
20.9 \\
18.9 \\
20.6\end{array}$ & $\begin{array}{l}52.2 \\
42.6 \\
42.8 \\
43.4 \\
42.9\end{array}$ & $\begin{array}{l}-\overline{11.6} \\
15.6 \\
15.1 \\
14.4\end{array}$ & $\begin{array}{l}56.3 \\
44.2 \\
41.5 \\
42.4 \\
42.9\end{array}$ & $\begin{array}{r}92.8 \\
96.3 \\
99.5 \\
102.3 \\
99.9\end{array}$ & $\begin{array}{l}75.7 \\
65.0 \\
67.6 \\
70.0 \\
68.2\end{array}$ & $\begin{array}{l}46.4 \\
18.3 \\
15.9 \\
11.6 \\
16.4\end{array}$ \\
\hline 3.5 & $\begin{array}{l}\text { Rinde } \\
\text { Splint } \\
\text { Mlitte } \\
\text { Kern } \\
\text { - Holz }\end{array}$ & $\begin{array}{l}- \\
1.0 \\
1.6 \\
2.5 \\
1.7\end{array}$ & $\begin{array}{l}41.8 \\
54.4 \\
58.7 \\
62.9 \\
59.3\end{array}$ & $\begin{array}{l}26.8 \\
34.9 \\
37.6 \\
40.3 \\
38.0\end{array}$ & $\begin{array}{l}- \\
66.3 \\
65.8 \\
70.5 \\
68.0\end{array}$ & $\begin{array}{l}23.0 \\
22.6 \\
18.4 \\
15.3 \\
18.3\end{array}$ & $\begin{array}{l}50.2 \\
42.5 \\
44.0 \\
44.4 \\
43.7\end{array}$ & $\begin{array}{l}\overline{11.1} \\
15.8 \\
14.2 \\
13.7\end{array}$ & $\begin{array}{l}54.5 \\
43.9 \\
42.8 \\
41.4 \\
42.5\end{array}$ & $\begin{array}{r}92.0 \\
96.9 \\
102.7 \\
107.3 \\
103.0\end{array}$ & $\begin{array}{l}71.8 \\
66.7 \\
68.5 \\
70.6 \\
68.9\end{array}$ & $\begin{array}{l}41.7 \\
18.5 \\
14.2 \\
10.9 \\
14.0\end{array}$ \\
\hline$\overline{14.5}$ & $\begin{array}{l}\text { Pinde } \\
\text { Splint } \\
\text { Jitte } \\
\text { Kern } \\
\text {. Holz }\end{array}$ & $\begin{array}{l}- \\
1.4 \\
2.0 \\
2.8 \\
2.2\end{array}$ & $\begin{array}{l}45.5 \\
52.9 \\
56.3 \\
58.3 \\
56.2\end{array}$ & $\begin{array}{l}29.2 \\
33.9 \\
36.1 \\
37.3 \\
36.0\end{array}$ & $\begin{array}{l}-\overline{64.4} \\
63.2 \\
65.3 \\
64.4\end{array}$ & $\begin{array}{l}20.2 \\
23.0 \\
21.8 \\
20.6 \\
21.8\end{array}$ & $\begin{array}{l}50.6 \\
43.1 \\
42.1 \\
42.1 \\
42.2\end{array}$ & $\begin{array}{l}12.6 \\
15.0 \\
14.1 \\
13.8\end{array}$ & $\begin{array}{l}52.6 \\
44.9 \\
42.8 \\
41.4 \\
42.8\end{array}$ & $\begin{array}{l}96.1 \\
96.0 \\
98.4 \\
99.4 \\
98.4\end{array}$ & $\begin{array}{l}77.7 \\
64.5 \\
65.7 \\
65.2 \\
65.2\end{array}$ & $\begin{array}{l}41.3 \\
18.0 \\
14.3 \\
10.6 \\
14.7\end{array}$ \\
\hline $\begin{array}{l}7.9 \\
\overline{-} \\
\overline{13.0}\end{array}$ & $\begin{array}{l}\text { Rinde } \\
\text { Splint } \\
\text { Mlitte } \\
\text { Korn } \\
\% \text { Holz }\end{array}$ & $\begin{array}{l}- \\
1.2 \\
2.0 \\
2.4 \\
1.9\end{array}$ & $\begin{array}{l}45.8 \\
54.9 \\
59.1 \\
64.0 \\
58.5\end{array}$ & $\begin{array}{l}29.3 \\
35.2 \\
37.9 \\
41.0 \\
37.5\end{array}$ & $\begin{array}{l}66.9 \\
66.3 \\
71.7 \\
67.5\end{array}$ & $\begin{array}{l}20.3 \\
28.1 \\
20.0 \\
17.9 \\
20.8\end{array}$ & $\begin{array}{l}50.4 \\
41.7 \\
42.1 \\
41.1 \\
41.7\end{array}$ & $\begin{array}{l}\overline{-} \\
10.0 \\
13.7 \\
10.4 \\
11.7\end{array}$ & $\begin{array}{l}52.4 \\
43.2 \\
41.6 \\
39.8 \\
41.6\end{array}$ & $\begin{array}{r}96.2 \\
96.6 \\
101.2 \\
105.1 \\
100.2\end{array}$ & $\begin{array}{l}74.7 \\
66.3 \\
69.5 \\
72.4 \\
69.4\end{array}$ & $\begin{array}{l}38.7 \\
17.2 \\
15.2 \\
14.6 \\
15.7\end{array}$ \\
\hline 10.1 & $\begin{array}{l}\text { Rinde } \\
\text { Splint } \\
\text { Jitte } \\
\text { Kern } \\
\% \text { Holz }\end{array}$ & $\begin{array}{l}1.7 \\
1.8 \\
1.7 \\
1.8\end{array}$ & $\begin{array}{l}49.3 \\
54.7 \\
62.0 \\
65.2 \\
59.1\end{array}$ & $\begin{array}{l}31.6 \\
35.1 \\
39.7 \\
41.8 \\
37.9\end{array}$ & $\begin{array}{l}66.7 \\
69.5 \\
73.1 \\
69.0\end{array}$ & $\begin{array}{l}19.3 \\
23.2 \\
18.5 \\
16.4 \\
20.3\end{array}$ & $\begin{array}{l}49.1 \\
41.7 \\
41.8 \\
41.8 \\
41.8\end{array}$ & $\begin{array}{l}\overline{10.1} \\
12.0 \\
10.5 \\
10.7\end{array}$ & $\begin{array}{l}49.9 \\
43.2 \\
40.3 \\
39.0 \\
41.4\end{array}$ & $\begin{array}{r}98.4 \\
96.4 \\
103.8 \\
107.0 \\
100.9\end{array}$ & $\begin{array}{l}79.9 \\
66.0 \\
71.7 \\
73.8 \\
69.4\end{array}$ & $\begin{array}{l}38.2 \\
17.1 \\
13.5 \\
11.6 \\
14.9\end{array}$ \\
\hline 12.3 & $\begin{array}{l}\text { Rinde } \\
\text { Holz }\end{array}$ & $\overline{1.0}$ & $\begin{array}{l}49.4 \\
58.6\end{array}$ & $\begin{array}{l}31.6 \\
37.6\end{array}$ & $\pi 1.4$ & $\begin{array}{l}19.0 \\
22.4\end{array}$ & $\begin{array}{l}49.4 \\
40.0\end{array}$ & $\overrightarrow{6.2}$ & $\begin{array}{l}50.2 \\
40.5\end{array}$ & $\begin{array}{l}98.8 \\
98.6\end{array}$ & $\begin{array}{l}80.7 \\
69.7\end{array}$ & $\begin{array}{l}3 \div .8 \\
16.0\end{array}$ \\
\hline \multicolumn{3}{|c|}{ 1-2j:ilır.Zwg. m. Knosp. } & 50.9 & 32.6 & - & 15.0 & 52.4 & - & 50.7 & 103.8 & 76.9 & 33.7 \\
\hline \multicolumn{3}{|c|}{ Ganzer Stamm } & 57.8 & 7.0 & 66.2 & 20.4 & 42.6 & 13.4 & - & 100.4 & - & - \\
\hline
\end{tabular}




\section{Eiche.}

Alter 50 Jahre.

2. Jnli 1881 .

Höhe $14 \mathrm{~m}$. Kronenansatz $7 \mathrm{~m}$. Inhalt $0.162 \mathrm{~cm}$. Wasser $45.9 \%$. Substanz 37.4 cem.

\begin{tabular}{|c|c|c|c|c|c|c|c|c|c|c|c|}
\hline \multirow{3}{*}{ 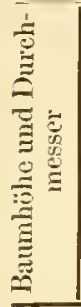 } & \multirow{3}{*}{ Baumtheil } & \multirow{3}{*}{ 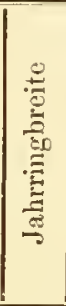 } & \multicolumn{3}{|c|}{$\begin{array}{l}\text { Organische Suhstanz } \\
\text { in } 110 \text { Ranmtheilen } \\
\text { frischen Holzes }\end{array}$} & \multirow{3}{*}{ 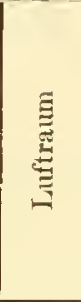 } & \multicolumn{3}{|c|}{ Wassergehalt } & \multirow{3}{*}{$\begin{array}{c}\begin{array}{c}\text { Specifisches } \\
\text { Gewicht }\end{array} \\
\text { frisch trocken }\end{array}$} & \multirow{3}{*}{ 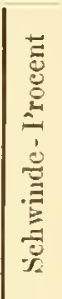 } \\
\hline & & & \multirow{2}{*}{ Gramme } & \multicolumn{2}{|c|}{ Ratumtheile } & & \multicolumn{2}{|c|}{ in 100 Raumtheil. } & \multirow{2}{*}{$\begin{array}{l}\text { auf } \\
100 \text { Ge- } \\
\text { wichts- } \\
\text { Ein- } \\
\text { heiten }\end{array}$} & & \\
\hline & & & & trocken & imbibirt & & $\operatorname{im}_{\text {Ganzen }}$ & $\begin{array}{l}\text { in flūss, } \\
\text { Zustand }\end{array}$ & & & \\
\hline$a$ & $\mathrm{~b}$ & c & $d$ & e & $\mathrm{f}$ & $g$ & h & i & k & $1 \mathrm{~m}$ & n \\
\hline $\begin{array}{c}1.3 \\
+ \\
0 \\
0 \\
18.5\end{array}$ & $\begin{array}{l}\text { Rinde } \\
\text { Splint } \\
\text { Hitte } \\
\text { Kern } \\
\text {. Holz }\end{array}$ & $\begin{array}{l}-\overline{2.0} \\
1.5 \\
2.1 \\
1.9\end{array}$ & $\begin{array}{l}33.9 \\
55.9 \\
59.6 \\
61.9 \\
59.7\end{array}$ & $\begin{array}{l}21.7 \\
35.8 \\
38.2 \\
39.7 \\
38.3\end{array}$ & $\begin{array}{l}-\overline{68.0} \\
66.8 \\
69.5 \\
68.6\end{array}$ & $\begin{array}{l}22.9 \\
13.1 \\
13.5 \\
18.9 \\
15.8\end{array}$ & $\begin{array}{l}55.4 \\
51.1 \\
48.3 \\
41.4 \\
45.9\end{array}$ & $\begin{array}{l}-\overline{18.9} \\
19.7 \\
11.6 \\
15.6\end{array}$ & $\begin{array}{l}62.0 \\
47.8 \\
44.8 \\
40.1 \\
43.5\end{array}$ & \begin{tabular}{|r|r|}
89.3 & 81.2 \\
107.0 & 69.2 \\
107.9 & 68.8 \\
103.3 & 70.0 \\
105.6 & 69.5 \\
\end{tabular} & $\begin{array}{l}58.2 \\
19.4 \\
13.4 \\
11.6 \\
14.1\end{array}$ \\
\hline $\begin{array}{c}3.5 \\
+ \\
0 \\
0 \\
15.5\end{array}$ & $\begin{array}{l}\text { Rinde } \\
\text { splint } \\
\text { Mlitte } \\
\text { Kern } \\
\text { //. 1Lolz }\end{array}$ & $\begin{array}{l}-.7 \\
1.4 \\
2.2 \\
1.9\end{array}$ & $\begin{array}{l}34.0 \\
54.4 \\
58.7 \\
62.2 \\
58.8\end{array}$ & $\begin{array}{l}21.8 \\
34.9 \\
37.6 \\
39.9 \\
37.7\end{array}$ & $\begin{array}{l}-\overrightarrow{66.3} \\
65.8 \\
69.8 \\
67.9\end{array}$ & $\begin{array}{l}25.2 \\
16.0 \\
16.9 \\
18.4 \\
17.3\end{array}$ & $\begin{array}{l}53.0 \\
49.1 \\
45 . .7 \\
41.7 \\
45.0\end{array}$ & $\begin{array}{l}-\overline{17.7} \\
17.3 \\
11.8 \\
14.8\end{array}$ & $\begin{array}{l}60.9 \\
47.4 \\
43.7 \\
40.2 \\
43.4\end{array}$ & \begin{tabular}{r|r|}
87.0 & 72.1 \\
103.5 & 67.5 \\
104.2 & 70.4 \\
103.9 & 69.9 \\
103.8 & 69.4
\end{tabular} & $\begin{array}{l}52.8 \\
19.7 \\
16.7 \\
11.0 \\
15.2\end{array}$ \\
\hline $\begin{array}{c}5.7 \\
+ \\
0 \\
0 \\
14.5\end{array}$ & $\begin{array}{l}\text { Rinde } \\
\text { Splint } \\
\text { Mitte } \\
\text { Kern } \\
\text {. Holz }\end{array}$ & $\begin{array}{l}-7 \\
1.5 \\
1.5 \\
2.2 \\
1.9\end{array}$ & $\begin{array}{l}34.2 \\
51.9 \\
56.6 \\
59.6 \\
56.7\end{array}$ & $\begin{array}{l}21.9 \\
33.3 \\
36.3 \\
38.2 \\
36.4\end{array}$ & $\begin{array}{l}- \\
63.3 \\
63.5 \\
66.8 \\
65.2\end{array}$ & $\begin{array}{l}25.4 \\
17.5 \\
16.4 \\
20.0 \\
18.1\end{array}$ & $\begin{array}{l}52.7 \\
49.2 \\
47.3 \\
41.8 \\
45.5\end{array}$ & $\begin{array}{l}- \\
19.2 \\
20.1 \\
13.2 \\
16.7\end{array}$ & $\begin{array}{l}60.6 \\
48.7 \\
45.5 \\
41.2 \\
44.6\end{array}$ & \begin{tabular}{|r|r|}
86.9 & 70.2 \\
101.1 & 64.7 \\
103.9 & 66.6 \\
101.4 & 68.1 \\
102.2 & 66.8
\end{tabular} & $\begin{array}{l}51.2 \\
19.8 \\
15.1 \\
12.5 \\
15.2\end{array}$ \\
\hline $\begin{array}{c}7.9 \\
+ \\
0 \\
0 \\
12.5\end{array}$ & $\begin{array}{l}\text { Rinde } \\
\text { Splint } \\
\text { Mitte } \\
\text { liern } \\
\% \text {. Holz }\end{array}$ & $\begin{array}{l}-1 \\
2.1 \\
2.0 \\
2.4 \\
2.2\end{array}$ & $\begin{array}{l}37.9 \\
54.4 \\
58.6 \\
59.4 \\
57.3\end{array}$ & $\begin{array}{l}24.3 \\
34.9 \\
37.6 \\
38.1 \\
36.8\end{array}$ & $\begin{array}{l}66.3 \\
65.8 \\
66.7 \\
66.2\end{array}$ & $\begin{array}{l}23.9 \\
16.0 \\
15.2 \\
20.3 \\
16.8\end{array}$ & $\begin{array}{l}51.8 \\
49.1 \\
47.2 \\
41.6 \\
46.4\end{array}$ & $\begin{array}{l}\overline{17.7} \\
19.0 \\
13.0 \\
17.0\end{array}$ & $\begin{array}{l}57.7 \\
47.4 \\
44.6 \\
41.2 \\
44.8\end{array}$ & \begin{tabular}{|r|r|}
89.7 & 78.5 \\
103.5 & 66.2 \\
10.5 & 67.7 \\
101.0 & 68.9 \\
103.7 & 67.6
\end{tabular} & $\begin{array}{l}51.7 \\
17.9 \\
13.7 \\
13.8 \\
15.2\end{array}$ \\
\hline $\begin{array}{c}10.1 \\
+-0 \\
0 \\
8.2\end{array}$ & $\begin{array}{l}\text { Rinde } \\
\text { Splint } \\
\text { M. u. K. } \\
\text { Holz }\end{array}$ & $\begin{array}{l}- \\
2.6 \\
1.7 \\
2.1\end{array}$ & $\begin{array}{l}37.7 \\
56.7 \\
61.1 \\
57.6\end{array}$ & $\begin{array}{l}24.2 \\
36.4 \\
39.2 \\
36.9\end{array}$ & $\begin{array}{l}69.2 \\
68.6 \\
69.0\end{array}$ & $\begin{array}{l}23.1 \\
14.8 \\
14.9 \\
14.9\end{array}$ & $\begin{array}{l}52.7 \\
48.8 \\
45.9 \\
48.2\end{array}$ & $\begin{array}{l}-\overline{16.0} \\
16.5 \\
16.1\end{array}$ & $\begin{array}{l}58.3 \\
46.3 \\
42.9 \\
45.5\end{array}$ & \begin{tabular}{r|r}
90.4 & 79.3 \\
105.5 & 70.1 \\
107.0 & 69.2 \\
105.8 & 69.9
\end{tabular} & $\begin{array}{l}52.4 \\
19.1 \\
11.8 \\
17.5\end{array}$ \\
\hline $\begin{array}{r}12.3 \\
4.0\end{array}$ & $\begin{array}{l}\text { Rinde } \\
\text { Holz }\end{array}$ & -7 & $\begin{array}{l}38.4 \\
56.4\end{array}$ & $\begin{array}{l}24.6 \\
36.1\end{array}$ & $\overline{6 s .6}$ & $\begin{array}{l}20.6 \\
14.6\end{array}$ & $\begin{array}{l}54.8 \\
49.3\end{array}$ & $\overline{16.8}$ & $\begin{array}{l}58.8 \\
46.5\end{array}$ & $\begin{array}{rr}93.2 & 85.2 \\
105.7 & 71.6\end{array}$ & $\begin{array}{l}54.9 \\
21.2\end{array}$ \\
\hline 1-2jäh & 7wg. olne & BI. & 44.6 & 28.6 & - & 9.0 & 62.4 & - & 58.3 & $107.0,80.4$ & 44.5 \\
\hline ljiilur. & Kwg. mit BI & lätt. & 31.6 & 20.2 & - & 23.8 & 56.0 & - & 63.9 & $87.6 \quad 76.3$ & 55.5 \\
\hline $\mathrm{Cia}$ & nzel Sitrumm & & 58.3 & 37.4 & 67.4 & 16.7 & 45.9 & 15.9 & - & 104.2 & - \\
\hline
\end{tabular}




\section{Eiche.}

Alter 50 . Iahre.

8. October 1881

Höhe $15 \mathrm{~m}$. Kronenansatz $5.8 \mathrm{~m}$. Iulalt $0.173 \mathrm{~cm}$. Wasser $44.1 \%$. Substanz $39.3 \mathrm{ccm}$.

\begin{tabular}{|c|c|c|c|c|c|c|c|c|c|c|c|c|}
\hline \multirow{3}{*}{ 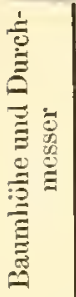 } & \multirow{3}{*}{ Bauntheil } & \multirow{3}{*}{ 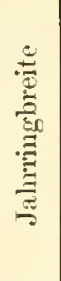 } & \multicolumn{3}{|c|}{$\begin{array}{l}\text { ()rganische Substanz } \\
\text { in } 100 \text { Raumtheilen } \\
\text { frischen Holzes }\end{array}$} & \multirow{3}{*}{ 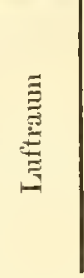 } & \multicolumn{3}{|c|}{ Wassergehalt } & \multicolumn{2}{|c|}{$\begin{array}{c}\text { Speeifisches } \\
\text { Gewieht }\end{array}$} & \multirow{3}{*}{ 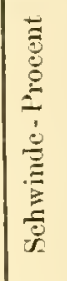 } \\
\hline & & & \multirow{2}{*}{ Grame } & \multicolumn{2}{|c|}{ Raumtheile } & & \multicolumn{2}{|c|}{ in 100 Raumtheil. } & \multirow{2}{*}{$\begin{array}{c}\text { auf } \\
100 \mathrm{Ge-} \\
\text { wichts- } \\
\text { Ein- } \\
\text { heiten }\end{array}$} & \multirow{2}{*}{\multicolumn{2}{|c|}{ frisch trocke }} & \\
\hline & & & & trocken & im bibirt & & $\operatorname{im}_{\text {Ganzen }}$ & $\begin{array}{l}\text { influss, } \\
\text { Zustand }\end{array}$ & & & & \\
\hline a & b & c & d & e & f & $\mathrm{g}$ & h & $\mathrm{i}$ & $\mathrm{k}$ & 1 & $\mathrm{~m}$ & $\mathrm{n}$ \\
\hline $\begin{array}{l}1.3 \\
- \\
\overline{-} \\
19.0\end{array}$ & $\begin{array}{l}\text { linde } \\
\text { Splint } \\
\text { Mitte } \\
\text { Kerm } \\
\text {. Holz }\end{array}$ & $\begin{array}{l}-- \\
2.1 \\
2.1 \\
2.4 \\
2.3\end{array}$ & $\begin{array}{l}42.5 \\
57.3 \\
60.3 \\
63.0 \\
60.6\end{array}$ & $\begin{array}{l}27.2 \\
36.7 \\
3 . .7 \\
40.4 \\
38.8\end{array}$ & $\begin{array}{l}6 \overline{-} .7 \\
67.7 \\
70.7 \\
69.8\end{array}$ & $\begin{array}{l}2.5 .9 \\
18.4 \\
15.3 \\
17.4 \\
17.1\end{array}$ & $\begin{array}{l}46.9 \\
44.9 \\
46.0 \\
42.2 \\
44.1\end{array}$ & $\begin{array}{l}1 \overline{11.9} \\
17.0 \\
12.1 \\
13.1\end{array}$ & $\begin{array}{l}52.5 \\
44.0 \\
43.3 \\
40.1 \\
42.2\end{array}$ & $\begin{array}{r}89.4 \\
102.2 \\
106.3 \\
105.2 \\
101.7\end{array}$ & $\begin{array}{l}86.3 \\
69.4 \\
6.8 \\
70.4 \\
69.7\end{array}$ & $\begin{array}{l}50.8 \\
17.5 \\
12.4 \\
10.6 \\
13.1\end{array}$ \\
\hline $\begin{array}{c}3.5 \\
- \\
- \\
17.5\end{array}$ & $\begin{array}{l}\text { Rinde } \\
\text { Splint } \\
\text { Alitte } \\
\text { Kern } \\
. \text { Holz }\end{array}$ & $\begin{array}{l}- \\
2.0 \\
2.0 \\
2.8 \\
2.4\end{array}$ & $\begin{array}{l}41.6 \\
57.3 \\
62.1 \\
63.8 \\
61.4\end{array}$ & & $\begin{array}{l}-\overline{69.7} \\
69.7 \\
71.4 \\
70.9\end{array}$ & $\begin{array}{l}27.3 \\
19.4 \\
14.0 \\
11.1 \\
16.3\end{array}$ & $\begin{array}{l}46.1 \\
43.9 \\
46.2 \\
43.1 \\
44.3\end{array}$ & $\begin{array}{l}\overline{10.9} \\
16.3 \\
12.5 \\
12.8\end{array}$ & $\begin{array}{l}40.3 \\
41.9\end{array}$ & $\begin{array}{r}87.7 \\
101.2 \\
108.3 \\
106.9 \\
105.7\end{array}$ & $\begin{array}{l}81.8 \\
68.6 \\
69.9 \\
71.0 \\
70.0\end{array}$ & $\begin{array}{l}49.1 \\
16.4 \\
11.2 \\
10.2 \\
12.3\end{array}$ \\
\hline $\begin{array}{c}5.7 \\
\overline{-} \\
\overline{-} \\
15.5\end{array}$ & $\begin{array}{l}\text { Rinde } \\
\text { splint } \\
\text { Ilitte } \\
\text { Kicrn } \\
\text {./. Holz }\end{array}$ & $\begin{array}{l}2 . \\
2.3 \\
2.4 \\
2.6 \\
2.5\end{array}$ & $\begin{array}{l}43.3 \\
58.5 \\
63.0 \\
64.1 \\
61.9\end{array}$ & $\begin{array}{l}37.6 \\
40.4 \\
41.1 \\
39.7\end{array}$ & $\begin{array}{l}7 \overline{71.4} \\
70.7 \\
71.9 \\
71.5\end{array}$ & $\begin{array}{l}19.6 \\
13.0 \\
15.4 \\
16.2\end{array}$ & $\begin{array}{l}43.5 \\
44.1\end{array}$ & $\begin{array}{r}\overline{9.0} \\
16.3 \\
12.7 \\
12.3\end{array}$ & $\begin{array}{l}51.8 \\
42.2 \\
42.5 \\
40.4 \\
41.6\end{array}$ & $\begin{array}{r}89.8 \\
101.3 \\
109.6 \\
107.6 \\
106.0\end{array}$ & $\begin{array}{l}80.2 \\
69.9 \\
72.3 \\
72.0 \\
71.4\end{array}$ & $\begin{array}{l}45.4 \\
16.3 \\
12.8 \\
10.9 \\
13.3\end{array}$ \\
\hline $\begin{array}{c}7.9 \\
- \\
\overline{-} \\
11.5\end{array}$ & $\begin{array}{l}\text { Rinde } \\
\text { Splint } \\
\text { Mitte } \\
\text { Kern } \\
\% \text { Holz }\end{array}$ & $\begin{array}{l}3.0 \\
3.0 \\
2.1 \\
2.5\end{array}$ & $\begin{array}{l}47.7 \\
59.7 \\
61.4 \\
61.9 \\
60.8\end{array}$ & $\begin{array}{l}38.3 \\
39.4 \\
39.7 \\
38.9\end{array}$ & $\begin{array}{l}-\overline{72.8} \\
68.9 \\
69.5 \\
70.4\end{array}$ & $\begin{array}{l}16.6 \\
17.4 \\
18.4 \\
17.5\end{array}$ & $\begin{array}{l}45.2 \\
45.1 \\
43.2 \\
41.9 \\
43.6\end{array}$ & $\begin{array}{l}\overline{10.6} \\
13.7 \\
12.1 \\
12.1\end{array}$ & $\begin{array}{l}41.3 \\
40.4 \\
41.8\end{array}$ & $\begin{array}{r}92.9 \\
104.8 \\
104.6 \\
103.8 \\
104.4\end{array}$ & $\begin{array}{l}91.2 \\
72.1 \\
73.1 \\
71.4 \\
72.1\end{array}$ & $\begin{array}{l}17.7 \\
17.2 \\
15.9 \\
13.3 \\
15.3\end{array}$ \\
\hline $\begin{array}{c}10.1 \\
- \\
7.5\end{array}$ & $\begin{array}{l}\text { Rinde } \\
\text { Splint } \\
\text { M. n. K. } \\
\text { Holz }\end{array}$ & $\begin{array}{l}- \\
2.8 \\
2.6 \\
2.7\end{array}$ & $\begin{array}{l}47.1 \\
61.0 \\
62.3 \\
61.4\end{array}$ & $\begin{array}{l}30.2 \\
39.1 \\
40.0 \\
39.4\end{array}$ & $\begin{array}{l}-\overline{74.3} \\
70.0 \\
72.9\end{array}$ & $\begin{array}{l}24.0 \\
17.5 \\
17.4 \\
17.4\end{array}$ & $\begin{array}{l}43.4 \\
42.6 \\
43.2\end{array}$ & $\begin{array}{r}-\overline{8.2} \\
12.6 \\
9.7\end{array}$ & $\begin{array}{l}41.6 \\
40.6 \\
41.3\end{array}$ & $\begin{array}{r}92.9 \\
104.4 \\
104.9 \\
104.6\end{array}$ & $\begin{array}{l}87.9 \\
74.4 \\
72.9 \\
79.9\end{array}$ & $\begin{array}{l}46.4 \\
18.0 \\
14.5 \\
16.9\end{array}$ \\
\hline $\begin{array}{r}12.3 \\
2.5\end{array}$ & $\begin{array}{l}\text { Rinde } \\
\text { Holz }\end{array}$ & $-\overline{2.0}$ & $\begin{array}{l}47.3 \\
64.6\end{array}$ & $\begin{array}{l}30.3 \\
41.4\end{array}$ & $\overline{88.7}$ & $\begin{array}{l}24.5 \\
16.4\end{array}$ & $\begin{array}{l}45.2 \\
42.2\end{array}$ & $\overline{4.9}$ & $\begin{array}{l}48.9 \\
39.5\end{array}$ & $\begin{array}{r}92.5 \\
106.8\end{array}$ & $\begin{array}{l}91.9 \\
79.4\end{array}$ & $\begin{array}{l}48.6 \\
18.7\end{array}$ \\
\hline \multicolumn{3}{|c|}{ 2jährige $Z$ weige } & 56.6 & 36.3 & - & 15.2 & 48.5 & - & 46.2 & 105.1 & 95.6 & 10.8 \\
\hline \multicolumn{3}{|c|}{ 1jähr.Zwg. ohne Blätt. } & 57.8 & 37.0 & - & 11.6 & 51. & - & 47.1 & 109.2 & 92.9 & 37.7 \\
\hline \multicolumn{3}{|c|}{ 1juihr. Zwrg. mit Blätt. } & 46.5 & 29.8 & - & 9 & 54.3 & - & 53.9 & 100.8 & 82.1 & 43.3 \\
\hline \multicolumn{3}{|c|}{ Ganzer Stamm } & 61.3 & 39.3 & 71.0 & 16.6 & 44.1 & 12.4 & - & 105.4 & - & - \\
\hline
\end{tabular}


Kiefer.

Alter 75 Jahre.

2. Janua 1882.

IIöhe $27 \mathrm{~m}$. Kronenansatz $17 \mathrm{~m}$. 1nhalt $1.278 \mathrm{em}$. Wasser $44.8 \%$. Substanz $27.8 \mathrm{ccm}$.

\begin{tabular}{|c|c|c|c|c|c|c|c|c|c|c|c|}
\hline \multirow{3}{*}{ 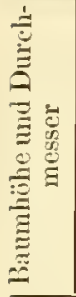 } & \multirow{3}{*}{ Baumtheil } & \multirow{3}{*}{ 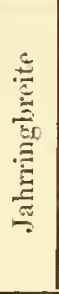 } & \multicolumn{3}{|c|}{$\begin{array}{c}\text { Organische Substanz } \\
\text { iu } 100 \text { Rammtheilen } \\
\text { frischen Holzes }\end{array}$} & \multirow{3}{*}{$\underset{\Xi}{\Xi}$} & \multicolumn{3}{|c|}{ Wassergehalt } & $\begin{array}{l}\text { Specifisches } \\
\text { Gewicht }\end{array}$ & \multirow{3}{*}{ 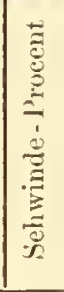 } \\
\hline & & & \multirow{2}{*}{ Gramme } & \multicolumn{2}{|c|}{ Raumtheile } & & \multicolumn{2}{|c|}{ in 100 Raumtheil. } & \multirow{2}{*}{$\begin{array}{c}\text { auf } \\
100 \text { Gre- } \\
\text { wichts- } \\
\text { Eint- } \\
\text { leiten }\end{array}$} & \multirow{2}{*}{ friscll trocken } & \\
\hline & & & & ken & bibirt| & & $\operatorname{im}_{\text {Ganzen }}$ & & & & \\
\hline a & b & c & d & e & $\mathrm{f}$ & $g$ & h & $\mathrm{i}$ & $\mathrm{k}$ & $\mathrm{m}$ & 11 \\
\hline $\begin{array}{l}1.5 \\
- \\
\overline{-} \\
40.0\end{array}$ & $\begin{array}{l}\text { Rinde } \\
\text { Splint } \\
\text { Ifitte } \\
\text { Kern } \\
\text {. Ilolz }\end{array}$ & $\begin{array}{l}- \\
1.4 \\
3.0 \\
8.3 \\
3.0\end{array}$ & $\begin{array}{l}21.7 \\
47.8 \\
44.8 \\
47.0 \\
46.6\end{array}$ & & $\begin{array}{l}-\overline{4} \\
47.4 \\
43.0 \\
44.5 \\
45.1\end{array}$ & $\begin{array}{l}37.3 \\
13.7 \\
29.7 \\
55.2 \\
27.9\end{array}$ & $\begin{array}{l}48.8 \\
55.7 \\
41.6 \\
14.7 \\
42.2\end{array}$ & $\begin{array}{r}38.9 \\
27.3 \\
0.3 \\
27.0\end{array}$ & $\begin{array}{l}69.2 \\
53.8 \\
43.1 \\
23.8 \\
47.5\end{array}$ & \begin{tabular}{rr|}
70.5 & 56.4 \\
103.5 & 55.2 \\
86.4 & 49.8 \\
61.7 & 52.6 \\
88.8 & 52.8
\end{tabular} & $\mid \begin{array}{r}01.5 \\
13.3 \\
9.9 \\
10.6 \\
11.6\end{array}$ \\
\hline $\begin{array}{l}4.6 \\
\overline{-} \\
\overline{-} \\
32.0\end{array}$ & $\begin{array}{l}\text { Rinde } \\
\text { Splint } \\
\text { Mitte } \\
\text { Kerm } \\
\text { \%. Holz }\end{array}$ & $\begin{array}{l}-.4 \\
1.4 \\
3.0 \\
4.3 \\
2.3\end{array}$ & $\begin{array}{l}22.9 \\
45.1\end{array}$ & & $\begin{array}{l}\overline{-} \\
44.8 \\
38.7 \\
36.0 \\
41.0\end{array}$ & $\begin{array}{l}83.1 \\
13.3 \\
27.4 \\
63.4 \\
27.7\end{array}$ & $\begin{array}{l}52.2 \\
57.8 \\
46.8 \\
12.3 \\
45.3\end{array}$ & $\begin{array}{r}-\overline{-} \\
43.9 \\
0.6 \\
31.3\end{array}$ & $\begin{array}{l}63.9 \\
56.2 \\
53.8 \\
24.4 \\
51.8\end{array}$ & $\begin{array}{rl}75.1 & 72.1 \\
102.9 & 52.2 \\
87.0 & 45.0 \\
50.2 & 42.0 \\
87.4 & 47.8\end{array}$ & $\begin{array}{r}68.2 \\
13.6 \\
10.6 \\
9.9 \\
11.9\end{array}$ \\
\hline $\begin{array}{l}7.7 \\
-\end{array}$ & $\begin{array}{l}\text { liinde } \\
\text { Splint } \\
\text { Hlitte } \\
\text { Kern } \\
\text {. Holz }\end{array}$ & \begin{tabular}{l|}
- \\
1.5 \\
4.0 \\
4.7 \\
2.7 \\
\end{tabular} & $\begin{array}{l}21.0 \\
44.2 \\
42.4 \\
39.9 \\
42.8\end{array}$ & & $\begin{array}{l}- \\
43.9 \\
40.8 \\
37.9 \\
41.6\end{array}$ & $\begin{array}{l}33.3 \\
15.4 \\
28.3 \\
61.8 \\
23.6 \\
\end{array}$ & $\begin{array}{l}53.2 \\
56.3 \\
44.5 \\
12.6 \\
44.0\end{array}$ & $\begin{array}{r}-\overline{40.7} \\
30.9 \\
0.3 \\
29.8\end{array}$ & $\begin{array}{l}71.7 \\
56.0 \\
51.2 \\
24.1 \\
50.7\end{array}$ & $\begin{array}{rr}74.2 & 63.1 \\
100.5 & 49.5 \\
86.9 & 48.0 \\
52.5 & 44.5 \\
86.8 & 48.1\end{array}$ & $\begin{array}{l}66.7 \\
10.7 \\
11.6 \\
10.3 \\
10.9\end{array}$ \\
\hline $\begin{array}{c}10.8 \\
- \\
- \\
27.0\end{array}$ & $\begin{array}{l}\text { Rinde } \\
\text { Splint } \\
\text { litte } \\
\text { Kiern } \\
\text { Holz }\end{array}$ & \begin{tabular}{|l|}
- \\
1.4 \\
2.9 \\
4.9 \\
3.5
\end{tabular} & $\begin{array}{l}24.4 \\
42.5 \\
41.4 \\
39.3 \\
41.5\end{array}$ & & $\begin{array}{l}-\overline{2} .2 \\
39.7 \\
37.3 \\
40.4\end{array}$ & $\begin{array}{l}33.3 \\
14.2 \\
32.2 \\
62.1 \\
30.4\end{array}$ & $\begin{array}{l}51.1 \\
58.6 \\
41.3 \\
12.7 \\
43.0\end{array}$ & $\begin{array}{r}43.6 \\
28.1 \\
0.6 \\
29.2\end{array}$ & \begin{tabular}{l|}
7.6 \\
7.9 \\
0.0 \\
4.3 \\
0.9
\end{tabular} & $\begin{array}{rr}75.5 & 69.2 \\
101.1 & 48.5 \\
82.7 & 47.2 \\
52.0 & 44.3 \\
84.5 & 47.2 \\
\end{array}$ & $\begin{array}{l}64.7 \\
12.3 \\
12.3 \\
11.2 \\
12.0\end{array}$ \\
\hline 3.9 & $\begin{array}{l}\text { Rinde } \\
\text { Splint } \\
\text { llitte } \\
\text { Kern } \\
\text {. Holz }\end{array}$ & \begin{tabular}{l|}
- \\
1.6 \\
2.5 \\
4.2 \\
2.3 \\
\end{tabular} & $\begin{array}{l}25.3 \\
42.9 \\
39.8 \\
3.4 \\
41.3 \\
\end{array}$ & & $\begin{array}{l}-\overline{4} .6 \\
33.2 \\
36.4 \\
40.5\end{array}$ & $\begin{array}{l}32.2 \\
13.6 \\
33.1 \\
63.5 \\
27.0\end{array}$ & \begin{tabular}{|l|}
51.6 \\
58.9 \\
41.4 \\
11.9 \\
46.5 \\
\end{tabular} & $\begin{array}{r}-- \\
43.8 \\
29.7 \\
0.1 \\
32.5\end{array}$ & $\begin{array}{l}67.1 \\
57.9 \\
51.0 \\
23.7 \\
52.9\end{array}$ & \begin{tabular}{rr|}
76.9 & 70.4 \\
101.8 & 49.0 \\
81.2 & 46.0 \\
50.3 & 42.7 \\
87.8 & 47.2 \\
\end{tabular} & $\begin{array}{l}01.1 \\
12.6 \\
13.5 \\
10.0 \\
12.4\end{array}$ \\
\hline 8.0 & $\begin{array}{l}\text { Rinde } \\
\text { Splint } \\
\text { Mitte } \\
\text { Kern } \\
\text {. Holz }\end{array}$ & $\begin{array}{l}2.1 \\
2.5 \\
3.1 \\
2.4 \\
\end{array}$ & $\begin{array}{l}27.1 \\
42.4 \\
40.6 \\
40.2 \\
41.7\end{array}$ & 4 & $\begin{array}{l}\overline{42.2} \\
39.0 \\
38.2 \\
40.9\end{array}$ & $\begin{array}{l}30.8 \\
11 i .7 \\
25.4 \\
61.7 \\
23.3 \\
\end{array}$ & \begin{tabular}{|l|}
51.8 \\
56.1 \\
48.6 \\
12.5 \\
50.0 \\
\end{tabular} & $\begin{array}{r}4 \overrightarrow{1 .} .1 \\
3.5 .6 \\
0.1 \\
35.8\end{array}$ & $\begin{array}{l}65.7 \\
57.0 \\
54.5 \\
23.7 \\
54.3\end{array}$ & $\begin{array}{ll}78.9 & 75.6 \\
98.5 & 47.4 \\
89.2 & 45.1 \\
52.7 & 43.4 \\
91.7 & 46.4 \\
\end{array}$ & $\begin{array}{r}64.2 \\
10.6 \\
10.0 \\
7.4 \\
10.1 \\
\end{array}$ \\
\hline 5.0 & $\begin{array}{l}\text { Pinde } \\
\text { Splint } \\
\text { II. u. K. } \\
\text { Hol\% }\end{array}$ & $\begin{array}{l}-2.1 \\
3.5 \\
2.6 \\
\end{array}$ & $\begin{array}{l}30.0 \\
41.3 \\
39.0 \\
41.2\end{array}$ & 20.4 & $\begin{array}{l}-\overline{11.1} \\
37.4 \\
40.7\end{array}$ & $\begin{array}{l}30.9 \\
15.4 \\
29.1 \\
18.8\end{array}$ & $\begin{array}{l}49.9 \\
58.1 \\
46.0 \\
54.8\end{array}$ & $\begin{array}{l}-\overline{-} \\
43.5 \\
33.5 \\
40.5\end{array}$ & $\begin{array}{l}62.5 \\
58.5 \\
54.1 \\
57.4 \\
\end{array}$ & $\begin{array}{ll}79.9 & 81.8 \\
99.4 & 47.3 \\
85.0 & 44.6 \\
96.0 & 46.6 \\
\end{array}$ & $\begin{array}{l}63.3 \\
12.7 \\
12.7 \\
12.7\end{array}$ \\
\hline 23.2 & $\begin{array}{l}\text { Rinde } \\
\text { Holz }\end{array}$ & $\overrightarrow{2.3}$ & $\begin{array}{l}30.6 \\
44.4\end{array}$ & & 45.2 & $\begin{array}{l}28.1 \\
18.7\end{array}$ & $\begin{array}{l}52.3 \\
52.8\end{array}$ & $\overline{36.1}$ & $\begin{array}{l}67.1 \\
54.3\end{array}$ & \begin{tabular}{l|l|}
82.9 & 84.2 \\
97.2 & 48.6
\end{tabular} & $\begin{array}{r}63.6 \\
8.7\end{array}$ \\
\hline 6.3 & Holz & 3.3 & 37.8 & 24.2 & 37.5 & 24.1 & 54.7 & 41.4 & 59.1 & $92.5 \quad 42.4$ & 10.9 \\
\hline ih & wg. m. N: & & 38.5 & 24.7 & - & 23.8 & 51.5 & - & 57.2 & $90.0 \quad 57.9$ & 33.5 \\
\hline ähr. & $\mathrm{wg} . \mathrm{m} . \mathrm{Nat}$ & & 37.3 & 24.0 & - & 20.2 & 5.5 .8 & - & 60.0 & $93.1 \quad 62.2$ & 40.0 \\
\hline & zer Stan & & 43.4 & 27.8 & 41.7 & 27.4 & 44.8 & 30.9 & - & 89.2 & - \\
\hline
\end{tabular}


Kiefer.

Alter 70 Jahre.

4. März 1882.

Höhe $24 \mathrm{~m}$. Kronenansatz $13 \mathrm{~m}$. Inhalt $0.918 \mathrm{~cm}$. Wasser $38.0 \%$. Substanz $26.9 \mathrm{ccm}$.

\begin{tabular}{|c|c|c|c|c|c|c|c|c|c|c|c|c|}
\hline \multirow{3}{*}{ 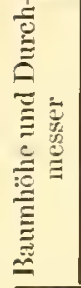 } & \multirow{3}{*}{ Baumtheil } & \multirow{3}{*}{ 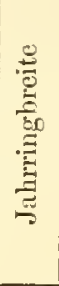 } & \multicolumn{3}{|c|}{$\begin{array}{c}\text { Organische Substanz } \\
\text { in } 100 \text { Raumtheilen } \\
\text { frischen Holzes }\end{array}$} & \multirow{3}{*}{$\stackrel{\Xi}{\Xi}$} & \multicolumn{3}{|c|}{ Wassergehalt } & \multicolumn{2}{|c|}{$\begin{array}{l}\text { Speeifisches } \\
\text { Gewicht }\end{array}$} & \multirow{3}{*}{ 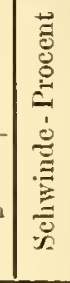 } \\
\hline & & & \multirow{2}{*}{ Gramme } & \multicolumn{2}{|c|}{ Raumtheile } & & \multicolumn{2}{|c|}{ in 100 Raumtheil. } & \multirow{2}{*}{$\begin{array}{c}\text { aof } \\
100 \mathrm{Ge}- \\
\text { wichts- } \\
\text { Lin- } \\
\text { heiten }\end{array}$} & \multirow{2}{*}{ frisch } & \multirow{2}{*}{ trocken } & \\
\hline & & & & trocken & imbibirt & & $\operatorname{im}_{\text {Ganzen }}$ & $\begin{array}{l}\text { in lüss, } \\
\text { Zustand }\end{array}$ & & & & \\
\hline a & $\mathrm{b}$ & e & d & $\mathrm{e}$ & f & $g$ & $\mathrm{~h}$ & $\mathrm{i}$ & $\mathrm{k}$ & 1 & $\mathrm{~m}$ & $\mathrm{n}$ \\
\hline $\begin{array}{l}1.5 \\
- \\
- \\
36.0\end{array}$ & $\begin{array}{l}\text { Splint } \\
\text { Mitte } \\
\text { Kerm } \\
\text {. Holz }\end{array}$ & $\begin{array}{l}-7 \\
1.1 \\
3.0 \\
6.7 \\
2.7\end{array}$ & $\begin{array}{l}40.8 \\
42.9\end{array}$ & $\begin{array}{l}26.1 \\
27.5\end{array}$ & $\overline{450}$ & $\begin{array}{l}39.1 \\
14.4 \\
45.3 \\
61.1 \\
38.7\end{array}$ & $\begin{array}{l}48.1 \\
56.6 \\
27.7 \\
12.8 \\
33.8\end{array}$ & $\begin{array}{r}40.6 \\
14.2 \\
0.3 \\
19.8\end{array}$ & & $\begin{array}{r}68.1 \\
101.8 \\
69.9 \\
23.6 \\
76.7\end{array}$ & $\begin{array}{l}53.6 \\
51.0 \\
46.5 \\
45.2 \\
47.7\end{array}$ & $\begin{array}{r}62.8 \\
11.5 \\
9.2 \\
9.7 \\
10.2\end{array}$ \\
\hline $\begin{array}{l}4.6 \\
- \\
\overline{2} \\
29.3\end{array}$ & $\begin{array}{l}\text { Rinde } \\
\text { Splint } \\
\text { Mlitte } \\
\text { Kern } \\
\text {. Holz }\end{array}$ & $\begin{array}{l}-\overline{1.2} \\
2.7 \\
4.9 \\
2.5\end{array}$ & $\begin{array}{l}23.0 \\
46.7 \\
43.7 \\
37.5 \\
43.3\end{array}$ & & $\overline{46.5}$ & $\begin{array}{l}36.3 \\
13.8 \\
41.3 \\
63.9 \\
36.2\end{array}$ & $\begin{array}{l}49.0 \\
56.2 \\
30.7 \\
12.0 \\
36.1\end{array}$ & $\begin{array}{r}3 \overline{9} .7 \\
16.7 \\
0.4 \\
22.3\end{array}$ & & $\begin{array}{r}72.0 \\
102.9 \\
74.4 \\
49.5 \\
79.4\end{array}$ & $\begin{array}{l}60.9 \\
53.3 \\
50.4 \\
42.1 \\
49.3\end{array}$ & $\begin{array}{l}62.1 \\
12.4 \\
13.3 \\
10.9 \\
12.3\end{array}$ \\
\hline $\begin{array}{c}7.7 \\
- \\
- \\
25.0\end{array}$ & $\begin{array}{l}\text { Pinde } \\
\text { Splint } \\
\text { llitte } \\
\text { Kern } \\
\text {. Holz }\end{array}$ & $\begin{array}{l}- \\
1.2 \\
2.8 \\
4.3 \\
2.3\end{array}$ & $\begin{array}{l}39.0 \\
40.9\end{array}$ & & & $\begin{array}{l}38.8 \\
17.1 \\
48.0 \\
62.7 \\
38.9\end{array}$ & $\begin{array}{l}47.2 \\
55.5 \\
26.2 \\
12.3 \\
34.9\end{array}$ & $\begin{array}{r}40.4 \\
13.3 \\
0.3 \\
21.6\end{array}$ & $\begin{array}{l}68.5 \\
56.6 \\
39.4 \\
24.1 \\
46.0\end{array}$ & $\begin{array}{l}69.0 \\
98.2 \\
66.5 \\
51.3 \\
75.8\end{array}$ & $\begin{array}{l}60.4 \\
43.2 \\
44.3 \\
43.3 \\
45.7\end{array}$ & $\begin{array}{r}134.0 \\
11.5 \\
9.2 \\
10.0 \\
10.4\end{array}$ \\
\hline $\begin{array}{c}10.8 \\
- \\
\overline{-} \\
22.7\end{array}$ & $\begin{array}{l}\text { Rinde } \\
\text { Splint } \\
\text { litte } \\
\text { Kem } \\
\text {. Holz }\end{array}$ & \begin{tabular}{|l|}
- \\
1.6 \\
2.4 \\
4.2 \\
2.5
\end{tabular} & $\begin{array}{l}42.4 \\
39.8 \\
39.5 \\
41.1\end{array}$ & & & $\begin{array}{l}39.7 \\
15.1 \\
43.6 \\
62.2 \\
32.9\end{array}$ & $\begin{array}{l}5.8 \\
7.7 \\
0.9 \\
2.5 \\
0.8\end{array}$ & $\begin{array}{r}\overline{42.7} \\
18.1 \\
0.4 \\
2 \overline{7} .1\end{array}$ & $\begin{array}{l}6.9 \\
7.6 \\
3.7 \\
4.0 \\
9.8\end{array}$ & $\begin{array}{r}68.5 \\
100.1 \\
70.7 \\
52.0 \\
81.9\end{array}$ & $\begin{array}{l}60.8 \\
47.8 \\
45.6 \\
44.0 \\
46.4\end{array}$ & $\begin{array}{l}62.7 \\
11.3 \\
12.7 \\
10.4 \\
11.4\end{array}$ \\
\hline 13.9 & $\begin{array}{l}\text { Rinde } \\
\text { Sinlint } \\
\text { Mlitte } \\
\text { Kern } \\
\text {. Holz }\end{array}$ & $\begin{array}{l}- \\
2.0 \\
2.7 \\
3.1 \\
2.5\end{array}$ & $\begin{array}{l}24.4 \\
41.6 \\
41.3 \\
39.0 \\
41.0\end{array}$ & $\begin{array}{l}15.6 \\
26.7 \\
26.5 \\
25.0 \\
26.3\end{array}$ & $\overline{41.4}$ & $\begin{array}{l}38.1 \\
15.7 \\
24.8 \\
62.8 \\
26.7\end{array}$ & $\begin{array}{l}46.3 \\
57.6 \\
48.7 \\
12.2 \\
47.0\end{array}$ & $\begin{array}{r}-\overline{42.9} \\
35.5 \\
0.2 \\
33.3\end{array}$ & $\begin{array}{l}65.5 \\
58.1 \\
54.1 \\
23.7 \\
58.4\end{array}$ & $\begin{array}{l}70.7 \\
99.2 \\
90.0 \\
51.2 \\
89.0\end{array}$ & $\begin{array}{l}67.1 \\
47.0 \\
46.3 \\
42.5 \\
45.9\end{array}$ & $\begin{array}{r}63.6 \\
11.6 \\
10.8 \\
8.1 \\
10.8\end{array}$ \\
\hline 17.0 & $\begin{array}{l}\text { Rinde } \\
\text { splint } \\
\text { M. 11. K. } \\
\text {. Holz }\end{array}$ & $\begin{array}{l}- \\
2.3 \\
3.2 \\
2.7\end{array}$ & $\begin{array}{l}26.3 \\
39.5 \\
40.4 \\
39.8 \\
\end{array}$ & $\begin{array}{l}16.9 \\
25.3 \\
25.9 \\
25.5 \\
\end{array}$ & $\begin{array}{c}- \\
39.2 \\
38.8 \\
39.0 \\
\end{array}$ & $\begin{array}{l}35.5 \\
13.6 \\
35.9 \\
20.2 \\
\end{array}$ & $\begin{array}{l}47.6 \\
61.1 \\
38.2 \\
54.3 \\
\end{array}$ & $\begin{array}{l}\overline{47.2} \\
25.3 \\
40.8 \\
\end{array}$ & $\begin{array}{l}64.4 \\
60.7 \\
48.6 \\
57.7 \\
\end{array}$ & $\begin{array}{r}73.9 \\
100.6 \\
78.6 \\
94.1 \\
\end{array}$ & $\begin{array}{l}67.2 \\
43.7 \\
42.7 \\
43.4 \\
\end{array}$ & $\begin{array}{r}150.8 \\
9.5 \\
5.3 \\
8.3 \\
\end{array}$ \\
\hline$\overline{7.5}$ & $\begin{array}{l}\text { Rinde } \\
\text { Sllint } \\
\text { M. u. K. } \\
\text { Holz }\end{array}$ & \begin{tabular}{|l|}
- \\
2.2 \\
1.6 \\
2.0 \\
\end{tabular} & $\begin{array}{l}30.0 \\
40.2 \\
37.5 \\
39.7\end{array}$ & $\begin{array}{l}19.2 \\
25.8 \\
24.1 \\
25.4\end{array}$ & $4 \overline{0.0}$ & $\begin{array}{l}30.9 \\
10.4 \\
25.8 \\
13.2 \\
\end{array}$ & $\begin{array}{l}49.9 \\
63.8 \\
50.1 \\
61.4\end{array}$ & $\begin{array}{l}49.6 \\
38.1 \\
47.7\end{array}$ & $\begin{array}{l}62.4 \\
61.4 \\
57.2 \\
60.7 \\
\end{array}$ & $\begin{array}{r}79.9 \\
104.0 \\
8 \% .6 \\
101.1\end{array}$ & $\begin{array}{l}79.2 \\
43.3 \\
41.0 \\
42.9 \\
\end{array}$ & $\begin{array}{r}62.1 \\
7.2 \\
8.5 \\
7.4 \\
\end{array}$ \\
\hline $\begin{array}{r}23.2 \\
1.5\end{array}$ & $\begin{array}{l}\text { Rinde } \\
\text { Holz }\end{array}$ & $\overline{1.5}$ & $\begin{array}{l}28.1 \\
35.8\end{array}$ & $\begin{array}{l}18.0 \\
22.6\end{array}$ & $3 \overline{5} .0$ & $\begin{array}{l}35.6 \\
25.7\end{array}$ & $\begin{array}{l}46.4 \\
51.7\end{array}$ & $\overline{39.3}$ & $\begin{array}{l}62.3 \\
59.6\end{array}$ & $\begin{array}{l}74.5 \\
86.9\end{array}$ & $\begin{array}{l}67.9 \\
38.3\end{array}$ & $\begin{array}{r}58.7 \\
8.0\end{array}$ \\
\hline \multicolumn{3}{|c|}{ 2jithr. ZNr.m. Nadeln } & 37.8 & 23.6 & - & 3 & 49.1 & - & 56.0 & 5.9 & 55.6 & 32.0 \\
\hline \multicolumn{3}{|c|}{ 1jähr. Zws. m. Nadeln } & 36.2 & 23.2 & 二 & 23.7 & 53.1 & - & 59.4 & 89.3 & 62.4 & 41.9 \\
\hline \multicolumn{3}{|c|}{ Ganzer Stam } & .0 & 26.9 & 40.3 & 35.1 & 83.0 & 24.6 & - & 80.0 & - & - \\
\hline
\end{tabular}




\section{Kiefer.}

Alter 75 Jahre.

14. MIärz 1881 .

Höhe $22 \mathrm{~m}$. Kronenausatz, - m. Inhalt $0.882 \mathrm{~cm}$. Wasser $35.1^{\circ} 0$. Substanz $28.7 \mathrm{ccm}$.

\begin{tabular}{|c|c|c|c|c|c|c|c|c|c|c|c|c|}
\hline \multirow{3}{*}{ 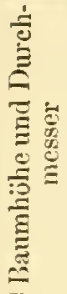 } & \multirow{3}{*}{ Baumtheil } & \multirow{3}{*}{ 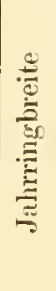 } & \multicolumn{3}{|c|}{$\begin{array}{l}\text { Organische Substanz } \\
\text { in } 100 \text { Raumtheiley } \\
\text { frischen Holzes }\end{array}$} & \multirow{3}{*}{$\stackrel{\Xi}{\stackrel{E}{E}}$} & \multicolumn{3}{|c|}{ Wassergehalt } & \multicolumn{2}{|c|}{$\begin{array}{l}\text { Specifisches } \\
\text { Gewicht }\end{array}$} & \multirow{3}{*}{ 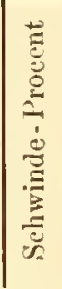 } \\
\hline & & & \multirow{2}{*}{ Gramme } & \multicolumn{2}{|c|}{ Raumtheile } & & \multicolumn{2}{|c|}{ in 100 Raumtheil. } & \multirow{2}{*}{$\begin{array}{l}\text { auf } \\
100 \mathrm{Ge}- \\
\text { wichts- } \\
\text { Ein- } \\
\text { heiten }\end{array}$} & \multirow{2}{*}{ friseh } & \multirow{2}{*}{ trockeu } & \\
\hline & & & & trockes & imbibirt & & $\lim _{\text {Ganzen }}$ & $\begin{array}{l}\text { tu tuss. } \\
\text { astand }\end{array}$ & & & & \\
\hline a & b & c & $d$ & $\mathrm{e}$ & $\mathrm{f}$ & $\mathrm{g}$ & $h_{1}$ & $\mathrm{i}$ & $\mathrm{k}$ & 1 & $\mathrm{~m}$ & $n$ \\
\hline 35.0 & $\begin{array}{l}\text { Rinde } \\
\text { Splint } \\
\text { Mitte } \\
\text { Kern } \\
\text {. Holz }\end{array}$ & $\begin{array}{l}-1.0 \\
5.7 \\
8.1 \\
2.7\end{array}$ & $\begin{array}{l}46.8 \\
45.8 \\
53.0 \\
48.0\end{array}$ & $\begin{array}{l}30.0 \\
29.3 \\
34.0 \\
30.8\end{array}$ & $\begin{array}{l}\overline{-} \\
46.5 \\
43.9 \\
50.9 \\
46.5\end{array}$ & $\begin{array}{l}19.6 \\
56.3 \\
48.9 \\
39.5\end{array}$ & $\begin{array}{l}50.4 \\
14.4 \\
17.1 \\
29.7\end{array}$ & $\begin{array}{c}\overline{-} \overline{3} .9 \\
(-0.2) \\
0.8 \\
14.0\end{array}$ & $\begin{array}{l}\overline{51.8} \\
23.8 \\
24.4 \\
39.1\end{array}$ & $\begin{array}{l}97.2 \\
60.2 \\
70.1 \\
77.7\end{array}$ & $\begin{array}{l}5- \\
54.3 \\
51.1 \\
60.0 \\
55.6\end{array}$ & \begin{tabular}{|l}
$-\overline{-}$ \\
13.7 \\
10.2 \\
11.6 \\
11.9
\end{tabular} \\
\hline $\begin{array}{l}4.6 \\
- \\
- \\
30.0\end{array}$ & $\begin{array}{l}\text { Rinde } \\
\text { Splint } \\
\text { Nitte } \\
\text { Kern } \\
\text {. Holz }\end{array}$ & \begin{tabular}{|l|}
- \\
1.0 \\
3.3 \\
5.5 \\
2.2
\end{tabular} & $\begin{array}{l}45.7 \\
42.9 \\
40.6 \\
43.8\end{array}$ & $\begin{array}{l}29.3 \\
27.5 \\
26.0 \\
28.1\end{array}$ & $\begin{array}{l}4 \overline{-} \\
45.4 \\
41.2 \\
3.5 \\
42.7\end{array}$ & $\begin{array}{l}-\overline{20.5} \\
57.4 \\
60.5 \\
40.6\end{array}$ & $\begin{array}{l}5 \overline{50.2} \\
1.1 .1 \\
13.5 \\
31.3\end{array}$ & $\begin{array}{r}-\overline{4} .1 \\
0.4 \\
1.0 \\
16.7\end{array}$ & $\begin{array}{l}-\overline{52.3} \\
24.7 \\
25.0 \\
41.7\end{array}$ & $\begin{array}{l}7 \overline{-} \\
95.9 \\
57.0 \\
54.1 \\
75.1\end{array}$ & $\begin{array}{l}\overline{4} .9 \\
49.7 \\
42.6 \\
50.9\end{array}$ & $\begin{array}{r}1- \\
16.8 \\
13.7 \\
1.7 \\
13.8\end{array}$ \\
\hline $\begin{array}{l}7.7 \\
\overline{-} \\
26.0\end{array}$ & $\begin{array}{l}\text { Rinde } \\
\text { Splint } \\
\text { Mlitte } \\
\text { Kern } \\
\text {.1Iolz }\end{array}$ & \begin{tabular}{|l|}
-1.3 \\
4.0 \\
3.7 \\
2.5
\end{tabular} & $\begin{array}{l}- \\
44.3 \\
44.0 \\
41.5 \\
43.7\end{array}$ & $\begin{array}{l}28.4 \\
28.2 \\
26.6 \\
28.0\end{array}$ & $\overline{44.0}$ & $\begin{array}{l}-\overline{22.9} \\
49.4 \\
59.7 \\
37.5\end{array}$ & $\begin{array}{l}\overline{48.7} \\
22.4 \\
19.7 \\
34.5\end{array}$ & $\begin{array}{r}-\overline{-} \\
83.1 \\
8.3 \\
1.0 \\
19.9\end{array}$ & $\begin{array}{l}5 \overline{-} \\
52.4 \\
33.7 \\
24.8 \\
44.1\end{array}$ & $\begin{array}{l}-\overline{-} \\
93.0 \\
66.4 \\
55.2 \\
78.2\end{array}$ & $\begin{array}{l}- \\
52.5 \\
50.5 \\
46.9 \\
50.9\end{array}$ & $\begin{array}{l}-1 \\
15.7 \\
12.9 \\
11.5 \\
14.1\end{array}$ \\
\hline 21.5 & $\begin{array}{l}\text { Iinde } \\
\text { Splint } \\
\text { Mitte } \\
\text { Kerm } \\
\% .11 \text { lolz }\end{array}$ & \begin{tabular}{|l|}
- \\
1.6 \\
3.5 \\
4.6 \\
2.7
\end{tabular} & $\begin{array}{l}-\overline{4} .9 \\
41.5 \\
42.5 \\
41.8\end{array}$ & $\begin{array}{l}- \\
29.4 \\
28.5 \\
27.2 \\
28.7\end{array}$ & $\begin{array}{l}45.6 \\
42.7 \\
40.3 \\
43.6\end{array}$ & $\begin{array}{l}-\overline{-} \\
20.3 \\
47.2 \\
58.5 \\
34.0\end{array}$ & $\begin{array}{l}5 \overline{0.8} \\
24.3 \\
14.3 \\
37.3\end{array}$ & $\begin{array}{l}3 \overline{4} .1 \\
10.1 \\
1.2 \\
22.4\end{array}$ & $\begin{array}{l}-\overline{52.3} \\
32.8 \\
25.2 \\
4.5 .4\end{array}$ & $\begin{array}{l}96.2 \\
68.8 \\
56.8 \\
82.1\end{array}$ & $\begin{array}{l}55.0 \\
49.6 \\
48.0 \\
52.8\end{array}$ & $\begin{array}{l}1- \\
16.4 \\
10.2 \\
11.4 \\
14.3\end{array}$ \\
\hline 17.0 & $\begin{array}{l}\text { linde } \\
\text { Splint } \\
\text { Mitte } \\
\text { Kern } \\
\text { K. Holz }\end{array}$ & \begin{tabular}{|l|}
- \\
2.0 \\
3.4 \\
4.1 \\
2.8
\end{tabular} & $\begin{array}{l}-\overline{4} \\
45.6 \\
43.3 \\
43.3 \\
41.9\end{array}$ & $\begin{array}{l}-\overline{2} .2 \\
27.7 \\
27.7 \\
28.8\end{array}$ & $\begin{array}{l}\overline{-} \\
45.3 \\
41.5 \\
40.8 \\
41.1\end{array}$ & $\begin{array}{l}\overline{17.9} \\
23.0 \\
59.2 \\
24.7\end{array}$ & $\begin{array}{l}5 \overline{-} \\
49.9 \\
13.1 \\
46.5\end{array}$ & $\left|\begin{array}{c}- \\
36.8 \\
35.5 \\
(-0.2) \\
31.2\end{array}\right|$ & $\begin{array}{c}-\overline{-} \\
53.7 \\
53.3 \\
23.2 \\
50.9\end{array}$ & $\begin{array}{l}\overrightarrow{98.5} \\
92.6 \\
56.4 \\
91.4\end{array}$ & $\begin{array}{l}\overline{5.3 .1} \\
52.8 \\
47.1 \\
52.1\end{array}$ & $\begin{array}{r}1- \\
14.0 \\
18.0 \\
8.0 \\
13.9\end{array}$ \\
\hline 12.5 & $\begin{array}{l}\text { Rinde } \\
\text { Splint } \\
\text { M. u. K. } \\
\therefore \text { Holz }\end{array}$ & $\begin{array}{l}- \\
3.0 \\
2.9 \\
3.0\end{array}$ & $\begin{array}{l}-\overline{46.8} \\
47.8 \\
46.8\end{array}$ & $\begin{array}{l}\overline{30.0} \\
30.6 \\
30.0\end{array}$ & $\begin{array}{l}-\overline{4} .5 \\
45.9 \\
46.3\end{array}$ & $\begin{array}{l}-\overline{13.1} \\
13.2 \\
15.8\end{array}$ & $\begin{array}{l}-\overline{56.9} \\
26.2 \\
54.2\end{array}$ & $\begin{array}{l}-\overline{4} \\
10.4 \\
37.9\end{array}$ & $\begin{array}{l}\overline{54.9} \\
35.4 \\
53.6\end{array}$ & $\begin{array}{r}-\overline{103.7} \\
74.0 \\
101.0\end{array}$ & $\begin{array}{l}- \\
51.4 \\
52.0 \\
54.2\end{array}$ & $\begin{array}{r}\overline{-} \\
14.1 \\
8.0 \\
13.6\end{array}$ \\
\hline 0.1 & $\begin{array}{l}\text { Rinde } \\
\text { Holz }\end{array}$ & $\overline{2.4}$ & $4 \overline{2} .1$ & $\overline{27.0}$ & $\overline{41.9}$ & $\overline{18.3}$ & $\overline{54.7}$ & $\overline{39.8}$ & $\overline{56.5}$ & $9 \overline{6} .8$ & $\overline{48.6}$ & $\sqrt{13.3}$ \\
\hline \multicolumn{3}{|c|}{ 1-2jühr. Zwg. m. Nad. } & 37.2 & 23.9 & - & 21.7 & 54.4 & - & 59.3 & 91.6 & - & - \\
\hline \multicolumn{3}{|c|}{ Ganzer Stamm } & 44.8 & 28.7 & 43.0 & 36.2 & 35.1 & 20.8 & - & 79.9 & - & - \\
\hline
\end{tabular}




\section{Kiefer.}

Alter 75 Jahre.

19. Ilai 1881.

Höhe $22 \mathrm{~m}$. Kronenansatz $14.5 \mathrm{~m}$. InJaIt $1.095 \mathrm{~cm}$. Wasser $82.5^{\circ} \mathrm{o}$. Substanz $26.9 \mathrm{ccm}$.

\begin{tabular}{|c|c|c|c|c|c|c|c|c|c|c|c|c|}
\hline \multirow{3}{*}{ 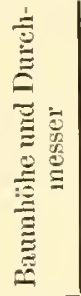 } & \multirow{3}{*}{ Bauntheil } & \multirow{3}{*}{ 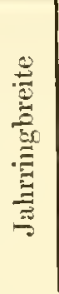 } & \multicolumn{3}{|c|}{$\begin{array}{l}\text { Organische Substanz } \\
\text { in } 100 \text { Ranmtheilen } \\
\text { frischen Holzes }\end{array}$} & \multirow{3}{*}{ 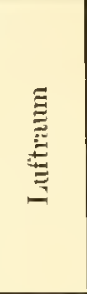 } & \multicolumn{3}{|c|}{ Wassergelualt } & \multicolumn{2}{|c|}{$\begin{array}{c}\text { Specifisches } \\
\text { Gewicht }\end{array}$} & \multirow{3}{*}{ 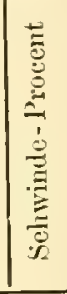 } \\
\hline & & & \multirow{2}{*}{ Gramme } & \multicolumn{2}{|c|}{ Raumtheile } & & \multicolumn{2}{|c|}{ in 100 Raumtheil. } & \multirow{2}{*}{$\mid \begin{array}{c}\text { aul' } \\
100 \text { Ge- } \\
\text { wichts- } \\
\text { Ein- } \\
\text { heiten }\end{array}$} & \multirow{2}{*}{ frisch } & \multirow{2}{*}{ trocken } & \\
\hline & & & & & & & Ganz & & & & & \\
\hline a & $\mathrm{b}$ & c & d & $\mathrm{e}$ & $\mathrm{f}$ & $g$ & $l_{1}$ & $\bar{i}$ & $\mathrm{k}$ & 1 & $\bar{m}$ & 11 \\
\hline $\begin{array}{l}1.5 \\
\bar{E} \\
\overline{-} \\
40.0\end{array}$ & $\begin{array}{l}\text { Rind } \\
\text { Spli } \\
\text { MLitt } \\
\text { Ker } \\
\text {. II }\end{array}$ & $\left|\begin{array}{l|}- \\
0.6 \\
3.3 \\
6.3 \\
2.8\end{array}\right|$ & $\begin{array}{l}45.7 \\
43.8 \\
41.1 \\
43.3\end{array}$ & $\begin{array}{l}19.6 \\
29.3 \\
28.1 \\
26.3 \\
27.7\end{array}$ & $\begin{array}{l}45.4 \\
42.2 \\
34.9 \\
41.8\end{array}$ & $\begin{array}{l}59.0 \\
59.9 \\
40.1\end{array}$ & $\begin{array}{l}54.0 \\
58.3 \\
32.6 \\
13.8 \\
32.2\end{array}$ & $\begin{array}{r}\overline{42.2} \\
18.5 \\
1.2 \\
18.1\end{array}$ & $\begin{array}{l}6.9 .9 \\
56.0 \\
42.7 \\
25.2 \\
42.6\end{array}$ & $\begin{array}{r}84.6 \\
104.0 \\
76.4 \\
54.9 \\
75.5\end{array}$ & $\begin{array}{l}58.9 \\
52.4 \\
49.0 \\
46.0 \\
48.8\end{array}$ & $\begin{array}{l}48.0 \\
12.7 \\
10.7 \\
10.8 \\
11.1\end{array}$ \\
\hline $\begin{array}{c}4.6 \\
- \\
- \\
- \\
33.0\end{array}$ & $\begin{array}{l}\text { Rinde } \\
\text { Splint } \\
\text { Mitte } \\
\text { línu } \\
\text { IIolz }\end{array}$ & \begin{tabular}{l|}
-9 \\
0.9 \\
3.7 \\
6.2 \\
2.6
\end{tabular} & $\begin{array}{l}82.3 \\
41.6 \\
41.2 \\
39.7 \\
40.9 \\
\end{array}$ & & $\begin{array}{l}1- \\
41.5 \\
39.6 \\
37.7 \\
39.6\end{array}$ & $\begin{array}{l}24.4 \\
23.6 \\
51.3 \\
61.0 \\
45.2 \\
\end{array}$ & $\begin{array}{l}54.9 \\
49.6 \\
22.8 \\
13.5 \\
28.6\end{array}$ & $\begin{array}{r}-\overline{34.9} \\
9.1 \\
1.3 \\
15.2\end{array}$ & $\begin{array}{l}63.0 \\
54.2 \\
35.1 \\
25.3 \\
41.2\end{array}$ & $\begin{array}{l}87.2 \\
91.4 \\
63.5 \\
53.2 \\
69.5\end{array}$ & $\begin{array}{l}60.9 \\
47.9 \\
46.6 \\
41.1 \\
46.2\end{array}$ & $\begin{array}{l}47.0 \\
12.8 \\
11.5 \\
10.0 \\
11.4\end{array}$ \\
\hline $\begin{array}{l}7.7 \\
- \\
\overline{-} \\
28.0\end{array}$ & $\begin{array}{l}\text { Rinde } \\
\text { Splint } \\
\text { Jitte } \\
\text { liern } \\
\text {.Holz }\end{array}$ & \begin{tabular}{|l|}
1.0 \\
2.9 \\
6.4 \\
2.5 \\
\end{tabular} & $\begin{array}{l}30.5 \\
39.9 \\
40.3 \\
40.9 \\
40.8 \\
\end{array}$ & $\begin{array}{l}19.5 \\
25.6 \\
25.8 \\
26.2 \\
25.8 \\
\end{array}$ & $\begin{array}{l}-\overline{39.7} \\
38.7 \\
38.8 \\
39.0\end{array}$ & $\begin{array}{l}26.4 \\
29.0 \\
50.5 \\
60.4 \\
45.3 \\
\end{array}$ & $\begin{array}{l}54.1 \\
45.4 \\
23.7 \\
13.4 \\
28.9\end{array}$ & $\begin{array}{r}-5 \\
31.8 \\
10.8 \\
0.8 \\
15.7\end{array}$ & $\begin{array}{l}63.9 \\
53.2 \\
37.1 \\
24.7 \\
41.8 \\
\end{array}$ & $\begin{array}{l}84.6 \\
85.8 \\
64.0 \\
54.8 \\
69.2\end{array}$ & $\begin{array}{l}64.2 \\
44.9 \\
47.5 \\
45.7 \\
46.1 \\
\end{array}$ & $\begin{array}{l}52.5 \\
11.2 \\
15.4 \\
10.5 \\
12.6\end{array}$ \\
\hline $\begin{array}{c}\overline{10.8} \\
- \\
- \\
24.5\end{array} \mid$ & $\begin{array}{l}\text { Rinde } \\
\text { Splint } \\
\text { Mitte } \\
\text { Keru } \\
\text { Holz }\end{array}$ & \begin{tabular}{|l|}
1.4 \\
2.7 \\
4.0 \\
2.4
\end{tabular} & $\begin{array}{l}3: .2 \\
41.2 \\
41.9 \\
42.4 \\
41.7\end{array}$ & & & & $\begin{array}{l}53.2 \\
48.0 \\
32.1 \\
13.2 \\
34.3\end{array}$ & $\begin{array}{r}-1.5 \\
18.6 \\
0.1 \\
20.4\end{array}$ & $\begin{array}{l}61.5 \\
63.8 \\
42.8 \\
23.8 \\
45.1\end{array}$ & $\begin{array}{l}86.4 \\
89.2 \\
74.0 \\
5.5 .6 \\
76.0\end{array}$ & $\begin{array}{l}67.2 \\
48.2 \\
47.5 \\
46.1 \\
47.4\end{array}$ & $\begin{array}{r}.50 . \\
14.7 \\
11.0 \\
8.0 \\
12.0\end{array}$ \\
\hline $\begin{array}{c}13.9 \\
- \\
- \\
\overline{19.0}\end{array}$ & $\begin{array}{l}\text { Rinde } \\
\text { Splint } \\
\text { Mlitte } \\
\text { Kern } \\
\text {. Holz }\end{array}$ & \begin{tabular}{|l|}
- \\
1.8 \\
3.5 \\
3.0 \\
2.6
\end{tabular} & $\begin{array}{l}3 \% .0 \\
42.7 \\
43.2 \\
41.0 \\
42.7 \\
\end{array}$ & $\begin{array}{l}22.4 \\
27.4 \\
27.7 \\
26.3 \\
27.4\end{array}$ & $\begin{array}{l}42.5 \\
41.6 \\
38.7 \\
41.9\end{array}$ & $\begin{array}{l}20.5 \\
25.0 \\
84.6 \\
61.2 \\
31.5 \\
\end{array}$ & $\begin{array}{l}57.1 \\
47.6 \\
37.7 \\
12.4 \\
41.1\end{array}$ & $\begin{array}{c}-\overline{32.5} \\
29.8 \\
(-0.2) \\
26.6\end{array}$ & $\begin{array}{l}62.0 \\
52.7 \\
46.6 \\
28.8 \\
49.0\end{array}$ & $\begin{array}{l}92.1 \\
90.8 \\
90.9 \\
58.4 \\
83.8 \\
\end{array}$ & $\begin{array}{l}72.4 \\
50.9 \\
48.8 \\
43.6 \\
49.3\end{array}$ & $\begin{array}{r}51.7 \\
16.0 \\
10.6 \\
6.0 \\
13.4\end{array}$ \\
\hline $\begin{array}{c}1.0 \\
- \\
13.0\end{array}$ & $\begin{array}{l}\text { Rinde } \\
\text { Splint } \\
\text { II. u. K. } \\
\text {. 1lolz }\end{array}$ & \begin{tabular}{|l|}
- \\
1.8 \\
2.7 \\
2.2
\end{tabular} & $\begin{array}{l}41.6 \\
42.7\end{array}$ & $\begin{array}{l}22.9 \\
27.7 \\
26.7 \\
27.4\end{array}$ & $\begin{array}{l}\overrightarrow{42.9} \\
40.1 \\
41.9\end{array}$ & $\begin{array}{l}19.6 \\
19.3 \\
32.7 \\
25.2 \\
\end{array}$ & $\begin{array}{l}57.5 \\
53.0 \\
40.6 \\
47.4\end{array}$ & $\begin{array}{l}3 \overline{37.8} \\
27.2 \\
32.9 \\
\end{array}$ & $\begin{array}{l}61.6 \\
54.2 \\
49.4 \\
52.7\end{array}$ & $\begin{array}{l}93.2 \\
96.2 \\
82.2 \\
90.1\end{array}$ & $\begin{array}{l}80.4 \\
48.9 \\
47.7 \\
48.5 \\
\end{array}$ & $\begin{array}{l}12 . \\
12 .\end{array}$ \\
\hline $\begin{array}{r}20.1 \\
6.5 \\
\end{array}$ & $\begin{array}{l}\text { Rinde } \\
\text { I oIz }\end{array}$ & 2.0 & $\begin{array}{l}38.0 \\
40.6 \\
\end{array}$ & & 40.3 & $\begin{array}{l}16.2 \\
16.8 \\
\end{array}$ & $\begin{array}{l}59.4 \\
57.2 \\
\end{array}$ & $\overline{42.9}$ & $\begin{array}{l}61.0 \\
58.5 \\
\end{array}$ & $\begin{array}{l}97.4 \\
97.8 \\
\end{array}$ & $\begin{array}{l}\$ 6.6 \\
46.7 \\
\end{array}$ & $\begin{array}{l}56.0 \\
13.0\end{array}$ \\
\hline-4 & $\pi$ & d. & 46.9 & 30.1 & - & 14.7 & 55.2 & - & 54.1 & 02.1 & $6 \div .2$ & L. \\
\hline & & & $\$ 1.9$ & 20.0 & 40.4 & 40.0 & $\Rightarrow$ & 19.0 & - & 74.4 & - & - \\
\hline
\end{tabular}


Kiefer.

Alter 70 Jahre.

9. Juli 1881.

Höhe $24 \mathrm{~m}$. Kromenansatz $15 \mathrm{~m}$. Inhait $1.542 \mathrm{~cm}$. Wasser $39.8^{\circ} \%$. Substanz $27.1 \mathrm{ecm}$.

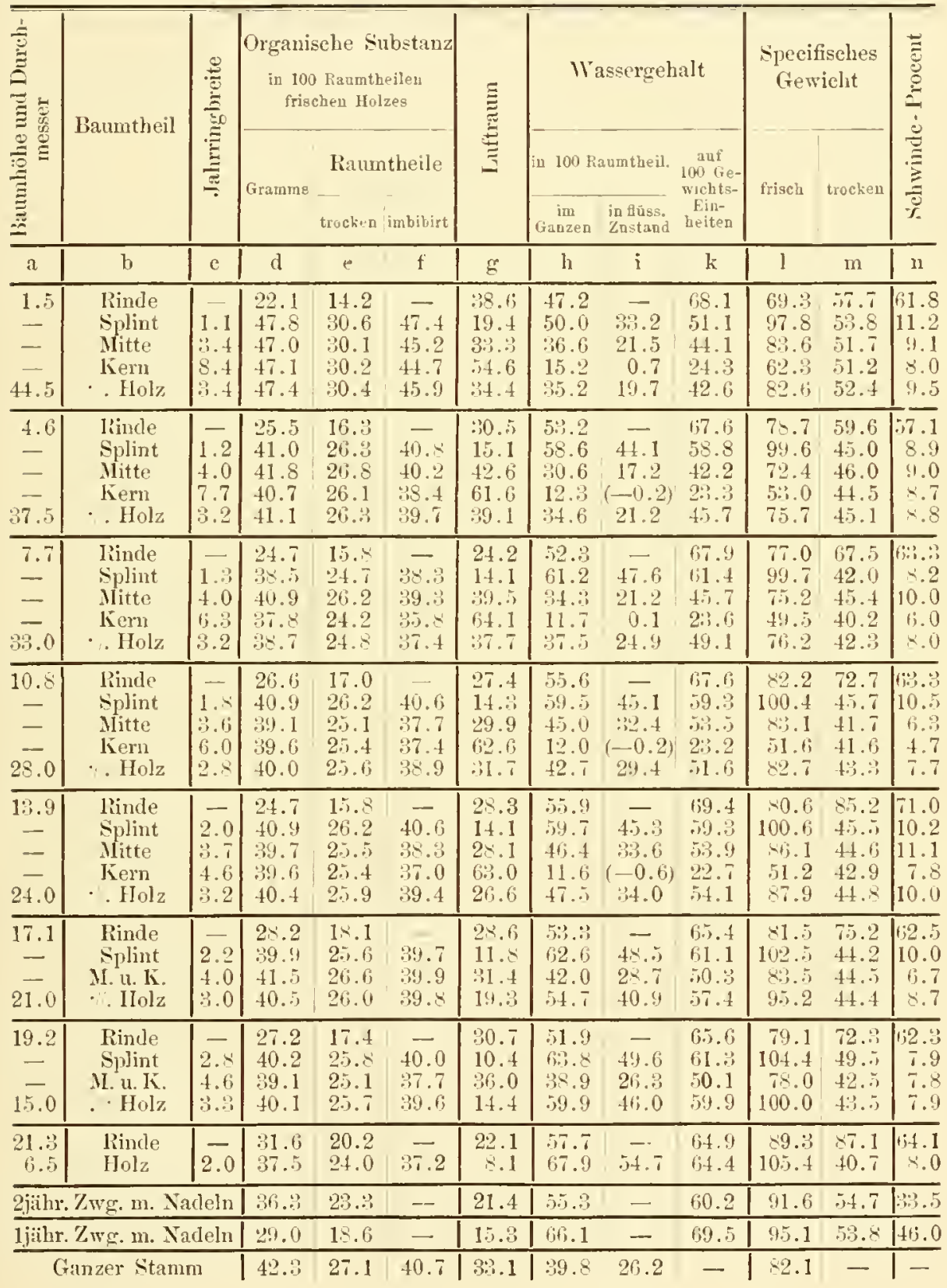


Kiefer.

Alter 70 Jahre.

12. October 1881.

Höhe $24 \mathrm{~m}$. Kronenansatz $18 \mathrm{~m}$. Inhalt $0.873 \mathrm{~cm}$. Wasser $39.5 \%$. Substanz $26.5 \mathrm{ccm}$.

\begin{tabular}{|c|c|c|c|c|c|c|c|c|c|c|c|c|}
\hline \multirow{3}{*}{ 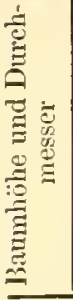 } & \multirow{3}{*}{ Banmtheil } & \multirow{3}{*}{ 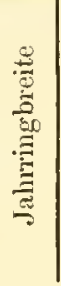 } & \multicolumn{3}{|c|}{$\begin{array}{l}\text { Organische Substanz } \\
\text { in } 100 \text { Raumtheilen } \\
\text { frisclien Holzes }\end{array}$} & \multirow{3}{*}{$\underset{\Xi}{\stackrel{\Xi}{\Xi}}$} & \multicolumn{3}{|c|}{ Wassergehalt } & \multicolumn{2}{|c|}{$\begin{array}{l}\text { Specifisches } \\
\text { Gewicht }\end{array}$} & \multirow{3}{*}{ 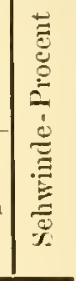 } \\
\hline & & & \multirow{2}{*}{ Gramme } & \multicolumn{2}{|c|}{ Raumtheile } & & \multicolumn{2}{|c|}{ in 100 Raumtheil. } & \multirow{2}{*}{$\begin{array}{c}\text { auf } \\
\text { I00 Ge- } \\
\text { wichts- } \\
\text { Ein- } \\
\text { beiten }\end{array}$} & \multirow{2}{*}{ frisch } & \multirow{2}{*}{ trocken } & \\
\hline & & & & trocken & imbibirt & & 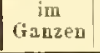 & $\begin{array}{l}\text { in flūss. } \\
\text { Zustand }\end{array}$ & & & & \\
\hline a & b) & $\mathrm{c}$ & d & e & f & $\mathrm{g}$ & h & $\mathrm{i}$ & k & 1 & $\mathrm{~m}$ & 11 \\
\hline $\begin{array}{l}1.5 \\
- \\
\overline{-} \\
32.5\end{array}$ & $\begin{array}{l}\text { Rinde } \\
\text { Splint } \\
\text { Hitte } \\
\text { Kern } \\
\text { Holz }\end{array}$ & $\begin{array}{l}-7 \\
1.8 \\
4.0 \\
6.0 \\
2.1\end{array}$ & $\begin{array}{l}19.6 \\
41.8 \\
41.1 \\
43.2 \\
42.0\end{array}$ & $\begin{array}{l}12.6 \\
26.8 \\
26.3 \\
27.7 \\
26.9\end{array}$ & $\begin{array}{l}- \\
41.5 \\
39.5 \\
41.0 \\
40.9\end{array}$ & $\begin{array}{l}41.0 \\
54.7 \\
34.9\end{array}$ & $\begin{array}{l}49.9 \\
56.9 \\
32.7 \\
17.6 \\
38.2\end{array}$ & $\begin{array}{r}- \\
42.2 \\
19.5 \\
4.3 \\
24.2\end{array} \mid$ & $\begin{array}{l}70.7 \\
57.7 \\
44.3 \\
29.0 \\
47.6\end{array}$ & $\begin{array}{l}69.5 \\
98.7 \\
73.8 \\
60.8 \\
80.2\end{array}$ & $\begin{array}{l}50.0 \\
47.0 \\
45.4 \\
47.4 \\
46.6\end{array}$ & $\begin{array}{r}50.7 \\
11.1 \\
9.3 \\
8.9 \\
9.9\end{array}$ \\
\hline \begin{tabular}{l|}
4.6 \\
- \\
- \\
28.5
\end{tabular} & $\begin{array}{l}\text { Rinde } \\
\text { Splint } \\
\text { Mitte } \\
\text { Kern } \\
\text { \%. I Iolz }\end{array}$ & \begin{tabular}{l|}
- \\
0.8 \\
3.8 \\
6.0 \\
2.0
\end{tabular} & \begin{tabular}{|l|}
18.3 \\
38.5 \\
40.6 \\
36.9 \\
38.7
\end{tabular} & $\begin{array}{l}11.7 \\
24.7 \\
26.0 \\
23.6 \\
24.8\end{array}$ & $\begin{array}{l}- \\
38.3 \\
39.0 \\
34.7 \\
37.4\end{array}$ & $\begin{array}{l}8.4 \\
3.1 \\
8.1 \\
5.3 \\
9.7\end{array}$ & $\begin{array}{l}49.9 \\
52.2 \\
35.9 \\
11.1 \\
35.5\end{array}$ & $\left|\begin{array}{c}- \\
38.6 \\
22.9 \\
(-0.2) \\
22.9\end{array}\right|$ & $\begin{array}{l}72.7 \\
57.5 \\
46.9 \\
24.1 \\
47.8\end{array}$ & $\begin{array}{l}68.2 \\
90.7 \\
76.5 \\
48.0 \\
74.2 \\
\end{array}$ & $\begin{array}{l}46.7 \\
42.9 \\
45.5 \\
41.0 \\
43.2 \\
\end{array}$ & $\begin{array}{r}60.7 \\
10.2 \\
10.8 \\
9.9 \\
10.3 \\
\end{array}$ \\
\hline $\begin{array}{l}7.7 \\
- \\
\overline{2} \\
25.5\end{array}$ & $\begin{array}{l}\text { Rinde } \\
\text { splint } \\
\text { Mlitte } \\
\text { Kern } \\
\text {. Holz }\end{array}$ & \begin{tabular}{|l|}
1.0 \\
3.6 \\
5.5 \\
2.1
\end{tabular} & \begin{tabular}{|l|}
26.3 \\
40.7 \\
38.1 \\
38.5 \\
39.4
\end{tabular} & $\begin{array}{l}24.4 \\
24.7 \\
25.2\end{array}$ & 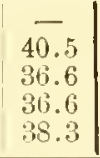 & $\begin{array}{l}40.1 \\
22.2 \\
41.3 \\
63.3 \\
37.0\end{array}$ & $\begin{array}{l}43.0 \\
51.7 \\
34.3 \\
12.0 \\
37.8\end{array}$ & $\begin{array}{r}-\overline{3} \\
37.3 \\
22.1 \\
0.1 \\
24.7\end{array}$ & & $\begin{array}{l}69.3 \\
92.4 \\
72.4 \\
50.5 \\
77.2\end{array}$ & $\begin{array}{l}61.9 \\
45.3 \\
42.9 \\
43.9 \\
44.1\end{array}$ & $\mid \begin{array}{l}57.6 \\
10.4 \\
11.2 \\
10.4 \\
10.6\end{array}$ \\
\hline $\begin{array}{c}10.8 \\
- \\
- \\
23.0\end{array}$ & $\begin{array}{l}\text { Rinde } \\
\text { splint } \\
\text { Mitte } \\
\text { Kerrin } \\
\text { Holz }\end{array}$ & $\begin{array}{l}\overrightarrow{1.2} \\
4.2 \\
4.0 \\
2.1\end{array}$ & \begin{tabular}{|l|}
23.2 \\
42.4 \\
40.6 \\
40.2 \\
41.5 \\
\end{tabular} & $\begin{array}{l}25.8 \\
26.6\end{array}$ & $\begin{array}{c}- \\
42.2 \\
39.0 \\
38.2 \\
40.4\end{array}$ & $\begin{array}{l}37.7 \\
20.2 \\
33.9 \\
61.7 \\
31.4\end{array}$ & $\begin{array}{l}47.4 \\
52.6 \\
40.1 \\
12.5 \\
42.0\end{array}$ & $\begin{array}{r}- \\
37.6 \\
27.1 \\
0.1 \\
28.2\end{array}$ & & 83.5 & $\begin{array}{l}62.0 \\
49.7 \\
46.6 \\
45.3 \\
47.1\end{array}$ & $\begin{array}{l}62.5 \\
11.5 \\
12.8 \\
11.8 \\
11.8\end{array}$ \\
\hline $\begin{array}{c}13.9 \\
- \\
\overline{-} \\
19.0\end{array}$ & $\begin{array}{l}\text { Minde } \\
\text { splint } \\
\text { Mitte } \\
\text { Kern } \\
\% \text { Holz }\end{array}$ & \begin{tabular}{l|}
-1.4 \\
2.8 \\
3.8 \\
2.2
\end{tabular} & \begin{tabular}{|l|}
23.3 \\
44.5 \\
42.5 \\
42.4 \\
43.5 \\
\end{tabular} & $\begin{array}{l}28.5 \\
27.2 \\
27.2 \\
27.9\end{array}$ & \begin{tabular}{l|}
44.2 \\
40.8 \\
40.3 \\
42.4
\end{tabular} & $\begin{array}{l}37.5 \\
20.6 \\
30.2 \\
56.0 \\
29.1\end{array}$ & $\begin{array}{l}47.6 \\
50.9 \\
42.6 \\
16.8 \\
43.0\end{array}$ & \begin{tabular}{r|}
- \\
35.2 \\
29.0 \\
3.7 \\
28.5
\end{tabular} & $\begin{array}{l}67.2 \\
53.3 \\
50.0 \\
28.3 \\
49.7\end{array}$ & $\begin{array}{l}59.2 \\
86.5\end{array}$ & $\begin{array}{l}63.1 \\
51.0 \\
47.8 \\
46.1 \\
49.1\end{array}$ & $\begin{array}{r}63.1 \\
12.6 \\
11.0 \\
8.0 \\
11.4\end{array}$ \\
\hline $\begin{array}{c}17.0 \\
\overline{-} \\
14.0\end{array}$ & $\begin{array}{l}\text { Rinule } \\
\text { splint } \\
\text { M1. u. K. } \\
\text {. Ilolz }\end{array}$ & \begin{tabular}{|l|}
1.4 \\
3.1 \\
2.0
\end{tabular} & $\begin{array}{l}24.8 \\
42.7 \\
42.4 \\
42.6\end{array}$ & $\begin{array}{l}15.9 \\
27.4 \\
27.2 \\
27.3\end{array}$ & $\begin{array}{l}42.5 \\
40.8 \\
41.8\end{array}$ & $\begin{array}{l}34.5 \\
20.2 \\
31.8 \\
23.9\end{array}$ & $\begin{array}{l}49.6 \\
52.4 \\
41.0 \\
48.8\end{array}$ & $\begin{array}{l}-\overline{37.3} \\
27.4 \\
34.3\end{array}$ & $\begin{array}{l}66.7 \\
55.1 \\
49.2 \\
53.4 \\
\end{array}$ & $\begin{array}{l}74.4 \\
95.1 \\
83.4 \\
91.4\end{array}$ & $\begin{array}{l}63.7 \\
49.0 \\
48.4 \\
48.8\end{array}$ & $\begin{array}{l}61.1 \\
12.8 \\
12.4 \\
12.7 \\
\end{array}$ \\
\hline $\begin{array}{c}\overline{20.1} \\
\overline{-} \\
9.5\end{array}$ & $\begin{array}{l}\text { Rinde } \\
\text { Splint } \\
\text { 11. u. Ki. } \\
\text {. Holz }\end{array}$ & \begin{tabular}{|l|}
-1.9 \\
2.0 \\
1.9
\end{tabular} & $\begin{array}{l}27.6 \\
42.4 \\
42.2 \\
42.4\end{array}$ & $\begin{array}{l}17.7 \\
27.2 \\
27.1 \\
27.2\end{array}$ & $\begin{array}{l}42.2 \\
40.7 \\
41.6\end{array}$ & $\begin{array}{l}30.9 \\
19.4 \\
27.9 \\
22.1\end{array}$ & $\begin{array}{l}51.4 \\
53.4 \\
45.0 \\
50.7\end{array}$ & $\begin{array}{l}-\overline{-} \\
38.4 \\
31.4 \\
36.3\end{array}$ & $\begin{array}{l}65.0 \\
55.7 \\
51.6 \\
54.5\end{array}$ & $\begin{array}{l}79.0 \\
95.8 \\
87.2 \\
93.1\end{array}$ & $\begin{array}{l}66.9 \\
48.6 \\
47.7 \\
48.3 \\
\end{array}$ & $\begin{array}{l}57.9 \\
12.6 \\
11.4 \\
12.3\end{array}$ \\
\hline $\begin{array}{r}23.2 \\
3.0\end{array}$ & $\begin{array}{l}\text { Rinde } \\
\text { llolz }\end{array}$ & 2.0 & $\begin{array}{l}30.0 \\
43.0\end{array}$ & $\begin{array}{l}19.2 \\
27.5 \\
\end{array}$ & $\overline{42.6}$ & $\begin{array}{l}23.6 \\
12.4 \\
\end{array}$ & $\begin{array}{l}57.2 \\
60.1\end{array}$ & $\overline{45.0}$ & $\begin{array}{l}65.7 \\
55.7\end{array}$ & $\begin{array}{r}87.2 \\
103.1 \\
\end{array}$ & $\begin{array}{l}77.9 \\
49.4 \\
\end{array}$ & $\begin{array}{l}61.6 \\
12.9 \\
\end{array}$ \\
\hline \multicolumn{3}{|c|}{ 1-2jïln.Zweige m.Ndln. } & 40.5 & 26.0 & - & 16.2 & 57.8 & - & 58.8 & 98.3 & 67.1 & 39.5 \\
\hline \multicolumn{3}{|c|}{ Gauzer Stanm } & 41.3 & 26.5 & 39.8 & 1.0 & 39.5 & 26.2 & - & 80.8 & - & - \\
\hline
\end{tabular}


Fichte.

Alter 80 Jahre.

2. Januar 1882.

Höhe $28 \mathrm{~m}$. Kronenansatz $14 \mathrm{~m}$. Inhalt $1.786 \mathrm{~cm}$. Wasser $40.7 \%$. Substanz 20.9 eem.

\begin{tabular}{|c|c|c|c|c|c|c|c|c|c|c|c|c|}
\hline \multirow{3}{*}{ 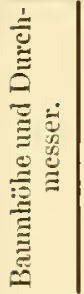 } & \multirow{3}{*}{ Baumtheil } & \multirow{3}{*}{ 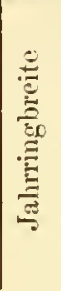 } & \multicolumn{3}{|c|}{$\begin{array}{l}\text { Organische Substanz } \\
\text { in } 100 \text { Ranmtbeileu } \\
\text { frischen Holzes }\end{array}$} & \multirow{3}{*}{ 芯 } & \multicolumn{3}{|c|}{ IV assergehalt } & \multicolumn{2}{|c|}{$\begin{array}{l}\text { Specifisches } \\
\text { Gewieht }\end{array}$} & \multirow{3}{*}{ 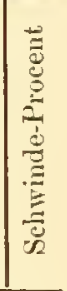 } \\
\hline & & & \multirow{2}{*}{ Gramme } & \multicolumn{2}{|c|}{ Ranmtheile } & & \multicolumn{2}{|c|}{ in 100 Ranmtleil. } & \multirow{2}{*}{$\begin{array}{l}\text { anf } \\
100 \mathrm{Ge}- \\
\text { wichts- } \\
\text { Ein- } \\
\text { beiten }\end{array}$} & \multirow{2}{*}{ frisch } & \multirow{2}{*}{ trocken } & \\
\hline & & & & ocke & ibe & & & & & & & \\
\hline it & $b$ & e & d & e & f & $\mathrm{g}$ & h & $\mathrm{i}$ & k & 1 & in & n \\
\hline $\begin{array}{l}1.5 \\
- \\
- \\
11.0\end{array}$ & $\begin{array}{l}\text { Splint } \\
\text { Jitte } \\
\text { Fern } \\
\text { IIolz }\end{array}$ & $\begin{array}{l}1.8 \\
2.4 \\
4.0 \\
2.8\end{array}$ & $\begin{array}{l}32.2 \\
32.5 \\
32.1 \\
32.0\end{array}$ & & $\begin{array}{l}- \\
33.0 \\
33.8 \\
30.4 \\
32.8\end{array}$ & $\begin{array}{r}26.4 \\
8.3 \\
53.6 \\
69.6 \\
40.4 \\
\end{array}$ & $\begin{array}{l}54.3 \\
71.1 \\
25.6 \\
10.5 \\
39.1\end{array}$ & $\begin{array}{c}-58.7 \\
13.1 \\
(-1.4) \\
26.8\end{array}$ & $\begin{array}{l}64.4 \\
68.8 \\
41.1\end{array}$ & $\begin{array}{r}81.4 \\
103.3 \\
78.1 \\
41.6 \\
71.1\end{array}$ & $\begin{array}{l}72.0 \\
37.0 \\
36.5 \\
34.3 \\
36.1\end{array}$ & $\begin{array}{r}58.2 \\
12.9 \\
11.2 \\
9.5 \\
11.4\end{array}$ \\
\hline 4.6 & $\begin{array}{l}\text { linde } \\
\text { splint } \\
\text { Mlitte } \\
\text { liem } \\
\text { 11olz }\end{array}$ & \begin{tabular}{|l|}
1.8 \\
2.9 \\
3.8 \\
2.8
\end{tabular} & $\begin{array}{l}26.4 \\
35.5 \\
31.6 \\
30.8 \\
30.0\end{array}$ & & $\begin{array}{l}\overline{-} \\
36.8 \\
32.3 \\
30.8 \\
33.9\end{array}$ & $\begin{array}{l}28.0 \\
13.5 \\
57.7 \\
69.7 \\
42.5\end{array}$ & $\begin{array}{l}55.1 \\
63.8 \\
22.1 \\
10.6 \\
36.3\end{array}$ & $\begin{array}{l}50.2 \\
10.0 \\
-1.2 \\
23.6\end{array}$ & $\begin{array}{l}25.6 \\
52.4\end{array}$ & $\begin{array}{l}81 . .5 \\
99.8 \\
53.7\end{array}$ & $\begin{array}{l}73.8 \\
40.0 \\
35.5 \\
34.9 \\
37.2\end{array}$ & $\begin{array}{l}6+.2 \\
11 . .3 \\
11.2 \\
11.8 \\
11.4\end{array}$ \\
\hline $\begin{array}{l}7.7 \\
- \\
- \\
4.5\end{array}$ & & \begin{tabular}{|l|}
1.9 \\
2.8 \\
4.7 \\
3.1
\end{tabular} & $\begin{array}{l}30.2 \\
32.1\end{array}$ & & & $\begin{array}{l}25.5 \\
10.7 \\
5.5 .7 \\
1.9 .9 \\
42.0\end{array}$ & $\begin{array}{l}57.6 \\
67.3 \\
24.4 \\
10.8 \\
37.4\end{array}$ & $\left|\begin{array}{c}54.1 \\
12.5 \\
(-0.8) \\
2.5 .1\end{array}\right|$ & $\begin{array}{l}26.2 \\
53.8\end{array}$ & $\begin{array}{l}57.5 \\
41.0 \\
69.5\end{array}$ & $\begin{array}{l}74.7 \\
39.0 \\
34.5 \\
33.4 \\
35.9\end{array}$ & $\begin{array}{r}6 i t .8 \\
12.0 \\
9.8 \\
9.6 \\
10.6\end{array}$ \\
\hline $\begin{array}{c}\overline{10.8} \\
- \\
- \\
32.0\end{array}$ & $\begin{array}{l}\text { lincle } \\
\text { splint } \\
\text { Mlitte } \\
\text { liem } \\
\text {. Holz }\end{array}$ & \begin{tabular}{|l|}
2.2 \\
2.7 \\
4.2 \\
3.1
\end{tabular} & $\begin{array}{l}27.5 \\
35.2 \\
32.6 \\
31.5 \\
31.2\end{array}$ & $\begin{array}{l}17.6 \\
22.6 \\
20.9 \\
20.2 \\
21.3\end{array}$ & $\begin{array}{l}33.4 \\
31.8 \\
34.1\end{array}$ & $\begin{array}{l}29.8 \\
10.3 \\
50.3 \\
68.2 \\
41.1\end{array}$ & $\begin{array}{l}53.1 \\
67.1 \\
2.8 \\
11.6 \\
37.6\end{array}$ & $\begin{array}{c}5 . \\
53.6 \\
16.3 \\
(-0.5) \\
24.8\end{array}$ & $\begin{array}{l}26.9 \\
53.1\end{array}$ & $\begin{array}{l}61.4 \\
43.1 \\
70.8\end{array}$ & $\begin{array}{l}7.7 \\
89.9 \\
36.5 \\
3.5 .0 \\
37.3\end{array}$ & $\begin{array}{l}14.5 \\
11.7 \\
10.5 \\
10.1 \\
10.8\end{array}$ \\
\hline $3 \overline{0.0}$ & $\begin{array}{l}\text { Rinde } \\
\text { splint } \\
\text { Mitte } \\
\text { Kern } \\
\text {. Holz } \\
\end{array}$ & \begin{tabular}{|l|}
2.0 \\
2.7 \\
4.1 \\
$\therefore .1$
\end{tabular} & $\begin{array}{l}29.4 \\
3.3 .3 \\
32.0 \\
31.0 \\
82.5 \\
32.5 \\
\end{array}$ & & $\begin{array}{l}-\overline{-} \\
32.1 \\
31.8 \\
33.3\end{array}$ & $\begin{array}{r}31.3 \\
9.8 \\
41.2 \\
17.6 \\
36.3 \\
\end{array}$ & $\begin{array}{l}49.9 \\
68.9 \\
3 . .3 \\
12.5 \\
42.9\end{array}$ & $\begin{array}{r}-76.1 \\
2: 3.0 \\
0.6 \\
\because 0.4\end{array}$ & $\begin{array}{l}62.9 \\
67.4 \\
52.4 \\
2.8 \\
57.1 \\
\end{array}$ & $\begin{array}{r}78.3 \\
102.2 \\
67.3 \\
43.5 \\
75.4\end{array}$ & $\begin{array}{l}7.2 .1 \\
36.6 \\
3.5 .0 \\
35.0 \\
35.6\end{array}$ & $\begin{array}{r}59.2 \\
9.2 \\
4.4 \\
11.4 \\
9.5 \\
\end{array}$ \\
\hline $\begin{array}{l}17.0 \\
- \\
- \\
25.5\end{array}$ & $\begin{array}{l}\text { linde } \\
\text { Splint } \\
\text { Mlitte } \\
\text { Kern } \\
\text { \%. Holz }\end{array}$ & \begin{tabular}{|l|}
2.7 \\
2.7 \\
4.1 \\
3.3
\end{tabular} & $\begin{array}{l}28.9 \\
32.4 \\
32.4 \\
34.0 \\
32.9\end{array}$ & $\begin{array}{l}18.5 \\
20.8 \\
20.8 \\
21.8 \\
21.1\end{array}$ & $\begin{array}{l}- \\
33.3 \\
33.8 \\
34.9 \\
3 * .8\end{array}$ & $\begin{array}{l}32.6 \\
9.9 \\
34.8 \\
63.8 \\
31.7\end{array}$ & $\begin{array}{l}48.9 \\
69.3 \\
44.4 \\
14.4 \\
47.2\end{array}$ & $\begin{array}{l}56.8 \\
31.9 \\
1.3 \\
34.5\end{array}$ & $\begin{array}{l}62.9 \\
68.1 \\
57.8 \\
29.8 \\
59.0\end{array}$ & $\begin{array}{r}77.8 \\
101.7 \\
76.8 \\
48.4 \\
80.1 \\
\end{array}$ & $\begin{array}{l}199.2 \\
39.8 \\
37.0 \\
38.4 \\
37.8 \\
\end{array}$ & $\begin{array}{l}5.8 \\
12.0 \\
12.5 \\
11.4 \\
11.9\end{array}$ \\
\hline 20.0 & $\begin{array}{l}\text { Mitte } \\
\text { Kern } \\
\text {. H1ol } \%\end{array}$ & \begin{tabular}{|l|}
3.0 \\
3.5 \\
3.6 \\
3.4
\end{tabular} & $\begin{array}{l}28.6 \\
33.0 \\
32.7 \\
33.6 \\
33.0 \\
\end{array}$ & $\begin{array}{l}18.3 \\
21.1 \\
21.0 \\
21.5 \\
21.1\end{array}$ & $\begin{array}{l}-\overline{-} \\
3: .8 \\
33.6 \\
34.4 \\
33.8\end{array}$ & $\begin{array}{r}3 \% .8 \\
9.4 \\
29.0 \\
69.8 \\
25.3\end{array}$ & $\begin{array}{l}47.9 \\
69.5 \\
50.0 \\
15.2 \\
53.6\end{array}$ & \begin{tabular}{r|}
- \\
56.8 \\
37.4 \\
2.8 \\
40.9
\end{tabular} & $\begin{array}{l}62.8 \\
67.8 \\
60.5 \\
31.1 \\
61.9\end{array}$ & $\begin{array}{r}76.5 \\
102.5 \\
82.7 \\
45.8 \\
86.6\end{array}$ & $\begin{array}{l}68.7 \\
37.2 \\
36.9 \\
36.7 \\
37.0\end{array}$ & $\begin{array}{r}58.3 \\
11.4 \\
11.5 \\
8.3 \\
10.8\end{array}$ \\
\hline $\begin{array}{l}23.2 \\
- \\
- \\
15.0\end{array}$ & $\begin{array}{l}\text { Rinde } \\
\text { splint } \\
\text { Mitte } \\
\text { Kienn } \\
\text { Holz } \\
\end{array}$ & \begin{tabular}{|l|}
2.8 \\
3.5 \\
5.0 \\
3.5
\end{tabular} & $\begin{array}{l}30.0 \\
32.2 \\
82.9 \\
37.0 \\
83.0\end{array}$ & $\begin{array}{l}19.2 \\
20.6\end{array}$ & $\begin{array}{l}- \\
32.9 \\
33.8 \\
37.9 \\
33.8 \\
\end{array}$ & $\begin{array}{l}34.5 \\
10.0 \\
35.2 \\
61.3 \\
24.3 \\
\end{array}$ & $\begin{array}{l}46.3 \\
69.4 \\
43.7 \\
15.0 \\
54.6\end{array}$ & $\begin{array}{r}57.1 \\
81.0 \\
0.8 \\
41.9\end{array}$ & $\begin{array}{l}60.7 \\
68.3 \\
57.0 \\
28.8 \\
62.3\end{array}$ & $\begin{array}{r}76.8 \\
101.6 \\
76.6 \\
52.0 \\
87.6\end{array}$ & $\begin{array}{l}68.0 \\
37.1 \\
37.5 \\
40.3 \\
37.7\end{array}$ & $\mid \begin{array}{r}5.5 .9 \\
13.5 \\
12.3 \\
8.2 \\
12.1 \\
12.3\end{array}$ \\
\hline $\begin{array}{r}26.3 \\
8.0\end{array}$ & $\begin{array}{l}\text { Rinde } \\
\text { lloly }\end{array}$ & $4-1$ & $\begin{array}{l}32.3 \\
36.6 \\
\end{array}$ & $\begin{array}{l}20.7 \\
23.5 \\
\end{array}$ & $\overline{37.6}$ & $\begin{array}{l}35.8 \\
15.9\end{array}$ & $\begin{array}{l}+4.0 \\
60.6\end{array}$ & $\overline{46.5}$ & $\begin{array}{l}57.6 \\
62.4\end{array}$ & $\begin{array}{l}76.3 \\
97.2 \\
\end{array}$ & $\begin{array}{l}70.3 \\
41.0 \\
\end{array}$ & $\begin{array}{l}31.0 \\
10.8\end{array}$ \\
\hline-2 jäl & Zw eige 11 & Nad. & 40.3 & 25.8 & - & 28.4 & 45.8 & 二 & 53.2 & 86.1 & 5.5 .2 & $20 \% .9$ \\
\hline & 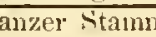 & & 32.6 & 20.9 & 3 & 38.4 & 40.7 & 28.2 & $\overline{-}$ & 79.3 & - & - \\
\hline
\end{tabular}


Fichte.

Alter 70 Jahre.

4. März 1\$82.

Höle $28 \mathrm{~m}$. Kronenansatz $12 \mathrm{~m}$. Inhalt $1.416 \mathrm{em}$. Wasser $29.4^{\circ} 0$. Substanz $25.6 \mathrm{cem}$.

\begin{tabular}{|c|c|c|c|c|c|c|c|c|c|c|c|c|}
\hline \multirow{3}{*}{ 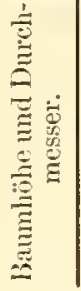 } & \multirow{3}{*}{ Bauntheil } & \multirow{3}{*}{ 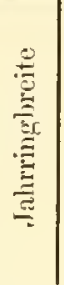 } & \multicolumn{3}{|c|}{$\begin{array}{c}\text { Organisehe Substanz } \\
\text { in } 100 \text { Raumtheilen } \\
\text { frischen Holzes }\end{array}$} & \multirow{3}{*}{$\underset{\Xi}{\Xi}$} & \multicolumn{3}{|c|}{ Wassergehalt } & \multicolumn{2}{|c|}{$\begin{array}{c}\text { Specifisches } \\
\text { Gewieht }\end{array}$} & \multirow{3}{*}{ 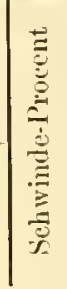 } \\
\hline & & & \multirow{2}{*}{ Gramm } & \multicolumn{2}{|c|}{ Raumtheile } & & \multicolumn{2}{|c|}{ in 100 Ranmtheil. } & \multirow{2}{*}{$\begin{array}{c}\text { auf } \\
100 \text { Ge- } \\
\text { wichts- } \\
\text { Ein- } \\
\text { helten }\end{array}$} & \multirow{2}{*}{ fri } & & \\
\hline & & & & trocken & ibirt & & in & $\begin{array}{l}\text { flüss. } \\
\text { ustand }\end{array}$ & & & & \\
\hline$a$ & b & $\mathrm{e}$ & d & e & $\mathrm{f}$ & $g$ & $\mathrm{~h}$ & $\mathrm{i}$ & $\mathrm{k}$ & 1 & $\mathrm{~m}$ & $\mathrm{n}$ \\
\hline 1.5 & $\begin{array}{l}\text { Rinde } \\
\text { Sylint } \\
\text { Jitte } \\
\text { Kern } \\
\text {. Holz }\end{array}$ & $\left|\begin{array}{r}- \\
2.1 \\
3.5 \\
4.0 \\
3.1\end{array}\right|$ & $\begin{array}{l}31.6 \\
40.7 \\
36.4 \\
3.7 .3 \\
38.2 \\
\end{array}$ & $\begin{array}{l}20.2 \\
26.1 \\
23.3 \\
22.6 \\
24.5 \\
\end{array}$ & $\begin{array}{l}4 \overline{1.6} \\
37.5 \\
35.0 \\
39.2 \\
\end{array}$ & $\begin{array}{l}30.9 \\
15.7 \\
57.2 \\
65.0 \\
39.5 \\
\end{array}$ & $\begin{array}{l}45.9 \\
58.2 \\
19.5 \\
12.4 \\
36.0\end{array}$ & $\left|\begin{array}{r}-\overline{42.5} \\
5.5 \\
-1.2) \\
21.3\end{array}\right|$ & $\begin{array}{l}60.7 \\
58.9 \\
34.8 \\
26.0 \\
48.6\end{array}$ & $\begin{array}{l}80.5 \\
98.9 \\
50.9 \\
47.7 \\
74.2\end{array}$ & $\begin{array}{l}71.7 \\
47.5 \\
41.8 \\
39.9 \\
43.7\end{array}$ & $\begin{array}{l}55.9 \\
14.4 \\
11.7 \\
10.1 \\
12.6\end{array}$ \\
\hline $\begin{array}{l}4.6 \\
- \\
- \\
4.5\end{array}$ & $\begin{array}{l}\text { Rinde } \\
\text { Splint } \\
\text { Nlitte } \\
\text { Kern } \\
\text {. Holz }\end{array}$ & \begin{tabular}{|l|}
-1 \\
2.1 \\
3.4 \\
4.3 \\
3.1
\end{tabular} & $\begin{array}{l}30.3 \\
41.0 \\
37.7 \\
35.4 \\
40.1\end{array}$ & & $\begin{array}{l}- \\
45.1 \\
39.5 \\
36.3 \\
41.1\end{array}$ & $\begin{array}{l}2 y .7 \\
16.4 \\
56.6 \\
61.6 \\
38.9\end{array}$ & $\begin{array}{l}50.9 \\
55.4 \\
19.3 \\
15.7 \\
35.4\end{array}$ & $\begin{array}{r}3 \overline{3} .5 \\
4.9 \\
2.1 \\
20.2\end{array}$ & $\begin{array}{l}30.6 \\
46.8\end{array}$ & $\begin{array}{l}51.0 \\
75.5\end{array}$ & $\begin{array}{l}69.2 \\
51.1 \\
41.5 \\
41.0 \\
46.9\end{array}$ & $\begin{array}{l}56.1 \\
13.8 \\
15.4 \\
13.6 \\
14.2\end{array}$ \\
\hline $\begin{array}{l}7.7 \\
-\end{array}$ & $\begin{array}{l}\text { Rinde } \\
\text { Splint } \\
\text { Mitte } \\
\text { Kern } \\
\text {. IIolz } \\
\end{array}$ & \begin{tabular}{|l|}
2.2 \\
3.5 \\
4.9 \\
3.5 \\
\end{tabular} & $\begin{array}{l}31.0 \\
43.5 \\
37.0 \\
37.2 \\
40.1 \\
\end{array}$ & $\begin{array}{l}25.8 \\
25.8 \\
\end{array}$ & $\begin{array}{l}4 \overline{-} \\
41.8 \\
37.9 \\
37.9 \\
41.8 \\
\end{array}$ & \begin{tabular}{|l}
80.1 \\
16.5 \\
56.6 \\
62.1 \\
28.2 \\
\end{tabular} & $\begin{array}{l}49.2 \\
55.8 \\
19.7 \\
14.1 \\
85.9\end{array}$ & $\left|\begin{array}{c}-\overline{3} \\
39.2 \\
5.5 \\
(-0.2) \\
20.4\end{array}\right|$ & $\begin{array}{l}61.4 \\
56.3 \\
34.7 \\
27.5 \\
47.2\end{array}$ & $\begin{array}{l}80.2 \\
99.1 \\
56.7 \\
51.3 \\
76.0\end{array}$ & $\begin{array}{l}74.0 \\
42.9 \\
42.1 \\
42.2 \\
45.4\end{array}$ & $\begin{array}{l}58.1 \\
11.5 \\
12.1 \\
12.0 \\
11.8\end{array}$ \\
\hline 10.4 & $\begin{array}{l}\text { Rinde } \\
\text { splint } \\
\text { Mitte } \\
\text { lieru } \\
\text { Holz }\end{array}$ & $\mid$\begin{tabular}{|l|}
-2.4 \\
3.5 \\
4.4 \\
3.4
\end{tabular} & $\begin{array}{l}31.8 \\
42.6 \\
37.3 \\
37.8 \\
39.8 \\
\end{array}$ & & $\begin{array}{l}\overline{43.7} \\
38.2 \\
38.2 \\
41.0\end{array}$ & $\begin{array}{l}30.8 \\
10.8 \\
47.1 \\
60.6 \\
38.1\end{array}$ & $\begin{array}{l}49.1 \\
62.4 \\
29.0 \\
15.5 \\
41.3 \\
\end{array}$ & $\begin{array}{r}-\overline{46.0} \\
14.7 \\
1.2 \\
25.9 \\
\end{array}$ & $\begin{array}{l}61.1 \\
59.4 \\
49.8 \\
29.3 \\
50.9 \\
\end{array}$ & $\begin{array}{r}80.4 \\
105.0 \\
66.3 \\
52.8 \\
81.2 \\
\end{array}$ & $\begin{array}{l}72.4 \\
49.1 \\
42.8 \\
43.3 \\
45.8 \\
\end{array}$ & $\begin{array}{l}515.7 \\
13.1 \\
15.5 \\
13.9 \\
13.9\end{array}$ \\
\hline $2 \overline{66.0}$ & & \begin{tabular}{|l|}
2.7 \\
4.0 \\
4.2 \\
3.5
\end{tabular} & $\begin{array}{l}30.7 \\
43.7 \\
40.7 \\
39.1 \\
41.6 \\
\end{array}$ & $\begin{array}{l}26.1 \\
25.0 \\
26.7 \\
\end{array}$ & \begin{tabular}{|l|}
44.8 \\
41.7 \\
40.0 \\
42.7 \\
\end{tabular} & $\begin{array}{r}31.6 \\
7.4 \\
31.3 \\
59.4 \\
20.2 \\
\end{array}$ & $\begin{array}{l}48.7 \\
64.6 \\
42.6 \\
15.6 \\
45.1 \\
\end{array}$ & $\begin{array}{r}\overline{4} \\
4 \overline{7} .8 \\
27.0 \\
0.6 \\
29.1 \\
\end{array}$ & $\begin{array}{l}51.1 \\
28.6 \\
52.0 \\
\end{array}$ & $\begin{array}{r}79.4 \\
108.3 \\
83.8 \\
54.7 \\
86.7 \\
\end{array}$ & $\begin{array}{l}71.3 \\
51.1 \\
46.8 \\
44.3 \\
48.0 \\
\end{array}$ & $\begin{array}{l}56.9 \\
14.5 \\
13.0 \\
11.7 \\
13.8\end{array}$ \\
\hline$\overline{17.0}$ & $\begin{array}{l}\text { Rinde } \\
\text { Splint } \\
\text { Mlitte } \\
\text { Kern } \\
\text {. Holz }\end{array}$ & $\left|\begin{array}{l|}2.8 \\
3.1 \\
4.7 \\
3.6\end{array}\right|$ & $\begin{array}{l}30.6 \\
43.8 \\
41.4 \\
39.9 \\
41.9 \\
\end{array}$ & $\begin{array}{l}19.6 \\
27.7 \\
26.5 \\
25.6 \\
26.9 \\
\end{array}$ & \begin{tabular}{|l|}
4.3 \\
12.4 \\
41.0 \\
43.0 \\
\end{tabular} & $\begin{array}{r}34.8 \\
5.0 \\
22.1 \\
57.1 \\
23.8 \\
\end{array}$ & $\begin{array}{l}45.6 \\
66.8 \\
51.4 \\
17.3 \\
49.8\end{array}$ & $\begin{array}{r}-\overline{4} \\
49.7 \\
35.9 \\
1.9 \\
89.2\end{array}$ & $\begin{array}{l}60.0 \\
60.5 \\
55.4 \\
30.3 \\
54.1\end{array}$ & $\begin{array}{r}76.2 \\
109.6 \\
92.8 \\
57.2 \\
91.2\end{array}$ & $\begin{array}{l}6.5 .1 \\
51.0 \\
47.1 \\
45.0 \\
48.3\end{array}$ & $\begin{array}{l}5.5 .4 \\
15.1 \\
122.1 \\
11.5 \\
13.3\end{array}$ \\
\hline $\begin{array}{c}- \\
15.0\end{array}$ & $\begin{array}{l}\text { linde } \\
\text { Spllint } \\
\text { Mitte } \\
\text { Kiern } \\
\text {. Holz }\end{array}$ & \begin{tabular}{|l|}
2.8 \\
3.4 \\
4.4 \\
3.5
\end{tabular} & $\begin{array}{l}30.9 \\
41.0 \\
45.8 \\
42.8 \\
41.2 \\
\end{array}$ & $\begin{array}{l}19.8 \\
28.2 \\
29.3 \\
27.4 \\
28.3 \\
\end{array}$ & \begin{tabular}{l|}
45.1 \\
46.9 \\
41.1 \\
45.5 \\
\end{tabular} & $\begin{array}{r}84.5 \\
5.4 \\
16.4 \\
56.9 \\
20.8 \\
\end{array}$ & $\begin{array}{l}45.7 \\
65.4 \\
54.8 \\
1: 3.7 \\
50.9\end{array}$ & $\begin{array}{c}-\overline{18.9} \\
36.7 \\
(-2.7) \\
39.9\end{array}$ & $\begin{array}{r}59.6 \\
59.8 \\
54.8 \\
24.3 \\
53.5 \\
\end{array}$ & \begin{tabular}{|r}
76.6 \\
$10 ! 1.4$ \\
100.1 \\
56.8 \\
95.1 \\
\end{tabular} & $\begin{array}{l}72.2 \\
53.4 \\
52.7 \\
45.0 \\
51.9 \\
\end{array}$ & $\begin{array}{l}57.1 \\
17.6 \\
13.2 \\
10.7 \\
14.9\end{array}$ \\
\hline $\begin{array}{l}\overline{23.2} \\
\overline{-} \\
9.0\end{array}$ & $\begin{array}{l}\text { Rinde } \\
\text { splint } \\
\text { M. u. K. } \\
\text {. Holz }\end{array}$ & \begin{tabular}{|l|}
2.6 \\
2.7 \\
2.7
\end{tabular} & $\begin{array}{l}29.2 \\
41.9 \\
41.8 \\
42.9\end{array}$ & $\begin{array}{l}18.7 \\
26.8 \\
28.7 \\
27.5\end{array}$ & $\begin{array}{l}12.9 \\
45.9 \\
41.0\end{array}$ & $\begin{array}{l}\because 4.4 \\
5.8 \\
22.8 \\
11.4\end{array}$ & $\begin{array}{l}46.4 \\
67.4 \\
48.5 \\
61.1\end{array}$ & $\begin{array}{l}51.3 \\
31.3 \\
44.6\end{array}$ & $\begin{array}{l}61.6 \\
61.6 \\
52.0 \\
58.8\end{array}$ & $\begin{array}{r}76.1 \\
109.3 \\
98.3 \\
104.0\end{array}$ & $\begin{array}{l}69.4 \\
49.2 \\
50.4 \\
49.6\end{array}$ & $\begin{array}{l}57.9 \\
14.8 \\
11.2 \\
18.6\end{array}$ \\
\hline $26 .: 1$ & $\begin{array}{l}\text { Finde } \\
\text { Holz }\end{array}$ & $\mid \overline{4.0}$ & $\begin{array}{l}45.2 \\
48.6\end{array}$ & $\begin{array}{l}2.5 \\
21.1\end{array}$ & $\overline{49.8}$ & $\begin{array}{l}32.4 \\
15.0\end{array}$ & $\begin{array}{l}45.1 \\
53.9\end{array}$ & $\overline{-2} .2$ & $\begin{array}{l}56.2 \\
.52 .6 \\
\end{array}$ & $\begin{array}{r}80.3 \\
102.5 \\
\end{array}$ & 50.5 & 11.4 \\
\hline \multicolumn{3}{|c|}{ jähr.Zweig m. Nadelı } & 41.7 & 26.7 & - & $31 .: 3$ & 42.0 & $=$ & 50.2 & 93.7 & 37.8 & $\overline{27.9}$ \\
\hline \multirow{2}{*}{\multicolumn{3}{|c|}{ 1jähr.Zweigm. Nadeln }} & 41.9 & 26.8 & - & 31.0 & 42.2 & - & 50.2 & 4.1 & 57.2 & $26 . \overline{7}$ \\
\hline & & & 39.9 & $25.1 i$ & 41.0 & 0 & 329.4 & 4.0 & 一 & 79.3 & - & - \\
\hline
\end{tabular}


Fichte.

Alter 80 Jahre.

14. Må̀z $1 \leq 81$.

Höhe $28 \mathrm{~m}$. Kronenansatz $-\mathrm{m}$. Inhalt $1.395 \mathrm{~cm}$. Wasser $37.9^{\circ} \mathrm{n}$ Substanz $25.6 \mathrm{eem}$.

\begin{tabular}{|c|c|c|c|c|c|c|c|c|c|c|c|c|}
\hline \multirow{3}{*}{ 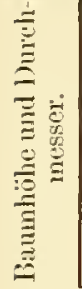 } & \multirow{3}{*}{ Baumtheil } & \multirow{3}{*}{ 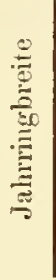 } & \multicolumn{3}{|c|}{$\begin{array}{l}\text { Crgauische Substanz } \\
\text { in } 120 \text { kamtheilen } \\
\text { frischen Holzes }\end{array}$} & \multirow{3}{*}{$\stackrel{\Xi}{\Xi}$} & \multicolumn{3}{|c|}{ Wassergehalt } & \multicolumn{2}{|c|}{$\begin{array}{l}\text { Apecitisches } \\
\text { Gewieht }\end{array}$} & \multirow{3}{*}{ 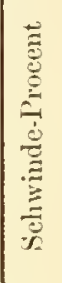 } \\
\hline & & & \multirow{2}{*}{ Gramme } & \multicolumn{2}{|c|}{ Raumtheile } & & \multirow{2}{*}{\multicolumn{3}{|c|}{\begin{tabular}{|c|c} 
is 100 Raumtheil. & $\begin{array}{c}\text { auf } \\
\text { Ito Ge- } \\
\text { wichts }\end{array}$ \\
im in flüss. & $\begin{array}{l}\text { Ein- } \\
\text { Geiten }\end{array}$ \\
Ganzen & Zustand \\
heiten
\end{tabular}}} & & & \\
\hline & & & & trocken & imbibirt & & & & & & & \\
\hline a & b & $\mathrm{e}$ & $\mathrm{d}$ & e & f & $\mathrm{g}$ & h & $\mathrm{i}$ & $\mathrm{k}$ & l & $\mathrm{m}$ & n \\
\hline 1.5 & & & & & & & - & - & 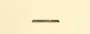 & & . & \\
\hline - & & & 4 & & 7 & 16.8 & 56.5 & 40.5 & 57.7 & 95.1 & 99.9 & 16.7 \\
\hline- & & & & & & & & & 5 & & & 1 \\
\hline 88.0 & $\begin{array}{l}\text { Merm } \\
\text {. Holz }\end{array}$ & $\begin{array}{l}5 . t \\
2 . .5\end{array}$ & $\begin{array}{l}36.4 \\
39.2\end{array}$ & & $\begin{array}{l}36.1 \\
40.2\end{array}$ & $\begin{array}{l}63.9 \\
40.8\end{array}$ & $\begin{array}{l}12.8 \\
34.1\end{array}$ & $\begin{array}{l}-1.21 \\
19.0\end{array}$ & $\begin{array}{l}26.0 \\
46.6\end{array}$ & 73.3 & $\begin{array}{l}42.4 \\
45.7\end{array}$ & $\begin{array}{l}14.0 \\
14.2\end{array}$ \\
\hline 4.6 & linde & - & & & & - & - & - & - & - & & - \\
\hline & & & 42. & & & & $\therefore .1$ & $4 ;$ & 57.7 & 100 & 52.2 & 18.2 \\
\hline - & & & 3 & & & & 0.3 & & 84.3 & & .9 & 15. \\
\hline & & & 38. & & & . & $1: 1$ & $(-1.5)$ & 25.6 & 51 & 3.1 & 11.4 \\
\hline 35.01 & $\therefore$ & & 40. & & & 41. & 33.3 & 17 & 45.8 & 7. & 7.5 & 15.54 \\
\hline 7.7 & & & & & & & - & - & - & - & E & $1-$ \\
\hline & & 1.4 & 4 & & & I & 66.1 & 40 & 7.5 & 97 & .8 & 16. \\
\hline - & & & & & & & 17.6 & & 2. & & & 1ii. \\
\hline & k & & & & & 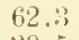 & 3.3 & $(-1)$ & 25.9 & & 9 & 13.5 \\
\hline 0.51 & $\because .1$ & & 39. & .3 & 0.5 & 39.5 & 85.2 & 20 & 47.1 & 74 & & 15.4 \\
\hline 10.8 & & - & & & & & & & 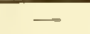 & & & \\
\hline - & & & & & .6 & 12.8 & -.1 & 4 & 56.1 & $10: 3.5$ & 4.3 & 10.2 \\
\hline & & & & & & 4 & 1.6 & & $t$ & & 1 & 15 \\
\hline- & & . & 7 & & & $\therefore \times 1$ & 16. & & 28 & 5 & 3.2 & 11. \\
\hline 28.51 & & & & & & 2 & 8.5 & & 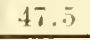 & & .1 & 14.8 \\
\hline 13.9 & & & & & & - & 一 & & - & & - & - \\
\hline - & & 1. & t & & & ; & 64.7 & 4 & 1.7 & 10 & $: 9$ & 17.8 \\
\hline & & & & & & & 2 & & $i$. & & .8 & 16. \\
\hline- & & $\therefore$. & & & & 62.2 & 12.4 & $(-2.8)$ & 23. & 58 & 4.7 & 11.4 \\
\hline 24.5 & - Holz & 2.3 & 40.0 & & & 29.7 & 44.7 & 29.3 & 52.8 & 84.7 & 48.1 & 16.1 \\
\hline$\overline{17.01}$ & & - & & & & - & & - & - & - & - & $1-$ \\
\hline . & & & & & & & .7 & & 62.9 & 10 & 7.3 & 16.7 \\
\hline & & & & & & 1 & 6.3 & 2 & $\therefore 0$ & & 4 & 12 \\
\hline & & & 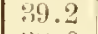 & & & (s) & 2.4 & $(-$ & 24.0 & 51 & & 8.2 \\
\hline 21.51 & . & 2.6 & & 2. & $:$ & $2 x .$. & 6.8 & 32 & .8 & 8 & 44.7 & 113.6 \\
\hline 20.1 & & & & & & - & - & - & - & - & - & \\
\hline & & 2. & & & & f & 7 & 50 & 61 & 1 & 8.8 & 14 \\
\hline & & & & & & & & & & & & $19 . \therefore$ \\
\hline & lie & is. & 4 & & & 60 & 13.6 & $(-1.9)$ & 2.5 & & $4: 3.9$ & 8. \\
\hline 17.5 & - Holz & 8.4 & 40.6 & 26.0 & 41.6 & 27.1 & 46.9 & 31.3 & 53.6 & 87.5 & 47.4 & $1+.5$ \\
\hline $2 \div 2$ & Rinde & -1 & 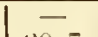 & & - & - & - & - & $\overline{-}$ & - & - & - \\
\hline & & 2. & & & & 12 & 61. & & 60.8 & 101 & & 14 \\
\hline & M. & 3. & 39 & & & 59 & 15 & $(-0.2)$ & 27 & & +5.3 & 12. \\
\hline 12.0 & $\therefore$ Ilolz & 2.9 & 89.7 & 25.5 & 0.8 & 23.7 & $50 .$. & 35.5 & 54.1 & 90.5 & 46.0 & 113.6 \\
\hline 26.0 & liin & - & - & - & 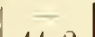 & - & $=$ & - & - & - & - & $=$ \\
\hline 6.0 & Hol\% & $2 . \therefore$ & 43.1 & 27.6 & 44.2 & 19.3 & 09.1 & 42.5 & 57.8 & 102.2 & 49.5 & 13.0 \\
\hline |-3jä & Zweig m. & Nad.| & 45.2 & 29.0 & - & 22.9 & 48.1 & - & 31.5 & $93 .: 3$ & - & - \\
\hline & izer sta & & 40.0 & 25.6 & 41.0 & 36.5 & 37.9 & 22.5 & - & 77.9 & - & \\
\hline
\end{tabular}


Fichte.

Alter 75 Jahre.

19. Mai 1881.

Höhe $30 \mathrm{~m}$. Kronenansatz - m. Inhalt $1.318 \mathrm{em}$. Wasser $37.7 \%$. Substanz 23.0 cem.

\begin{tabular}{|c|c|c|c|c|c|c|c|c|c|c|c|c|}
\hline \multirow{3}{*}{ 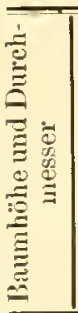 } & \multirow{3}{*}{ Baumtheil } & \multirow{3}{*}{ 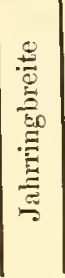 } & \multicolumn{3}{|c|}{$\begin{array}{l}\text { Organiselıe Substanz } \\
\text { in } 100 \text { Raumtheilen } \\
\text { frischeo Holzes }\end{array}$} & \multirow{3}{*}{ 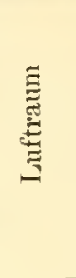 } & \multicolumn{3}{|c|}{ Wassergehalt } & \multicolumn{2}{|c|}{$\begin{array}{l}\text { Speeifiselies } \\
\text { Gewicht }\end{array}$} & \multirow{3}{*}{ 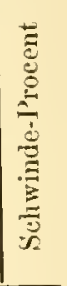 } \\
\hline & & & \multirow{2}{*}{ Gramme } & \multicolumn{2}{|c|}{ Raumtheile } & & \multicolumn{2}{|r|}{ theil. } & \multirow{2}{*}{$\begin{array}{c}\text { anf } \\
100 \mathrm{Ge}- \\
\text { wichts- } \\
\text { Ein- } \\
\text { heiten }\end{array}$} & \multirow{2}{*}{ frisch } & \multirow{2}{*}{ trocken } & \\
\hline & & & & \multicolumn{2}{|c|}{ trocken imbibirt } & & $\lim _{\text {Gavzen }}$ & $\begin{array}{l}\text { in flúss. } \\
\text { Zustand }\end{array}$ & & & & \\
\hline a & $\mathrm{b}$ & e & d & $\mathrm{e}$ & $\mathrm{f}$ & $\mathrm{g}$ & h & $\mathrm{i}$ & k & 1 & $\mathrm{~m}$ & 11 \\
\hline .5 & $\mathrm{P}$ & - & 0.2 & 5.8 & & 1.0 & 53.2 & 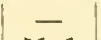 & 56.9 & 93.4 & 79.2 & 49.3 \\
\hline & & 1.2 & & & 35.8 & & 5 & 51 & & & & \\
\hline & & & & & & & 18.3 & & 34.2 & & 40.1 & 12.2 \\
\hline & & 81 & 36. & & 4.8 & & 11.7 & $(-2.2)$ & 24.5 & 47.8 & 39.0 & 7.6 \\
\hline 36.0 & $\therefore \mathrm{Holz}$ & 2.3 & 35. & 22 & 36.2 & +3. & 33.5 & 19 & 48.7 & & 40.3 & 12.4 \\
\hline 4.6 & Rinde & - & 38. & 24.7 & & 17.8 & 58.0 & & 60.3 & $\overline{9 t}$ & 84.6 & 54 \\
\hline & & 1.2 & & & 36.3 & 14. & 63.0 & & 6 & & 42.3 & 1.5 \\
\hline - & & & & 2 & & (1) & 18.2 & & ( & 5 & 40.7 & 13 \\
\hline & lier & & 83 & & & 67. & 11.1 & $(-1$ & 24.6 & & 38.3 & 11.5 \\
\hline $3+.0$ & Holz & 2.6 & 85.0 & 2 & 35.8 & 46.2 & 31.4 & 18. & 47.2 & 66 & 40.6 & 13.7 \\
\hline$\overline{7.7}$ & & - & 36. & 23.6 & & 6.9 & 49.5 & & 57.3 & & 74.4 & 50.3 \\
\hline - & & 1.2 & & & 36.5 & & & & 65.2 & 10 & 2.3 & 15 \\
\hline & & & 84 & & & & 22.0 & & 39. & & 40.7 & 15 \\
\hline & & 5.0 & 35 & 22 & 34.0 & 66.0 & 11.1 & $(-3)$ & 23. & & 39.4 & 9 \\
\hline 31.0 & $\mathrm{lz}$ & 2.7 & 35 & 2 & 36.0 & 42.8 & 34.7 & & 49.7 & 65 & 40.9 & 11.1 \\
\hline$\overline{10.8}$ & $\mathrm{Ri}$ & $1-1$ & 3 & & - & 21. & 53.5 & & 58.1 & 92.1 & 79.5 & 51.4 \\
\hline & & 1.4 & & & 36.6 & 9 & 67. & & & 10 & 42.9 & \\
\hline & & & 3 & & 85.5 & 52 & 25.1 & & 42.1 & 5. & 40.0 & 13 \\
\hline & K & 5.0 & & & 3 & 65.2 & 11.5 & $(-2.5)$ & 24.0 & 47 & 41.5 & 12 \\
\hline 8.0 & Holz & 2.8 & 3. & 2 & 36.3 & 40.2 & 87.1 & 23 & 51.1 & & $\$ 1.4$ & $11+$ \\
\hline 13.9 & lii & -1 & 9 & 9 & - & 21.4 & 53.6 & & 57.9 & & 5.3 & 8.2 \\
\hline- & & - & & & & & & & $\therefore$ & & 6 & 15.2 \\
\hline 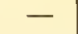 & & (.) & & & 3 & 40 & 37.4 & 24 & 51 & & 41.7 & 6.0 \\
\hline & & & & & & & 14.1 & $(-c)$ & 27. & & 43.2 & 12 \\
\hline 24.0 & $z$ & $10=$ & 8 & & 37.4 & 83.9 & 42.7 & 28 & 54.0 & 7 & 42.8 & 14.7 \\
\hline 7.0 & $\bar{R}$ & - & 41. & 26.5 & & 18.3 & 55.2 & & 57.2 & 96.6 & 80.2 & $4 \leq .4$ \\
\hline & & 2.1 & & & 3 & & & & 64.1 & & & \\
\hline - & & & & & & & 47 & 32 & 55 & & 45.1 & 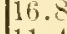 \\
\hline & & 2.9 & 40 & & 41 & 58 & 16. & & 28.7 & 5 & 45.4 & 11 \\
\hline 21.0 & Holz & 2.6 & 38.3 & 24.5 & 39. & 23.0 & 52.5 & & 57.8 & 94 & 45.4 & $1:$ \\
\hline 20.1 & Rinde & & 39. & 25.5 & - & 23.4 & 51.1 & & 56.2 & $y$ & 78.5 & 149.8 \\
\hline & & 2.5 & & & 39.2 & & 68. & .33 & 64.2 & 106.9 & 44.8 & $1: 3$ \\
\hline & MI. $\mathrm{u}$ & 3.3 & 38 & a & 39.5 & 46 & 29 & & 42.9 & & & 18 \\
\hline 16.0 & $\mathrm{Holz}$ & 3.0 & 38.4 & 24.6 & 39.4 & 21.5 & 53.9 & 39 & 58.4 & & 44.4 & $1: 3.4$ \\
\hline 23.2 & Rinde & - & 41. & 26 & - & 23.3 & 50.2 & & 54.9 & y1.5 & 75.2 & 45.1 \\
\hline & Spl & 2.3 & & & 41.5 & 7 & 66 & ic & 61.8 & & 48.5 & 15.5 \\
\hline & M. u. K. & 3.1 & 44 & & & : 15. & & & 44 & & 45.7 & \\
\hline 10.5 & - Ilolz & 2.6 & +1.8 & 26.8 & 40.9 & 14.3 & 58.9 & 44 & 58.5 & 100.7 & 45.6 & $1: 3.8$ \\
\hline 26,3 & Rinde & $1-1$ & 39. & 25 & & 22.6 & 51.9 & & 57.6 & 93.7 & 81.6 & 51.2 \\
\hline & & 3.0 & & & 42.4 & +.1 & $00 .+4$ & 00.0 & 61.6 & & $\frac{6.8}{0.5}$ & 11.6 \\
\hline$-1 j$ & Kweig m. & Nad. & 14.8 & 28.7 & - & 19.4 & 51.9 & - & 53.7 & 96.7 & 09.5 & 24.7 \\
\hline & nzer Stan & & 35.9 & 23.0 & 36.81 & 39.3 & 37.7 & 28.4 & - & 73.6 & $15-$ & . \\
\hline
\end{tabular}


Fichte.

Alter 65 Jahre.

9. Juli 1881 .

Höhe $28 \mathrm{~m}$. Krouenansatz $1 \mathrm{Im}$. Iuhalt $1.464 \mathrm{~cm}$. Wasser $48.1^{\circ}$ \%. Substauz $22.5 \mathrm{ccm}$.

\begin{tabular}{|c|c|c|c|c|c|c|c|c|c|c|c|c|}
\hline \multirow{3}{*}{ 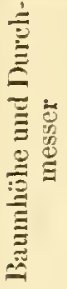 } & \multirow{3}{*}{ Baumtheil } & \multirow{3}{*}{ 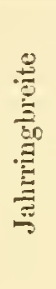 } & \multicolumn{3}{|c|}{$\begin{array}{c}\text { Organische Substanz } \\
\text { in } 100 \text { linumtheilen } \\
\text { frischen Holzes }\end{array}$} & \multirow{3}{*}{$\stackrel{\Xi}{\Xi}$} & \multicolumn{3}{|c|}{ Wassergehalt } & \multicolumn{2}{|c|}{$\begin{array}{c}\text { Specifisches } \\
\text { Gewicht }\end{array}$} & \multirow{3}{*}{ 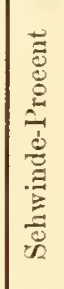 } \\
\hline & & & \multirow{2}{*}{ Gramme } & \multirow{2}{*}{\multicolumn{2}{|c|}{$\begin{array}{l}\text { Raumtheile } \\
\text { trocken inbibirt }\end{array}$}} & & \multicolumn{2}{|c|}{ in 100 Raumtheil. } & \multirow{2}{*}{$\begin{array}{l}\text { auf } \\
100 \mathrm{Ge} \\
\text { wrichts- } \\
\text { Ein- } \\
\text { heiten }\end{array}$} & \multirow{2}{*}{ frisch } & \multirow{2}{*}{ trucken } & \\
\hline & & & & & & & & & & & & \\
\hline a & b & $\mathrm{c}$ & d & e & $f$ & $\mathrm{~g}$ & h & i & $\mathrm{k}$ & 1 & un & n \\
\hline 1.5 & & & 34.5 & & $\begin{array}{l}- \\
37.3 \\
34.4\end{array}$ & $\begin{array}{r}27.6 \\
9.3 \\
32.8 \\
67.0 \\
33.0\end{array}$ & $\begin{array}{l}50.2 \\
67.4 \\
45.7 \\
11.7 \\
44.9\end{array}$ & $\begin{array}{l}-7 \\
5 . .4 \\
32.8 \\
\left(\frac{1.1}{31.7}\right)\end{array}$ & 59.2 & $\begin{array}{r}84.8 \\
103.7 \\
79.2 \\
45.0 \\
79.4\end{array}$ & $\begin{array}{l}80.1 \\
42.3 \\
37.8 \\
36.4 \\
38.9\end{array}$ & $\begin{array}{r}56.8 \\
14.2 \\
10.3 \\
8.5 \\
11.3\end{array}$ \\
\hline $4.6 i$ & & $\begin{array}{l}-5 \\
2.4 \\
3.5 \\
5.2 \\
3.8\end{array}$ & 34.5 & & 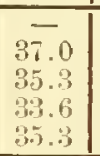 & $\begin{array}{l}29.9 \\
10.5 \\
31.9 \\
64.8 \\
34.5\end{array}$ & & $\begin{array}{r}2.1 \\
30.2\end{array}$ & 59.4 & $\begin{array}{r}72.1 \\
102.5 \\
80.5 \\
4.5 \\
77.9\end{array}$ & $\begin{array}{l}78.4 \\
41.8 \\
39.0 \\
37.3 \\
39.4\end{array}$ & $\begin{array}{l}57.8 \\
13.6 \\
11.6 \\
11.9 \\
12.5\end{array}$ \\
\hline $\begin{array}{l}7.7 \\
-\end{array}$ & $\begin{array}{l}\text { Rinde } \\
\text { sinlint } \\
\text { Jlitte } \\
\text { Keru } \\
\text {. IIolz }\end{array}$ & $\begin{array}{l}2.9 \\
4.0 \\
6.0 \\
4.3\end{array}$ & & & $\overline{-1}$ & & & $\left(\frac{-0.1}{27.8}\right)$ & . 13.8 & & & $\begin{array}{l}86.6 \\
8.6 \\
9.1 \\
8.9 \\
8.8\end{array}$ \\
\hline 9.5 & & $\begin{array}{l}3.7 \\
3.4 \\
3.1 \\
3.7\end{array}$ & & & & & & & 57.7 & $\begin{array}{r}80.7 \\
104.1 \\
23.4 \\
50.6 \\
\times 4.7\end{array}$ & $\begin{array}{l}76.7 \\
41.2 \\
40.2 \\
36.9 \\
41.0\end{array}$ & $\begin{aligned} 16 i f .8 \\
11 . .3 \\
12.6 \\
6.0 \\
12.7 \\
\end{aligned}$ \\
\hline 3.9 & $\begin{array}{l}\text { Kinde } \\
\text { Splint } \\
\text { Mitte } \\
\text { Kern } \\
\text { Holz }\end{array}$ & $\begin{array}{l}- \\
2.4 \\
4.0 \\
5.3 \\
3.7\end{array}$ & 34.6 & & $\overline{35.5}$ & $\begin{array}{r}25.4 \\
5.3 \\
23.6 \\
61.7 \\
24.8\end{array}$ & IS.: & - & $\begin{array}{l}57.1 \\
66.8\end{array}$ & $\begin{array}{r}84.6 \\
104.1 \\
67.6 \\
50.6 \\
87.6\end{array}$ & $\begin{array}{l}7 \times .8 \\
40.8 \\
32.7 \\
37.5 \\
39 . .\end{array}$ & $\begin{array}{r}5: 3.9 \\
15.1 \\
9.0 \\
8.7 \\
12.3\end{array}$ \\
\hline 7.0 & $\begin{array}{l}\text { Rinde } \\
\text { Spliut } \\
\text { Mitte } \\
\text { liern } \\
\text { Holz }\end{array}$ & $\begin{array}{l}-3.8 \\
4.2\end{array}$ & $\begin{array}{l}35.8 \\
36.4\end{array}$ & & - & & & & & $\begin{array}{r}10.1 \\
108.1 \\
100.9 \\
59.0 \\
95.2\end{array}$ & $\begin{array}{l}79.8 \\
40.0 \\
41.0 \\
32.5 \\
40.0\end{array}$ & $\begin{array}{r}57.9 \\
10.0 \\
8.9 \\
7.1 \\
9.1\end{array}$ \\
\hline 20.1 & $\begin{array}{l}\text { Rimde } \\
\text { Splint } \\
\text { MI. u. K. } \\
\text {. Holz }\end{array}$ & $\begin{array}{l}5.0 \\
3.9\end{array}$ & $\begin{array}{l}36.7 \\
35.0\end{array}$ & & & $\begin{array}{r}29.0 \\
9.6 \\
35.6 \\
17.3\end{array}$ & & & 63.3 & $\begin{array}{r}8 \% .1 \\
102.7 \\
72.6 \\
95.8\end{array}$ & $\begin{array}{l}81.5 \\
40.5 \\
40.5 \\
40.5\end{array}$ & $\begin{array}{r}58.6 \\
15.2 \\
9.8 \\
13.5\end{array}$ \\
\hline 23.2 & $\begin{array}{l}\text { Rinde. } \\
\text { splint } \\
\text { M. 11. K. } \\
\text {. Holz. }\end{array}$ & $\begin{array}{l}5.0 \\
4.4\end{array}$ & $\begin{array}{l}40.8 \\
27.0\end{array}$ & $\begin{array}{l}2 \\
2\end{array}$ & $\overline{36.8}$ & $\begin{array}{r}29.4 \\
8.1 \\
21.0 \\
11.8\end{array}$ & 5.0 & & 59.9 & $\begin{array}{r}82.5 \\
104.8 \\
92.7 \\
102.0\end{array}$ & $\begin{array}{l}81.5 \\
42.1 \\
44.5 \\
42.6\end{array}$ & $\begin{array}{r}-19.4 \\
15.9 \\
8.0 \\
13.2 \\
\end{array}$ \\
\hline $\begin{array}{r}26.3 \\
4.5\end{array}$ & $\begin{array}{l}\text { Rinde } \\
\text { Holz }\end{array}$ & 23.8 & \begin{tabular}{|l|}
31.0 \\
37.1
\end{tabular} & & $8 \overline{8.1}$ & $\begin{array}{r}25.5 \\
5.8\end{array}$ & & $\overline{5} \overline{5.6}$ & $\begin{array}{l}63.8 \\
6.5 .\end{array}$ & $\begin{array}{r}85.6 \\
10 \% .0\end{array}$ & $\begin{array}{l}86.3 \\
42.5\end{array}$ & $\mid \begin{array}{l}64.1 \\
12.1 \\
12.7\end{array}$ \\
\hline \multicolumn{3}{|c|}{ jälr. Zweigm. Nadeln } & 38.8 & 24.9 & 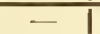 & 2.3 .2 & 51.9 & ב- & 57.2 & 90.7 & 8.6 & iii. \\
\hline \multicolumn{3}{|c|}{ 1jähr.Zweig m. Nadehn } & 27.1 & 17.8 & - & 13.2 & 69.5 & - & 71.9 & 915.6 & 50.0 & 145.8 \\
\hline & 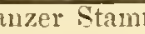 & & 85.1 & 22.5 & 36.0 & 24.4 & 8.1 & $\ddot{4} 4.6$ & & 83.2 & - & \\
\hline
\end{tabular}


Fichte.

Alter 80 Jahre.

12. Oetober 1881.

Höhe $29 \mathrm{~m}$. Kronenansatz $15 \mathrm{~m}$. Juhalt $1.137 \mathrm{em}$. Wasser $39.2 \%$. Substanz $26.1 \mathrm{ccm}$.

\begin{tabular}{|c|c|c|c|c|c|c|c|c|c|c|c|c|}
\hline \multirow{4}{*}{ 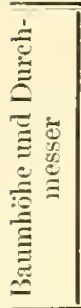 } & \multirow{4}{*}{ Bauntheil } & \multirow{4}{*}{ 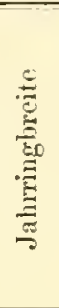 } & \multirow{2}{*}{\multicolumn{3}{|c|}{$\begin{array}{c}\text { Organische Substanz } \\
\text { in } 100 \text { Raumtheilen } \\
\text { frischen Holzes }\end{array}$}} & \multirow{4}{*}{ 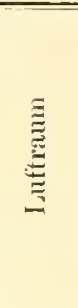 } & \multirow{2}{*}{\multicolumn{3}{|c|}{ Wassergelialt }} & \multirow{2}{*}{\multicolumn{2}{|c|}{$\begin{array}{l}\text { Specifisehes } \\
\text { Gerwicht }\end{array}$}} & \multirow{4}{*}{ 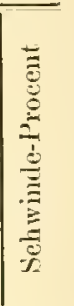 } \\
\hline & & & & & & & & & & & & \\
\hline & & & \multirow{2}{*}{ Gramme } & \multicolumn{2}{|c|}{ Raumtheile } & & \multicolumn{2}{|c|}{ in 100 Rauntheil. } & \multirow{2}{*}{$\begin{array}{l}\operatorname{auf} \\
100 \mathrm{Ge-} \\
\text { wichts- } \\
\text { Ein- } \\
\text { heiten }\end{array}$} & \multirow{2}{*}{ frisch } & \multirow{2}{*}{ trocken } & \\
\hline & & & & trucken & nbibirt & & $\operatorname{im}_{\text {Grozen }}$ & $\begin{array}{l}\text { in flüss. } \\
\text { Zustand }\end{array}$ & & & & \\
\hline$a$ & $\mathrm{~b}$ & 8 & $d$ & $\mathrm{e}$ & $f$ & $\mathrm{~g}$ & $\bar{l}$ & $\mathrm{i}$ & $\mathrm{k}$ & 1 & $m$ & n \\
\hline 1.5 & $\mathrm{~B}$ & - & 28.8 & 18.5 & - - & 32.6 & 45.9 & & 62.9 & 77.7 & 71.6 & 59.8 \\
\hline & & 1.3 & 42.6 & & 43.7 & 12.2 & 60.5 & 44 & 7 & 103.1 & 9.9 & \\
\hline & & & 39.1 & & & & 18.2 & & & 7.3. & 4.5 & 12.0 \\
\hline & & 4.7 & 36.3 & 33.8 & 35.2 & & 11.9 & $(-2.1)$ & 24. & 48.2 & 39.8 & 8.8 \\
\hline 6.0 & Iolz & 2.5 & 40.0 & 25. & 41.0 & 39.0 & $\therefore .4$ & 20.0 & 46.9 & 75.4 & 45.6 & 12.4 \\
\hline 4.6 & Rinde & & 29.7 & 19.0 & & 29.0 & 52.0 & - & 69.7 & 81.7 & 81.5 & 163.5 \\
\hline & & 1.1 & 39.6 & & 40.6 & 0 & .0 & 43 & & 98.6 & i.3 & 14 \\
\hline - & & 0 & 39.8 & & 1 & 8 & 0.8 & & 34 & 60.6 & 6.3 & 13.9 \\
\hline & Ke & 4.7 & 37.2 & & & 68. & 12.3 & 0) & 24 & 49.5 & .5 & 12 \\
\hline 31.0 & $\cdot 110 l z$ & 2.1 & 39.1 & 28 & 1 & 89.9 & 85.0 & 20 & 47. & 73.1 & 45.8 & \\
\hline 7.7 & Rinde & - & .99 .4 & & & 27.6 & 28.6 & & 6 & $8: 0$ & $79 .:$ & 162.9 \\
\hline & & 1.2 & $=$ & & 43.5 & 1) s & 600 & 43.7 & & 102.5 & .9 & 3.1 \\
\hline & & & 4 & & & 53 & 18.9 & & & 61.4 & -2 & 11 \\
\hline & & 4.0 & & & 0 & 61.2 & $1 \therefore 4$ & $(-1.8)$ & 25. & 53.1 & 41.9 & 11.5 \\
\hline$\therefore$ & $\% \mathrm{Holz}$ & 2.0 & 41.9 & 21 & 43.0 & 37.5 & 35.6 & 19.5 & 46. & 77.5 & 47.7 & |12.3 \\
\hline 10.8 & $\overline{l i}$ & 1 - & by. & & & 28.1 & 52.5 & - & $6 t$ & 82.7 & 4.0 & $\longdiv { 1 0 6 . 4 }$ \\
\hline & & 1.2 & 43. & & 44.8 & 11. & 60.8 & 44 & & $10 \pm .1$ & 5 & 14 \\
\hline & & & & & & & 26. & 11.1 & & 66.4 & & 14 \\
\hline & Ke & 4.0 & 39. & 2. & 38.8 & 61.2 & 13.8 & $(-2.0)$ & 25. & 58.1 & 44.9 & 11 \\
\hline 5.5 & Holz & 2.1 & 11.3 & 26.5 & 42.4 & 36.1 & 37.4 & 21.5 & 47.6 & 78.7 & 47.8 & 13.6 \\
\hline 19.9 & Rinde & - & $30 . \ddot{3}$ & 19. & & 26.7 & 53.9 & - & 0 & 84.2 & $80.0 \%$ & 163.3 \\
\hline & & & 4 & & & & & 51 & & 108.4 & & 12 \\
\hline & & & 3 & & 3 & 40 & 84.5 & 19. & & 74.3 & 46.2 & 13 \\
\hline & & & & & & 59 & 13.8 & $(-2.3)$ & & 55.7 & 47.9 & 12 \\
\hline 2.5 & $\therefore \mathrm{Holz}$ & 2.0 & 40.8 & 2 & 41.8 & 27.4 & 46.5 & 30. & $5 \%$ & 87.3 & 47.1 & 18 \\
\hline 17.0 & $\mathrm{R}$ & & 5 & 1 & & 25.5 & 52.0 & & 60 & 82.5 & 79.0 & $\sqrt{113}$ \\
\hline & & 1.6 & & & & & 67.4 & 51 & & 110.1 & $50 . \therefore$ & |1.7 \\
\hline & & & & & & & 47.8 & & & 89.4 & & 13 \\
\hline & Kel & & 46.8 & & & 52 & 17.5 & $(-0.3)$ & 27 & 63.8 & 51.4 & 10 \\
\hline 18.3 & $1.1 \mathrm{folz}$ & 2.2 & 43.1 & 27.6 & 44.1 & 19.3 & 5.1 & 36.6 & 5.5 .2 & 96.2 & 49.9 & |18. \\
\hline 20.1 & Rinde & L- & 31.4 & & & 29.3 & 50.6 & & 61.5 & $8 \% 0$ & $79 . .5$ & 100.4 \\
\hline & & 1 & & & & & 9 & & & 109.8 & & \\
\hline & M. U. K. & 2.8 & 42.9 & & & 36.4 & 86.1 & Is & 46 & 79.0 & to. 8 & 11.9 \\
\hline 14.0 & $\mathrm{Hol}_{z}$ & 2.2 & 42.3 & 27.1 & 43.4 & 16.7 & 56.2 & 39.9 & $\approx$ & 98.5 & 4.9 & 13.5 \\
\hline 23.2 & lin & - & 82.0 & & & 30.0 & 49.5 & & 60.7 & 81.5 & 76.1 & 157.9 \\
\hline & & 1. & & & & 3 & & 53 & & 111.5 & 49.0 & \\
\hline & 11. 11. & 2. & 46. & & & & & & & & 32.2 & 10 \\
\hline 8.0 & $\cdot 11 \circlearrowleft l_{z}$ & 1.8 & 43.9 & 28.1 & 45.0 & 10.8 & 61.1 & 4.2 & 58.2 & 105.0 & 50.4 & 12.0 \\
\hline $26 .: 1$ & Rincle & - & 92.4 & & - & 26.5 & 52.7 & & & 85.1 & 1.4 & 600.2 \\
\hline & & 3.0 & 51.4 & 52.4 & 52.6 & 8.4 & 58.7 & 89.0 & 53.3 & 110.1 & 56.8 & $\begin{array}{l}9.5 \\
\end{array}$ \\
\hline jihr. & weige $\mathrm{m}$. & Tad. & 41.8 & 26.8 & - & 25.3 & 47.9 & - & 53.4 & 89.7 & 60.2 & 130.6 \\
\hline ihr. & weige 111. & acl. & By.: & 25.2 & - & 2.2 .7 & 50.1 & - & 57.0 & 91.4 & 60.5 & 135.0 \\
\hline & zer stam & & 40.7 & 26.1 & 41.8 & $\ddot{34.7}$ & $8 y .2$ & 4.5 & - & 79.9 & - & \\
\hline
\end{tabular}


Lärche.

Alter 55 Jahre.

24. Närz 1881.

Höhe $14 \mathrm{~m}$. Kronenansatz $\leftarrow$ m. Inlaalt $0.234 \mathrm{~cm}$. Wasser $23.2 \%$. Substanz $28.5 \mathrm{ccm}$.

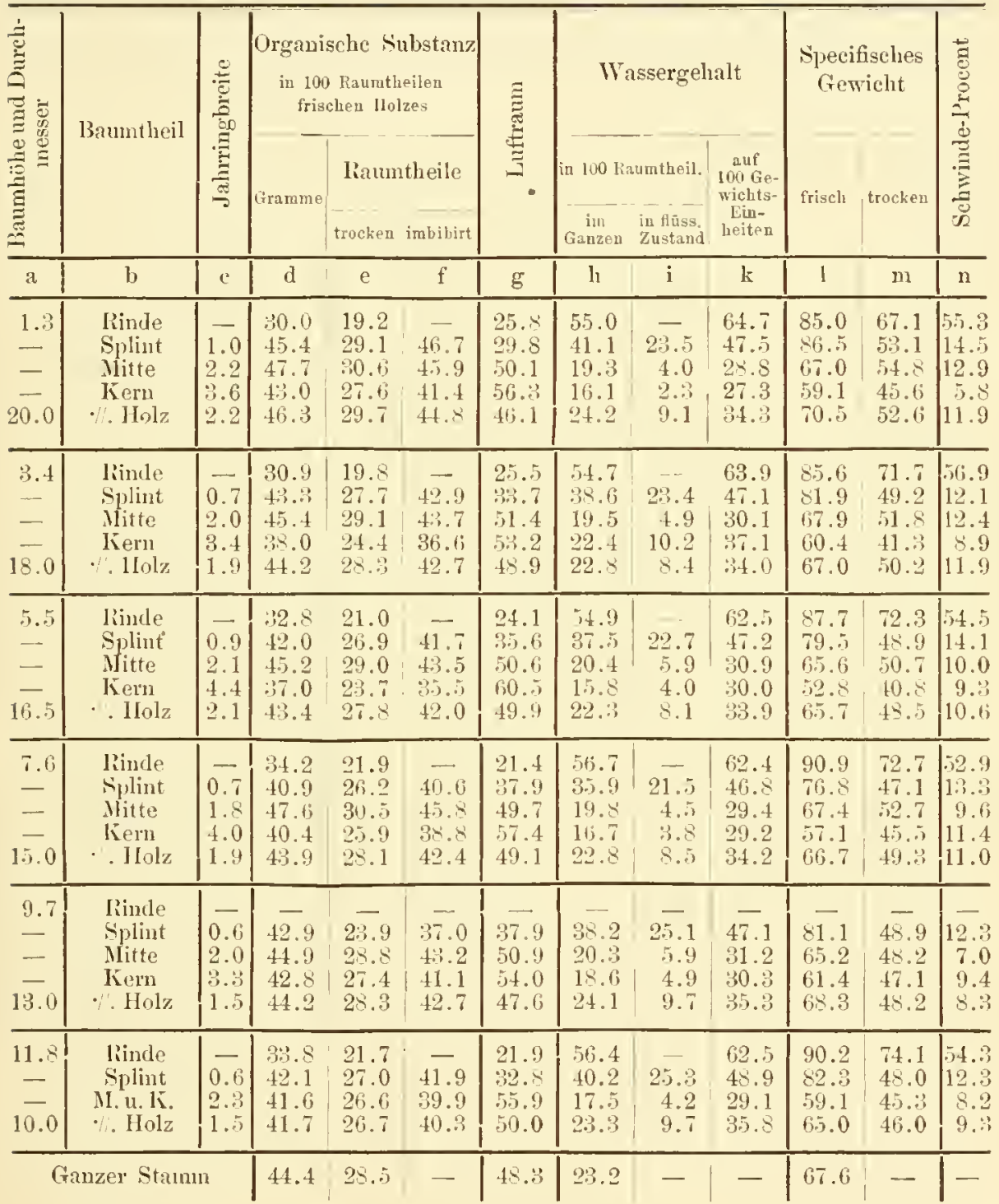




\section{Lärche.}

Alter 55 Jahre.

2. Juli 1881 .

Höhe $15 \mathrm{~m}$. Kronenansatz $5 \mathrm{~m}$. Inhalt $0.219 \mathrm{~cm}$. Wasser $31.7^{\circ}{ }^{\circ}$. Substanz $30.3 \mathrm{eem}$.

\begin{tabular}{|c|c|c|c|c|c|c|c|c|c|c|c|c|}
\hline \multirow{3}{*}{ 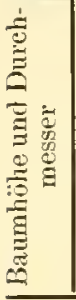 } & \multirow{3}{*}{ Baumtheil } & \multirow{3}{*}{ 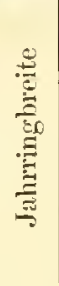 } & \multicolumn{3}{|c|}{$\begin{array}{c}\text { Orgatuische Substanz } \\
\text { in } 100 \text { Raumtheilen } \\
\text { frischen Holzes }\end{array}$} & \multirow{3}{*}{ 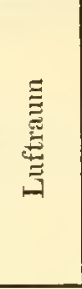 } & \multicolumn{3}{|c|}{ Wassergehalt } & \multicolumn{2}{|c|}{$\begin{array}{l}\text { Specifisches } \\
\text { Gewicht }\end{array}$} & \multirow{3}{*}{ 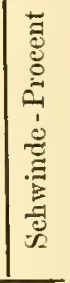 } \\
\hline & & & \multirow{2}{*}{ Gramme } & \multicolumn{2}{|c|}{ Raumtheile } & & \multicolumn{2}{|c|}{ iv 100 Raumtheil. } & \multirow{2}{*}{$\begin{array}{c}\text { auf } \\
100 \mathrm{Ge}- \\
\text { wichts- } \\
\text { Ein- } \\
\text { heiten }\end{array}$} & \multirow{2}{*}{ frisch } & \multirow{2}{*}{ trocken } & \\
\hline & & & & trocken & imobibirt & & \begin{tabular}{|l} 
im \\
Ganzen \\
\end{tabular} & $\begin{array}{l}\text { in finss: } \\
\text { Zustand }\end{array}$ & & & & \\
\hline a & b & c & d & $\mathrm{e}$ & $f$ & $\mathrm{~g}$ & h & $\mathrm{i}$ & $\mathrm{k}$ & 1 & $\mathrm{~m}$ & $\mathrm{n}$ \\
\hline $\begin{array}{c}1.3 \\
- \\
\overline{-} \\
20.0\end{array}$ & $\begin{array}{l}\text { Rinde } \\
\text { Splint } \\
\text { Mitte } \\
\text { lieru } \\
\text {. IIolz }\end{array}$ & $\begin{array}{l}1.2 \\
2.0 \\
3.2 \\
1.9\end{array}$ & $\begin{array}{l}81.1 \\
46.8 \\
47.2 \\
49.8 \\
48.0\end{array}$ & $\begin{array}{l}19.9 \\
29.7 \\
30.2 \\
31.9 \\
30.8\end{array}$ & $\begin{array}{l}4 . \\
46.0 \\
45.3 \\
47.9 \\
46.5\end{array}$ & $\begin{array}{r}24.7 \\
9.0 \\
46.7 \\
49.9 \\
37.7\end{array}$ & $\begin{array}{l}55.4 \\
61 . . \\
23.1 \\
18.2 \\
31.5\end{array}$ & $\begin{array}{r}- \\
45.0 \\
8.0 \\
2.2 \\
15.8 \\
\end{array}$ & $\begin{array}{l}64.0 \\
57.0 \\
31.8 \\
26.8 \\
39.6\end{array}$ & $\begin{array}{r}86.5 \\
107.6 \\
70.3 \\
68.0 \\
79.5 \\
\end{array}$ & $\begin{array}{l}81.7 \\
52.5 \\
53.9 \\
58.1 \\
55.4\end{array}$ & $\begin{array}{l}61.9 \\
13.8 \\
12.4 \\
14.2 \\
13.4 \\
\end{array}$ \\
\hline $\begin{array}{l}3.4 \\
- \\
\overline{-} \\
18.0\end{array}$ & $\begin{array}{l}\text { Rinde } \\
\text { Splint } \\
\text { Mlitte } \\
\text { Kern } \\
\text {. Holz }\end{array}$ & $\left|\begin{array}{l}- \\
1.4 \\
1.8 \\
3.6 \\
2.0\end{array}\right|$ & $\begin{array}{l}31.2 \\
46.8 \\
47.9 \\
46.7 \\
47.1\end{array}$ & & $\begin{array}{l}46.5 \\
46.1 \\
44.9 \\
45.9\end{array}$ & $\begin{array}{l}25.2 \\
11.1 \\
50.1 \\
53.5 \\
38.4\end{array}$ & $\begin{array}{l}.44 .8 \\
58.9 \\
19.2 \\
16.6 \\
31.4\end{array}$ & $\begin{array}{r}-\overline{4} \\
42.4 \\
3.8 \\
1.6 \\
15.7\end{array}$ & $\begin{array}{l}6: 3.7 \\
55.7 \\
28.6 \\
27.4 \\
39.2\end{array}$ & $\begin{array}{r}86.0 \\
105.7 \\
67.1 \\
63.3 \\
78.5 \\
\end{array}$ & $\begin{array}{l}81.9 \\
54.8 \\
53.8 \\
53.5 \\
53.8\end{array}$ & $\begin{array}{l}61.9 \\
13.7 \\
10.8 \\
12.8 \\
12.5\end{array}$ \\
\hline $\begin{array}{c}5.5 \\
- \\
- \\
16.0\end{array}$ & $\begin{array}{l}\text { Kincle } \\
\text { Splint } \\
\text { llitte } \\
\text { Kern } \\
\text { \%. IIolz }\end{array}$ & $\left|\begin{array}{l|}1-2 \\
1.7 \\
2.8 \\
2.0\end{array}\right|$ & $\begin{array}{l}39.6 \\
45.6 \\
4 \div .6 \\
-\end{array}$ & $\begin{array}{c}21.7 \\
29.2 \\
29.2 \\
- \\
\end{array}$ & $\begin{array}{c}- \\
- \\
43.8 \\
43.8 \\
-\end{array}$ & $\begin{array}{c}21.8 \\
-76.4 \\
54.7 \\
-\end{array}$ & $\begin{array}{c}57.0 \\
- \\
24.4 \\
16.1 \\
-\end{array}$ & $\begin{array}{l}- \\
\overline{9} .8 \\
1.5 \\
-\end{array}$ & $\begin{array}{l}62.8 \\
3 \overline{4} .8 \\
26.1 \\
-\end{array}$ & $\begin{array}{l}90.8 \\
70.0 \\
61.7 \\
-\end{array}$ & $\begin{array}{c}83.7 \\
52.3 \\
49.6 \\
- \\
\end{array}$ & $\mid \begin{array}{c}59.6 \\
- \\
12.6 \\
8.0 \\
-\end{array}$ \\
\hline $\begin{array}{c}7.6 \\
- \\
\overline{-} \\
14.5\end{array}$ & $\begin{array}{l}\text { Pinde } \\
\text { Splint } \\
\text { Nitte } \\
\text { Kenn } \\
\text { •. Holz }\end{array}$ & $\mid \begin{array}{l}- \\
1.1 \\
2.9 \\
3.3 \\
2.4\end{array}$ & $\begin{array}{l}3 \% .7 \\
45.5 \\
46.0 \\
46.8 \\
46.2 \\
\end{array}$ & & $\begin{array}{l}-5.1 \\
45.1 \\
4.2 \\
45.0 \\
41.7\end{array}$ & $\begin{array}{l}24.0 \\
15.9 \\
43.6 \\
54.4 \\
40.8\end{array}$ & $\begin{array}{l}74.4 \\
55.0 \\
26.9 \\
15.6 \\
29.6\end{array}$ & $\begin{array}{r}-\overline{39.0} \\
12.2 \\
0.6 \\
14.5\end{array}$ & $\begin{array}{l}61.7 \\
74.9 \\
36.9 \\
25.0 \\
39.0\end{array}$ & $\begin{array}{r}88.1 \\
100.5 \\
72.9 \\
62.4 \\
75.8\end{array}$ & $\begin{array}{l}81.2 \\
53.3 \\
51.5 \\
51.5 \\
51.9 \\
\end{array}$ & $\begin{array}{r}58.5 \\
14.6 \\
10.7 \\
9.1 \\
11.0 \\
\end{array}$ \\
\hline $\begin{array}{c}9.7 \\
- \\
- \\
11.5\end{array}$ & $\begin{array}{l}\text { Rinde } \\
\text { splint } \\
\text { Ilitte } \\
\text { Kern } \\
\text {. Ilolz }\end{array}$ & $\begin{array}{l}-1 \\
1.1 \\
2.9 \\
2.7 \\
2.0\end{array}$ & $\begin{array}{l}85.9 \\
47.7 \\
48.7 \\
46.9 \\
47.8\end{array}$ & $\begin{array}{l}31.2 \\
30.1 \\
30.6\end{array}$ & $\begin{array}{l}-\overline{4} \\
47.4 \\
46.8 \\
45.2 \\
46.5\end{array}$ & $\begin{array}{l}23.5 \\
15.8 \\
50.4 \\
5.4 .4 \\
36.1 \\
\end{array}$ & $\begin{array}{l}53.5 \\
54.1 \\
18.4 \\
16.5 \\
38.5 \\
38.5\end{array}$ & $\begin{array}{r}- \\
37.3 \\
2.8 \\
1.4 \\
17.4 \\
\end{array}$ & $\begin{array}{l}59.8 \\
53.2 \\
27.4 \\
25.9 \\
41.0\end{array}$ & \begin{tabular}{|r|}
89.4 \\
101.8 \\
67.1 \\
63.4 \\
81.1 \\
\end{tabular} & \begin{tabular}{|l|}
84.3 \\
56.0 \\
53.4 \\
52.9 \\
54.6 \\
\end{tabular} & $\begin{array}{r}57.3 \\
14.8 \\
8.8 \\
11.2 \\
12.0 \\
\end{array}$ \\
\hline $\begin{array}{c}11.8 \\
- \\
7.5\end{array}$ & $\begin{array}{l}\text { Rinde } \\
\text { Splint } \\
\text { M. u. K. } \\
\text {. Holz }\end{array}$ & \begin{tabular}{|l|}
-1 \\
$\therefore .0$ \\
1.6
\end{tabular} & $\begin{array}{l}\because 3.9 \\
48.6 \\
47.9 \\
48.8\end{array}$ & $\begin{array}{l}21.7 \\
31.1 \\
30.7 \\
31.0 \\
\end{array}$ & $\begin{array}{l}-5.2 \\
46.1 \\
47.4\end{array}$ & $\begin{array}{l}25.5 \\
16.8 \\
49.9 \\
30.3\end{array}$ & $\begin{array}{l}52.8 \\
52.1 \\
19.4 \\
38.7 \\
\end{array}$ & $\begin{array}{r}- \\
35.0 \\
4.0 \\
22.8\end{array}$ & $\begin{array}{l}60.8 \\
51.7 \\
28.8 \\
41.5 \\
\end{array}$ & $\begin{array}{r}86.7 \\
100.7 \\
67.3 \\
87.0 \\
\end{array}$ & $\begin{array}{l}81.1 \\
56.7 \\
51.9 \\
54.4 \\
\end{array}$ & $\begin{array}{r}-\overline{14.8} \\
7.7 \\
11.6 \\
\end{array}$ \\
\hline $\begin{array}{r}13.9 \\
4.0 \\
\end{array}$ & $\begin{array}{l}\text { Rincle } \\
\text { Holz }\end{array}$ & 1.0 & $\begin{array}{l}35.8 \\
45.2 \\
\end{array}$ & $\begin{array}{l}22.6 \\
29.0 \\
\end{array}$ & 45.0 & $\begin{array}{r}9.2 .2 \\
27.2 \\
\end{array}$ & $\begin{array}{r}72.2 \\
43.8 \\
\end{array}$ & 27.8 & $\begin{array}{l}59.6 \\
49.2 \\
\end{array}$ & $\begin{array}{l}87.5 \\
89.0 \\
\end{array}$ & $\begin{array}{l}88.4 \\
50.8 \\
\end{array}$ & $\begin{array}{l}60.0 \\
11.0 \\
\end{array}$ \\
\hline \multicolumn{3}{|c|}{ Mehrjähr.Zwg. ohne $\mathrm{N}$. } & 43.5 & 27.9 & - & 15.6 & 56.5 & - & .56 .5 & 100.0 & - & - \\
\hline \multicolumn{3}{|c|}{ Ganzer Stamm } & 47.2 & 30.3 & - & 00.0 & 31.7 & - & - & 78.9 & - & 一 \\
\hline
\end{tabular}


Kiefer.

Alter 25 Jahre.

2. Januar 1882.

Höhe $9 \mathrm{~m}$. Kronenansatz - m. Inhalt $0.051 \mathrm{~cm}$. Wasser $64.6 \%$. Substanz $22.1 \mathrm{ccm}$.

\begin{tabular}{|c|c|c|c|c|c|c|c|c|c|c|c|c|}
\hline \multirow{3}{*}{ 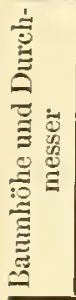 } & \multirow{3}{*}{ Baumtheil } & \multirow{3}{*}{ 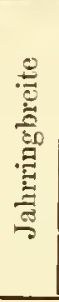 } & \multicolumn{3}{|c|}{$\begin{array}{c}\text { Organische Substanz } \\
\text { in } 100 \text { Rantheilen } \\
\text { frischen Holzes }\end{array}$} & \multirow{3}{*}{$\stackrel{\Xi}{\Xi}$} & \multicolumn{3}{|c|}{ Wassergehalt } & \multicolumn{2}{|c|}{$\begin{array}{l}\text { Specifisches } \\
\text { Gewicht }\end{array}$} & \multirow{3}{*}{ 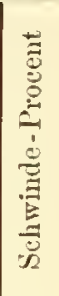 } \\
\hline & & & \multirow{2}{*}{ Gramme } & \multicolumn{2}{|c|}{ Raumtheile } & & \multicolumn{2}{|c|}{ in 100 Manntheil. } & \multirow{2}{*}{$\begin{array}{l}\text { auf } \\
100 \text { Ge- } \\
\text { wichts- } \\
\text { Ein- } \\
\text { heiten }\end{array}$} & \multirow{2}{*}{ frisch } & \multirow{2}{*}{ trocken } & \\
\hline & & & & trocken & imbibirt & & Ganzen & $\begin{array}{l}\text { in flüss. } \\
\text { Znstand }\end{array}$ & & & & \\
\hline a & $b$ & c & $d$ & $\mathrm{e}$ & f & $g$ & h & i & $\mathrm{k}$ & 1 & $\mathrm{~m}$ & n \\
\hline 1.3 & Rinde & - & 19.0 & 12.2 & - & 40.7 & 47.1 & - & 71.3 & 66.1 & 58.3 & 67.4 \\
\hline - & Splint & 3.1 & 35.9 & 23.0 & 35.6 & 11.6 & 65.4 & 52.8 & 64.5 & 101.8 & 40.5 & 11.2 \\
\hline- & MI. u. K. & 3.5 & 35.2 & 22.5 & 33.7 & 18.8 & 58.7 & 47.5 & 62.5 & 93.9 & 39.6 & 11.0 \\
\hline 11.5 & •\% Holz & 3.2 & 35.8 & 23.0 & 35.4 & 13.1 & 63.9 & 51.5 & 64.2 & 99.7 & 40.3 & 11.2 \\
\hline 3.4 & Rinde & - & 23.1 & 14.8 & - & 30.9 & 54.8 & - & 70.2 & 77.4 & 72.6 & 68.2 \\
\hline 11.0 & Holz & 3.9 & 34.2 & 21.9 & 33.9 & 13.1 & 65.0 & 53.0 & 65.5 & 99.2 & 39.0 & 12.1 \\
\hline 5.5 & Rinde & - & 23.1 & 14.8 & - & 25.5 & 36.7 & - & 72.2 & 79.8 & 69.4 & 66.7 \\
\hline 8.0 & Holz & 4.1 & 32.9 & 21.1 & 32.7 & 13.7 & 65.6 & 54.0 & 66.6 & 98.5 & 36.9 & 10.6 \\
\hline 7.6 & Rinde & - & 24.7 & 15.8 & - & 32.0 & 52.2 & - & 67.9 & 76.9 & 74.0 & 66.7 \\
\hline 3.0 & Holz & 3.0 & 33.4 & 21.4 & 33.2 & - & 62.1 & 50.3 & 65.0 & 95.5 & 38.2 & 12.4 \\
\hline & . & & .6 & 22.1 & 34.3 & - & 64.6 & 52.4 & - & 99.2 & - & - \\
\hline
\end{tabular}




\section{Kiefer.}

Alter 3athe.

4. März 1982.

11öhe $14 \mathrm{~m}$. Kronenausatz $-\mathrm{m}$. Inbalt $0.143 \mathrm{~cm}$. Wasser $55.8^{\circ} 0$. Substanz $27.0 \mathrm{ccm}$.

\begin{tabular}{|c|c|c|c|c|c|c|c|c|c|c|c|c|}
\hline \multirow{3}{*}{ 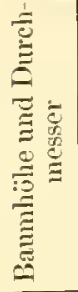 } & \multirow{3}{*}{ Baumtheil } & \multirow{3}{*}{ 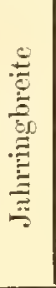 } & \multicolumn{3}{|c|}{$\begin{array}{l}\text { Organische Substanz } \\
\text { in } 100 \text { Rauntbeilen } \\
\text { frischen Holzes }\end{array}$} & \multirow{3}{*}{ 䓌 } & \multicolumn{3}{|c|}{ Wassergehalt } & \multicolumn{2}{|c|}{$\begin{array}{l}\text { Specifisches } \\
\text { Gewicht }\end{array}$} & \multirow{3}{*}{ 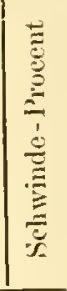 } \\
\hline & & & \multirow{2}{*}{ Gramme } & \multirow{2}{*}{\multicolumn{2}{|c|}{$\begin{array}{l}\text { Raumtheile } \\
\text { trocken imbibirt }\end{array}$}} & & \multicolumn{2}{|c|}{ in 100 Raumtheil. } & \multirow{2}{*}{$\begin{array}{l}\text { auf } \\
100 \text { Ge- } \\
\text { wichts- } \\
\text { Ein- } \\
\text { Leiten }\end{array}$} & \multirow{2}{*}{ friscl } & \multirow{2}{*}{ trocken } & \\
\hline & & & & & & & $\operatorname{im}_{\text {Ganzen }}$ & $\begin{array}{l}\text { in flüsss } \\
\text { Zustand } \\
\end{array}$ & & & & \\
\hline a & b) & $\mathrm{c}$ & d & e & $f$ & $g$ & h & i & $\mathrm{k}$ & 1 & $\mathrm{~m}$ & n \\
\hline 1.3 & linde & - & 21.9 & 14.0 & - & 33.9 & 52.1 & - & 70.5 & 74.0 & 55.3 & 60.5 \\
\hline - & Splint & 1.9 & 46.4 & 29.7 & 44.0 & 14.1 & 56.2 & 41.9 & 54.8 & 102.6 & 53.5 & 13.3 \\
\hline - & M. и. K. & 3.6 & 39.6 & 25.4 & 38.1 & 29.9 & 44.7 & 32.0 & 53.1 & 84.3 & 47.2 & 16.1 \\
\hline 17.5 & $\cdot$. Ilolz & 2.5 & 44.4 & 28.5 & 43.6 & 18.7 & 52.8 & 37.7 & .54 .4 & 97.2 & 51.7 & 14.1 \\
\hline$\therefore .4$ & Rinde & - & 23.1 & 14.8 & - & 30.7 & 54.5 & - & 70.2 & 77.6 & 60.9 & 62.0 \\
\hline - & Splint & 2.3 & 40.1 & 27.6 & 42.8 & 12.8 & 59.6 & 44.4 & 58.0 & 102.7 & 49.2 & 12.4 \\
\hline - & M. и. K. & 4.8 & 38.2 & 24.5 & 266.8 & 35.0 & 37.5 & 25.2 & 49.6 & 75.7 & 42.6 & 10.4 \\
\hline 15.0 & $\% . \mathrm{Ilolz}$ & 2.8 & 41.9 & 26.8 & 41.8 & 18.7 & 54.5 & 40.0 & 56.5 & 96.4 & 47.6 & 11.9 \\
\hline 5.5 & Rinde & - & 28.4 & 15.0 & - & 32.3 & 52.7 & - & 69.3 & 76.1 & 71.5 & 67.5 \\
\hline- & Splint & 2.5 & 41.9 & 26.8 & 11.5 & 13.0 & 60.2 & 45.5 & 58.9 & 102.1 & 48.5 & 13.6 \\
\hline- & M. и. К. & 4.0 & 37.5 & 24.0 & 86.0 & 25.9 & 50.1 & 38.1 & 5.1 & 87.6 & 40.0 & 10.8 \\
\hline 13.5 & $\% .1 \mathrm{olz}$ & 2.9 & 40.8 & 26.1 & 40.2 & 16.4 & 57.5 & 43.4 & 58.5 & 98.3 & 46.8 & 12.8 \\
\hline 7.6 & Rinde & - & 25.1 & 16.3 & - & 80.1 & $5: .3$ & - & 67.6 & 78.7 & 65.4 & 61.2 \\
\hline 11.0 & Holz & 2.7 & 40.0 & 25.6 & 39.7 & 13.5 & 60.9 & 46.8 & 60.3 & 100.9 & 46.4 & 13.7 \\
\hline 9.7 & Rinde & - & 25.2 & 18.1 & - & 28.7 & 53.2 & - & 65.4 & 81.4 & 71.1 & 60.4 \\
\hline 7.0 & Holz & 3.2 & 40.9 & 26.2 & 40.6 & 14.7 & 59.1 & 11.7 & 59.1 & 100.0 & 40.1 & 12.9 \\
\hline 11.8 & Rinde & - & 26.2 & 16.8 & - & 32.4 & 50.8 & - & 66.0 & 77.0 & 81.5 & 67.8 \\
\hline 5.0 & Holz & 3.8 & 39.3 & 25.2 & 39.1 & 12.7 & 62.1 & 18.2 & 61.2 & 101.4 & 43.8 & 10.3 \\
\hline & & & 42.1 & 27.0 & 41.9 & 17.2 & in. 8 & 40.9 & 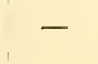 & 97.9 & - & - \\
\hline
\end{tabular}


Kiefer.

Alter 20 Jahre.

14. März $181^{2}$

Höhe $7 \mathrm{~m}$. Kronenansatz $-\mathrm{m}$. Inhalt $0.014 \mathrm{~cm}$. Wasser $59.6 \%$. Substanz $22.7 \mathrm{ccm}$.

\begin{tabular}{|c|c|c|c|c|c|c|c|c|c|c|c|c|}
\hline \multirow{2}{*}{ 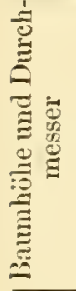 } & \multirow{2}{*}{ Banmtheil } & \multirow{2}{*}{ 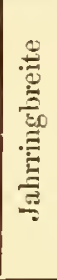 } & \multicolumn{3}{|c|}{$\begin{array}{l}\text { Organische Substanz } \\
\text { in i00 Raumtheilen } \\
\text { frischen Holzes }\end{array}$} & \multirow{2}{*}{ 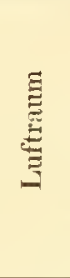 } & \multicolumn{3}{|c|}{ Wassergehalt } & \multicolumn{2}{|c|}{$\begin{array}{c}\text { Specifisches } \\
\text { Gewicht }\end{array}$} & \multirow{2}{*}{ 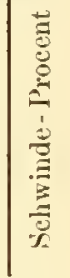 } \\
\hline & & & Gramme & \multicolumn{2}{|c|}{$\begin{array}{c}\text { Raumtheile } \\
\text { trocken imbibirt }\end{array}$} & & 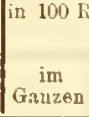 & $\begin{array}{l}\text { inmtheil. } \\
\text { in flüss. } \\
\text { Zustand }\end{array}$ & $\begin{array}{l}\text { anf } \\
\text { 100 Ge- } \\
\text { wichts- } \\
\text { Ein- } \\
\text { heiten }\end{array}$ & frisch & trocken & \\
\hline a & b & $\mathrm{e}$ & d & e & $\mathrm{f}$ & $g$ & h & $\mathrm{i}$ & $\mathrm{k}$ & 1 & $\mathrm{~m}$ & n \\
\hline 1.3 & Holz & 2.2 & 85.7 & 22.9 & 35.5 & 19.1 & 58.0 & 45.4 & 61.9 & 93.7 & 39.2 & 9.0 \\
\hline 3.4 & Holz & 2.6 & 35.3 & 22.6 & 35.0 & 14.9 & 62.5 & 50.1 & 63.9 & 97.8 & 39.4 & 10.3 \\
\hline 5.5 & Holz & 3.3 & 34.2 & 21.9 & 33.9 & 19.4 & 58.7 & 46.7 & 63.2 & 92.9 & 39.1 & 12.7 \\
\hline & er Sta & & 35.4 & 22.7 & 35.2 & 17.7 & 59.6 & 47.1 & - & 95.0 & - & - \\
\hline
\end{tabular}

Alter 20 Jahre.

Kiefer.

Höhe $5 \mathrm{~m}$. Kronenansatz $-\mathrm{m}$. Inhalt $0.010 \mathrm{~cm}$. Wasser $58.0^{\circ} \%$. Substanz $23.7 \mathrm{ccm}$.

\begin{tabular}{|c|c|c|c|c|c|c|c|c|c|c|c|c|}
\hline \multirow{3}{*}{ 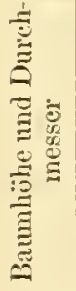 } & \multirow{3}{*}{ Bauntheil } & \multirow{3}{*}{ 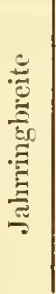 } & \multicolumn{3}{|c|}{$\begin{array}{c}\text { Organische Substanz } \\
\text { iu } 100 \text { Raumtheilen } \\
\text { frischen Holzes }\end{array}$} & \multirow{3}{*}{ 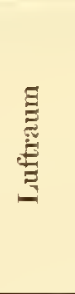 } & \multicolumn{3}{|c|}{ W'assergehalt } & \multicolumn{2}{|c|}{$\begin{array}{l}\text { Speelfisches } \\
\text { Gewicht }\end{array}$} & \multirow{3}{*}{ 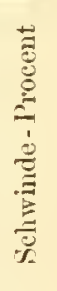 } \\
\hline & & & \multirow{2}{*}{ Gramme } & \multicolumn{2}{|c|}{ Raumtbeile } & & \multicolumn{2}{|c|}{ in 100 R:mmtheil. } & \multirow{2}{*}{$\begin{array}{l}\text { auf } \\
100 \text { Ge- } \\
\text { wichts- } \\
\text { Ein- } \\
\text { heiten }\end{array}$} & \multirow{2}{*}{ frisch } & \multirow{2}{*}{ trocken } & \\
\hline & & & & trocken & imbibirt & & Ganzen & $\begin{array}{l}\text { in flüss. } \\
\text { Zastand }\end{array}$ & & & & \\
\hline a & $\mathrm{b}$ & $\mathrm{c}$ & d & $\mathrm{e}$ & f & $g$ & $\mathrm{~h}$ & i & $\bar{k}$ & 1 & $m$ & $n$ \\
\hline 1.3 & Rincle & - & 30.1 & 19.3 & - & 24.1 & 56.3 & - & 65.1 & 86.4 & 70.3 & 57.1 \\
\hline 7.0 & Holz & 2.1 & 37.4 & 24.0 & 37.2 & 18.7 & 57.3 & .44 .1 & 60.6 & 94.7 & 43.9 & 14.8 \\
\hline 3.4 & Rinde & - & 32.7 & 21.0 & - & 19.7 & 59.3 & - & 64.4 & 92.0 & 76.3 & 57.1 \\
\hline 4.0 & Hlolz & 2.0 & 36.1 & 23.1 & 35.8 & 16.6 & 60.3 & 47.6 & 62.5 & 96.4 & 41.0 & 11.8 \\
\hline \multicolumn{3}{|c|}{ Ganzer Stamm } & 37.0 & 23.7 & 36.7 & 18.3 & .8 .0 & 45.0 & - & 95.0 & - & - \\
\hline
\end{tabular}




\section{Kiefer.}

Alter 25 Jahre.

9. Juli 1881.

Höhe $9 \mathrm{~m}$. Kronenansatz $-\mathrm{m}$. Inhait $0.047 \mathrm{~cm}$. Wassel $64.6 \%$. Substanz $22.8 \mathrm{ccm}$.

\begin{tabular}{|c|c|c|c|c|c|c|c|c|c|c|c|c|}
\hline \multirow{3}{*}{ 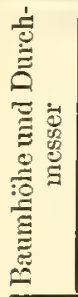 } & \multirow{3}{*}{ Baumtheil } & \multirow{3}{*}{ 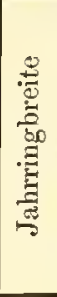 } & \multicolumn{3}{|c|}{$\begin{array}{l}\text { Organische Substanz } \\
\text { in } 100 \text { Rauntheilen } \\
\text { frischen Holzes }\end{array}$} & \multirow{3}{*}{ 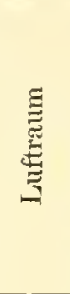 } & \multicolumn{3}{|c|}{ Wassergehalt } & \multicolumn{2}{|c|}{$\begin{array}{l}\text { Specifisches } \\
\text { Gewicht }\end{array}$} & \multirow{3}{*}{ 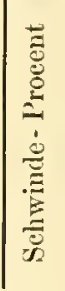 } \\
\hline & & & \multirow{2}{*}{ Gramue } & \multicolumn{2}{|c|}{ Raumtheile } & & \multicolumn{2}{|c|}{ in 100 Ranmtheil. } & \multirow{2}{*}{$\begin{array}{l}\text { auf } \\
\text { 100 Ge- } \\
\text { wichts- } \\
\text { Ein- } \\
\text { leiten }\end{array}$} & \multirow{2}{*}{ frisch } & \multirow{2}{*}{ trock $\in \mathbf{n}$} & \\
\hline & & & & trocken & imbibirt & & \begin{tabular}{|l} 
im \\
Ganzen
\end{tabular} & $\begin{array}{l}\text { in fluss. } \\
\text { Zustand }\end{array}$ & & & & \\
\hline a & $\mathrm{b}$ & c & $d$ & $\mathrm{e}$ & $f$ & $\mathrm{~g}$ & $\mathrm{~h}_{1}$ & $\mathrm{i}$ & k & 1 & $\mathbf{m}$ & n \\
\hline 1.9 & Rinde & - & 22.8 & 14.6 & - & 24.8 & 60.6 & - & 72.7 & 83.4 & 72.7 & 68.6 \\
\hline - & Splint & 2.8 & 39.5 & 25.3 & 39.2 & 11.7 & 63.0 & 49.1 & 61.5 & 102.5 & 45.4 & 13.0 \\
\hline - & M. u. K. & 3.0 & 36.3 & 23.3 & 34.9 & 31.0 & 45.7 & 34.1 & 55.7 & 82.0 & 41.5 & 12.5 \\
\hline 11.0 & /. Holz & 2.9 & 39.1 & 25.1 & 38.9 & 14.0 & 60.9 & 47.1 & 60.9 & 100.0 & 44.9 & 12.9 \\
\hline 3.4 & Rinde & - & 22.3 & 14.3 & - & 26.2 & 59.5 & - & 72.7 & 81.8 & 82.9 & 78.1 \\
\hline - & Splint & 3.2 & 34.3 & 22.0 & 34.1 & 11.4 & 66.6 & 54.5 & 66.0 & 100.9 & 39.7 & 12.9 \\
\hline - & M. u. K. & 3.8 & 31.2 & 20.0 & 30.0 & 26.3 & 58.7 & 43.7 & 63.2 & 84.9 & - & - \\
\hline 10.0 & $\% . \mathrm{Holz}$ & 3.5 & 33.9 & 21.7 & 33.6 & 13.5 & 64.8 & 52.9 & 65.7 & 98.7 & - & - \\
\hline 5.5 & Rinde & - & 23.7 & 15.2 & - & 24.1 & 60.7 & - & 71.9 & 84.4 & 79.0 & 70.0 \\
\hline 8.0 & Holz & 4.2 & 32.9 & 21.1 & 32.7 & 9.0 & 69.9 & 58.3 & $6 S .0$ & 102.8 & 36.7 & 10.5 \\
\hline 7.6 & lỉinde & - & 24.0 & 15.4 & - & 26.2 & 58.4 & - & 70.9 & 82.4 & 77.5 & 69.1 \\
\hline 3.5 & Holz & 4.2 & 29.3 & 18.8 & 29.1 & 9.1 & 72.1 & 61.8 & 71.1 & 101.4 & 33.6 & 12.7 \\
\hline & $\mathrm{cr}$ & & 35.6 & 22.8 & 35.3 & 12.6 & 64.6 & 52.1 & - & 100.2 & - & - \\
\hline
\end{tabular}


Kiefer.

Alter 35 Jahre.

12. Oetober 1881 .

Höhe $11 \mathrm{~m}$. Kronenansatz $-\mathrm{m}$. Inhalt $0.061 \mathrm{~cm}$. Wasser $60.5 \%$. Substanz $27.8 \mathrm{ccm}$.

\begin{tabular}{|c|c|c|c|c|c|c|c|c|c|c|c|c|}
\hline \multirow{3}{*}{ 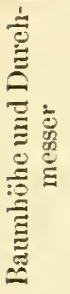 } & \multirow{3}{*}{ Baumtheil } & \multirow{3}{*}{ 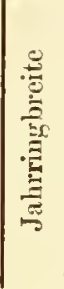 } & \multicolumn{3}{|c|}{$\begin{array}{l}\text { Organische Substanz } \\
\text { in } 100 \text { Ramtheilen } \\
\text { frischen Holzes }\end{array}$} & \multirow{3}{*}{$\underset{\Xi}{\Xi}$} & \multicolumn{3}{|c|}{ Wassergehalt } & \multicolumn{2}{|c|}{$\begin{array}{l}\text { Speeifisches } \\
\text { Gewicht }\end{array}$} & \multirow{3}{*}{ 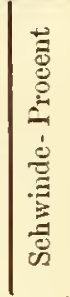 } \\
\hline & & & & Raun & theile & & \multicolumn{2}{|c|}{ in 100 Ranmtheil. } & \multirow{2}{*}{$\begin{array}{l}\text { anf } \\
100 \mathrm{Ge-} \\
\text { wichts- } \\
\text { Ein- } \\
\text { heiten }\end{array}$} & \multirow{2}{*}{ frisch } & \multirow{2}{*}{ trocken } & \\
\hline & & & & trocken & imbibirt & & Gamen & Znst: & & & & \\
\hline $\mathrm{a}$ & $\mathrm{b}$ & c & d & $\mathrm{e}$ & $\mathrm{f}$ & $g$ & $\mathrm{~h}$ & i & $\mathrm{k}$ & 1 & $\mathrm{~m}$ & n \\
\hline 1.3 & Rinde & - & 22.8 & 14.6 & - & - & 51.6 & - & 69.4 & 74.4 & 68.0 & 66.7 \\
\hline - & Splint & 1.8 & 46.8 & 30.0 & 46.5 & 9.7 & 60.3 & 43.8 & 56.2 & 107.1 & 55.3 & 15.2 \\
\hline - & M. u. K. & 2.8 & 40.8 & 26.1 & 39.2 & 20.7 & 53.2 & 40.1 & 56.5 & 94.0 & 46.3 & 11.7 \\
\hline 12.0 & $\% . \mathrm{Holz}$ & 2.1 & 45.3 & 29.0 & 41.7 & 12.6 & 58.4 & 42.7 & 56.3 & 103.7 & 52.9 & 14.8 \\
\hline 3.4 & Rinde & - & 22.5 & 14.4 & - & - & 53.4 & - & 70.8 & 75.9 & 66.0 & 66.0 \\
\hline - & Splint & 2.4 & 42.9 & 27.5 & 42.6 & 9.1 & 63.4 & 48.3 & 59.6 & 106.3 & 49.3 & 13.0 \\
\hline - & il. u. li. & 3.5 & $: 9.1$ & 25.0 & 37.5 & 22.8 & 57.2 & 39.7 & 59.4 & 96.3 & 43.5 & 10.8 \\
\hline 10.5 & $\% . \mathrm{Holz}$ & 2.7 & 42.1 & 27.0 & 41.6 & 10.9 & 62.1 & 47.5 & 59.6 & 104.2 & 48.1 & 12.5 \\
\hline 5.5 & Rinde & - & 24.2 & 15.5 & - & - & 53.4 & - & 68.8 & 77.6 & 72.1 & 66.5 \\
\hline 9.0 & Holz & 2.9 & 42.2 & 27.0 & 41.9 & 10.0 & 63.0 & 48.1 & 59.9 & 10.5 .2 & 48.1 & 12.2 \\
\hline 7.6 & Rinde & - & 29.5 & 18.9 & - & - & 56.8 & - & 65.3 & 86.3 & 84.8 & 65.2 \\
\hline 6.5 & Holz & 3.2 & 44.7 & 28.7 & 44.5 & 12.4 & 58.9 & 43.1 & 56.9 & 103.6 & 50.9 & 12.3 \\
\hline 9.7 & Rinde & - & 25.8 & 16.5 & - & - & 55.0 & 一 & 68.1 & 80.8 & 76.1 & 66.2 \\
\hline 3.0 & Holz & 3.7 & 39.9 & 25.6 & 39.7 & 14.2 & 60.2 & 46.1 & 60.1 & 100.1 & 44.4 & 10.5 \\
\hline & & & 43.5 & 27.8 & 43.1 & 11.6 & 60.5 & 45.3 & - & 104.0 & - & - \\
\hline
\end{tabular}




\section{Fichte.}

Alter 25 Jahre.

2. Januar 1882.

Höhe $9 \mathrm{~m}$. Kroneuansatz $-\mathrm{m}$. Inhalt $-\mathrm{em}$. Wasser $62.9^{\circ} 0$. Substanz $25.8 \mathrm{ccm}$.

\begin{tabular}{|c|c|c|c|c|c|c|c|c|c|c|c|c|}
\hline \multirow{3}{*}{ 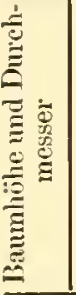 } & \multirow{3}{*}{ Baumtheil } & \multirow{3}{*}{ 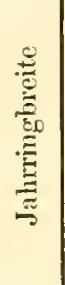 } & \multicolumn{3}{|c|}{$\begin{array}{l}\text { Organische Substanz } \\
\text { in } 100 \text { Ranmtireilen } \\
\text { frischen Holzes }\end{array}$} & \multirow{3}{*}{$\stackrel{\Xi}{\stackrel{\Xi}{\Xi}}$} & \multicolumn{3}{|c|}{ Wassergehalt } & \multicolumn{2}{|c|}{$\begin{array}{l}\text { Specifisches } \\
\text { Gewicht }\end{array}$} & \multirow{3}{*}{ 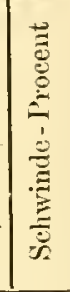 } \\
\hline & & & \multirow{2}{*}{ Gramme } & \multicolumn{2}{|c|}{ Raumtheile } & & \multicolumn{2}{|c|}{ in 100 Ranmtheil. } & \multirow{2}{*}{$\begin{array}{c}\operatorname{anf} \\
100 \mathrm{Ge}- \\
\text { wichts- } \\
\text { Ein- } \\
\text { heiten }\end{array}$} & \multirow{2}{*}{ frisch } & \multirow{2}{*}{ trocken } & \\
\hline & & & & trocken & imbibirt & & \begin{tabular}{|c|} 
in \\
Ganzen
\end{tabular} & $\begin{array}{l}\text { in flûss. } \\
\text { Znstand }\end{array}$ & & & & \\
\hline$a$ & $\mathrm{~b}$ & $\mathrm{c}$ & d & $\mathrm{e}$ & $f$ & $g$ & $\mathrm{~h}$ & $\mathrm{i}$ & $\mathrm{k}$ & 1 & $\mathrm{~m}$ & $\mathrm{n}$ \\
\hline 1.3 & Riude & - & 27.8 & 17.8 & - & 28.2 & 54.0 & - & 66.0 & 81.8 & 72.4 & 61.5 \\
\hline - & Splint & 1.8 & 40.5 & 26.0 & 41.6 & 11.4 & 62.6 & 47.0 & 60.7 & 103.1 & 47.0 & 13.2 \\
\hline 11.0 & $\because \mathrm{Holz}$ & - & - & - & - & - & - & - & - & - & - & - \\
\hline 3.4 & Rinde & - & 25.5 & 16.3 & - & 25.9 & 57.8 & - & 69.3 & 83.3 & 74.5 & 65.7 \\
\hline- & Splint & 2.3 & 43.8 & 28.1 & 45.0 & 9.7 & 62.2 & 45.3 & 58.7 & 106.0 & 51.2 & 14.5 \\
\hline - & M. u. K. & 3.8 & 40.4 & 25.9 & 41.4 & 45.7 & 28.4 & 12.9 & 41.3 & 68.8 & 46.9 & 14.0 \\
\hline - & . Holz & 2.7 & 42.7 & 27.4 & 43.8 & 21.5 & 51.1 & 34.7 & 54.5 & 93.8 & 49.8 & 14.4 \\
\hline 5.5 & Rinde & - & 23.7 & 15.2 & - & 31.9 & 52.9 & - & 69.1 & 76.6 & 63.6 & 62.7 \\
\hline - & Splint & 2.6 & 40.7 & 26.1 & 41.8 & 8.8 & 6.5 .6 & 49.9 & 61.7 & 106.3 & 46.6 & 12.7 \\
\hline - & M. u. K. & 4.0 & 38.6 & 24.7 & 39.5 & 37.8 & 37.5 & 22.7 & 49.3 & 76.1 & 42.0 & 8.2 \\
\hline- & $\cdot \% \mathrm{Holz}$ & - & 40.1 & 25.7 & 41.1 & 15.7 & 58.6 & 43.2 & 59.4 & 98.7 & 45.4 & 11.6 \\
\hline 7.6 & Rinde & - & 24.9 & 16.0 & - & 35.8 & 48.2 & - & 65.9 & 73.1 & 69.1 & 63.9 \\
\hline 4.5 & Holz & 3.5 & 40.2 & 25.8 & 41.3 & 11.8 & 62.9 & 47.4 & 61.0 & 103.1 & 45.0 & 10.7 \\
\hline & & & - & - & - & - & - & - & - & - & - & \\
\hline
\end{tabular}


Tab. 41.

Fichte.

Alter 35 Jahre.

4. März 1882.

Höhe $15 \mathrm{~m}$. Kronenansatz - m. Inhalt $0.154 \mathrm{~cm}$. Wasser $60.9 \%$. Substanz $22.7 \mathrm{ccm}$.

\begin{tabular}{|c|c|c|c|c|c|c|c|c|c|c|c|c|}
\hline \multirow{3}{*}{ 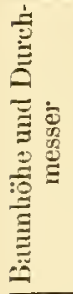 } & \multirow{3}{*}{ Baumtheil } & \multirow{3}{*}{ 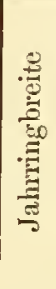 } & \multicolumn{3}{|c|}{$\begin{array}{l}\text { Organische Substanz } \\
\text { in } 100 \text { Ranmtheilen } \\
\text { fischen Hotzes }\end{array}$} & \multirow{3}{*}{$\stackrel{\Xi}{\Xi}$} & \multicolumn{3}{|c|}{ Wassergehalt } & \multicolumn{2}{|c|}{$\begin{array}{l}\text { Specifisches } \\
\text { Gewicht }\end{array}$} & \multirow{3}{*}{ 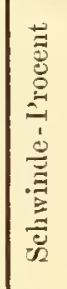 } \\
\hline & & & \multirow{2}{*}{ Gramme } & \multicolumn{2}{|c|}{ Rauntheile } & & \multicolumn{2}{|c|}{$0 \mathrm{Rat}$} & \multirow{2}{*}{$\begin{array}{l}\text { auf } \\
100 \mathrm{Ge}- \\
\text { wichits- } \\
\text { Ein- } \\
\text { heiten }\end{array}$} & \multirow{2}{*}{ friseli } & \multirow{2}{*}{ trocken } & \\
\hline & & & & trocken & bibirt & & $\begin{array}{c}\text { im } \\
\text { cinnzen }\end{array}$ & $\begin{array}{l}\text { in fứss. } \\
\text { Zustand }\end{array}$ & & & & \\
\hline a & b & $\mathrm{c}$ & $d$ & e & $\mathrm{f}$ & $g$ & h & $\mathrm{i}$ & $\mathrm{k}$ & 1 & $\mathrm{~m}$ & $\mathbf{n}$ \\
\hline 1.3 & Rinde & - & 30.6 & 19.6 & - & 33.5 & 46.9 & $\rightarrow$ & 60.5 & 77.5 & 69.7 & 56.0 \\
\hline - & Splint & 2.8 & 37.2 & 23.9 & 38.2 & 7.6 & 68.5 & 54.2 & 64.8 & 105.7 & 41.2 & 9.9 \\
\hline- & M. u. K. & 3.2 & 36.6 & 23.5 & 37.6 & 42.3 & 34.2 & 20.1 & 48.8 & 70.8 & 40.8 & 10.3 \\
\hline 16.5 & $\cdot \%$ Holz & 3.0 & 36.9 & 23.7 & 37.9 & 19.7 & 56.6 & 42.4 & 60.5 & 93.5 & 41.1 & 10.0 \\
\hline 3.4 & Rinde & - & 28.6 & 18.3 & - & 34.3 & 47.4 & - & 62.4 & 76.0 & 67.5 & 57.7 \\
\hline- & Splint & $\because 3.3$ & 34.6 & 22.2 & 35.5 & 8.7 & 69.1 & 55.8 & 66.6 & 103.7 & 39.4 & 12.3 \\
\hline- & M. u. K. & 3.5 & 35.9 & 23.0 & 36.8 & 45.9 & 81.1 & 17.3 & 46.5 & 67.0 & 39.9 & 10.2 \\
\hline 15.0 & $\% . \mathrm{Holz}$ & 3.4 & 34.9 & 22.4 & 35.8 & 19.1 & 58.5 & 45.1 & 62.6 & 93.4 & 39.6 & 11.7 \\
\hline 5.5 & Rinde & - & 29.6 & 19.0 & - & 34.2 & 46.8 & 一 & 61.3 & 76.4 & 67.1 & 56.0 \\
\hline 一 & Splint & 3.3 & 34.0 & 21.8 & 34.9 & 5.5 & 72.7 & 59.6 & 68.1 & 106.7 & 39.0 & 12.6 \\
\hline- & M. u. K. & 4.3 & 36.5 & 23.4 & 37.4 & 37.5 & 39.1 & 25.1 & 51.7 & 75.6 & 40.9 & 10.7 \\
\hline 14.0 &.$/ \cdot \mathrm{Holz}$ & 3.7 & 34.8 & 22.3 & 35.7 & 15.4 & 62.3 & 48.9 & 64.1 & 97.1 & 39.6 & 12.1 \\
\hline 7.6 & Rinde & - & 30.0 & 19.2 & - & 34.9 & 45.9 & - & 60.4 & 75.9 & 68.8 & 56.0 \\
\hline - & Splint & 4.2 & 35.3 & 22.6 & 36.2 & 8.5 & 68.9 & 55.5 & 66.1 & 104.2 & 39.4 & 10.5 \\
\hline - & 11. u. K. & 4.7 & 38.4 & 24.6 & 39.4 & 24.6 & 50.8 & 36.0 & 57.0 & 89.2 & 42.8 & 9.4 \\
\hline 12.0 & \%. Holz & 4.4 & 36.2 & 23.2 & 37.1 & 13.6 & 60.2 & 49.3 & 63.5 & 99.4 & 40.8 & 10.1 \\
\hline 9.7 & Rinde & - & 28.1 & 18.0 & $\ldots$ & 86.2 & 45.8 & - & 61.9 & 73.9 & 65.6 & 57.1 \\
\hline 一 & Splint & 4.3 & 32.5 & 20.8 & 293.3 & 5.4 & 73.8 & 61.3 & 69.4 & 106.3 & 37.2 & 12.7 \\
\hline 一 & II. I. K. & 3.8 & 37.2 & 23.9 & 35.2 & 21.2 & 54.9 & 40.6 & 59.6 & 92.1 & 40.6 & 8.2 \\
\hline 10.0 & - Holz & 4.1 & 33.8 & 21.7 & 34.7 & 9.9 & 68.4 & 5.5 .4 & 66.9 & 102.2 & 38.2 & 11.5 \\
\hline 11.8 & Rinde & - & 27.4 & 5 & - & 35.8 & 46.7 & - & 63.1 & 74.1 & 65.9 & $\$ 8.5$ \\
\hline 6 & Holz & 5.5 & 33.1 & 21.2 & 33.9 & 10.3 & 68.5 & 55.8 & 67.4 & 101.6 & 38.3 & 13.5 \\
\hline 13.9 & Holz & 4.0 & 40.3 & 25.8 & 41.3 & 10.3 & 63.9 & 48.4 & 61.3 & 104.2 & 43.4 & 10.2 \\
\hline & & & 35.4 & 22.7 & 36.3 & 16.4 & 60.9 & 46.8 & - & 96.3 & - & - \\
\hline
\end{tabular}


Tab. 42.

\section{Fichte.}

Alter 25 Jahre.

19. Mlai 1881.

Höhe $9.0 \mathrm{~m}$. Kronenansatz $-\mathrm{m}$. Inhalt $0.0244 \mathrm{~cm}$. Wasser $60.5 \%$. Substanz 23.7 cem.

\begin{tabular}{|c|c|c|c|c|c|c|c|c|c|c|c|c|}
\hline \multirow{3}{*}{ 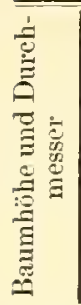 } & \multirow{3}{*}{ Baumtheil } & \multirow{3}{*}{ 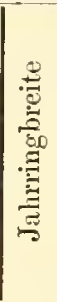 } & \multicolumn{3}{|c|}{$\begin{array}{l}\text { Organische Substanz } \\
\text { in } 100 \text { Ranmtheilen } \\
\text { frischen IIolzes }\end{array}$} & \multirow{3}{*}{ 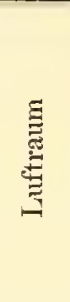 } & \multicolumn{3}{|c|}{ Wassergehalt } & \multicolumn{2}{|c|}{$\begin{array}{c}\text { Specifisches } \\
\text { Gewicht }\end{array}$} & \multirow{3}{*}{ 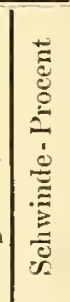 } \\
\hline & & & \multirow{2}{*}{ Gramme } & \multicolumn{2}{|c|}{ Raumtheile } & & \multicolumn{2}{|c|}{ in 100 Ranntheil. } & \multirow{2}{*}{$\begin{array}{l}\text { anf } \\
100 \mathrm{Ge-} \\
\text { wichts- } \\
\text { Ein- } \\
\text { heiten }\end{array}$} & \multirow{2}{*}{ frisch } & \multirow{2}{*}{ trocken } & \\
\hline & & & & trocken & imbibirt & & $\operatorname{im}_{\text {Ganzen }}$ & $\begin{array}{l}\text { in } \text { Aūss. } \\
\text { Zustand }\end{array}$ & & & & \\
\hline$\vec{a}$ & b & $\mathrm{c}$ & d & e & $f$ & $\mathrm{~g}$ & $\bar{h}$ & $\bar{i}$ & $\mathrm{k}$ & 1 & $m$ & n \\
\hline 1.3 & Rinde & - & 86.9 & 23.7 & 一 & 23.5 & 52.8 & - & 58.9 & 89.7 & 77.4 & 52.3 \\
\hline 8.5 & $\mathrm{Holz}$ & 2.3 & 37.4 & 24.0 & 38.4 & 15.2 & 60.8 & 46.4 & 61.9 & 98.2 & 43.5 & 14.1 \\
\hline 3.4 & Rinde & - & 37.0 & 23.7 & - & 21.0 & 55.3 & - & 59.9 & 92.3 & 77.6 & 52.3 \\
\hline 7.0 & Holz & 2.6 & 38.2 & 24.5 & 39.2 & 17.4 & 58.1 & 43.4 & 60.4 & 96.3 & 43.5 & 12.4 \\
\hline 5.5 & Rinde & - & 37.0 & 23.7 & - & 15.1 & 61.2 & - & 62.4 & 98.2 & 86.6 & 57.3 \\
\hline 5.0 & llolz & 3.6 & 35.1 & 22.5 & 36.0 & 13.7 & 63.8 & 50.3 & 64.5 & 98.9 & 40.5 & 13.3 \\
\hline 1.0 & Rinde & - & 39.7 & 25.4 & - & 一 & 75.1 & - & 65.4 & 114.8 & 92.7 & 57.1 \\
\hline 3.0 & Holz & 4.0 & 36.0 & 23.1 & 37.0 & 14.6 & 62.3 & 48.4 & 63.4 & 98.3 & 40.6 & 11.1 \\
\hline & 1. St & & 37.0 & 23.7 & 37.9 & 15.8 & 60.5 & 46.3 & - & 97.5 & - & \\
\hline
\end{tabular}


Tab. 43.

\section{Fichte.}

Alter 25 Jahre.

9. Juli 1881.

Höhe $9 \mathrm{~m}$. Kronenansatz - m. Inhalt $0.0253 \mathrm{~cm}$. Wasser $26.7 \%$. Substanz $23.1 \mathrm{ccm}$.

\begin{tabular}{|c|c|c|c|c|c|c|c|c|c|c|c|c|}
\hline \multirow{3}{*}{ 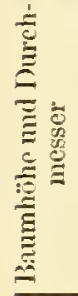 } & \multirow{3}{*}{ Banmtheil } & \multirow{3}{*}{ 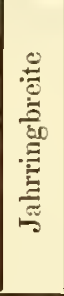 } & \multicolumn{3}{|c|}{$\begin{array}{c}\text { Organische Substanz } \\
\text { in } 100 \text { Ranmtheilen } \\
\text { frischen Holzes }\end{array}$} & \multirow{3}{*}{ 㐏 } & \multicolumn{3}{|c|}{ Wassergehalt } & \multicolumn{2}{|c|}{$\begin{array}{l}\text { Specifisches } \\
\text { Gewicht }\end{array}$} & \multirow{3}{*}{ 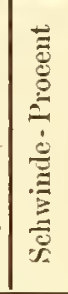 } \\
\hline & & & \multirow{2}{*}{ Gramme } & \multicolumn{2}{|c|}{ Raumtheile } & & \multicolumn{2}{|c|}{ in 100 Raumtheil. } & \multirow{2}{*}{$\begin{array}{l}\text { anf } \\
100 \text { Go- } \\
\text { wichts- } \\
\text { Ein- } \\
\text { heiten }\end{array}$} & \multirow{2}{*}{ frisch } & \multirow{2}{*}{ trocken } & \\
\hline & & & & trocken & imbibirt & & Ganzen & $\begin{array}{l}\text { in fluss. } \\
\text { Zustand }\end{array}$ & & & & \\
\hline a & $\mathrm{b}$ & c & $d$ & e & f & $\mathrm{g}$ & h & $\mathrm{i}$ & $\mathrm{k}$ & 1 & $\mathrm{~m}$ & $\mathrm{n}$ \\
\hline 1.3 & Rinde & - & 32.4 & 20.8 & - & 31.5 & 47.7 & - & 60.3 & 79.1 & 74.3 & 37.7 \\
\hline 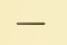 & Splint & 1.6 & 38.4 & 24.6 & 39.4 & 8.8 & 66.6 & 51.8 & 63.4 & 10.5 & 43.1 & 10.9 \\
\hline 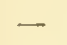 & M. и. K. & 2.9 & 40.5 & 26.0 & 41.6 & 44.9 & 29.1 & 13.5 & 41.1 & 69.6 & 44.6 & 9.8 \\
\hline 8.0 & . Holz & 2.1 & 39.0 & 25.0 & 40.0 & 18.5 & 56.5 & 41.5 & 59.2 & 95.5 & 43.5 & 10.1 \\
\hline 3.4 & linde & - & 28.8 & 18.5 & - & 80.0 & 51.5 & - & 64.1 & 80.3 & 74.6 & 61.4 \\
\hline - & Splint & 2.7 & 35.2 & 22.6 & 36.2 & 6.5 & 70.9 & 57.3 & 66.8 & 106.1 & 41.0 & 14.0 \\
\hline 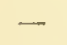 & M. u. K. & 3.6 & 35.2 & 22.6 & 36.2 & 38.6 & 38.8 & 25.2 & 52.4 & 74.0 & 38.3 & 8.0 \\
\hline 7.0 & $\because$ Holz & 3.1 & 35.2 & 22.6 & 36.2 & 13.8 & 63.6 & 50.0 & 61.4 & 98.8 & $40 .: 3$ & 12.7 \\
\hline 5.5 & Rinde & - & 27.2 & 17.4 & - & 28.9 & 53.7 & - & 66.4 & 80.9 & $\pi 2.8$ & 62.6 \\
\hline 6.0 & Holz & 3.5 & 33.1 & 21.2 & 33.9 & 10.0 & 68.8 & 56.1 & 67.6 & 101.9 & 38.6 & 13.2 \\
\hline 7.6 & Rinde & - & 24.6 & 15.8 & - & 26.8 & 57.9 & - & 70.2 & 82.5 & 73.8 & 66.4 \\
\hline 3.5 & Holz & 4.0 & 31.6 & 20.2 & 32.3 & 6.2 & 73.6 & 61.5 & 69.9 & 105.2 & 37.7 & 16.1 \\
\hline & 9 & & 36.0 & 23.1 & 37.0 & 14.2 & 62.7 & 48.8 & - & 98.7 & - & - \\
\hline
\end{tabular}




\section{Fichte.}

Alter 35 Jahre.

12. October 1881.

Höhe $12 \mathrm{~m}$. Kronenansatz $-\mathrm{m}$. Inhalt $0.040 \mathrm{~cm}$. Wasser $43.2 \%$. Substanz $22.7 \mathrm{ccm}$.

\begin{tabular}{|c|c|c|c|c|c|c|c|c|c|c|c|c|}
\hline \multirow{3}{*}{ 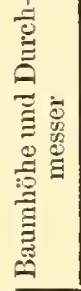 } & \multirow{3}{*}{ Baumtheil } & \multirow{3}{*}{ 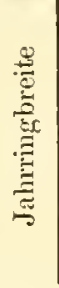 } & \multicolumn{3}{|c|}{$\begin{array}{c}\text { Organische Substanz } \\
\text { in } 100 \text { Raumtheilen } \\
\text { frischen Holzes }\end{array}$} & \multirow{3}{*}{ 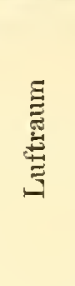 } & \multicolumn{3}{|c|}{ Wassergelıatt } & \multicolumn{2}{|c|}{$\begin{array}{l}\text { Specifisches } \\
\text { Gewicht }\end{array}$} & \multirow{3}{*}{ 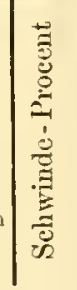 } \\
\hline & & & \multirow{2}{*}{ Gramme } & \multirow{2}{*}{\multicolumn{2}{|c|}{ Raumtheile }} & & \multicolumn{2}{|c|}{ in 100 Raum theil. } & \multirow{2}{*}{$\begin{array}{l}\text { auf } \\
100 \mathrm{Ge}- \\
\text { wichts- } \\
\text { Ein- } \\
\text { heiten }\end{array}$} & \multirow{2}{*}{ frisch } & \multirow{2}{*}{ trocken } & \\
\hline & & & & & & & $\operatorname{im}_{\text {Gamzen }}$ & $\begin{array}{l}\text { in funse. } \\
\text { Zustand }\end{array}$ & & & & \\
\hline a & b & $\mathrm{c}$ & $d$ & $\mathrm{e}$ & $f$ & $g$ & $\mathrm{~h}$ & i & $\mathrm{k}$ & I & $\mathrm{m}$ & $\mathrm{n}$ \\
\hline 1.3 & Rinde & - & 27.3 & 17.5 & - & 32.2 & 50.3 & - & 64.8 & 77.6 & 66.3 & 58.9 \\
\hline 一 & Splint & 1.4 & 38.3 & 24.5 & 39.2 & 12.5 & 63.0 & 48.3 & 62.2 & 101.8 & 42.4 & 9.7 \\
\hline - & M. u. K. & 3.5 & 32.8 & 21.0 & 33.6 & 59.2 & 19.8 & 7.2 & 37.7 & 52.6 & 36.2 & 9.5 \\
\hline 9.5 & ./. Holz & 1.5 & 35.8 & 22.9 & 36.6 & 33.9 & 43.2 & 29.5 & 54.7 & 79.0 & 39.6 & 9.6 \\
\hline .3 .4 & Rinde & - & 26.0 & 16.6 & - & 32.9 & 50.5 & - & 66.0 & 76.5 & 67.1 & 61.2 \\
\hline - & Splint & 1.9 & 36.7 & 23.5 & 37.6 & 21.4 & 55.1 & 41.0 & 60.0 & 91.8 & 42.5 & 13.4 \\
\hline - & M. u. K. & 3.0 & 34.3 & 22.0 & 35.2 & 57.5 & 20.5 & 7.3 & 37.3 & 54.8 & 38.7 & 11.2 \\
\hline 8.5 & $\cdot / / \mathrm{Holz}$ & 2.3 & 36.0 & 23.1 & 37.0 & 34.5 & 42.1 & 28.9 & 54.1 & 77.4 & 41.0 & 12.3 \\
\hline 5.5 & linde & - & 27.5 & 17.6 & - & 31.3 & 51.1 & - & 65.0 & 78.6 & 70.5 & 60.9 \\
\hline - & Splint & 2.3 & 36.3 & 23.3 & 37.3 & 22.9 & 53.8 & 39.8 & 59.7 & 90.1 & 41.7 & 12.9 \\
\hline- & M. u. K. & 4.0 & 33.9 & 21.7 & 34.7 & 62.8 & 15.5 & 2.5 & $\$ 1.3$ & 49.4 & 37.6 & 9.7 \\
\hline 7.0 & $\%$ Holz & 3.0 & 35.2 & 22.5 & 36.0 & 40.2 & 37.3 & 23.8 & 51.4 & 72.8 & 39.9 & 11.5 \\
\hline 7.6 & Rinde & - & 26.7 & 17.1 & - & 34.4 & 48.5 & - & 64.4 & 75.2 & 78.4 & 63.6 \\
\hline 5.5 & Ilolz & 3.8 & 34.6 & 22.1 & 35.4 & 32.2 & 45.7 & 32.4 & 56.9 & 80.3 & 39.7 & 12.7 \\
\hline 9.7 & Rinde & 一 & 24.1 & 15.5 & - & 80.4 & 54.1 & - & 69.2 & 78.2 & 61.3 & 60.6 \\
\hline 3.5 & Holz & 3.5 & 32.7 & 20.9 & 33.4 & 12.7 & 66.4 & 53.9 & 67.0 & 99.1 & 36.8 & 11.1 \\
\hline & & & 35.4 & 22.7 & 36.3 & 34.1 & 43.2 & 29.6 & - & 78.6 & - & \\
\hline
\end{tabular}


Raumverhältnisse zwischen Luft und flüssigem Wasser.

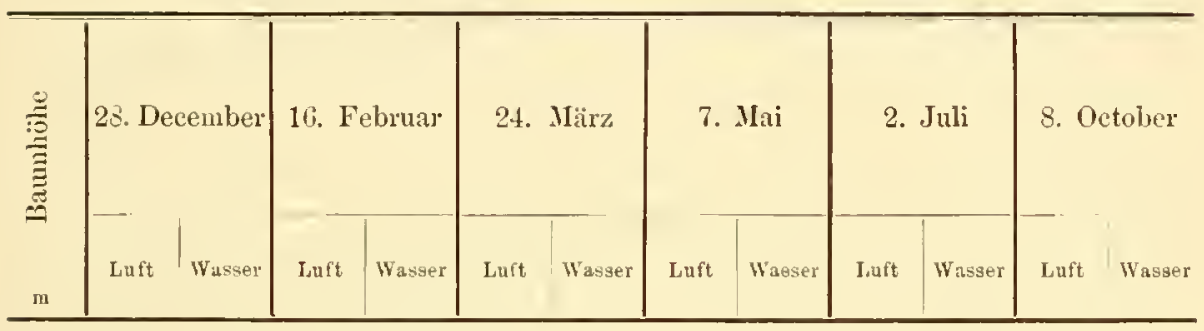

Birke. Ganzer Holzkörper.

\begin{tabular}{c|cc|c|c|cc|c|c|c|c|c|c}
\hline 1.3 & 53.7 & 46.3 & 56.2 & 43.8 & 32.4 & 67.6 & 37.8 & 62.2 & 55.7 & 44.3 & 68.7 & 31.3 \\
3.5 & 54.9 & 45.1 & 53.9 & 46.1 & 33.0 & 67.0 & 40.6 & 59.4 & 49.9 & 50.1 & 60.9 & 39.1 \\
5.7 & 61.3 & 38.7 & 58.3 & 41.7 & 32.1 & 67.9 & 37.6 & 62.4 & 41.3 & 55.7 & 57.7 & 42.3 \\
7.9 & 66.9 & 33.1 & 57.9 & 43.1 & 30.0 & 70.0 & 26.4 & 73.6 & 47.6 & 52.4 & 56.3 & 43.7 \\
10.1 & 71.8 & 28.2 & 59.3 & 40.7 & 24.3 & 75.7 & 15.0 & 55.0 & 33.3 & 66.7 & 60.2 & 39.8 \\
$\%$. & 56.7 & 43.3 & 56.4 & 43.6 & 32.1 & 67.9 & 36.6 & 63.4 & 51.3 & 48.7 & 62.8 & 37.2 \\
\hline
\end{tabular}

Birke. Splint.

\begin{tabular}{r|c|c|c|c|c|c|c|c|c|c|c|c}
\hline 1.3 & 50.0 & 50.0 & 60.2 & 39.8 & 31.2 & 68.8 & 33.1 & 66.9 & 51.8 & 48.2 & 71.4 & 28.6 \\
3.5 & 59.8 & 46.7 & 56.4 & 43.6 & 26.9 & 73.1 & 31.9 & 68.1 & 49.4 & 50.6 & 61.8 & 38.2 \\
5.7 & 65.3 & 34.7 & 71.2 & 28.8 & 29.9 & 70.1 & 28.8 & 71.2 & 41.1 & 58.9 & 52.7 & 41.3 \\
7.9 & 66.9 & 33.1 & 57.9 & 42.1 & 30.0 & 70.0 & 26.4 & 73.6 & 47.6 & 52.4 & 56.3 & 4.7 .7 \\
10.1 & 71.8 & 28.2 & 59.3 & 40.7 & 24.3 & 75.7 & 15.0 & 85.0 & 33.3 & 66.7 & 60.2 & 39.8 \\
.$"$. & 54.9 & 45.1 & 61.0 & 39.0 & 29.6 & 70.4 & 30.3 & 69.7 & 48.7 & 51.3 & 64.4 & 35.6 \\
\hline
\end{tabular}

Rothbuche. Ganzer Holzkörper.

\begin{tabular}{r|c|c|c|c|c|c|c|c|c|c|c|c}
\hline 1.5 & 52.1 & 47.9 & 62.1 & 37.9 & 70.4 & 29.6 & 61.6 & 38.4 & 51.4 & 48.6 & 63.6 & 36.4 \\
3.7 & 47.5 & 52.5 & 62.2 & 37.8 & 58.2 & 41.8 & 55.4 & 41.6 & 49.0 & 51.0 & 60.3 & 39.7 \\
5.9 & 40.3 & 59.7 & 60.5 & 39.5 & 55.6 & 44.4 & 56.6 & 43.4 & 50.8 & 49.2 & 58.1 & 41.9 \\
8.1 & 35.4 & 64.6 & 55.8 & 41.2 & 52.0 & 48.0 & 54.7 & 45.5 & 47.9 & 52.1 & 54.8 & 45.2 \\
10.3 & 30.2 & 69.8 & 48.6 & 51.4 & 50.6 & 49.4 & 50.1 & 49.9 & - & - & 58.9 & 41.1 \\
12.5 & 27.4 & 72.6 & 47.4 & 52.6 & 49.8 & 50.2 & 47.0 & 53.0 & 44.7 & 55.3 & 57.2 & 42.8 \\
14.7 & 24.2 & 75.8 & 44.1 & 55.9 & 37.2 & 52.8 & 46.6 & 53.4 & 47.6 & 52.4 & 56.9 & 43.1 \\
16.9 & 25.3 & 74.7 & 41.8 & 58.2 & - & - & - & - & 4.5 & 54.5 & 46.5 & 5.3 .5 \\
$\%$ & 41.3 & 58.7 & 57.0 & 43.0 & 53.2 & 41.8 & 58.8 & 41.2 & 49.4 & 50.6 & 59.0 & 41.0 \\
\hline
\end{tabular}

Rothbuche. Splint.

\begin{tabular}{r|c|c|c|c|c|c|c|c|c|c|c|c}
\hline 1.5 & 39.2 & 60.8 & 49.8 & 50.2 & 64.9 & 35.1 & 45.2 & 54.8 & 36.0 & 64.0 & 53.3 & 47.7 \\
3.7 & 28.7 & 71.3 & 48.7 & 51.3 & 52.8 & 47.2 & 38.6 & 61.4 & 28.4 & 71.6 & 45.3 & 54.7 \\
5.9 & 31.1 & 68.9 & 47.3 & 52.7 & 50.1 & 49.9 & 42.5 & 57.5 & 27.1 & 72.9 & 42.2 & 57.8 \\
8.1 & 27.7 & 72.3 & 48.8 & 51.2 & 48.6 & 51.4 & 36.5 & 63.5 & 22.2 & 77.8 & 40.4 & 59.6 \\
10.3 & 26.1 & 73.9 & 40.0 & 60.0 & 49.2 & 50.8 & 30.8 & 69.2 & - & - & 43.7 & 56.3 \\
12.5 & 25.2 & 74.8 & 38.9 & 61.1 & 47.3 & 52.7 & 29.6 & 70.4 & 25.4 & 74.6 & 40.9 & 59.1 \\
14.7 & 25.7 & 74.3 & 41.7 & 58.3 & 37.2 & 52.8 & 46.6 & 53.4 & 39.2 & 60.8 & 40.6 & 59.4 \\
16.9 & 23.1 & 76.9 & 32.1 & 67.9 & - & - & - & - & 45.5 & 54.0 & 36.5 & 69.5 \\
$\because \%$ & 30.4 & 69.6 & 46.8 & 54.2 & 53.3 & 46.7 & 39.2 & 60.8 & 29.3 & 70.7 & 44.5 & 55.5
\end{tabular}




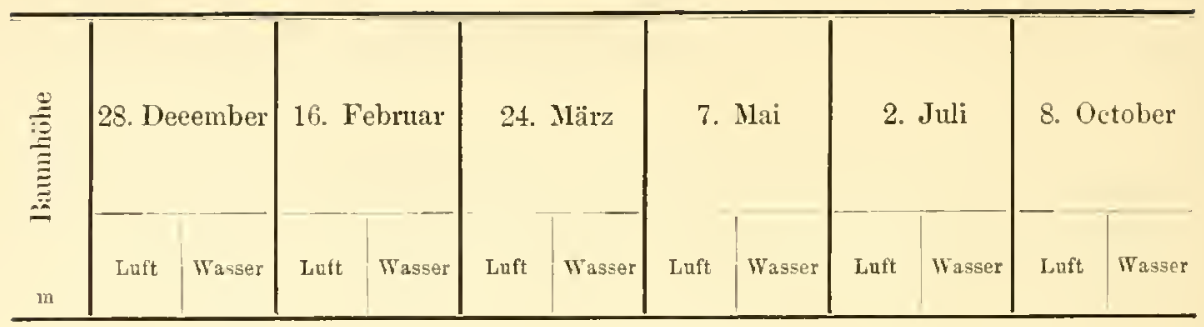

Eiche. Ganzer Holzkörper.

\begin{tabular}{c|c|c|c|c|c|c|c|c|c|c|c|c}
\hline 1.3 & 57.3 & 42.7 & 59.6 & 40.4 & - & - & 58.8 & 41.2 & 50.3 & 49.7 & 56.6 & 43.4 \\
3.5 & 61.2 & 38.8 & 61.6 & 38.4 & - & - & 57.2 & 42.8 & 53.9 & 46.1 & 56.0 & 44.0 \\
5.7 & 62.2 & 37.8 & 64.9 & 35.1 & - & - & 61.5 & 35.5 & 52.0 & 48.0 & 56.8 & 43.2 \\
7.9 & 65.7 & 34.3 & 68.5 & 31.5 & - & - & 64.0 & 36.0 & 49.7 & 50.3 & 58.5 & 41.2 \\
10.1 & 76.5 & 23.5 & 68.1 & 31.9 & - & - & 65.5 & 34.5 & 48.1 & 51.9 & 64.2 & 35.8 \\
12.3 & 80.1 & 19.9 & 87.1 & 12.9 & - & - & 78.3 & 21.7 & 46.5 & 53.5 & 77.0 & 23.0 \\
$\%$ & 61.4 & 38.6 & 61.5 & 38.5 & - & - & 60.4 & 39.6 & 51.2 & 43.5 & 57.3 & 42.7 \\
\hline
\end{tabular}

Eiche. Splint.

\begin{tabular}{r|c|c|c|c|c|c|c|c|c|c|c|c}
\hline 1.3 & 59.0 & 41.0 & 64.5 & 3.5 .5 & - & - & 66.5 & 33.5 & 40.9 & 59.1 & 60.7 & 39.3 \\
3.5 & 65.2 & 34.8 & 67.6 & 32.4 & - & - & 67.1 & 32.9 & 47.5 & 52.5 & 64.0 & 36.0 \\
5.7 & 63.8 & 36.2 & 74.6 & 25.4 & - & - & 64.6 & 35.4 & 47.7 & 52.3 & 68.5 & 31.5 \\
7.9 & 70.3 & 29.7 & 73.6 & 26.4 & - & - & 69.8 & 30.2 & 47.5 & 52.5 & 61.0 & 39.0 \\
10.1 & 76.5 & 23.5 & 71.7 & 28.3 & - & - & 69.7 & 30.3 & 48.0 & 52.0 & 68.1 & 31.9 \\
12.3 & 80.1 & 19.9 & 87.1 & 12.9 & - & - & 78.3 & 21.7 & 46.5 & 53.5 & 77.0 & 23.0 \\
.. & 65.8 & 24.2 & 70.0 & 30.0 & - & - & 67.6 & 32.4 & 46.0 & 54.0 & 64.1 & 35.9 \\
\hline
\end{tabular}

Lärche. Ganzer Holzkörper.

\begin{tabular}{r|l|l|l|l|l|l|l|l|l|l|l|l}
\hline 1.3 & - & - & - & - & 83.5 & 16.5 & - & - & 70.5 & 29.5 & - & - \\
3.4 & - & - & - & - & 85.3 & 14.7 & - & - & 70.9 & 29.1 & - & - \\
5.5 & - & - & - & - & 86.0 & 14.0 & - & - & - & - & - & - \\
7.6 & - & - & - & - & 85.3 & 14.7 & - & - & 73.8 & 26.2 & - & - \\
9.7 & - & - & - & - & 83.2 & 16.8 & - & - & 67.5 & 32.5 & - & - \\
11.8 & - & - & - & - & 83.7 & 16.5 & - & - & 57.6 & 42.4 & - & - \\
13.9 & - & - & - & - & - & - & - & - & 49.5 & 50.5 & - & - \\
. & - & - & - & - & 84.5 & 15.5 & - & - & 70.0 & 30.0 & - & - \\
\hline
\end{tabular}

Lärche. Splint.

\begin{tabular}{r|c|c|cc|cc|c|c|c|c|c|c}
\hline 1.3 & - & - & - & - & 55.9 & 44.1 & - & - & 16.7 & 83.3 & - & - \\
3.4 & - & - & - & - & 59.0 & 41.0 & - & - & 20.8 & 79.2 & - & - \\
5.5 & - & - & - & - & 61.1 & 38.1 & - & - & - & - & - & - \\
7.6 & - & - & - & - & 63.8 & 36.2 & - & - & 23.9 & 71.1 & - & - \\
9.7 & - & - & - & - & 60.1 & 39.9 & - & - & 29.1 & 70.9 & - & - \\
11.8 & - & - & - & - & 56.4 & 43.6 & - & - & 32.4 & 67.6 & - & - \\
13.9 & - & - & - & - & - & - & - & - & 49.5 & 50.5 & - & - \\
1. & - & - & - & - & 59.5 & 40.5 & - & - & 24.8 & 75.2 & - & -
\end{tabular}




\begin{tabular}{|c|c|c|c|c|c|c|c|c|c|c|}
\hline \multirow{2}{*}{ 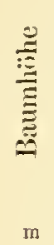 } & \multicolumn{2}{|c|}{ 2. Januar } & 4. März & \multicolumn{2}{|c|}{ 14. Miirz } & 19. Mai & \multicolumn{2}{|c|}{ 9. Juli } & \multicolumn{2}{|c|}{ 12. October } \\
\hline & Luft & Wasser & Luft Wasser & Luft & Wasser & Luft Wasser & Luft & Wasser & Luft & Wasser \\
\hline
\end{tabular}

Kiefer. Ganzer Holzkürper.

\begin{tabular}{r|c|c|c|c|c|c|c|c|c|c|c|c}
\hline 1.5 & 50.8 & 49.2 & 66.2 & 33.8 & 73.8 & 26.2 & 68.9 & 31.1 & 63.6 & 36.4 & 59.1 & 40.9 \\
4.6 & 47.0 & 53.0 & 61.9 & 38.1 & 70.9 & 29.1 & 74.8 & 25.2 & 64.8 & 35.2 & 63.4 & 36.0 \\
7.7 & 18.9 & 51.1 & 64.3 & 35.7 & 65.3 & 34.7 & 74.3 & 25.7 & 60.2 & 39.8 & 60.0 & 40.0 \\
$\mathbf{1 0 . 8}$ & 51.0 & 49.0 & 54.8 & 45.2 & 60.3 & 39.7 & 65.7 & 34.3 & 51.9 & 45.1 & 52.7 & 47.3 \\
13.9 & 45.4 & 54.6 & 44.5 & 55.5 & 44.2 & 55.8 & 54.2 & 45.8 & 43.9 & 56.1 & 50.5 & 49.5 \\
$\mathbf{1 7 . 0}$ & 39.4 & 60.6 & 33.1 & 66.9 & 29.4 & 70.6 & 43.4 & 56.6 & 32.0 & 68.0 & 41.1 & 58.9 \\
20.1 & 31.7 & 68.3 & 21.7 & 78.3 & 31.5 & 68.5 & 28.1 & 71.9 & 23.8 & 76.2 & 37.8 & 62.2 \\
23.2 & 34.1 & 65.9 & 39.5 & 60.5 & - & - & - & - & 12.9 & 87.1 & 21.6 & 75.4 \\
.$\%$ & 47.0 & 53.0 & 58.8 & 41.2 & 63.5 & 36.5 & 65.9 & 31.1 & 55.8 & 44.2 & 56.4 & 43.6 \\
\hline
\end{tabular}

Kiefer. Splint.

\begin{tabular}{r|l|l|l|l|l|l|l|l|l|l|l|l}
\hline 1.5 & 26.0 & 74.0 & 26.2 & 73.8 & 36.6 & 63.4 & 22.7 & 77.3 & 36.9 & 63.1 & 27.8 & 72.2 \\
4.6 & 24.1 & 75.9 & 25.8 & 74.2 & 37.5 & 62.5 & 40.8 & 59.7 & 25.5 & 74.5 & 37.4 & 62.6 \\
7.7 & 27.4 & 72.6 & 29.7 & 70.3 & 40.9 & 59.1 & 48.1 & 51.9 & 22.8 & 77.2 & 37.3 & 62.7 \\
10.8 & 24.5 & 75.5 & 26.1 & 73.9 & 37.3 & 62.7 & 42.6 & 57.4 & 24.1 & 75.9 & 34.9 & 65.1 \\
13.9 & 23.7 & 76.3 & 26.8 & 73.2 & 32.7 & 67.8 & 43.7 & 56.5 & 23.7 & 76.3 & 36.9 & 68.1 \\
17.0 & 28.8 & 71.2 & 22.4 & 77.6 & 24.5 & 75.5 & 83.8 & 66.2 & 13.6 & 80.4 & 35.1 & 64.9 \\
20.1 & 26.1 & 73.9 & 17.3 & 82.7 & 31.5 & 68.5 & 28.1 & 71.9 & 17.3 & 82.7 & 33.4 & 60.6 \\
23.2 & 34.1 & 63.9 & 39.5 & 60.5 & - & - & - & -1 & 12.9 & 87.1 & 21.6 & 78.4 \\
$\therefore$ & 25.8 & 74.2 & 26.3 & 73.7 & 36.8 & 63.2 & 37.0 & 63.0 & 26.1 & 73.9 & 34.3 & 65.7 \\
\hline
\end{tabular}

Fichte. Ganzer Holzkörper.

\begin{tabular}{c|c|c|c|c|c|c|c|c|c|c|c|c}
\hline 1.5 & 60.1 & 49.9 & 64.9 & 35.1 & 60.0 & 40.0 & 68.8 & 31.2 & 51.0 & 49.0 & 66.1 & 33.9 \\
4.6 & 64.3 & 35.7 & 66.0 & 34.0 & 69.6 & 30.4 & 71.9 & 25.1 & 53.5 & 46.7 & 66.6 & 33.4 \\
7.7 & 62.6 & 37.4 & 65.3 & 34.7 & 66.4 & 33.6 & 66.9 & 33.1 & 56.8 & 43.7 & 6.5 & 34.2 \\
10.8 & 62.4 & 37.6 & 56.1 & 43.9 & 60.8 & 39.2 & 63.1 & 36.9 & 44.5 & 55.5 & 62.7 & 37.3 \\
13.9 & 54.4 & 45.6 & 49.2 & 50.8 & 50.3 & 49.7 & 54.1 & 45.9 & 38.4 & 61.6 & 47.1 & 52.9 \\
17.0 & 47.9 & 52.1 & 41.7 & 58.3 & 47.1 & 52.9 & 37.8 & 62.2 & 28.5 & 71.5 & 34.5 & 65.5 \\
20.1 & 38.2 & 61.8 & 38.0 & 62.0 & 46.4 & 53.6 & 35.4 & 64.6 & 26.9 & 73.1 & 29.5 & 70.5 \\
23.2 & 36.7 & 63.3 & 20.4 & 79.6 & 40.0 & 60.0 & 24.2 & 75.8 & 18.2 & 81.8 & 19.6 & 80.4 \\
$\%$ & 57.6 & 42.4 & 59.3 & 40.7 & 61.9 & 35.1 & 62.2 & 37.8 & 46.0 & 54.0 & 59.6 & 40.4 \\
\hline
\end{tabular}

Fichte. Splint.

\begin{tabular}{r|r|r|r|r|r|r|r|r|r|r|r|r}
\hline 1.5 & 12.4 & 87.6 & 27.0 & 73.0 & 29.3 & 70.7 & 20.4 & 79.6 & 14.8 & 85.2 & 21.7 & 78.3 \\
4.6 & 21.2 & 78.8 & 29.9 & 70.1 & 25.4 & 74.6 & 22.4 & 77.6 & 16.7 & 83.3 & 26.3 & 73.7 \\
7.7 & 16.5 & 83.5 & 29.6 & 70.4 & 30.1 & 69.9 & 16.2 & 83.8 & 22.6 & 77.4 & 29.6 & 77.4 \\
10.8 & 16.1 & 83.9 & 18.3 & 81.7 & 24.0 & 76.0 & 14.8 & 85.2 & 14.8 & 85.2 & 20.6 & 79.4 \\
13.9 & 14.9 & 85.1 & 13.4 & 86.6 & 16.3 & 83.7 & 11.2 & 88.8 & 12.9 & 87.1 & 11.1 & 88.9 \\
17.0 & 14.9 & 85.2 & 10.8 & 89.2 & 13.4 & 86.6 & 11.7 & 88.3 & 7.6 & 92.4 & 9.2 & 90.8 \\
20.1 & 14.2 & 85.8 & 11.6 & 88.4 & 11.7 & 88.3 & 11.3 & 88.7 & 14.8 & 85.2 & 9.1 & 90.9 \\
23.2 & 14.9 & 85.1 & 10.2 & 89.8 & 21.8 & 78.2 & 12.9 & 57.1 & 12.8 & 87.2 & 6.5 & 93.5 \\
$\%$ & 15.9 & 84.1 & 22.0 & 78.0 & 28.3 & 76.7 & 17.3 & 82.7 & 15.2 & 84.8 & 19.0 & 81.0
\end{tabular}


Verhältniss zwischen Luftraum und Gesammtwasser der Rinde.

\begin{tabular}{|c|c|c|c|c|c|c|c|c|c|c|c|}
\hline 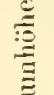 & \multicolumn{2}{|c|}{$\begin{array}{l}\text { 2. Januar } \\
\text { 28. December }\end{array}$} & \multicolumn{2}{|c|}{$\begin{array}{l}\text { 4. Mlärz } \\
\text { 16. Februar }\end{array}$} & \multicolumn{2}{|c|}{$\begin{array}{l}\text { 14. März } \\
\text { 24. Mäirz }\end{array}$} & \multicolumn{2}{|c|}{$\begin{array}{l}\text { 19. N1ai } \\
\text { 7. Mlai }\end{array}$} & \multicolumn{2}{|c|}{$\begin{array}{l}\text { 9. Juli } \\
\text { 2. Juli }\end{array}$} & $\begin{array}{l}\text { 12. October } \\
\text { 8. October }\end{array}$ \\
\hline $\mathrm{m}$ & Luft & Wasser & Luft & Wasser & Luft & Wasser & Luft & Wasser & Luft & Wasser & Wasser \\
\hline
\end{tabular}

Birke.

\begin{tabular}{|c|c|c|c|c|c|c|c|c|c|c|c|c|}
\hline $\begin{array}{r}1.3 \\
3.5 \\
5.7 \\
7.9 \\
10.1\end{array}$ & $\begin{array}{l}31.8 \\
39.8 \\
26.3 \\
34.9 \\
31.3 \\
34.2\end{array}$ & $\begin{array}{l}65.2 \\
66.2 \\
63.7 \\
65.1 \\
68.7 \\
65.8\end{array}$ & $\begin{array}{l}27.8 \\
22.0 \\
26.7 \\
25.4 \\
35.3 \\
27.3\end{array}$ & $\begin{array}{r}72.7 \\
78.0 \\
73.3 \\
74.6 \\
64.7 \\
72.7\end{array}$ & $\begin{array}{l}13.3 \\
22.8 \\
13.8 \\
20.2 \\
15.6 \\
18.9\end{array}$ & $\begin{array}{l}86.7 \\
77.7 \\
86.7 \\
79.8 \\
84.4 \\
81.1\end{array}$ & $\begin{array}{l}27.4 \\
30.2 \\
27.4 \\
28.5 \\
15.0 \\
24.7\end{array}$ & $\begin{array}{r}72.6 \\
69.8 \\
72.6 \\
76.5 \\
85.0 \\
75.8\end{array}$ & $\begin{array}{l}27.4 \\
31.3 \\
27.4 \\
27.3 \\
21.3 \\
26.9\end{array}$ & $\begin{array}{l}27.6 \\
68.7 \\
72.6 \\
72.7 \\
78.7 \\
73.1\end{array}$ & $\begin{array}{l}20.9 \\
22.6 \\
29.4 \\
29.0 \\
38.3 \\
28.1\end{array}$ & $\begin{array}{l}79.1 \\
77.4 \\
70.6 \\
71.0 \\
61.7 \\
71.9\end{array}$ \\
\hline
\end{tabular}

Rothbuche.

\begin{tabular}{r|cc|cc|c|c|c|c|c|c|c|c}
\hline 1.5 & 29.6 & 70.4 & 29.8 & 70.2 & 24.2 & 75.8 & 21.1 & 78.9 & 21.5 & 78.5 & 31.1 & 68.9 \\
3.7 & 24.0 & 76.0 & 30.7 & 69.3 & 24.3 & 75.7 & 16.8 & 83.2 & 21.1 & 78.9 & 31.3 & 68.7 \\
5.9 & 31.7 & 68.3 & 33.0 & 67.0 & 20.9 & 79.1 & 16.1 & 83.9 & 22.5 & 77.5 & 31.4 & 68.6 \\
5.1 & 32.4 & 67.6 & 28.8 & 71.2 & - & - & 16.8 & 83.2 & 22.5 & 77.5 & 29.6 & 70.4 \\
10.8 & - & - & 32.3 & 67.7 & 22.4 & 77.6 & 19.4 & 80.6 & 24.5 & 75.5 & 32.1 & 67.9 \\
12.5 & 31.7 & 68.3 & - & - & 26.4 & 73.6 & 18.2 & 81.8 & 23.1 & 76.9 & 30.8 & 69.2 \\
14.7 & 36.3 & 63.7 & 34.6 & 65.4 & 20.9 & 79.1 & 17.6 & 82.4 & 20.4 & 79.6 & 34.3 & 65.7 \\
16.9 & 40.2 & 59.8 & 35.2 & 64.8 & - & - & - & - & 20.2 & 79.8 & 31.2 & 68.8 \\
.0 & 32.3 & 67.7 & 32.1 & 67.9 & 23.2 & 76.8 & 18.0 & 82.0 & 22.0 & 78.0 & 31.5 & 68.5 \\
\hline
\end{tabular}

Eiche.

\begin{tabular}{|c|c|c|c|c|c|c|c|c|c|c|c|c|}
\hline 1.8 & 37.6 & 62.4 & 40.2 & 59.8 & - & - & 29.5 & 70.5 & 29.1 & 70.9 & 35.6 & 64.4 \\
\hline 3.5 & $\therefore 8.7$ & 61.3 & 41.4 & 5. & 一 & 一 & 31.4 & 68.6 & 32.2 & 67.8 & 37.2 & 62.8 \\
\hline 5.7 & 38.0 & 62. & 88.7 & 61 & - & - & 28.5 & 7 & 32.5 & 67.5 & 35.7 & 64 \\
\hline 1.9 & 38 & 61. & 97.6 & 62 & - & - & 20.7 & 71.3 & 31.6 & 68.4 & 34.7 & \\
\hline 0.1 & 39. & 60 & 38.4 & 61 & - & - & 28.2 & 71 & 30.5 & 69.5 & 34.4 & fi.). \\
\hline 12. & $\therefore$ & 62.9 & 40.9 & .59 & - & - & 27.8 & 72.2 & 27.3 & 72.7 & 35.1 & 64.9 \\
\hline . & $\therefore s$ & 62.0 & 39.5 & 60 & - & - & 29.0 & 71.0 & 30.5 & 69.5 & 35.4 & 64.6 \\
\hline
\end{tabular}

Kiefer.

\begin{tabular}{r|c|c|c|c|c|c|c|c|c|c|c|c}
\hline 1.5 & 43.3 & 56.7 & 41.9 & 55.1 & - & - & 32.8 & 67.2 & 45.0 & 55.0 & 42.9 & 57.1 \\
4.6 & 38.8 & 61.2 & 42.6 & 57.4 & - & - & 30.6 & 69.4 & 36.4 & 63.6 & 43.5 & 56.5 \\
7.7 & 38.5 & 61.5 & 45.1 & 54.9 & - & - & 32.8 & 67.2 & 31.7 & $6 . .3$ & 48.3 & 51.7 \\
10.8 & 39.5 & 60.5 & 46.4 & 53.6 & - & - & 32.4 & 67.6 & 33.0 & 67.0 & 41.3 & 55.7 \\
13.4 & 38.4 & 61.6 & 45.1 & 54.9 & - & - & 26.4 & 73.6 & 33.6 & 66.4 & 41.1 & 55.9 \\
17.0 & 37.3 & 62.7 & 42.7 & 57.3 & - & - & 25.4 & 74.6 & 34.9 & 65.1 & 41.0 & 59.0 \\
20.1 & 39.2 & 61.8 & 38.2 & 61.8 & - & - & 21.5 & 78.5 & 37.1 & 62.9 & 37.5 & 62.5 \\
23.2 & 34.9 & 65.1 & 43.4 & 56.6 & - & - & - & - & 27.7 & 72.7 & 29.2 & 70.8 \\
$\ddots$. & 35.6 & 61.4 & 43.6 & 56.4 & - & - & 28.9 & 71.1 & 34.9 & 65.1 & 41.3 & 58.7 \\
\hline
\end{tabular}

Fichte.

\begin{tabular}{r|c|c|c|c|c|c|cc|c|c|cc}
\hline 1.5 & 32.7 & 67.3 & 38.7 & 61.3 & - & - & 28.3 & 71.7 & 35.5 & 64.5 & 40.0 & 60.0 \\
4.6 & 33.7 & 66.3 & 36.8 & 63.8 & - & - & 23.0 & 77.0 & 38.0 & 62.0 & 35.8 & 64.2 \\
7.7 & 30.7 & 69.3 & 37.6 & 62.4 & - & - & 35.2 & 64.8 & 38.2 & 61.8 & 34.0 & 66.0 \\
10.8 & 35.6 & 64.4 & 38.5 & 61.5 & - & - & 29.0 & 71.0 & 39.6 & 60.4 & 34.7 & 65.3 \\
13.9 & 39.5 & 61.5 & 39.3 & 60.7 & - & - & 28.5 & 71.5 & 37.0 & 63.0 & 33.2 & 66.8 \\
17.0 & 40.0 & 60.0 & 43.3 & 56.7 & - & - & 24.9 & 75.0 & 38.2 & 61.8 & 34.2 & 65.8 \\
20.1 & 41.4 & 59.6 & 43.0 & 57.0 & - & - & 31.4 & 69.6 & 38.5 & 61.5 & 36.6 & 63.4 \\
23.2 & 42.7 & 57.3 & 42.3 & 57.7 & - & - & 31.7 & 69.3 & 37.3 & 62.7 & 37.7 & 62.7 \\
26.3 & 44.5 & 55.5 & 41.8 & 58.2 & - & - & 30.3 & 69.7 & 31.8 & 68.2 & 33.4 & 136.6 \\
. & 3.8 & 62.2 & 40.1 & 59.9 & - & - & 29.2 & 70.8 & 37.1 & 62.9 & 35.5 & 64.5
\end{tabular}




\section{Einfluss des Holzalters und der Jahrringbreite}

auf die Menge der örganischen Substanz, auf das Trockengewicht und das Schwinden des Ho!zes.

\begin{tabular}{|c|c|c|c|c|c|c|c|}
\hline \multirow{2}{*}{$\begin{array}{l}\text { Zahl } \\
\text { der } \\
\text { Splint- } \\
\text { stücke }\end{array}$} & \multirow{2}{*}{$\begin{array}{l}\text { Zahl } \\
\text { der } \\
\text { Kern- } \\
\text { stücke }\end{array}$} & \multirow{2}{*}{$\begin{array}{c}\text { Durch- } \\
\text { schnittliche } \\
\text { Jahrringbreite } \\
\text { mm }\end{array}$} & $\begin{array}{c}\text { Organische } \\
\text { Substanz } \\
\text { in } 100 \text { Volumtheilen }\end{array}$ & \multicolumn{2}{|c|}{$\begin{array}{l}\text { Specifisches } \\
\text { Trocken- } \\
\text { gewicht }\end{array}$} & \multicolumn{2}{|c|}{$\begin{array}{l}\text { Schwinden } \\
\text { beim Trocknen } \\
\text { fro } 100 \text { Frischvolumina }\end{array}$} \\
\hline & & & splint | Kern & Splint & Kerm & Splint & Kern \\
\hline
\end{tabular}

Eiche.

\begin{tabular}{|c|c|c|c|c|c|c|c|c|}
\hline $\begin{array}{l}8 \\
4 \\
6 \\
3\end{array}$ & $\begin{array}{r}7 \\
15 \\
17 \\
6\end{array}$ & $\begin{array}{l}1.0-1.5 \\
1.6-2.0 \\
2.1-2.5 \\
2.6-2.0\end{array}$ & $\begin{array}{l}55.5 \\
57.0 \\
57.5 \\
59.1\end{array}$ & $\begin{array}{l}59.5 \\
59.7 \\
59.7 \\
61.3\end{array}$ & $\begin{array}{l}67.2 \\
69.2 \\
69.3 \\
72.2\end{array}$ & $\begin{array}{l}68.0 \\
69.0 \\
69.2 \\
69.8\end{array}$ & $\begin{array}{l}17.7 \\
17.7 \\
17.1 \\
18.1\end{array}$ & $\begin{array}{l}13.9 \\
18.2 \\
12.1 \\
12.1\end{array}$ \\
\hline 21 & 45 & $\begin{array}{l}\text { Durchschnitt } \\
\text { Splint u. Kem }\end{array}$ & 56.8 & 59.7 & 68.9 & 69.0 & 17.6 & 10 \\
\hline
\end{tabular}

Rothbuche.

\begin{tabular}{r|r|c|c|c|c|c|c|c}
\hline 16 & 19 & $0.5-1.0$ & 57.6 & 56.2 & 67.8 & 68.0 & 15.5 & 17.2 \\
9 & 22 & $1.1-1.5$ & 57.8 & 56.1 & 70.7 & 68.3 & 15.9 & 17.7 \\
8 & 17 & $1.6-2.0$ & 58.3 & 57.3 & 70.0 & 69.1 & 16.8 & 17.0 \\
8 & 8 & $2.1-2.5$ & 59.9 & 56.6 & 71.0 & 68.2 & 15.6 & 17.0 \\
4 & - & $2.6-3.0$ & 62.4 & - & 76.1 & - & 17.8 & - \\
\hline 45 & 66 & Durchsehnitt & 58.4 & 56.6 & 70.0 & 68.4 & 16.5 & 17.3 \\
111 & & Splint u. Kem & \multicolumn{2}{|c|}{57.8} & & 69.1 & \multicolumn{2}{|c|}{17.0}
\end{tabular}

Birke.

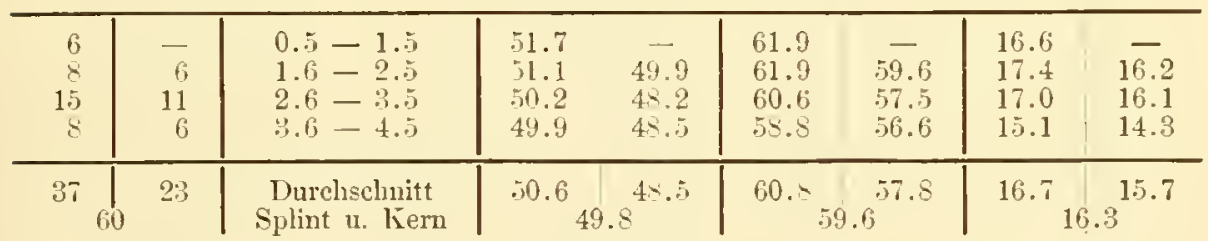

Alte Fichte.

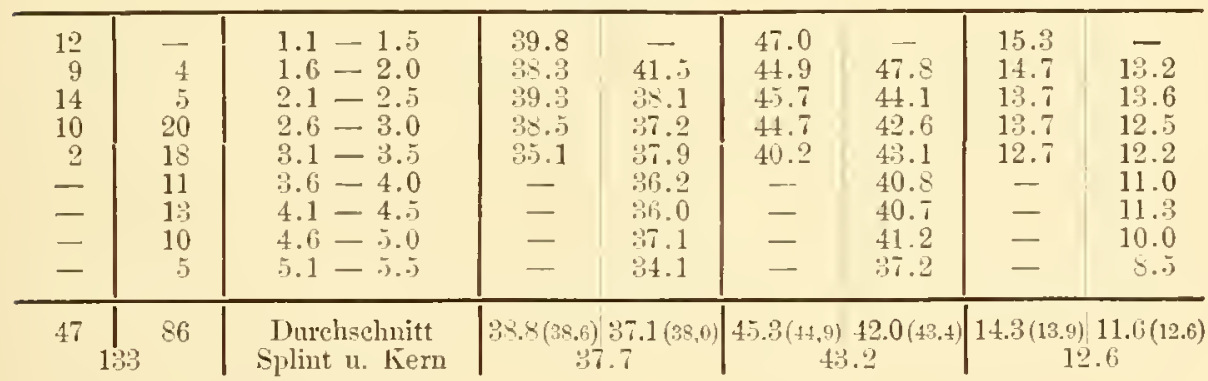


Tab. 47.

\begin{tabular}{|c|c|c|c|c|c|c|c|c|}
\hline \multirow{2}{*}{$\begin{array}{c}\text { Zahl } \\
\text { der } \\
\text { Splint- } \\
\text { stiicke }\end{array}$} & \multirow{2}{*}{$\begin{array}{l}\text { Zahl } \\
\text { der } \\
\text { Kern- } \\
\text { stïcke }\end{array}$} & \multirow{2}{*}{$\begin{array}{c}\text { Dureh- } \\
\text { schnittliche } \\
\text { Jahrringbreite }\end{array}$} & \multicolumn{2}{|c|}{$\begin{array}{l}\text { Organische } \\
\text { Substanz } \\
\text { in } 100 \text { Volumtheilen }\end{array}$} & \multicolumn{2}{|c|}{$\begin{array}{l}\text { Specifisches } \\
\text { Trocken- } \\
\text { gewicht }\end{array}$} & \multicolumn{2}{|c|}{$\begin{array}{c}\text { Sehwiuden } \\
\text { beim Trockuen } \\
\text { pro } 100 \text { Frischrolnmina }\end{array}$} \\
\hline & & & Splint & Kern & Splint & Kern & Splint & Kern \\
\hline
\end{tabular}

Junge Fichte.

\begin{tabular}{c|c|c|c|c|c|c|c|c}
\hline 3 & - & $1.6-2.0$ & 38.5 & - & 44.2 & - & 12.5 & - \\
3 & - & $2.1-2.5$ & 39.2 & - & 45.5 & - & 13.8 & - \\
6 & - & $2.6-3.0$ & 37.7 & - & 42.6 & - & 11.6 & - \\
9 & - & $3.1-3.5$ & 34.9 & - & 39.4 & - & 11.4 & - \\
8 & - & $3.6-4.0$ & 36.0 & - & 40.5 & - & 11.1 & - \\
4 & - & $4.1-4.5$ & 35.7 & - & 39.9 & - & 10.8 & - \\
\hline 33 & - & Durchschnitt & $36.5(38.3)$ & - & $41.3(43.7)$ & - & $11.6(12.4)$ & -
\end{tabular}

Alte Kiefer.

\begin{tabular}{|c|c|c|c|c|c|c|c|c|}
\hline 7 & - & $0.5-1.0$ & 42.7 & - & 48.9 & - & 12.5 & - \\
\hline 16 & - & $1.1-1.5$ & 43.2 & - & 49.2 & - & 11.8 & - \\
\hline 14 & - & $1.6-2.0$ & 42.2 & - & 48.2 & - & 12.3 & - \\
\hline 7 & 4 & $2.1-2.5$ & 41.4 & 41.1 & 46.2 & 46.3 & 10.3 & 11.2 \\
\hline- & 15 & $2.6-3.0$ & - & 42.4 & - & 47.9 & - & 10.8 \\
\hline - & 11 & $3.1-3.5$ & - & 42.3 & - & 47.5 & - & 10.8 \\
\hline - & 15 & $3.6-4.0$ & - & 41.1 & - & 45.7 & - & 9.9 \\
\hline - & 6 & $4.1-4.5$ & - & 39.8 & 一 & 44.3 & - & 10.2 \\
\hline - & 6 & $4.6-5.0$ & - & 39.6 & - & 44.1 & - & 9.9 \\
\hline - & 6 & $5.1-6.0$ & - & 40.8 & - & 44.6 & - & 8.1 \\
\hline - & 9 & $6.1-8.5$ & - & 43.1 & - & 47.7 & - & 9.5 \\
\hline 4 & 72 & $\begin{array}{l}\text { Durchschnitt } \\
\text { Splint u. Kiern }\end{array}$ & 42.6 & $(41.6$ & 48 & 4 & 11.8 & \\
\hline
\end{tabular}

Junge Kiefer.

\begin{tabular}{c|c|c|c|c|c|c|c|c}
\hline 3 & - & $1.6-2.0$ & 43.9 & - & 49.9 & - & 13.4 & - \\
5 & - & $2.1-2.5$ & 40.2 & - & 46.0 & - & 12.5 & - \\
7 & - & $2.6-3.0$ & 38.2 & - & 43.6 & - & 12.2 & - \\
7 & - & $3.1-3.5$ & 37.8 & - & 41.9 & - & 11.9 & - \\
6 & - & $3.6-4.0$ & 36.9 & - & 42.9 & - & 11.9 & - \\
4 & - & $4.1-4.5$ & 33.8 & - & 37.4 & - & 11.1 & - \\
\hline 32 & - & Dutehschnitt & $38.1(37.5)$ & - & $43.3(41.2)$ & - & $12.1(11.6)$ & -
\end{tabular}

Lärche.

\begin{tabular}{|c|c|c|c|c|c|c|c|c|}
\hline 7 & - & $0.5-1.0$ & 43.1 & - & 49.3 & - & 12.0 & - \\
\hline 5 & - & $1.1-1.5$ & 47.0 & - & 54.7 & - & 14.1 & - \\
\hline 一 & 6 & $1.6-2.0$ & - & 46.4 & - & 52.1 & - & 10.8 \\
\hline - & 4 & $2.1-2.5$ & - & 46.1 & - & 52.2 & - & 11.3 \\
\hline - & 6 & $2.6-3.0$ & - & 46.9 & - & 52.1 & 一 & 9.6 \\
\hline 一. & 3 & $3.1-3.5$ & - & 42.5 & - & 46.6 & - & 9.1 \\
\hline - & 3 & $3.6-4.5$ & - & 40.1 & - & 44.0 & 一 & 8.8 \\
\hline 12 & 22 & $\begin{array}{l}\text { Durchschnitt } \\
\text { Splint u. Keru }\end{array}$ & 44.7 & $0^{45.1}$ & 51.6 & $7^{50.3}$ & 12.9 & $1^{10.1}$ \\
\hline
\end{tabular}




\section{Teränderungen}

drs millleren Wassergehaltes der Birke

im laule des Jahres.
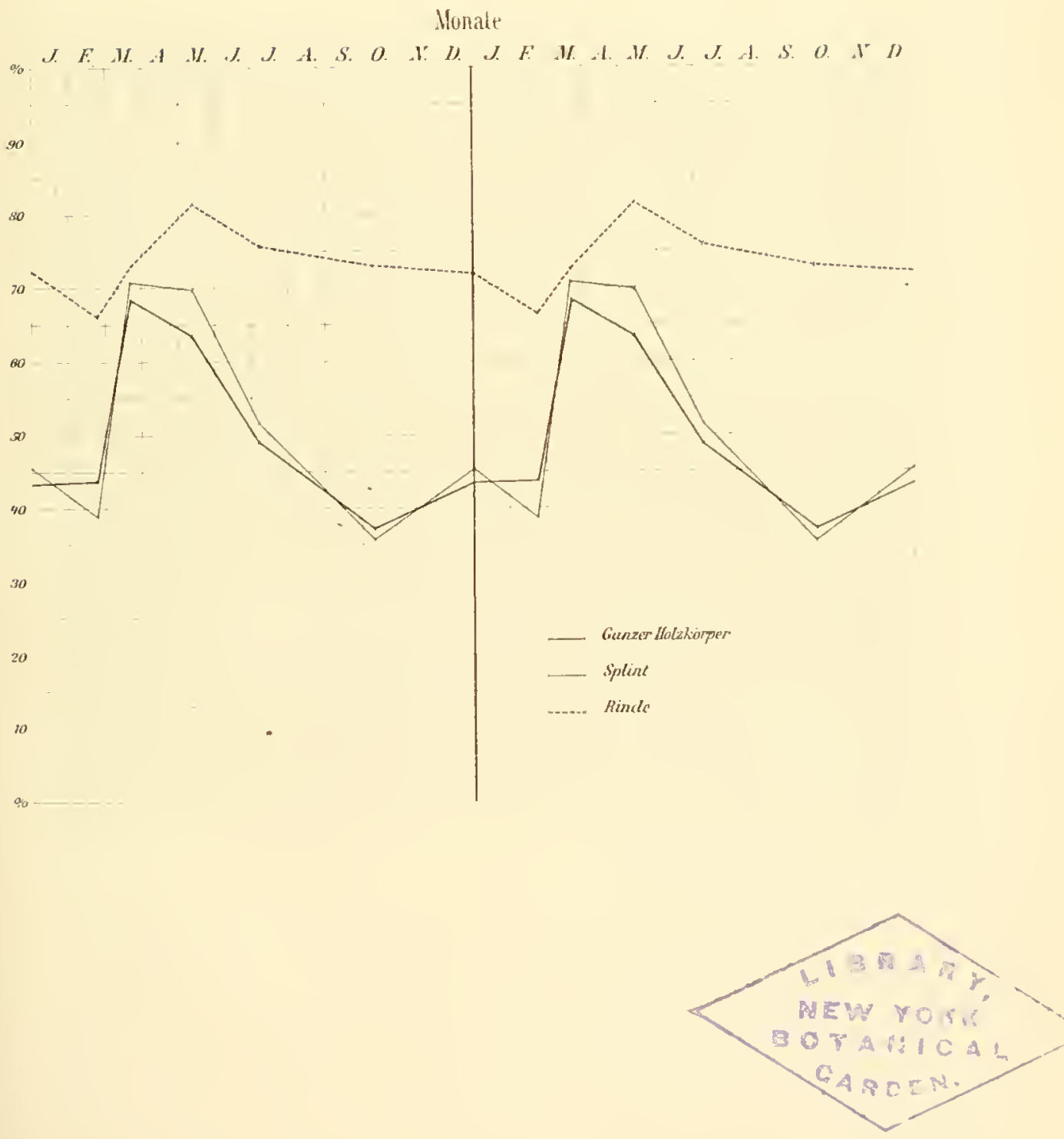

"rat".

\section{limallumss}

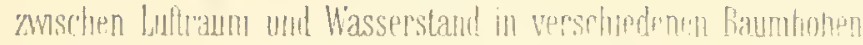
der Birke llianzer Holzkilfur!

Baumhohe

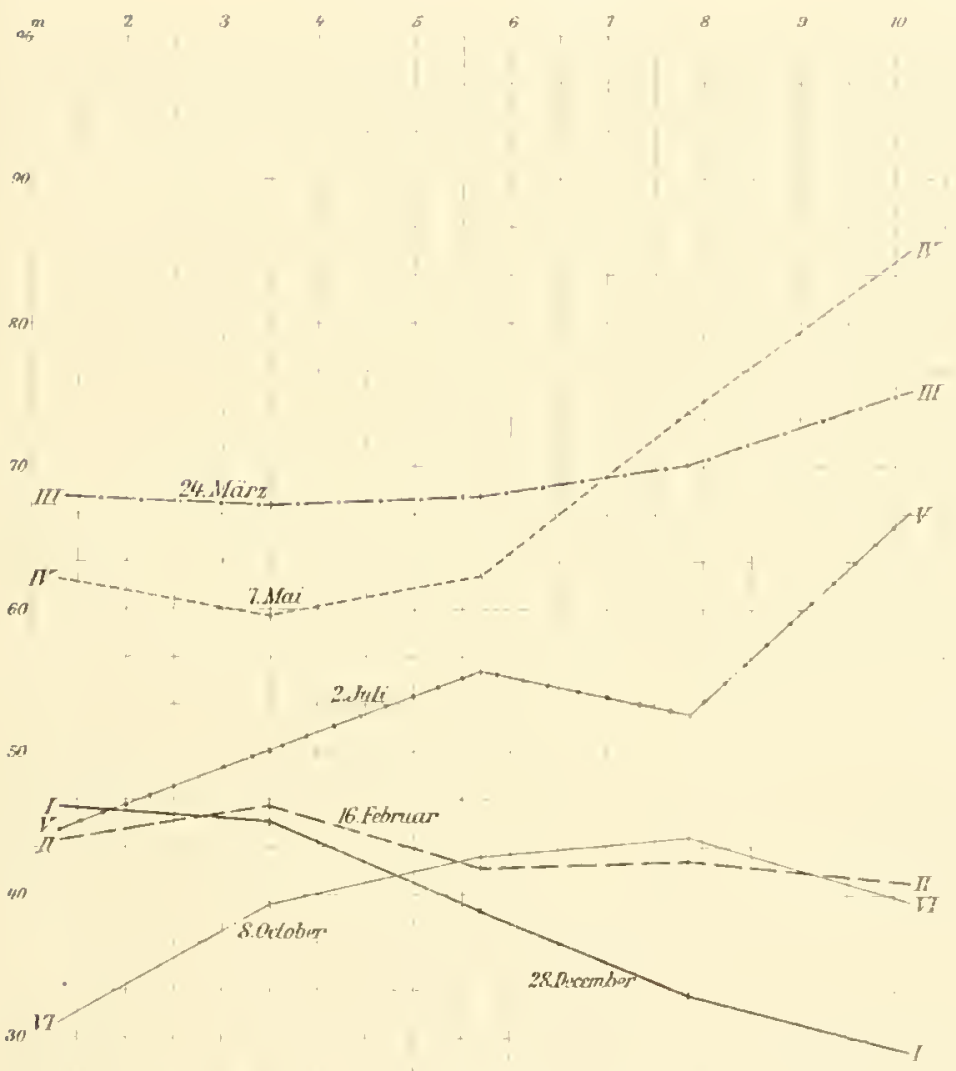





\section{liphiallu!ss}

7.wisehen Luttraum und Wasserstand in verschledenen Baumhohen der Burke SSulini

Baminnluthe
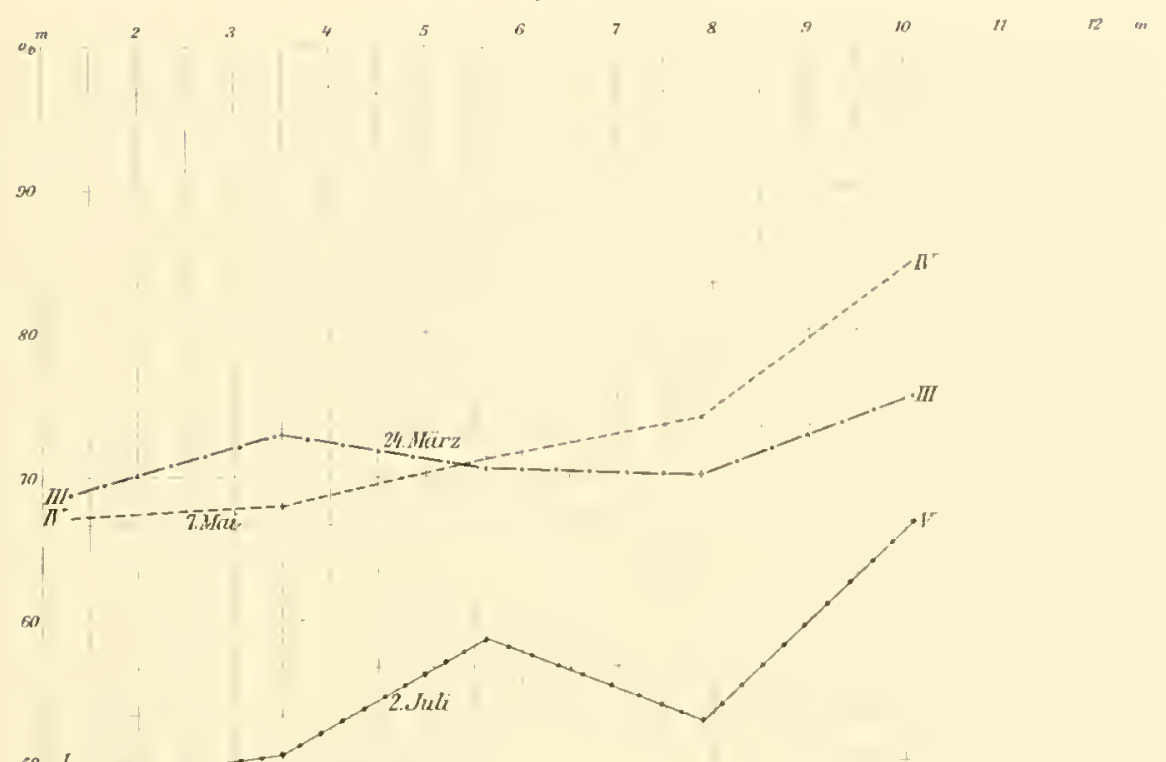

so

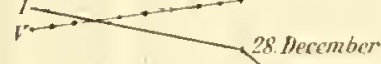

$4011-\frac{16}{6}$ Februar

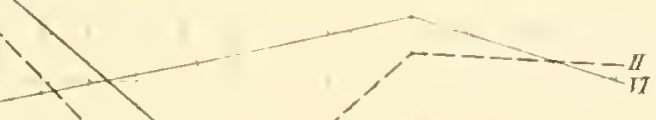

30

S.October

17

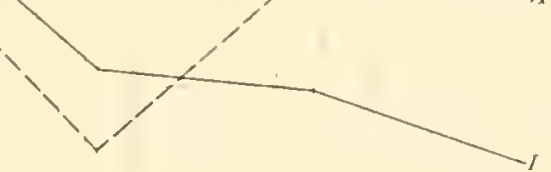



Veränderungen

des miltieren Wassergehaltes der Rothbuche

im Laufe des Jahres.

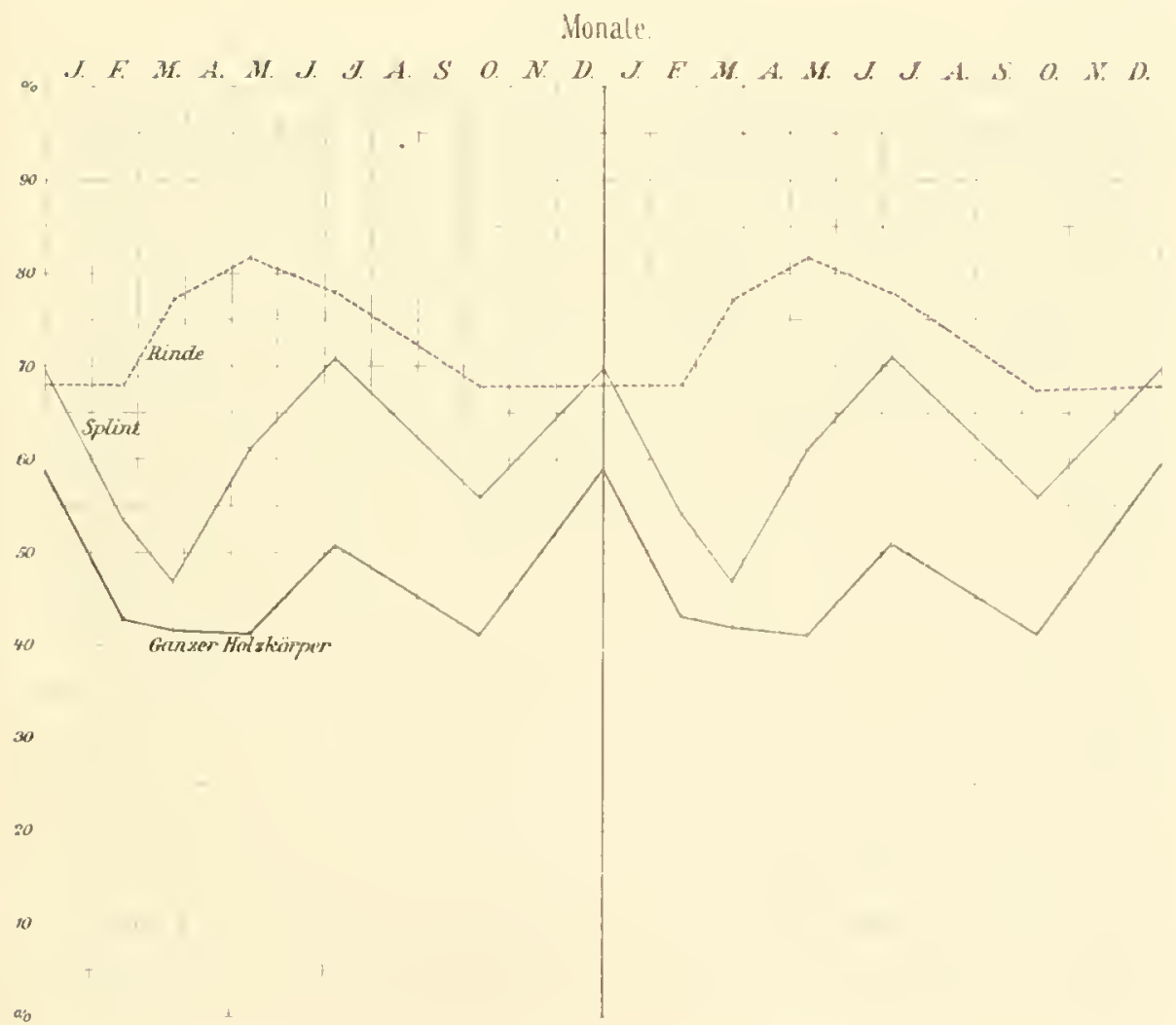



Tat'.5.

\section{Verhalunss}

zuischen Luftriumn und Wasserstand in verschluedenen Baumhohen der Ruthbuche (Ganzer liolzkorper)

Baumhohe

o.

m

23

5678

910

$12 \quad 25$

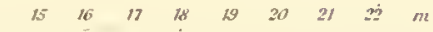

9

80

$x$

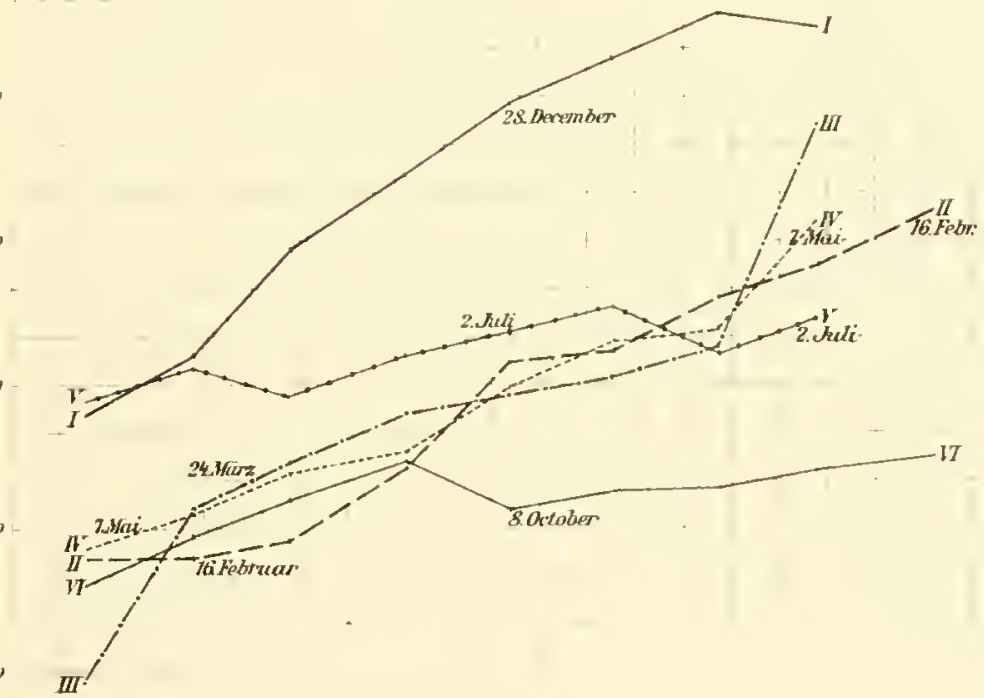

20

10 

Taf 6.

\section{Verthaltmss}

zwschen luftraum und Wasserstand in verschedenen Baumhohen der Rothouche ISpint

liaumhoten

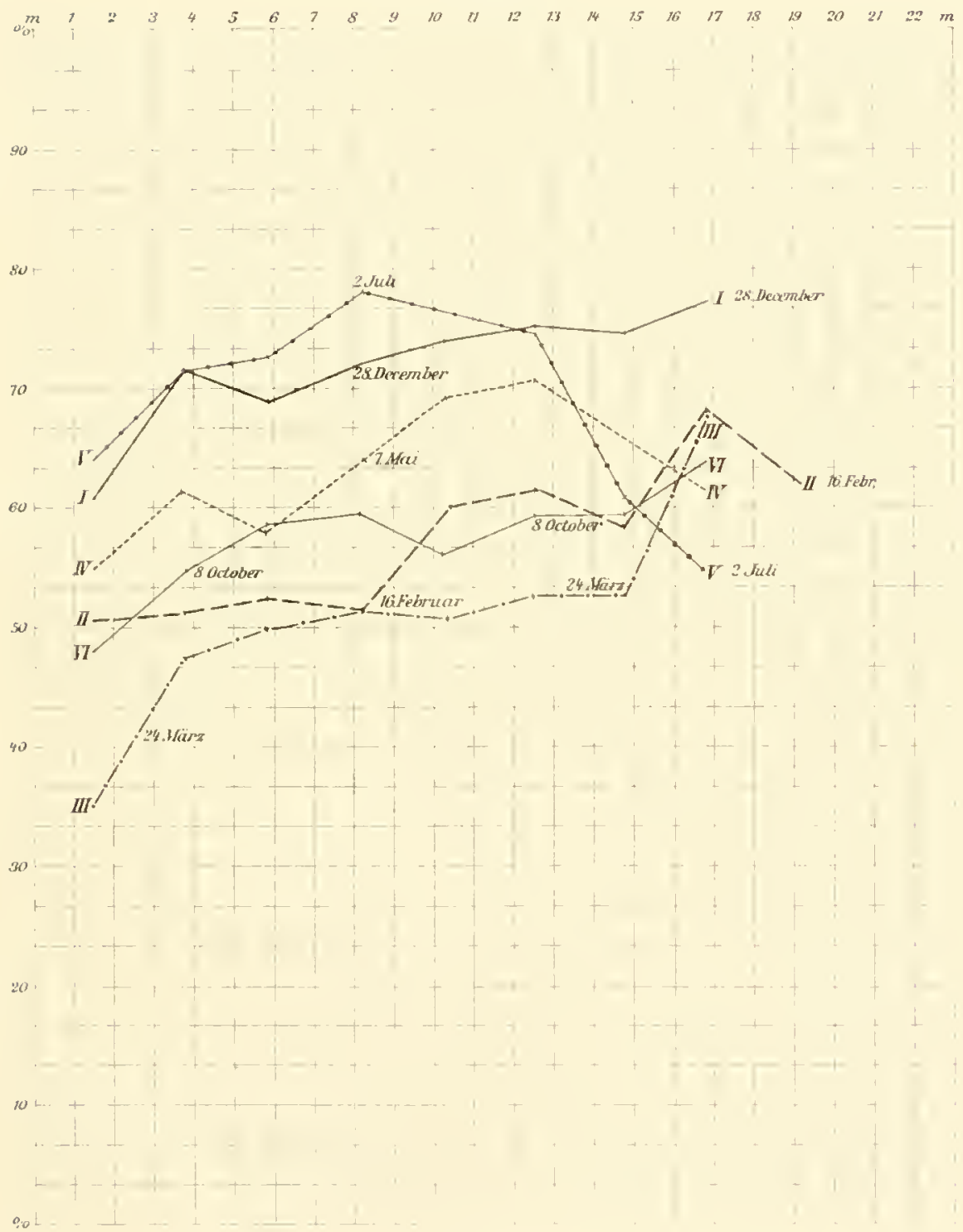





\section{leränderungen}

des mulleren Wassergehalles der Fiche

in laufe des Jahres.

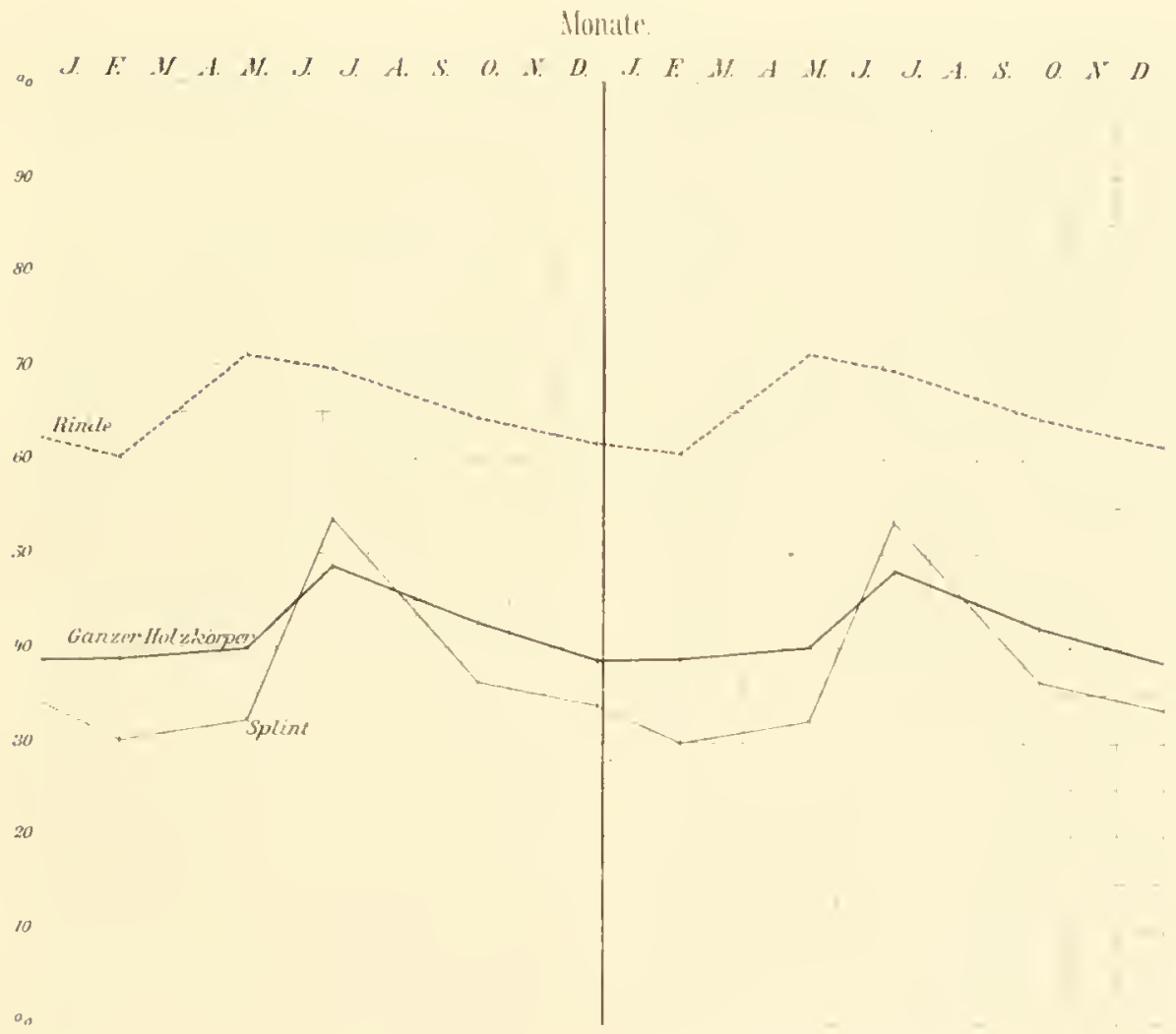



Tat:8.

Viphaltinss

zanschent Lufteaum und Wasserstanl in versohnedenen Paumhohem dep Eiche If fanzel Holzkurperi

Baumhohe

8

90

80

3n

80
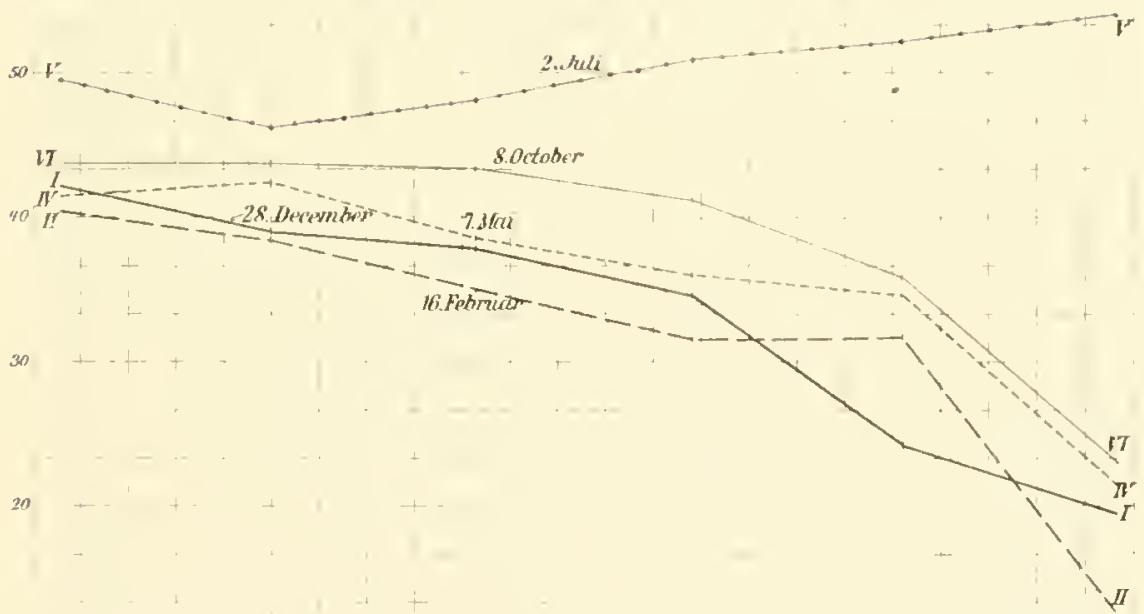

10 

Taโ.ง

lerhattnss

zansthen Lutleadum und llassershand on versinedenen Paumhohen der Eirche (Sinhtunt)

Baumhohe

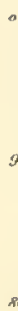

sto

sio

(s)
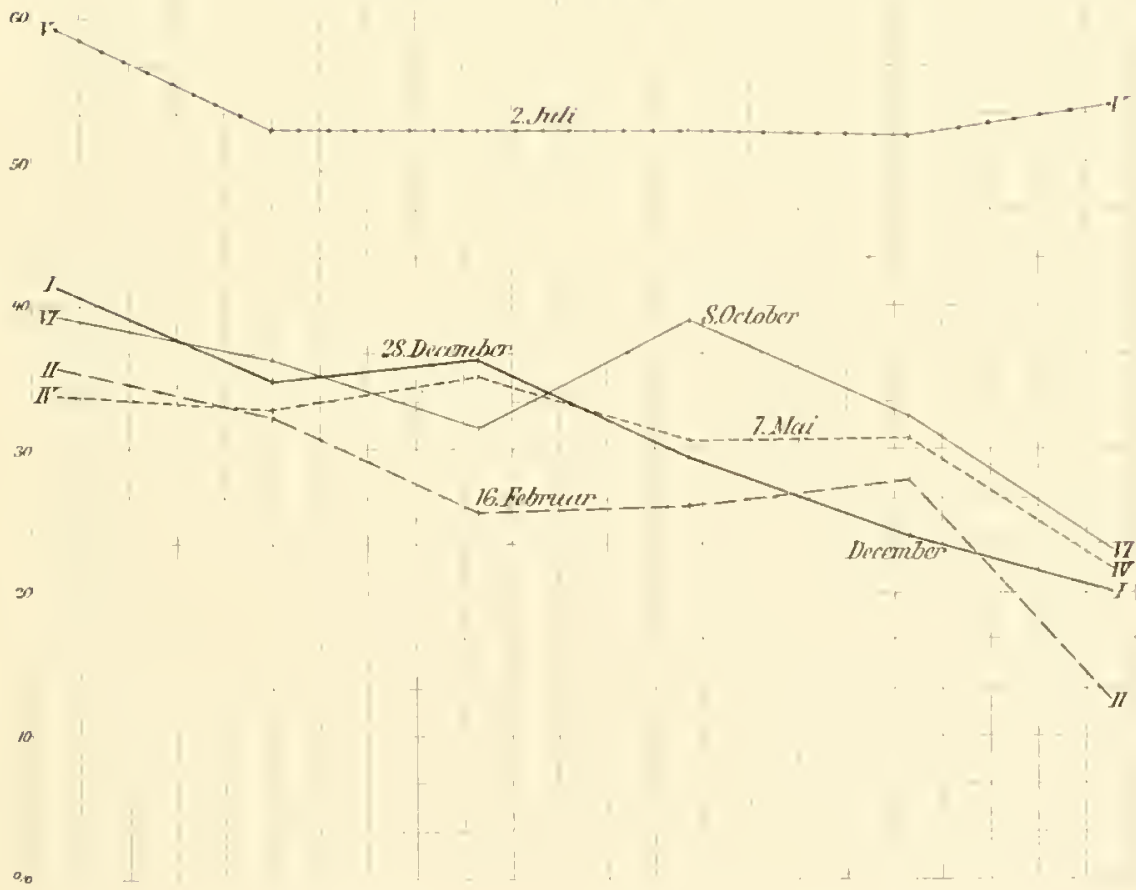

Taf: 10.

Verhältniss

zwischen Luftiam und Wasserstand in verschiedenen Baumholen Aer lärche (Canzer Holzkörper und Splint

Baumbohe.

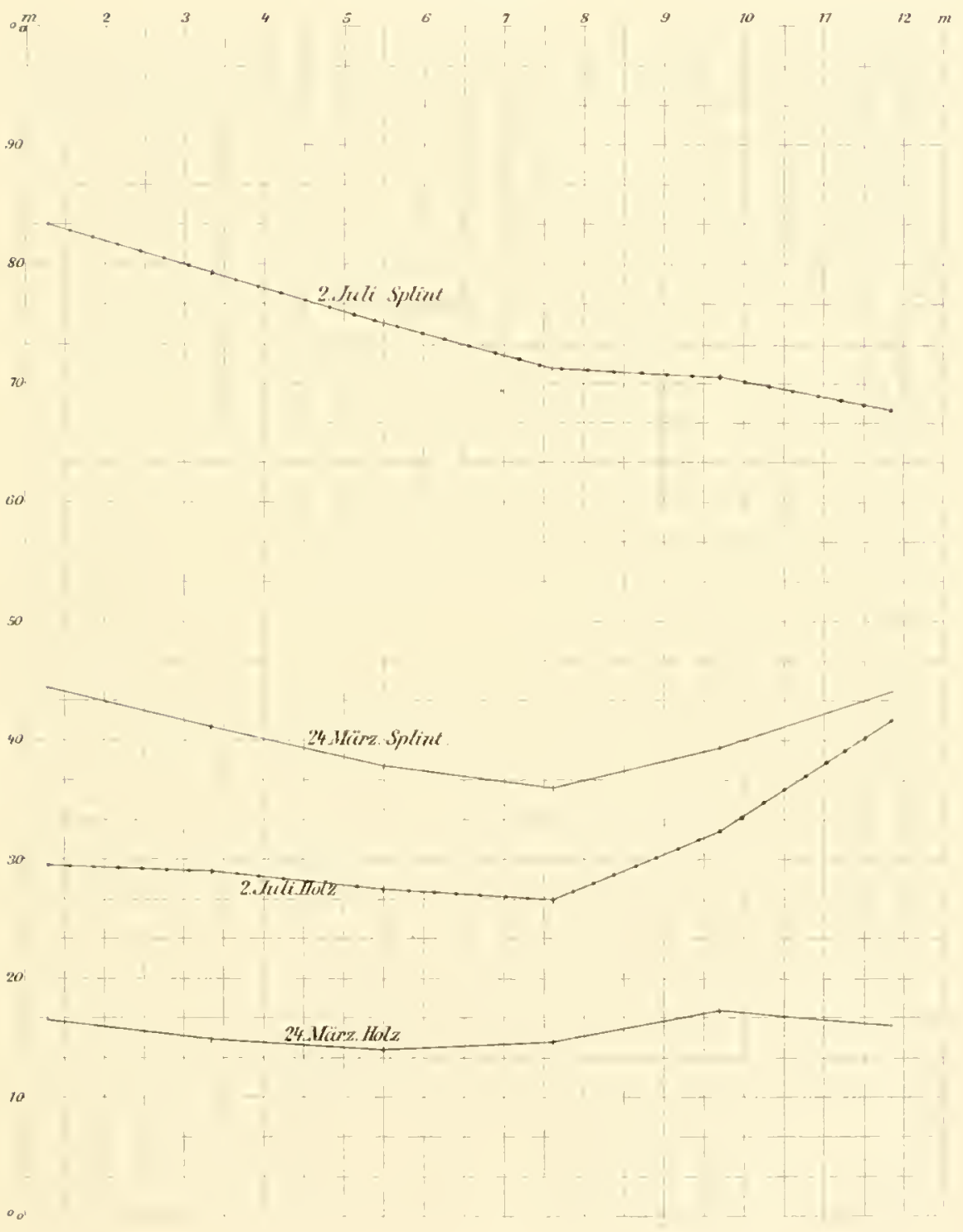



Taf.11.

\section{Veränderungen}

des intuleren Wassergehaltes der hiefer

im Lanfe des Jahres.

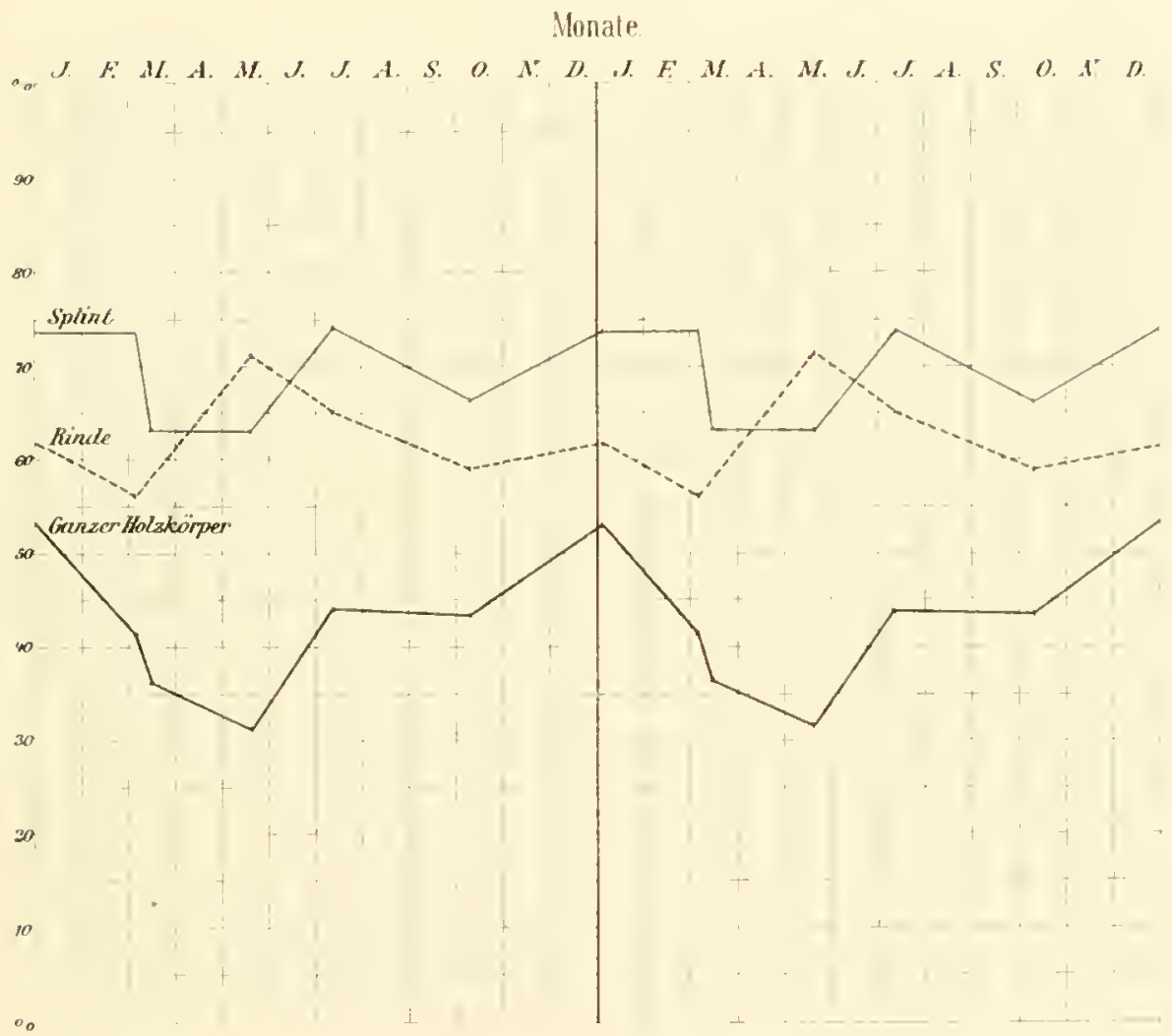



Taf'12.

Verthälunss

zwsschen bultraum und Wasserstand in versehuedenen Baumbohen der hiefer ( Ganzer Holzkorperl)

Basmhohe

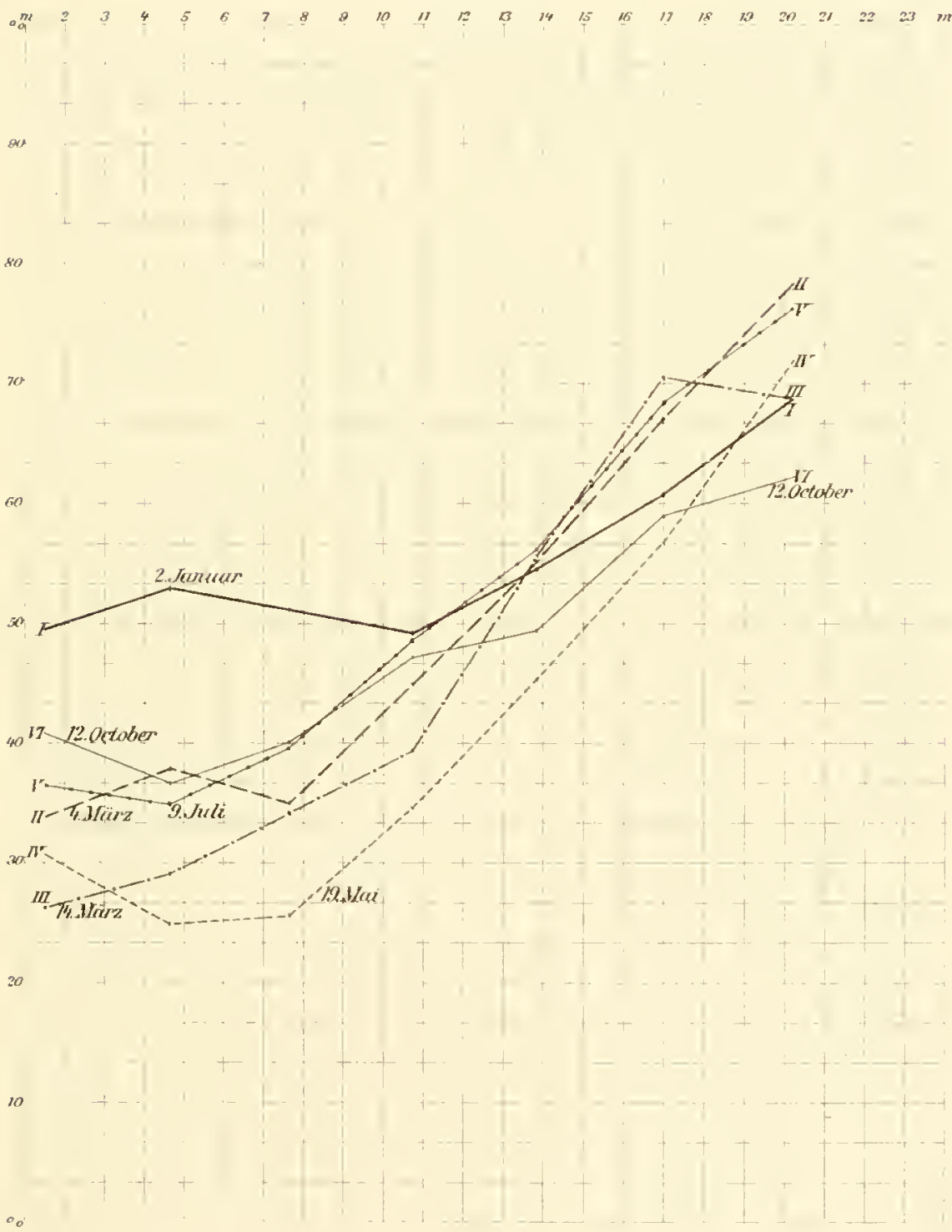



Taf. 13.

\section{lephältniss}

zwischen bultradn und Wasserstand in verschiedenen Baumhölen der Kiefer (Splint)

Baumbinhe.

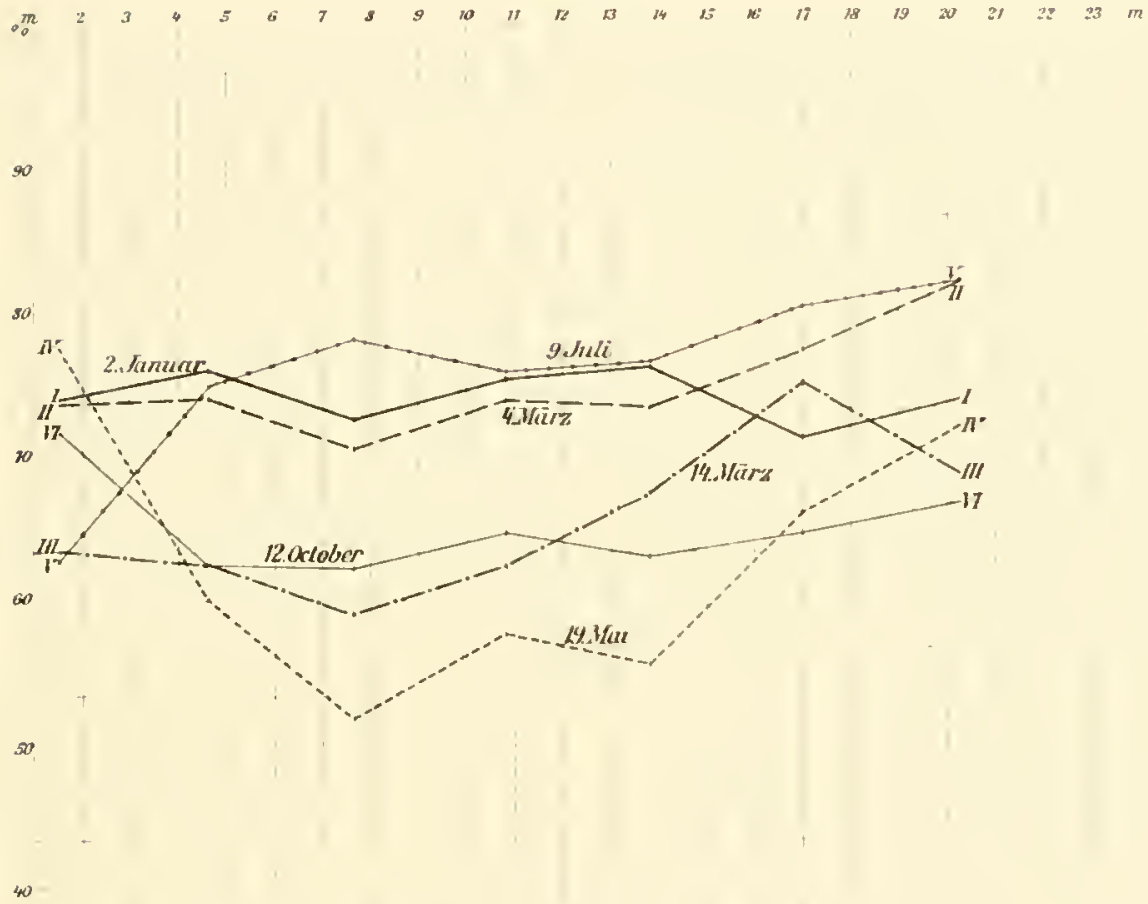

3

20

10 



\section{Veränderungeı}

des mitteren Wassergehaltes der Fichte in laufe des Jahres.

Monatr.

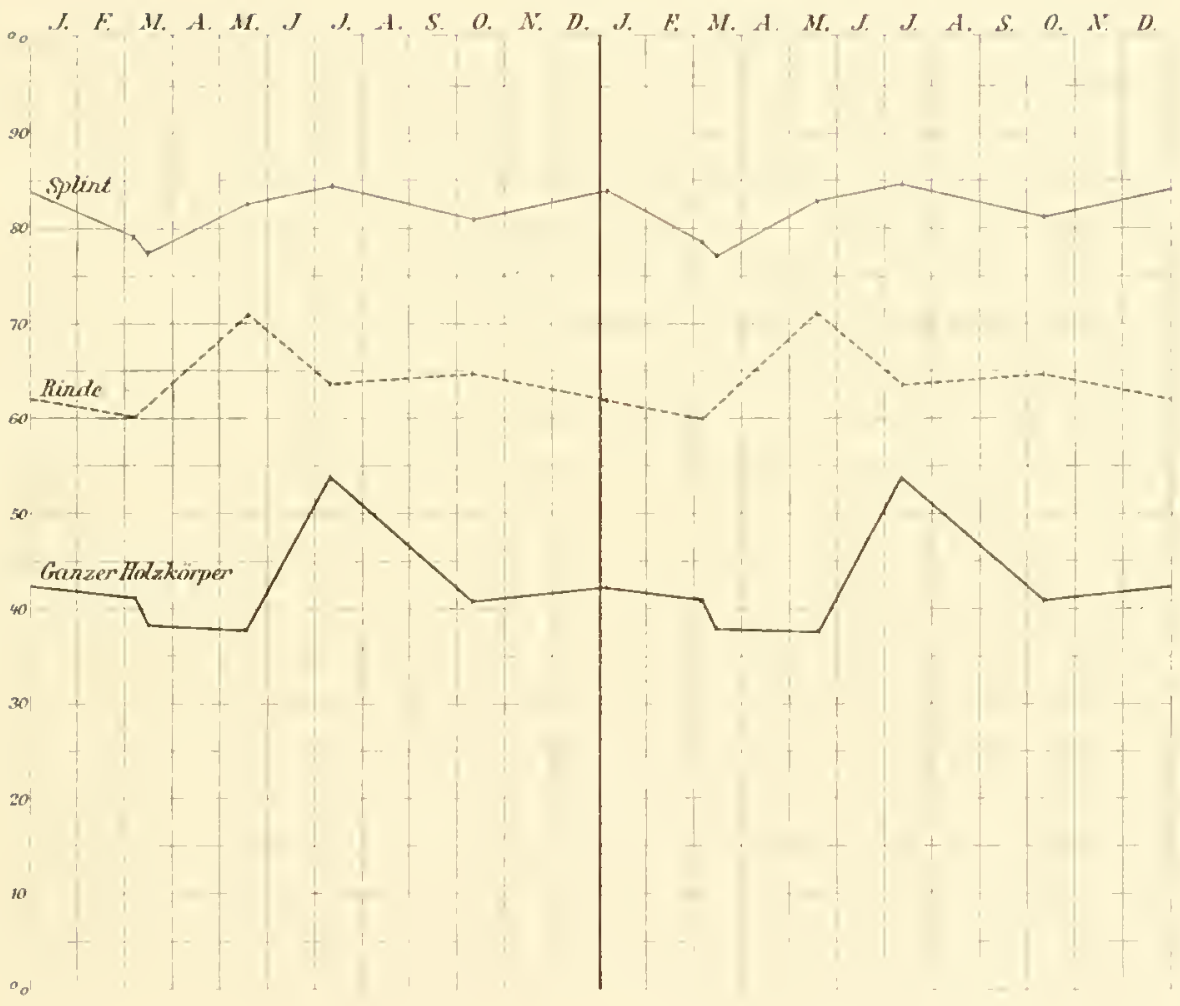





\section{Perhälınเss}

awnsthen ludtraum und Wasserstand in verschiedenen Baunhöhen der Fithte (Cranzer Holzkorper:)

Baumhöhe.

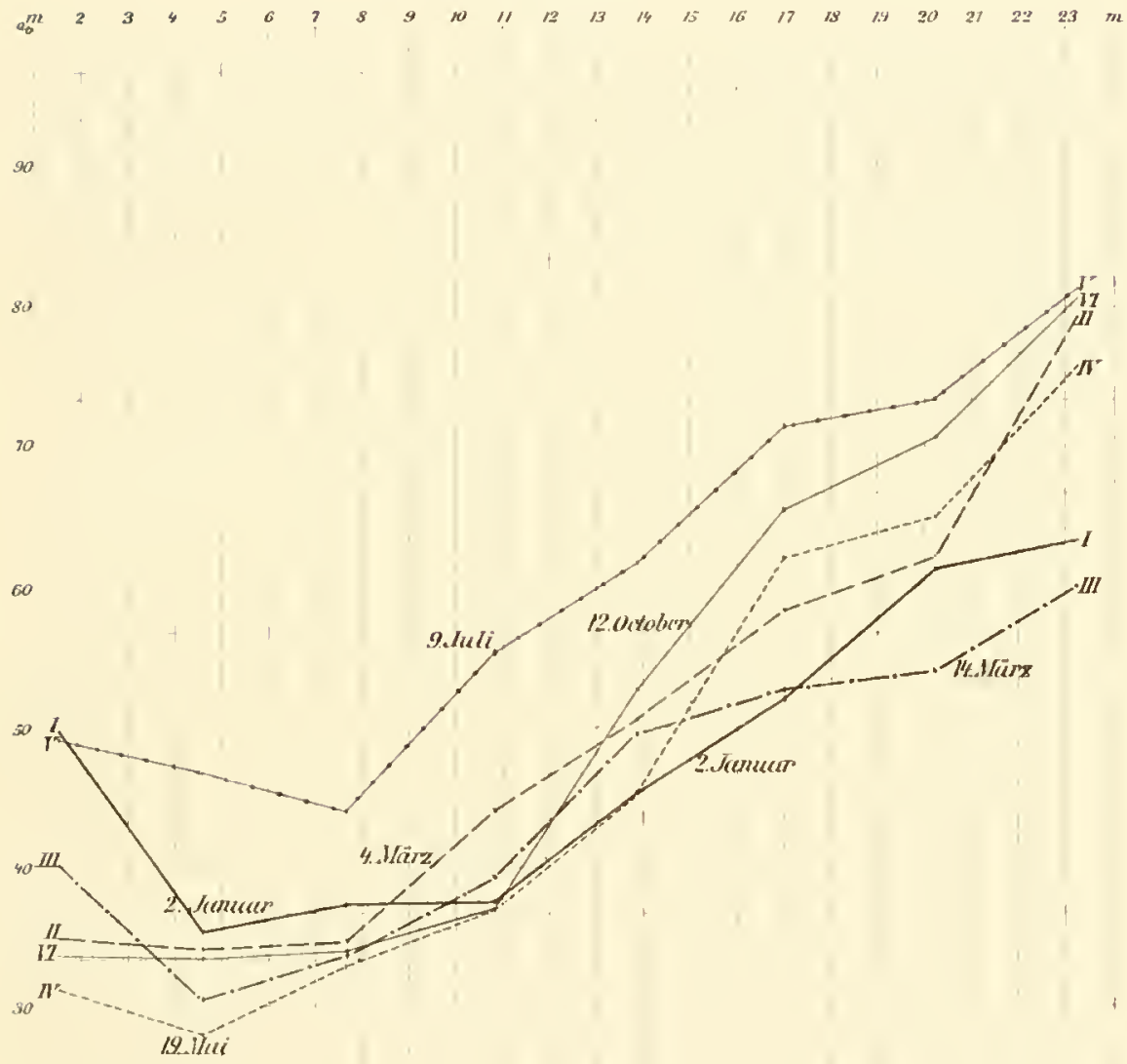



Tat: 16.

lerhältıniss

awschen Lultranm und Wassersland in verschedenen Baumhuhen der Fichte (S'Plint)

Baumhohp

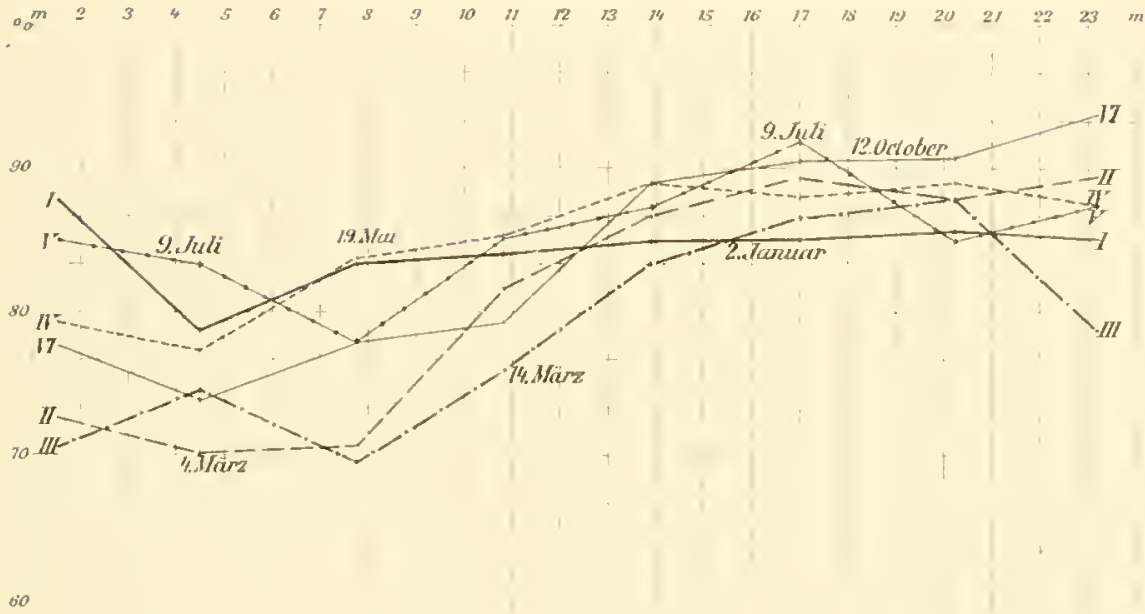

.5) 



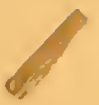




Verlagsbuchhandlung von Julius Springer in Berlin N., Monbijouplatz 3.

Untersuchungen

aus dem

forstbotanischen Institut zu München.

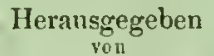

Dr. Robert Hartic,

Professor an der Universitāt in Müchen.

I.

Mit 9 lithographirten Tafeln und 3 Holzsclmitten. Preis geb. 14 M.

\title{
Lehrbuch der Baumkrankheiten. \\ Von
}

Dr. Robert Hartig,

Professor an der Universităt München.

Mit 186 Figuren auf 11 lithogr. Tafeln und 86 Holzsehnitten.

Elegant gebunden Preis 12 M.

\section{Wichtige Krankheiten der Waldbäume.}

\section{Beiträge zur}

Mycologie und Phytopathologie fiir Botaniker und Forstmänner. Von

Dr. Robert Hartig,

Professor an der Universitit Brunchen.

Mit 160 Figuren auf lithographirten Doppeltafeln.

gr. 8. eart. Preis $12 \mathrm{M}$.

\section{Die Zersetzungserscheinungen}

des Holzes der Nadelbaime und der Eiche.

In forstlicher, botanischer und chemischer Richtung bearbeitet von

Dr. Robert Hartig,

Professor an der Universitāt Mnuchen.

Mit 21 lithogr. Tafeln in Farbendruck. - Preis 36 II.

\section{Anatomie und Physiologie}

der Holzptlanzen.

Dargestellt in der Entstehungsweise und im Entwickelungsverlaufe der Einzelzelle, der Zellsysteme, der Pflanzenglieder und der Gesammtpflanze

\section{Dr. 'Theodor Hartig,}

Hirzogl. Braunscliw. Oberforstrath und Professor a. D.

Mit 113 Originalfiguren in Holzsehnitt und 6 lithogr. 'Tafeln.

Preis $20 \mathrm{M}$.

\section{Anatomie der Baumrinden.}

Vergleichende Studien

\author{
von
}

Dr. J. Moeller,

Adjunkt der K. If. forstl. Versnchsleitang. Docent an der technischen Hochschule in Wien.

Nit 146 Originalfiguren in Holzschnitt. - Preis 18 M.

Q Zu berichan dureh jede Buchhandlung. 